\title{
Nढ़
}

\section{Report on Residential}

\section{Fireground Field Experiments}

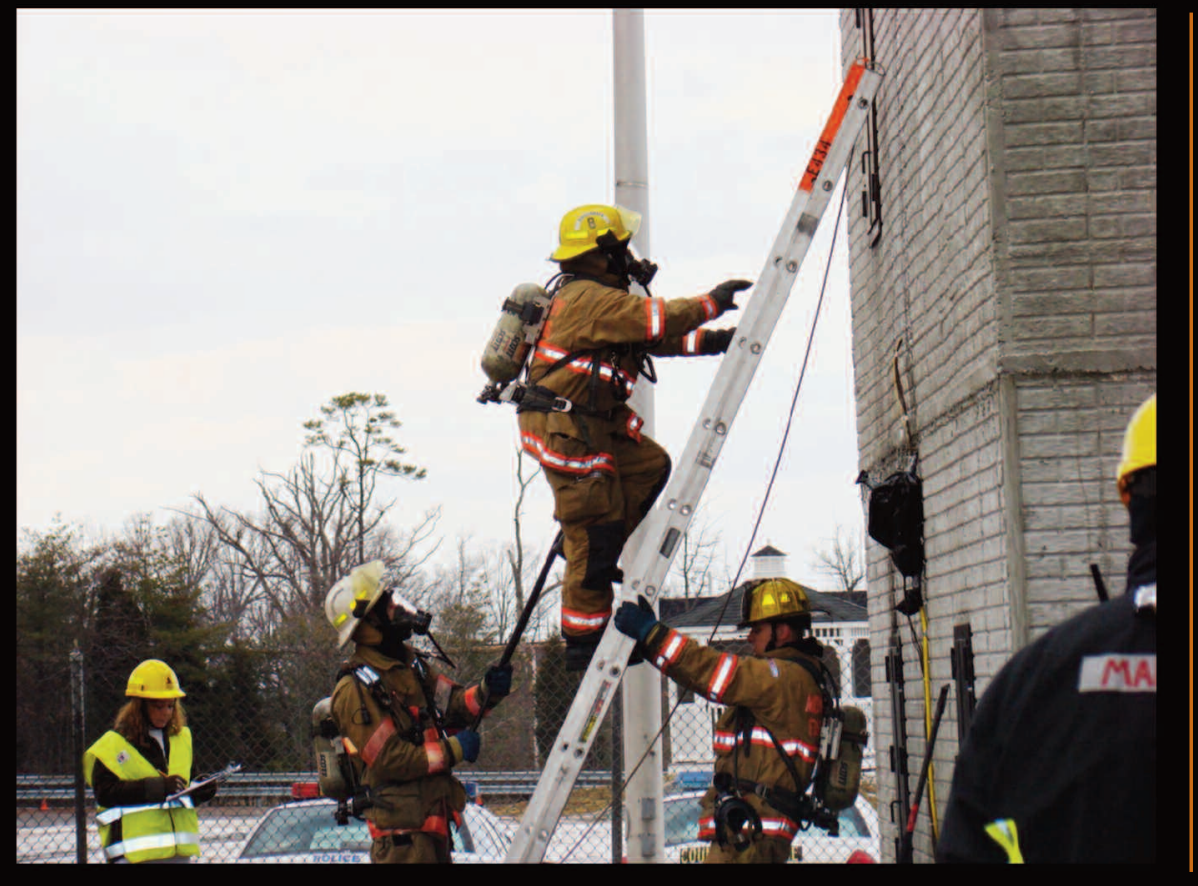

NIST Technical Note 1661

Jason D. Averill
Lori Moore-Merrell

Adam Barowy

Robert Santos

Richard Peacock

Kathy A. Notarianni

Doug Wissoker

Edited by Bill Robinson

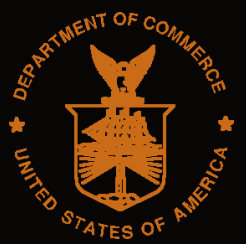

U.S. Department of Commerce Gary Locke, Secretary

National Institute of Standards and Technology

Patrick D. Gallagher, Director 


\title{
April 2010 \\ NIST Technical Note 1661 \\ Report on Residential Fireground Field Experiments
}

\author{
Jason D. Averill \\ Lori Moore-Merrell \\ Adam Barowy \\ Robert Santos \\ Richard Peacock \\ Kathy A. Notarianni \\ Doug Wissoker
}

Edited by Bill Robinson

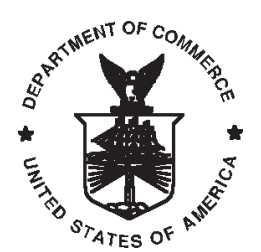

U.S. Department of Commerce

Gary Locke, Secretary

National Institute of Standards and Technology

Patrick D. Gallagher, Director 
Certain commercial entities, equipment, or materials may be identified in this document in order to describe an experimental procedure or concept adequately. Such identification is not intended to imply recommendation or endorsement by the National Institute of Standards and Technology, nor is it intended to imply that the entities, materials, or equipment are necessarily the best available for the purpose. 
National Institute of Standards and Technology Technical Note 1661, 104 pages (March 2010) CODEN:

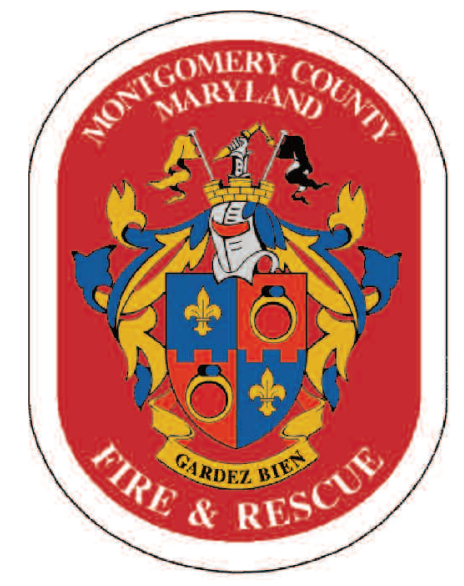

Produced with the Cooperation of Montgomery County

Fire and Rescue

Chief Richard Bowers

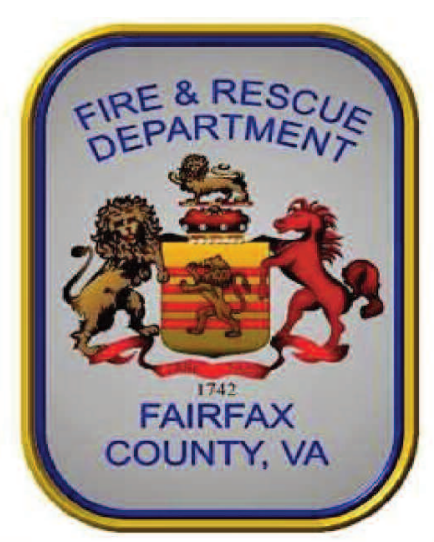

Produced with the Cooperation of

Fairfax County

Fire and Rescue

Chief Ronald Mastin

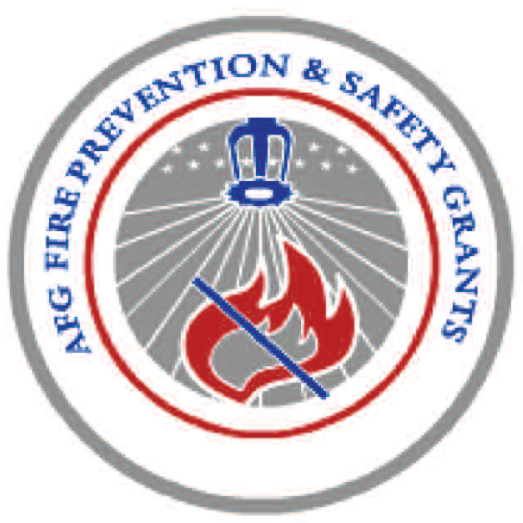

Funding provided through DHS/FEMA Grant Program Directorate for FY 2008 Assistance to Firefighters Grant Program - Fire Prevention and Safety Grants (EMW-2008-FP-01603) 


\section{NLT \\ National Institute of Standards and Technology \\ U.S. Department of Commerce}
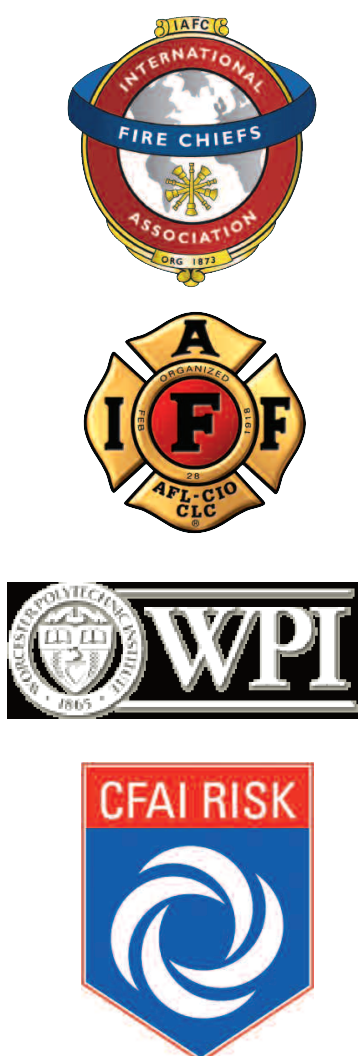


\section{Table of Contents}

Abstract

Executive Summary

Background .12

Problem 13

Review of Literature 14

Purpose and Scope of the Study 16

A Brief Overview of Fire Department Fireground Operations ....17

The Relation of Time-to-Task Completion and Risk .18

Standards of Response Cover

Part 1: Planning for the Field Experiments.

Part 2: Time-to-Task Experiments

Field Experiment Methods

Field Site

Overview of Field Experiments

Instrumentation

Safety Protocols

Crew Size

Department Participation

Crew Orientation

Tasks

Data Collection: Standardized Control Measures

Task Flow Charts and Crew Cue Cards

Radio communications

Task Timers

Video records
Response Time Assumptions 28

Part 3: Room and Contents Fires

Fuel Packages for the Room and Contents Fires

29

Experimental Matrix for Room and Contents Fires

Procedure for Minimizing the Effect of Variance in Fire Growth Rate

Analysis of Experimental Results

Time-to-task Analysis

Data Queries

Statistical Methods - Time to Task

Regression Analysis

Measurement Uncertainty

How to Interpret Time-to-Task Graphs

Time-to-Task Graphs

Part 4: Fire Modeling

Time to Untenable Conditions: Research Questions

Fire Modeling Methods

Fire Growth Rates

Fractional Effective Dose (FED)

Results from Modeling Methods

Interior Firefighting Conditions and Deployment Configuration

Physiological Effects on Firefighters: Comparison by Crew Size ........50

Study Limitations

Conclusions. .52

Future Research .53

Acknowledgments . .55

References. .56 


\section{Abstract}

$\mathrm{S}$

ervice expectations placed on the fire service, including Emergency Medical Services (EMS), response to natural disasters, hazardous materials incidents, and acts of terrorism, have steadily increased. However, local decision-makers are challenged to balance these community service expectations with finite resources without a solid technical foundation for evaluating the impact of staffing and deployment decisions on the safety of the public and firefighters.

For the first time, this study investigates the effect of varying crew size, first apparatus arrival time, and response time on firefighter safety, overall task completion, and interior residential tenability using realistic residential fires. This study is also unique because of the array of stakeholders and the caliber of technical experts involved. Additionally, the structure used in the field experiments included customized instrumentation; all related industry standards were followed; and robust research methods were used. The results and conclusions will directly inform the NPFA 1710 Technical Committee, who is responsible for developing consensus industry deployment standards.
This report presents the results of more than 60 laboratory and residential fireground experiments designed to quantify the effects of various fire department deployment configurations on the most common type of fire - a low hazard residential structure fire. For the fireground experiments, a 2,000 sq ft (186 $\mathrm{m}^{2}$ ), two-story residential structure was designed and built at the Montgomery County Public Safety Training Academy in Rockville, MD. Fire crews from Montgomery County, MD and Fairfax County, VA were deployed in response to live fires within this facility. In addition to systematically controlling for the arrival times of the first and subsequent fire apparatus, crew size was varied to consider two-, three-, four-, and five-person staffing. Each deployment performed a series of 22 tasks that were timed, while the thermal and toxic environment inside the structure was measured. Additional experiments with larger fuel loads as well as fire modeling produced additional insight. Report results quantify the effectiveness of crew size, first-due engine arrival time, and apparatus arrival stagger on the duration and time to completion of the key 22 fireground tasks and the effect on occupant and firefighter safety. 
B oth the increasing demands on the fire service - such as the growing number of Emergency Medical Services (EMS) responses, challenges from natural disasters, hazardous materials incidents, and acts of terrorism - and previous research point to the need for scientifically based studies of the effect of different crew sizes and firefighter arrival times on the effectiveness of the fire service to protect lives and property. To meet this need, a research partnership of the Commission on Fire Accreditation International (CFAI), International Association of Fire Chiefs (IAFC), International Association of Firefighters (IAFF), National Institute of Standards and Technology (NIST), and Worcester Polytechnic Institute (WPI) was formed to conduct a multiphase study of the deployment of resources as it affects firefighter and occupant safety. Starting in FY 2005, funding was provided through the Department of Homeland Security (DHS) / Federal Emergency Management Agency (FEMA) Grant Program Directorate for Assistance to Firefighters Grant Program - Fire Prevention and Safety Grants. In addition to the low-hazard residential fireground experiments described in this report, the multiple phases of the overall research effort include development of a conceptual model for community risk assessment and deployment of resources, implementation of a generalizable department incident survey, and delivery of a software tool to quantify the effects of deployment decisions on resultant firefighter and civilian injuries and on property losses.

The first phase of the project was an extensive survey of more than 400 career and combination (both career and volunteer) fire departments in the United States with the objective of optimizing a fire service leader's capability to deploy resources to prevent or mitigate adverse events that occur in risk- and hazard-filled environments. The results of this survey are not documented in this report, which is limited to the experimental phase of the project. The survey results will constitute significant input into the development of a future software tool to quantify the effects of community risks and associated deployment decisions on resultant firefighter and civilian injuries and property losses.

The following research questions guided the experimental design of the low-hazard residential fireground experiments documented in this report:

1. How do crew size and stagger affect overall start-to-completion response timing?

2. How do crew size and stagger affect the timings of task initiation, task duration, and task completion for each of the 22 critical fireground tasks?

3. How does crew size affect elapsed times to achieve three critical events that are known to change fire behavior or tenability within the structure:

a. Entry into structure?

b. Water on fire?

c. Ventilation through windows (three upstairs and one back downstairs window and the burn room window).
4. How does the elapsed time to achieve the national standard of assembling 15 firefighters at the scene vary between crew sizes of four and five?

In order to address the primary research questions, the research was divided into four distinct, yet interconnected parts:

Part 1 - Laboratory experiments to design appropriate fuel load

Part 2 - Experiments to measure the time for various crew sizes and apparatus stagger (interval between arrival of various apparatus) to accomplish key tasks in rescuing occupants, extinguishing a fire, and protecting property

Part 3 - Additional experiments with enhanced fuel load that prohibited firefighter entry into the burn prop - a building constructed for the fire experiments

- Part 4 - Fire modeling to correlate time-to-task completion by crew size and stagger to the increase in toxicity of the atmosphere in the burn prop for a range of fire growth rates.

The experiments were conducted in a burn prop designed to simulate a low-hazard ${ }^{1}$ fire in a residential structure described as typical in NFPA $1710^{\circledR}$ Organization and Deployment of Fire Suppression Operations, Emergency Medical Operations, and Special Operations to the Public by Career Fire Departments. NFPA 1710 is the consensus standard for career firefighter deployment, including requirements for fire department arrival time, staffing levels, and fireground responsibilities.

Limitations of the study include firefighters' advance knowledge of the burn prop, invariable number of apparatus, and lack of experiments in elevated outdoor temperatures or at night. Further, the applicability of the conclusions from this report to commercial structure fires, high-rise fires, outside fires, terrorism/natural disaster response, HAZMAT or other technical responses has not been assessed and should not be extrapolated from this report.

\section{Primary Findings}

Of the 22 fireground tasks measured during the experiments, results indicated that the following factors had the most significant impact on the success of fire fighting operations. All differential outcomes described below are statistically significant at the $95 \%$ confidence level or better.

\section{Overall Scene Time:}

The four-person crews operating on a low-hazard structure fire completed all the tasks on the fireground (on average) seven minutes faster - nearly $30 \%$ - than the two-person crews. The four-person crews completed the same number of fireground tasks (on average) 5.1 minutes faster - nearly $25 \%$ - than the three-person crews. On the low-hazard residential structure fire, adding a fifth person to the crews did not decrease overall fireground task times. However, it should be noted that the

1 A low-hazard occupancy is defined in the NFPA Handbook as a one-, two-, or three-family dwelling and some small businesses. Medium hazards occupancies include apartments, offices, mercantile and industrial occupancies not normally requiring extensive rescue or firefighting forces. High-hazard occupancies include schools, hospitals, nursing homes, explosive plants, refineries, high-rise buildings, and other highlife hazard or large fire potential occupancies. 
benefit of five-person crews has been documented in other evaluations to be significant for medium- and high-hazard structures, particularly in urban settings, and is recognized in industry standards. ${ }^{2}$

\section{Time to Water on Fire:}

There was a $10 \%$ difference in the "water on fire" time between the two- and three-person crews. There was an additional $6 \%$ difference in the "water on fire" time between the three- and four-person crews. (i.e., four-person crews put water on the fire $16 \%$ faster than two person crews). There was an additional $6 \%$ difference in the "water on fire" time between the four- and five-person crews (i.e. five-person crews put water on the fire $22 \%$ faster than two-person crews).

\section{Ground Ladders and Ventilation:}

The four-person crews operating on a low-hazard structure fire completed laddering and ventilation (for life safety and rescue) $30 \%$ faster than the two-person crews and $25 \%$ faster than the three-person crews.

\section{Primary Search:}

The three-person crews started and completed a primary search and rescue $25 \%$ faster than the two-person crews. The four- and five-person crews started and completed a primary search $6 \%$ faster than the three-person crews and $30 \%$ faster than the two-person crew. A $10 \%$ difference was equivalent to just over one minute.

\section{Hose Stretch Time:}

In comparing four-and five-person crews to two-and three-person crews collectively, the time difference to stretch a line was 76 seconds. In conducting more specific analysis comparing all crew sizes to the two-person crews the differences are more distinct. Two-person crews took 57 seconds longer than three-person crews to stretch a line. Two-person crews took 87 seconds longer than four-person crews to complete the same tasks. Finally, the most notable comparison was between two-person crews and five-person crews - more than 2 minutes (122 seconds) difference in task completion time.

\section{Industry Standard Achieved:}

As defined by NFPA 1710, the "industry standard achieved" time started from the first engine arrival at the hydrant and ended when 15 firefighters were assembled on scene. ${ }^{3}$ An effective response force was assembled by the five-person crews three minutes faster than the four-person crews. Based on the study protocols, modeled after a typical fire department apparatus deployment strategy, the total number of firefighters on scene in the two- and three-person crew scenarios never equaled 15 and therefore the two- and three-person crews were unable to assemble enough personnel to meet this standard.

\section{Occupant Rescue:}

Three different "standard" fires were simulated using the Fire Dynamics Simulator (FDS) model. Characterized in the Handbook of the Society of Fire Protection Engineers as slow-, medium-, and fast-growth rate ${ }^{4}$, the fires grew exponentially with time. The rescue scenario was based on a non-ambulatory occupant in an upstairs bedroom with the bedroom door open.

Independent of fire size, there was a significant difference between the toxicity, expressed as fractional effective dose (FED), for occupants at the time of rescue depending on arrival times for all crew sizes. Occupants rescued by early-arriving crews had less exposure to combustion products than occupants rescued by late-arriving crews. The fire modeling showed clearly that two-person crews cannot complete essential fireground tasks in time to rescue occupants without subjecting them to an increasingly toxic atmosphere. For a slow-growth rate fire with two-person crews, the FED was approaching the level at which sensitive populations, such as children and the elderly are threatened. For a medium-growth rate fire with two-person crews, the FED was far above that threshold and approached the level affecting the general population. For a fast-growth rate fire with two-person crews, the FED was well above the median level at which $50 \%$ of the general population would be incapacitated. Larger crews responding to slow-growth rate fires can rescue most occupants prior to incapacitation along with early-arriving larger crews responding to medium-growth rate fires. The result for late-arriving (two minutes later than early-arriving) larger crews may result in a threat to sensitive populations for medium-growth rate fires. Statistical averages should not, however, mask the fact that there is no FED level so low that every occupant in every situation is safe.

\section{Conclusion:}

More than 60 full-scale fire experiments were conducted to determine the impact of crew size, first-due engine arrival time, and subsequent apparatus arrival times on firefighter safety and effectiveness at a low-hazard residential structure fire. This report quantifies the effects of changes to staffing and arrival times for residential firefighting operations. While resource deployment is addressed in the context of a single structure type and risk level, it is recognized that public policy decisions regarding the cost-benefit of specific deployment decisions are a function of many other factors including geography, local risks and hazards, available resources, as well as community expectations. This report does not specifically address these other factors.

The results of these field experiments contribute significant knowledge to the fire service industry. First, the results provide a quantitative basis for the effectiveness of four-person crews for low-hazard response in NFPA 1710. The results also provide valid measures of total effective response force assembly on scene for fireground operations, as well as the expected performance time-to-critical-task measures for low-hazard structure fires. Additionally, the results provide tenability measures associated with a range of modeled fires.

Future research should extend the findings of this report in order to quantify the effects of crew size and apparatus arrival times for moderate- and high-hazard events, such as fires in high-rise buildings, commercial properties, certain factories, or warehouse facilities, responses to large-scale non-fire incidents, or technical rescue operations.

2 NFPA Standard 1710 - A.5.2.4.2.1 ... Other occupancies and structures in the community that present greater hazards should be addressed by additional fire fighter functions and additional responding personnel on the initial full alarm assignment.

3 NFPA 1710 Standard for the Organization and Deployment of Fire Suppression Operations, Emergency Medical Operations, and Special Operations to the Public by Career Fire Departments. Section 5.2.1 - Fire Suppression Capability and Section 5.2.2 Staffing.

4 As defined in the handbook, a fast fire grows exponentially to $1.0 \mathrm{MW}$ in 150 seconds. A medium fire grows exponentially to $1 \mathrm{MW}$ in 300 seconds. A slow fire grows exponentially to $1 \mathrm{MW}$ in 600 seconds. A $1 \mathrm{MW}$ fire can be thought-of as a typical upholstered chair burning at its peak. A large sofa might be 2 to 3 MWs. 
$\mathrm{T}$

he fire service in the United States has a deservedly proud tradition of service to community and country dating back hundreds of years. As technology advances and the scope of service grows (e.g., more EMS obligations and growing response to natural disasters, hazardous materials incidents, and acts of terrorism), the fire service remains committed to a core mission of protecting lives and property from the effects of fire. Firefighting is a dangerous business with substantial financial implications. In 2007, U.S. municipal fire departments responded to an estimated 1,557,500 fires. These fires killed 3,430 civilians (non-firefighters) and contributed to 17,675 reported civilian fire injuries. Direct property damage was estimated at $\$ 14.6$ billion dollars (Karter, 2008). In spite of the vigorous nationwide efforts to promote firefighter safety, the number of firefighter deaths has consistently remained tragically high. In both 2007 and 2008, the U.S. Fire Administration reported 118 firefighter fatalities (USFA 2008).

Although not all firefighter deaths occur on the fireground accidents in vehicles and training fatalities add to the numbers every statistical analysis of the fire problem in the United States identifies residential structure fires as a key component in firefighter and civilian deaths, as well as direct property loss. Consequently, community planners and decision-makers need tools for optimally aligning resources with the service commitments needed for adequate protection of citizens. 


\section{Problem}

espite the magnitude of the fire problem in the United

States, there are no scientifically based tools available to

community and fire service leaders to assess the effects of prevention, fixed sprinkler systems, fire fighting equipment, or deployment and staffing decisions. Presently, community and fire service leaders have a qualitative understanding of the effect of certain resource allocation decisions. For example, a decision to double the number of firehouses, apparatus, and firefighters would likely result in a decrease in community fire losses, while cutting the number of firehouses, apparatus, and firefighters would likely yield an increase in the community fire losses, both human and property. However, decision-makers lack a sound basis for quantifying the total impact of enhanced fire resources on the number of firefighter and civilian lives saved and injuries prevented.

Studies on adequate deployment of resources are needed to enable fire departments, cities, counties, and fire districts to design an acceptable level of resource deployment based upon community risks and service provision commitment. These studies will assist with strategic planning and municipal and state budget processes. Additionally, as resource studies refine data collection methods and measures, both subsequent research and improvements to resource deployment models will have a sound scientific basis. 
$\mathbf{R}$ esearch to date has documented a consistent relationship between resources deployed and firefighter and civilian safety. Studies documenting engine and ladder crew performance in diverse simulated environments as well as actual responses show a basic relationship between apparatus staffing levels and a range of important performance variables and outcome measurements such as mean on-scene time, time-to-task completion, incidence of injury among fire service personnel, and costs incurred as a result of on-scene injuries (Cushman 1981, McManis 1984, Morrison 1990, Ontario 1991, Phoenix 1991, Roberts 1993).

Reports by fire service officials and consulting associates reviewing fire suppression and emergency response by fire crews in U.S. cities were the first publications to describe the relationship between adequate staffing levels and response time, time to completion of various fireground tasks, overall effectiveness of fire suppression, and estimated value of property loss for a wide range of real and simulated environments. In 1980, the Columbus Fire Division's report on firefighter effectiveness showed that for a predetermined number of personnel initially deployed to the scene of a fire, the proportion of incidents in which property loss exceeded $\$ 5,000$ and horizontal fire spread of more than $25 \mathrm{sq} \mathrm{ft}\left(2.3 \mathrm{~m}^{2)}\right.$ was significantly greater for crews whose numbers fell below the set thresholds of 15 total fireground personnel at residential fires and 23 at large-risk fires (Backoff 1980). The following year, repeated live experiments at a one-family residential site using modern apparatus and equipment demonstrated that larger units performed tasks and accomplished knockdown more quickly, ultimately resulting in a lower percentage of loss attributable to factors controlled by the fire department. The authors of this article highlighted that the fire company is the fire department's basic working unit and further emphasized the importance of establishing accurate and up-to-date performance measurements to help collect data and develop conclusive strategies to improve staffing and equipment utilization (Gerard 1981).

Subsequent reports from the United States Fire Administration (USFA) and several consulting firms continued to provide evidence for the effects of staffing on fire crews' ability to complete tasks involved in fire suppression efficiently and effectively. Citing a series of tests conducted in 1977 by the Dallas Fire Department that measured the time it took three-, four-, and five-person teams to advance a line and put water on a simulated fire at the rear of the third floor of an old school, officials from the USFA underscored that time-to-task completion and final level of physical exhaustion for crews markedly improved not after any one threshold, but with the addition of each new team member. This report went on to outline the manner in which simulated tests exemplify a clear-cut means to record and analyze the resources initially deployed and finally utilized at fire scenes (NFA 1981). A later publication detailing more Dallas Fire Department simulations - ninety-one runs each for a private residential fire, high-rise office fire, and apartment house fire — showed again that increased staffing levels greatly enhanced the coordination and effectiveness of crews' fire suppression efforts during a finite time span (McManis Associates 1984). Numerous studies of local departments have supported this conclusion using a diverse collection of data, including a report by the National Fire
Academy (NFA) on fire department staffing in smaller communities, which showed that a company crew staffed with four firefighters could perform rescue of potential victims approximately $80 \%$ faster than a crew staffed with three firefighters (Morrison 1990).

During the same time period that the impact of staffing levels on fire operations was gaining attention, investigators began to question whether staffing levels could also be associated with the risk of firefighter injuries and the cost incurred as a result of such injuries at the fire scene. Initial results from the Columbus Fire Division showed that "firefighter injuries occurred more often when the total number of personnel on the fireground was less than 15 at residential fires and 23 at large-risk fires" (Backoff 1980), and mounting evidence has indicated that staffing levels are a fundamental health and safety issue for firefighters in addition to being a key determinant of immediate response capacity. One early analysis by the Seattle Fire Department for that city's Executive Board reviewed the average severity of injuries suffered by three-, four-, and five-person engine companies, with the finding that "the rate of firefighter injuries expressed as total hours of disability per hours of fireground exposure were $54 \%$ greater for engine companies staffed with 3 personnel when compared to those staffed with 4 firefighters, while companies staffed with 5 personnel had an injury rate that was only one-third that associated with four-person companies" (Cushman 1981). A joint report from the International Association of Fire Fighters (IAFF) and Johns Hopkins University concluded, after a comprehensive analysis of the minimum staffing levels and firefighter injury rates in U.S. cities with populations of 150,000 or more, that jurisdictions operating with crews of less than four firefighters had injury rates nearly twice the percentage of jurisdictions operating with crews of four-person crews or more (IAFF, JHU 1991).

More recent studies have continued to support the finding that staffing per piece of apparatus integrally affects the efficacy and safety of fire department personnel during emergency response and fire suppression. Two studies in particular demonstrate the consistency of these conclusions and the increasing level of detail and accuracy present in the most recent literature, by looking closely at the discrete tasks that could be safely and effectively performed by three- and four-person fire companies. After testing drills comprised of a series of common fireground tasks at several fire simulation sites, investigators from the Austin Fire Department assessed the physiological impact and injury rates among the variably staffed fire crews. In these simulations, an increase from a three- to four-person crew resulted in marked improvements in time-to-task completion or efficiency for the two-story residential fire drill, aerial ladder evolution, and high-rise fire drill, leading the researchers to conclude that loss of life and property increases when a sufficient number of personnel are not available to conduct the required tasks efficiently, independent of firefighter experience, preparation, or training. Reviews of injury reports by the Austin Fire Department furthermore revealed that the injury rate for three-person companies in the four years preceding the study was nearly one-and-a-half that of crews staffed with four or more personnel (Roberts 1993). In a sequence of similar tests, the Office of the Fire Marshal of Ontario, Canada likewise found that three-person 
fire companies were unable to safely perform deployment of backup protection lines, interior suppression or rescue operations, ventilation operations that required access to the roof of the involved structure, use of large hand-held hose lines, or establish a water supply from a static source without additional assistance and within the time limits of the study. Following these data, Fire Marshal officials noted that three-person crews were also at increased risk for exhaustion due to insufficient relief at fire scenes and made recommendations for the minimum staffing levels per apparatus necessary for suppression and rescue related tasks (Office of the Fire Marshal of Ontario 1993).

The most comprehensive contemporary studies on the implications of fire crew staffing now include much more accurate performance measures for tasks at the fireground, in addition to the basic metric of response time. They include environmental measures of performance, such as total water supply, which expand the potential for assessing the cost-effectiveness of staffing not only in terms of fireground personnel injury rates but also comparative resource expenditure required for fire suppression. Several examples from the early 1990s show investigators and independent fire departments beginning to gather the kind of specific, comprehensive data on staffing and fireground tasks such as those suggested and outlined in concurrent local government publications that dealt with management of fire services (Coleman 1988). A report by the Phoenix Fire Department laid out clear protocols for responding to structure fires and response evaluation in terms of staffing, objectives, task breakdowns, and times in addition to outlining the responsibilities of responding fire department members and the order in which they should be accomplished for a full-scale simulation activity (Phoenix 1991). One attempt to devise a prediction model for the effectiveness of manual fire suppression similarly reached beyond response time benchmarks to describe fire operations and the step-by-step actions of firefighters at incident scenes by delineating the time-to-task breakdowns for size-up, water supply, equipment selection, entry, locating the fire, and advancing hose lines, while also comparing the predicted time-to-task values with the actual times and total resources (Menker 1994). Two separate studies of local fire department performance, one from Taoyuan County in Taiwan and another from the London Fire Brigade, have drawn ties between fire crews' staffing levels and total water demand as the consequence of both response time and fire severity. Field data from Taoyuan County for cases of fire in commercial, business, hospital, and educational properties showed that the type of land use as well as response time had a significant impact on the water volume necessary for fire suppression, with the notable quantitative finding that the water supply required on-scene doubled when the fire department response increased by ten minutes (Chang 2005).

Response time as a predictor of residential fire outcomes has received less study than the effect of crew size. A Rand Institute study demonstrated a relationship between the distance the responding companies traveled and the physical property damage. This study showed that the fire severity increased with response distance, and therefore the magnitude of loss increased proportionally (Rand 1978). Using records from 307 fires in nonresidential buildings over a three-year period, investigators in the United Kingdom correspondingly found response time to have a significant impact on final fire area, which in turn was proportional to total water demand (Sardqvist 2000).

Recent government and professional literature continues to demonstrate the need for more data that would quantify in depth and illustrate the required tasks, event sequences, and necessary response times for effective fire suppression in order to determine with accuracy the full effects of either a reduction or increase in fire company staffing (Karter 2008). A report prepared for National Institute of Standards and Technology (NIST) stressed the ongoing need to elucidate the relationship between staffing and personnel injury rates, stating that "a scientific study on the relationship between the number of firefighters per engine and the incidence of injuries would resolve a long-standing question concerning staffing and safety" (TriData 2005). While not addressing staffing levels as a central focus, an annual review of fire department calls and false alarms by the National Fire Protection Association (NFPA) exemplified the need to capture not only the number of personnel per apparatus for effective fire suppression but also to clarify the demands on individual fire departments with resolution at the station level (NFPA 2008).

In light of the existing literature, there remain unanswered questions about the relationships between fire service resource deployment levels and associated risks. For the first time this study investigates the effect of varying crew size, first apparatus arrival time, and response time on firefighter safety, overall task completion and interior residential tenability using realistic residential fires. This study is also unique because of the array of stakeholders and the caliber of technical advisors involved. Additionally, the structure used in the field experiments included customized instrumentation for the experiments; all related industry standards were followed; robust research methods were used; and the results and conclusions will directly inform the NFPA 1710 Technical Committee, as well as public officials and fire chiefs. ${ }^{5}$

\footnotetext{
5 NFPA is a registered trademark of the National Fire Protection Association, Quincy, Massachusetts. NFPA 1710 defines minimum requirements relating to the organization and deployment of fire suppression operations, emergency medical operations, and special operations to the public by substantially all career fire

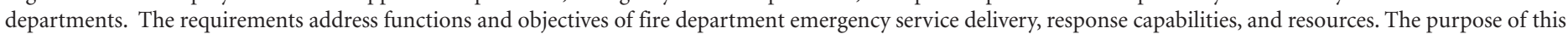

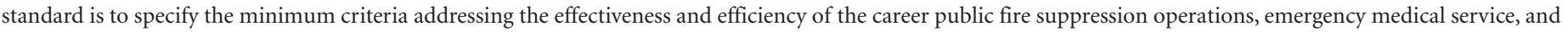
special operations delivery in protecting the citizens of the jurisdiction and the occupational safety and health of fire department employees. At the time of the experiments, the 2004 edition of NFPA 1710 was the current edition.
} 
T his project systematically studies deployment of fire fighting resources and the subsequent effect on both firefighter safety and the ability to protect civilians and their property. It is intended to enable fire departments and city/county managers to make sound decisions regarding optimal resource allocation to meet service commitments using the results of scientifically based research. Specifically, the residential fireground experiments provide quantitative data on the effect of crew size, first-due engine arrival time, and subsequent apparatus stagger on time-to-task for critical steps in response and fire fighting.

The first phase of the multiphase project was an extensive survey of more than 400 career and combination fire departments in the United States with the objective of optimizing a fire service leader's capability to deploy resources to prevent or mitigate adverse events that occur in risk- and hazard-filled environments. The results of this survey are not documented in this report, which is limited to the experimental phase of the project, but they will constitute significant input into future applications of the data presented in this document.

This report describes the second phase of the project, divided into four parts:

Part 1 - Laboratory experiments to design the appropriate fuel packages to be used in the burn facility specially constructed for the research project

Part 2 - Field tests for critical time-to-task completion of key tasks in fire suppression

Part 3 - Field tests with real furniture (room and contents experiments)

Part 4 - Fire modeling to apply data gathered to slow-, medium-, and fast-growth rate fires
The scope of this study is limited to understanding the relative influence of deployment variables on low-hazard, residential structure fires, similar in magnitude to the hazards described in NFPA ${ }^{\circledR} 1710$, Standard for the Organization and Deployment of Fire Suppression Operations, Emergency Medical Operations, and Special Operations to the Public by Career Fire Departments. The standard uses as a typical residential structure a 2,000 sq ft $\left(186 \mathrm{~m}^{2}\right)$ two-story, single-family dwelling with no basement and no exposures (nearby buildings or hazards such as stacked flammable material).

The limitations of the study, such as firefighters' advance knowledge of the facility constructed for this experiment, invariable number of apparatus, and lack of experiments in extreme temperatures or at night, will be discussed in the Limitations section of this report. It should be noted that the applicability of the conclusions from this report to commercial structure fires, high-rise fires, outside fires, and response to hazardous material incidents, acts of terrorism, and natural disasters or other technical responses has not been assessed and should not be extrapolated from this report. 


\section{A Brief Overview of the Fireground Operations}

$\mathrm{R}$ egardless of the size of a structure on fire, firefighting crews identify four priorities: life safety of occupants and firefighters, confinement of the fire, property conservation, and reduction of adverse environmental impact. Interdependent and coordinated activities of all fire fighting personnel are required to meet the priority objectives.

NFPA 1710 specifies that the number of on-duty fire suppression personnel must be sufficient to carry out the necessary fire fighting operations given the expected fire fighting conditions. During each fireground experiment, the following were dispatched to the test fire building:

three engine companies

one truck company

a command vehicle with a battalion chief and a command aide

Staffing numbers for the engine and truck crews and response times were varied for the purposes of the tests. Additional personnel available to ensure safety will be described later in this report.

The following narrative account describes the general sequence of activities in part 2 of the experiments (time-to-task), when the fuel load permitted firefighter entry:

The first arriving engine company conducts a size-up or initial life safety assessment of the building to include signs of occupants in the home, construction features, and location of the original fire and any extension to other parts of the structure. This crew lays a supply line from a hydrant close to the building for a continuous water supply.

The truck company usually arrives in close proximity to the first engine company. The truck company is responsible for gaining access or forcing entry into the building so that the engine company can advance the first hose line into the building to locate and extinguish the fire. Usually, they assist the engine company in finding the fire. The NFPA and OSHA $2 \mathrm{In} / 2 \mathrm{Out}^{6} \mathrm{crew}$ is also assembled prior to anyone entering an atmosphere that is immediately dangerous to life or health (IDLH). This important safety requirement will have a large impact on availability of firefighters to enter the building when small crews are deployed.

Once a door is opened, the engine crew advances a hose line (attack line) toward the location of the fire. At the same time, members from the truck crew accompany the engine crew and assist in ventilating the building to provide a more tenable atmosphere for occupants and firefighters. Ventilation also helps by improving visibility in an otherwise "pitch black" environment, but it must be coordinated with the attack line crew to ensure it helps control the fire and does not contribute to fire growth. The truck crew performs a systematic rapid search of the entire structure starting in the area where occupants would be in the most danger. The most dangerous area is proximate to the fire and the areas directly above the fire.

Depending upon the travel distance, the battalion chief and command aide will have arrived on the scene and have taken command of the incident and established a command post. The role of the incident commander is to develop the action plan to mitigate the incident and see that those actions are carried out in a safe, efficient, and effective manner. The command aide is responsible for situational assessment and communications, including communications with crew officers to ensure personnel accountability.

Depending on response time or station location, the second (engine 2) and possibly the third engine company (engine 3 ) arrive. The second arriving engine (engine 2) connects to the fire hydrant where the first engine (engine 1) laid their supply line. Engine 2 pumps water from the hydrant through the supply line to the first engine for fire fighting operations. According to NFPA 1710, water should be flowing from the supply line to the attack engine prior to the attack crew's entry into the structure.

The crew from the second engine advances a second hand line as a backup line to protect firefighters operating on the inside and to prevent fire from spreading to other parts of the structure.

The third engine crew is responsible for establishing a Rapid Intervention Team (RIT), a rescue team staged at or near the command post or as designated by the Incident Commander (in the front of the building) with all necessary equipment needed to locate and/or rescue firefighters that become trapped or incapacitated. The RIT plans entry/exit portals and removes hazards, if found, to assist interior crews.

As the fire fighting, search and rescue, and ventilation operations are continuing, two members of the truck company are tasked with placing ground ladders to windows and the roof to provide a means of egress for occupants or firefighters. The truck crew is responsible for controlling interior utilities such as gas and electric after their ventilation, search, and rescue duties are completed.

Once the fire is located and extinguished and occupants are

6 The " $2 \mathrm{In} / 2$ Out" policy is part of paragraph $(\mathrm{g})(4)$ of OSHAs revised respiratory protection standard, 29 CFR 1910.134. This paragraph applies to private sector workers engaged in interior structural fire fighting and to Federal employees covered under Section 19 of the Occupational Safety and Health Act. States that have chosen to operate OSHA-approved occupational safety and health state plans are required to extend their jurisdiction to include employees of their state and local governments. These states are required to adopt a standard at least as effective as the Federal standard within six months.

OSHAs interpretation on requirements for the number of workers required to be present when conducting operations in atmospheres that are immediately dangerous to life and health (IDLH) covers the number of persons who must be on the scene before fire fighting personnel may initiate an attack on a structural fire. An interior structural fire (an advanced fire that has spread inside of the building where high temperatures, "heat" and dense smoke are normally occurring) would present an IDLH atmosphere and therefore, require the use of respirators. In those cases, at least two standby persons, in addition to the minimum of two persons inside needed to fight the fire, must be present before fire fighters may enter the building.

Letter to Thomas N. Cooper, Purdue University, from Paula O. White, Director of Federal-State Operations, U.S. Department of Labor, Occupational Safety \& Health Administration, November 1, 1995. 
removed, the incident commander reassesses the situation and provides direction to conduct a very thorough secondary search of the building to verify that the fire has not extended into void spaces and that it is fully extinguished. (In a nonexperimental fire situation, salvageable property would be covered or removed to minimize damage.)

Throughout the entire incident, each crew officer is responsible for the safety and accountability of his or her personnel along with air management. The location and wellness of crews is tracked by the command aide through a system of personal accountability checks conducted at 20-minute intervals.

Following extinguishment of the fire, an onsite review is conducted to identify actions for improvement. Crews are monitored, hydrated and rested before returning to work in the fire building.

\section{The Relation of Time-to-Task Completion and Risk}

Delayed response, particularly in conjunction with the deployment of inadequate resources, reduces the likelihood of controlling the fire in time to prevent major damage and possible loss of life and increases the danger to firefighters.

Figure 1 illustrates a hypothetical sequence of events for response to a structure fire. During fire growth, the temperature of a typical compartment fire can rise to over $1,000^{\circ} \mathrm{F}\left(538^{\circ} \mathrm{C}\right)$. When a fire in part of a compartment reaches flashover, the rapid transition between the growth and the fully developed fire stage, flame breaks out almost at once over the surface of all objects in the compartment, with results for occupants, even firefighters in full gear, that are frequently deadly.

Successful containment and control of a fire require the coordination of many separate tasks. Fire suppression must be coordinated with rescue operations, forcible entry, and utilities control. Ventilation typically occurs only after an attack line is in place and crews are ready to move in and attack the fire. The incident commander needs up-to- the-minute knowledge of crew activities and the status of task assignments which could result in a decision to change from an offensive to a defensive strategy.

\section{Standards of Response Cover}

Developing a standard of response cover - the policies and procedures that determine the distribution, concentration, and reliability of fixed and mobile resources for response to fire (as well as other kinds of technical response) — related to service commitments to the community is a complex task. Fire and rescue departments must evaluate existing (or proposed) resources against identified risk levels in the community and against the tasks necessary to conduct safe, efficient and effective fire suppression at structures identified in these various risk levels. Leaders must also evaluate geographic distribution and depth or concentration of resources deployed based on time parameters.

Recognition and reporting of a fire sets off a chain of events before firefighters arrive at the scene: call receipt and processing, dispatch of resources, donning protective gear, and travel to the scene. NFPA 1710 defines the overall time from dispatch to scene arrival as the total response time. The standard divides total

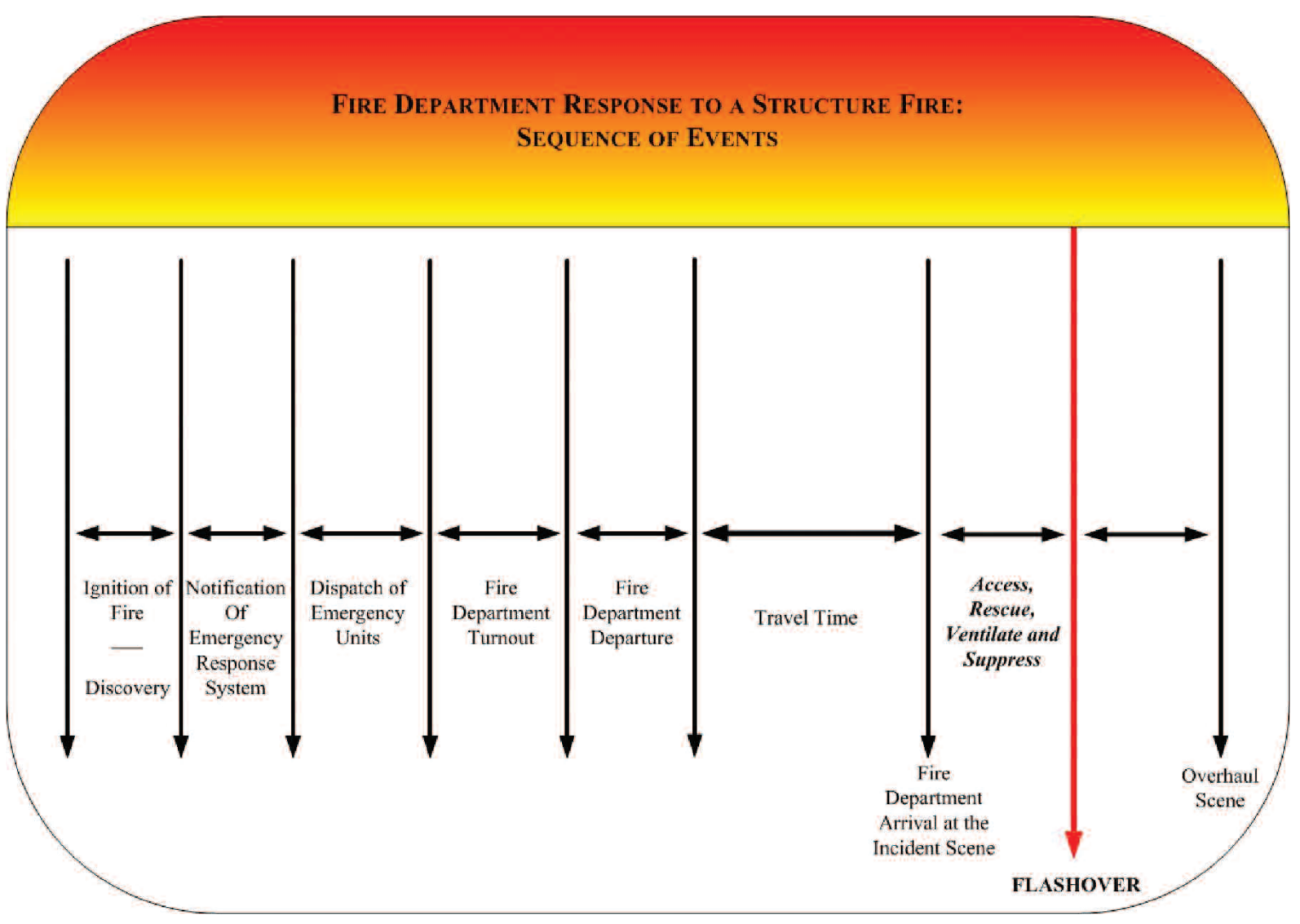

Figure 1: Hypothetical Timeline of Fire Department Response to Structure Fire 
response time into a number of discrete segments, of which travel time - the time interval from the beginning of travel to the scene to the arrival at the scene - is particularly important for this study.

Arrival of a firefighting response force must be immediately followed by organization of the resources into a logical, properly phased sequence of tasks, some of which need to be performed simultaneously. Knowing the time it takes to accomplish each task with the allotted number of personnel and equipment is critical. Ideally crews should arrive and intervene in sufficient time to prevent flashover or spread beyond the room of origin. Decision-making about staffing levels and geographic distribution of resources must consider those times when there will be simultaneous events requiring resource deployment.

There should be sufficient redundancy or overlap in the system to allow for simultaneous calls and high volume of near simultaneous responses without compromising the safety of the public or firefighters.

Policy makers have long lacked studies that quantify changes in fireground performance based on apparatus staffing levels and on-scene arrival time intervals. These experiments were designed to observe the impact of apparatus staffing levels and apparatus arrival times on the time it takes to execute essential fireground tasks and on the tenability inside the burn prop for a full initial alarm assignment response. It is expected that the results of this study will be used to evaluate the related performance objectives in NFPA 1710. 


\section{Part 1: Planning for the Field Experiments}

\section{Laboratory Experiments}

The purpose of the first segment, the laboratory experiments, was to characterize the burning behavior of the wood pallets as a function of:

number of pallets and the subsequent peak heat release rate (HRR)

compartment effects on burning of wood pallets

effect of window ventilation on the fire

effect on fire growth rate of the loading configuration of excelsior (slender wood shavings typically used as packing material)

Characterization of the fuel package was critical in order to ensure that the field experiments would not result in a flashover condition, one of the primary safety considerations in complying with the protocols in NFPA 1403: Standard on Live fire Training Evolutions. ${ }^{7}$ Appendix A of this report contains the methods and full results for the laboratory experiments, which are summarized below. Figure 2 shows a test burn of pallets in the laboratory.

\section{Results of Laboratory Experiments}

The objective of the laboratory experiments was to quantify the spread of heat and smoke throughout the planned burn prop in order to ensure that the fuel package would result in a fire large enough to generate heat and smoke consistent with a residential structure fire, yet not so large as to transition to flashover. The full results of the laboratory experiments and modeling are shown in Appendix A and Appendix B. To summarize briefly, a four-pallet configuration, which produced a peak of approximately $2 \mathrm{MW}$, was determined to be the largest fuel load the room could support without the threat of transitioning to flashover. The compartment produced a negligible effect on the heat release rate of the fire compared to open burning conditions. The presence of an open window in the burn room reduced the

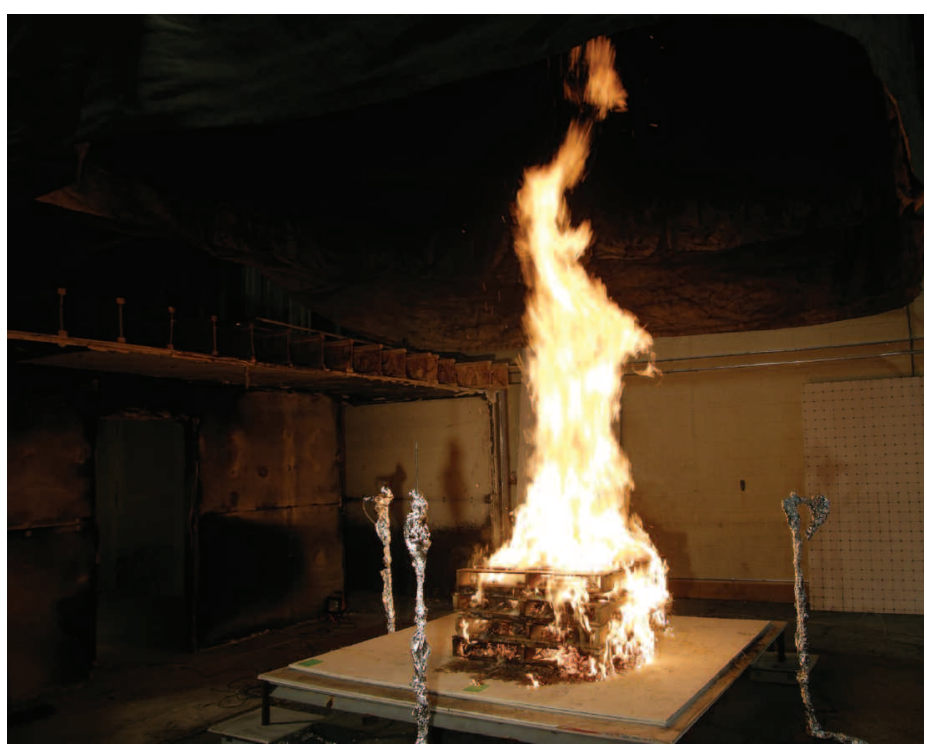

Figure 2: Test Burn of Pallets in Laboratory

production of carbon monoxide and carbon dioxide gases, primarily through enhanced oxygen availability and dilution, respectively. The location and quantity of excelsior had a significant impact on the growth rate of fire. More excelsior located nearer the bottom of the pallets resulted in a more rapid achievement of peak burning.

The results of the fuel load experiments to inform the building and experimental design indicated development of untenable conditions in the field experiments between $5 \mathrm{~min}$ and $15 \mathrm{~min}$, depending upon several factors: fire growth rate, ventilation conditions, the total leakage of heat into the building and through leakage paths, and manual fire suppression. This time frame allowed for differentiation of the effectiveness of various fire 


\section{Part 2: Field Experiment Methods}

department response characteristics.

n part 2, fire experiments were conducted in a residential-scale burn prop at the Montgomery County Public Safety Training

Academy in Rockville, MD.

\section{Field Site}

Montgomery County (MD) Fire and Rescue Department provided an open space to construct a temporary burn prop, with ready access to water and electrical utilities, at the Montgomery County Fire and Rescue Training Facility in Rockville, MD.

The burn prop was constructed as a two-story duplex with a common stairwell and movable walls between the sections to allow for multiple experiments daily. Symmetrically dividing the structure about the short axis allowed one side of the test structure to cool and dry out after a fire test with suppression. The burn prop contained two mirror-image, two-story units each totaling $2,000 \mathrm{ft}^{2}\left(186 \mathrm{~m}^{2}\right)$, without basement or nearby exposures - each therefore a typical model of a low-hazard single-family residence identified in NFPA 1710. An exterior view of the burn prop is shown in Figure 3. For each experiment there was a confirmed fire in the living room in the first floor rear of one unit

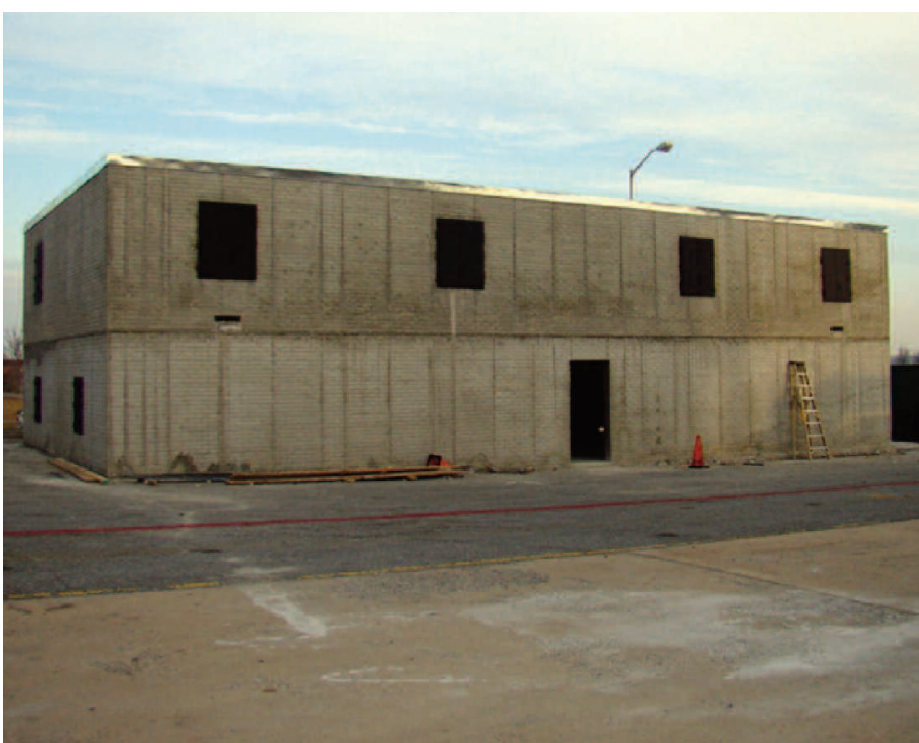

Figure 3: Exterior View of Burn Prop of the structure.

Details and dimension are shown in the floor plan in Figure 4.

The black lines in Figure 4 indicate load-bearing reinforced concrete walls and red lines indicate the gypsum over steel stud partition walls. The ceiling height was 94 in $(2.4 \mathrm{~m})$ throughout the entire structure except in the burn compartments, where additional hardening was installed to protect against repeated exposure to fire during the experiments. This additional fire proofing slightly reduced the ceiling height. Complete details about the building construction are included in Appendix C.

Noncombustible furniture (angle iron and gypsum board construction) was fashioned to represent obstacles of realistic size and location for firefighters navigating the interior of the structure. The dimensions were typical of residential furnishings. Figure 5 shows an example of the noncombustible furniture used in the time-to-task experiments.

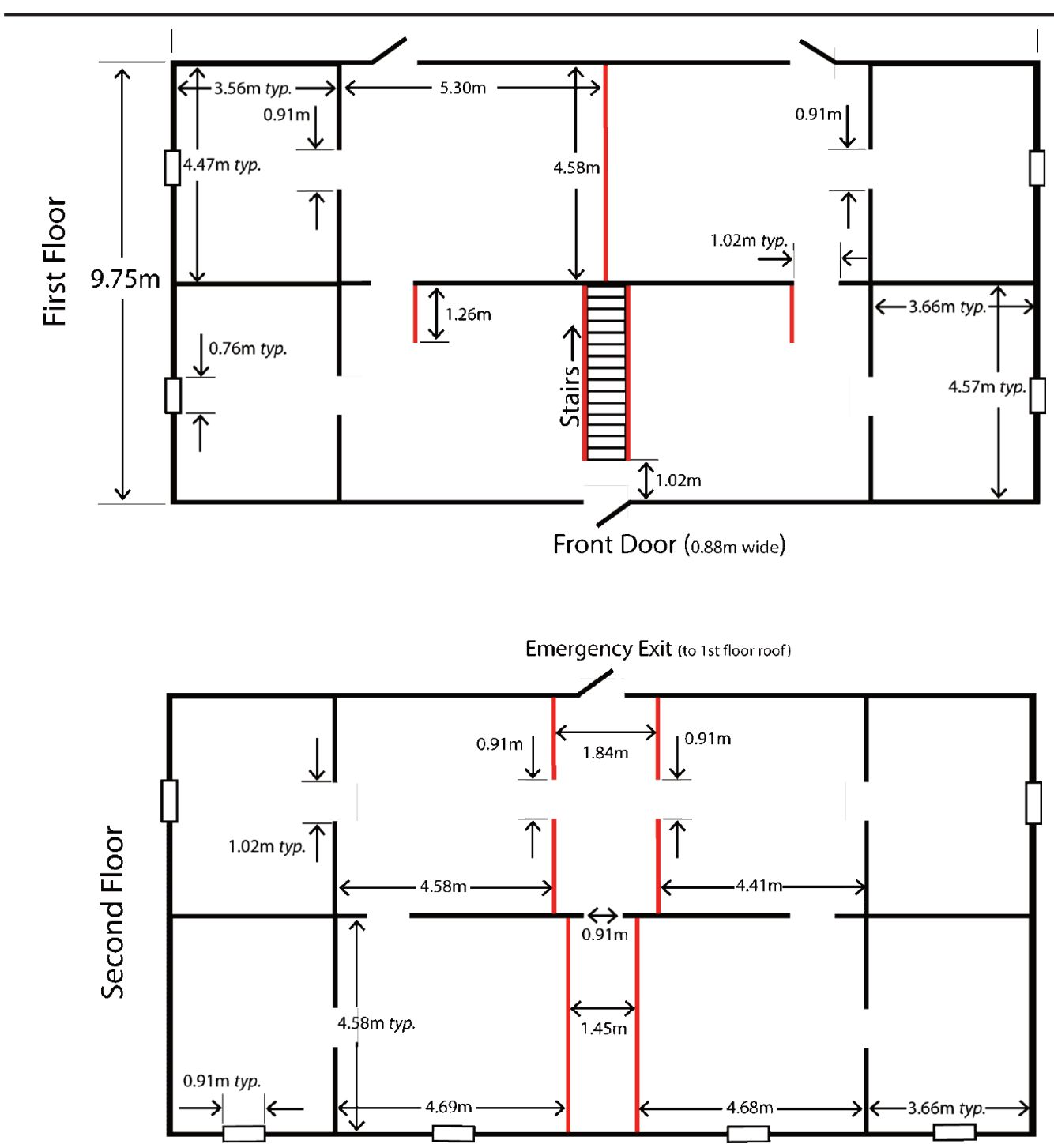




\section{Overview of Field Experiments}

In order to evaluate the performance representative of a NFPA 1710-compliant fire department, the field experiments consisted of two parts (the second and third parts of the four described in this report). In the first of the two parts of the field experiments, firefighter participants from Montgomery County (MD) and Fairfax County (VA) Fire Departments simulated an initial alarm assignment response to a structure described in NFPA 1710 as a low-hazard residential structure to which firefighters respond on a regular basis. The staffing level of fire apparatus was varied incrementally from two to five personnel per piece. The interval between apparatus on-scene arrival times was varied at either $60 \mathrm{~s}$ or $120 \mathrm{~s}$. Trained timing staff were used to record the start and completion times of 22 tasks deemed essential for mitigation of a residential fire incident by the study's technical experts. The pallet and excelsior configuration chosen from the laboratory experiments repeatably produced a consistent and realistic quantity of heat and smoke, similar to what firefighters encounter at a residential structure fire.

Although the fire source used in part 2 of the field experiments created a realistic amount of heat and smoke, the requirements of NFPA 1403 prevented use of a fire source which could potentially reach flashover within the structure. Therefore, part 3 of the fire experiments was conducted in order to change the fuel package to be representative of realistic fuel loading that could be found in a living room in a residential structure (sleeper-sofa, upholstered chairs, end tables, etc). The intent of this part of the study was to determine how the times of firefighter interactions, averaged with respect to the staffing and arrival intervals, impacted the interior tenability conditions. Fire fighting tactics were performed in a manner which complied with NFPA 1403; ventilation was performed with proper personal protective equipment (PPE) and hand tools from the exterior of the burn prop. Suppression was performed with an interior remote suppression device operated from the exterior of the burn prop.

\section{Instrumentation}

Instrumentation to measure gas temperature, gas concentrations, heat flux, visual obscuration, video, and time during the experiments was installed throughout the burn prop. The data were recorded at 1 -second intervals on a computer-based data acquisition system. Figure 6 presents a schematic plan view of the instrumentation. All instruments were wired to a centralized data collection room attached as a separate space on the west side of the building, which is described later in this report ensuring physical separation for the data collection personnel from the effects of the fire, while minimizing the wire and tube lengths to the data logging equipment. See Appendix C for additional details about the instrumentation.

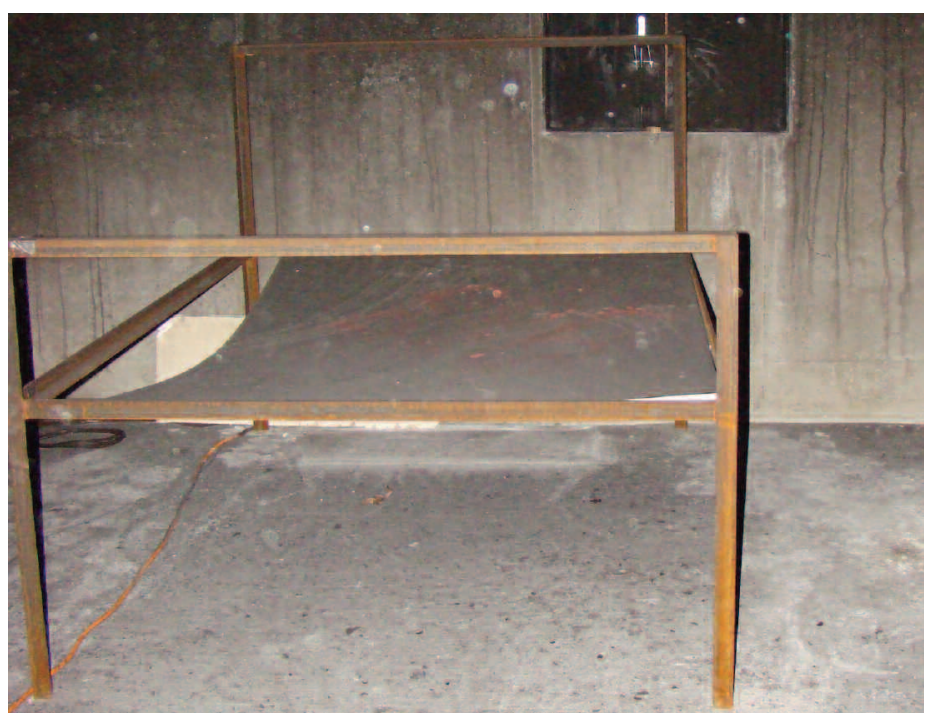

Figure 5: Noncombustible Furniture Used in the Time-to-Task Experiments
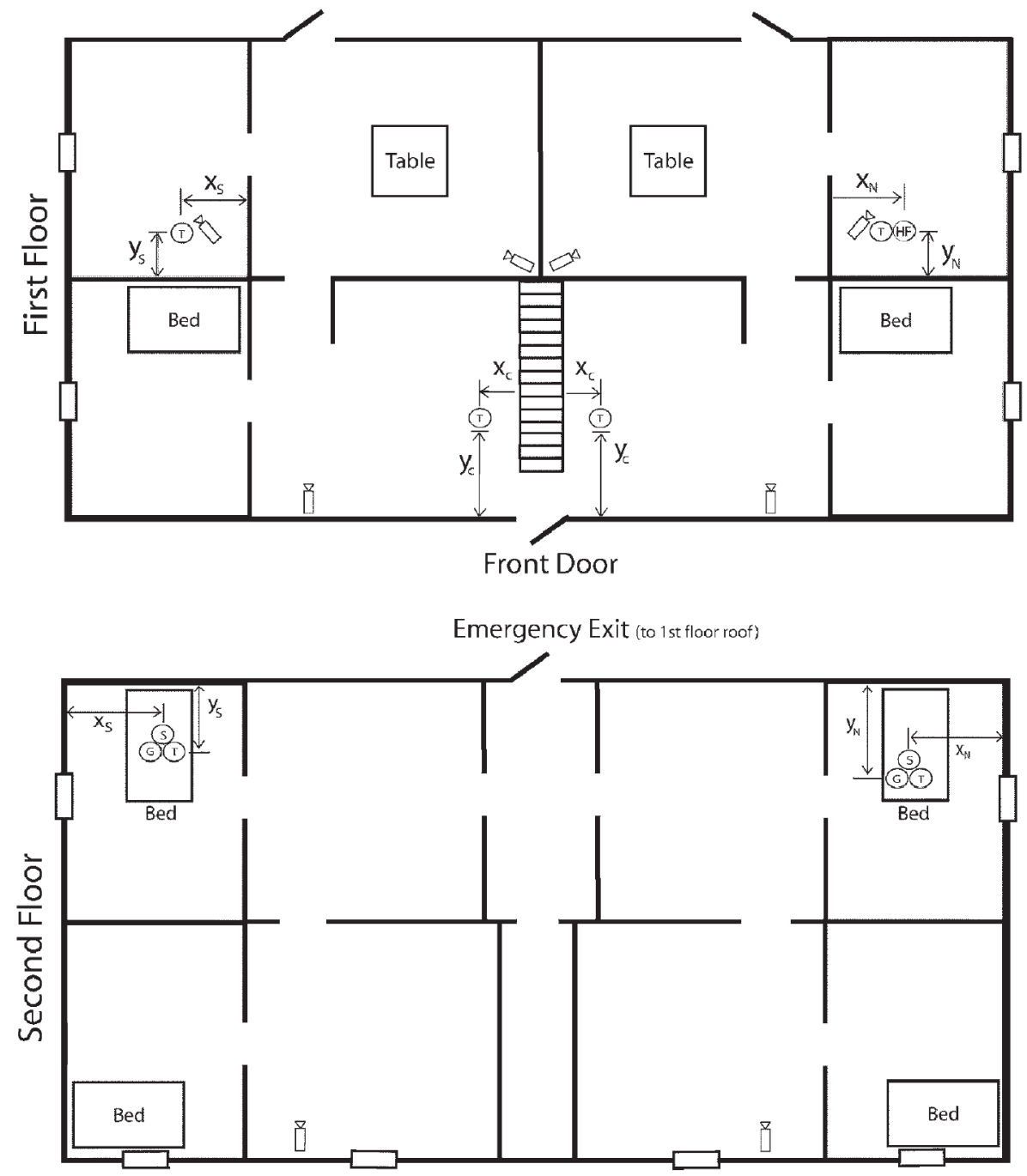

Figure 6: Instrumentation and Furniture Prop Layout
Key:

(T) Thermocouple

(HF) Heat Flux

(G) Gas Probe

(5) Smoke Meter

$\$$ video 


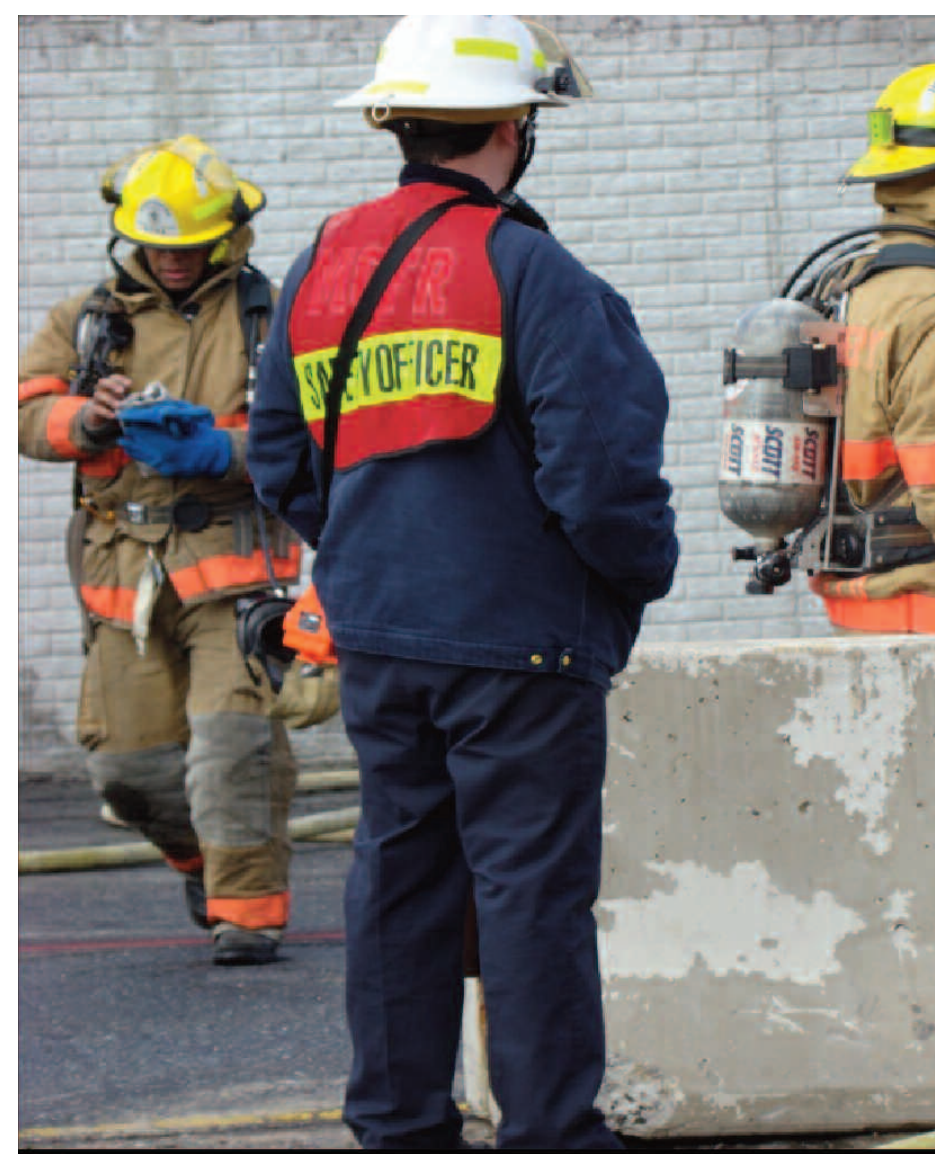

Figure 7: Fireground Safety Officer

\section{Safety Protocols}

Firefighter safety was always a primary concern in conducting the research. Participants were drawn from two departments Fairfax County, VA and Montgomery County, MD — that regularly conduct NFPA 1403 compliant live fire training for their staff and recruits.
A safety officer was assigned to the experiments by the Montgomery County Fire and Rescue Department to assure compliance with NFPA 1403. The safety officer (Figure 7) participated in all orientation activities, daily briefings, and firefighter gear checks and was always actively involved in overseeing all experiments. The safety officer had full authority to terminate any operation if any safety violation was observed. In addition to the safety officer, a rapid intervention team (RIT), assigned from dedicated crews not in the actual experiment, was in place for each experiment, and a staffed ambulance was on standby at the site. Radio communication was always available during the experiments should a "mayday" emergency arise.

Experiments were stopped for any action considered to be a protocol breach or safety concern. For example, all ladders - 24 $\mathrm{ft}(7.3 \mathrm{~m})$ or $28 \mathrm{ft}(8.5 \mathrm{~m})$ - were to be raised by two firefighters. As crew sizes were reduced, some firefighters attempted to place ladders single-handedly in an effort to complete the task more quickly. This procedure, while vividly illustrating how firefighters try to do more with less in the field, is unsafe and could potentially result in strain or impact injuries.

Additional safety features were built in to the field structure. A deluge sprinkler system oriented to the known location of the fuel package could be remotely activated for rapid fire suppression. All first floor rooms had direct access to the exterior of the building through either doors or windows. The second story had an emergency exit to the roof of the attached instrumentation room.

A closely related concern to ensure firefighter safety and readiness to repeat experiments with equivalent performance was adequate rehabilitation (see Figure 8). At the beginning and end of each day, crews completed a health and safety check. The importance of staying well-hydrated before and during experiments was especially emphasized.
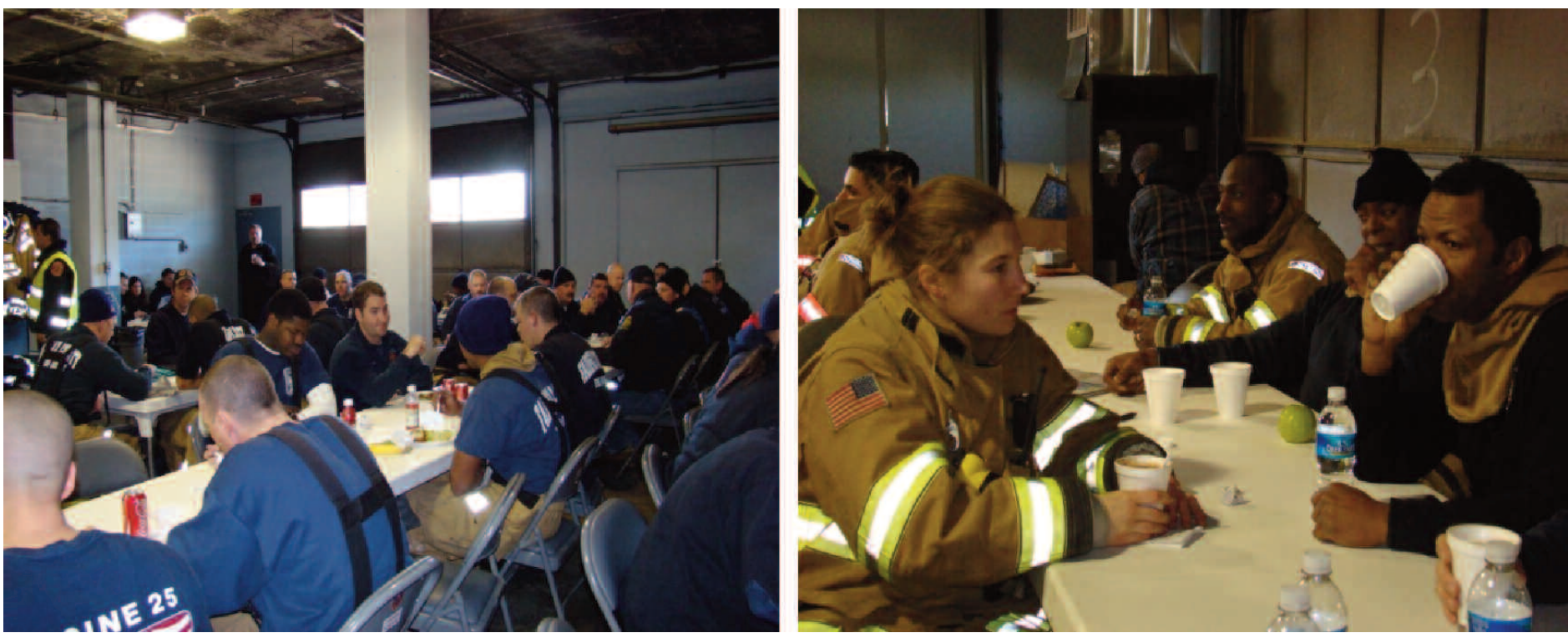

Figure 8: Crew Rehabilitation 


\section{Time-to-Task Experiments}

\section{On-Scene Fire Department Tasks}

The on-scene fire department task part of the study focused on the tasks firefighters perform after they arrive on the scene of a low-hazard residential structure fire. A number of nationally recognized fire service experts were consulted during the development of the on-scene fire department tasks in order to ensure a broad applicability and appropriateness of the task distribution. ${ }^{8}$ The experiments compared crew performance and workload for a typical fire fighting scenario using two-, three-, four-, and five-person crews. 24 total experiments were conducted to assess the time it took various crew sizes to complete the same tasks on technically similar fires in the same structure. In addition to crew sizes, the experiments assessed the effects of stagger between the arriving companies. Close stagger was defined as a 1 -minute time difference in the arrival of each responding company. Far stagger was defined as a 2-minute time difference in the arrival of each responding company. One-minute and two-minute arrival stagger times were determined from analysis of deployment data from more than 300 U.S. fire departments responding to a survey of fire department operations conducted by the International Association of Fire Chiefs (IAFC) and the International Association of Fire Fighters (IAFF). Considering both crew size and company stagger there were eight experiments conducted in triplicate totaling twenty-four tests, as shown in the full replicate block in Table 1. A full replicate was completed in a randomized order (determined by randomization software) before a test configuration was repeated.

\section{Crew Size}

For each experiment, three engines, a ladder-truck and a battalion chief and an aide were dispatched to the scene of the residential structure fire. The crew sizes studied included two-, three-, four-, and five-person crews assigned to each engine and truck dispatched. Resultant on-scene staffing totals for each experiment follow: $(\mathrm{FF}=$ firefighter $)$

Two Person crews $=8$ FFs + Chief and Aide $=10$ total on-scene

Three Person crews $=12$ FFs + Chief and Aide $=14$ total on-scene

Four Person crews $=16$ FFs + Chief and Aide $=18$ total on-scene

Five Person crews $=20 \mathrm{FFs}+$ Chief and Aide $=22$ total on-scene ${ }^{9}$

\section{Department Participation}

The experiments were conducted in Montgomery County, MD at the Montgomery County Fire Rescue Training Academy during the months of January and February 2009. All experiments took place in daylight between 0800 hours and 1500 hours. Experiments were postponed for heavy rain, ice, or snow and rescheduled for a later date following other scheduled experiments.

Montgomery County (MD) and Fairfax County (VA) firefighters participated in the field experiments. Each day both departments committed three engines, a ladder truck and

\begin{tabular}{|c|c|}
\hline Crew Size & Apparatus Stagger \\
\hline 2 Person & Close Stagger (One minute) \\
\hline 3 Person & Close Stagger (One minute) \\
\hline 4 Person & Close Stagger (One minute) \\
\hline 5 Person & Close Stagger (One minute) \\
\hline 2 Person & Far Stagger (Two minutes) \\
\hline 3 Person & Far Stagger (Two minutes) \\
\hline 4 Person & Far Stagger (Two minutes) \\
\hline 5 Person & Far Stagger (Two minutes) \\
\hline
\end{tabular}

Table 1: Primary Variables for Time-to-Task Experiments

associated crews, as well as a battalion chief to the experiments. The two battalion chiefs, alternated between the roles of battalion chief and aide. Firefighters and officers were identified by participating departments and oriented to the experiments. Each experiment included engine crews, truck crews and command officers from each participating department. Participants varied with regard to age and experience. Crews that normally operated together as a company were kept intact for the experiments to assure typical operation for the crew during the scenarios. However, in all experiments crews were used from both departments, including engine crews, truck crews, and officers.

This allocation of resources made it possible to conduct back-to-back experiments by rotating firefighters between field work and rehabilitation areas.

\section{Crew Orientation}

All study participants were required to attend an orientation prior to the beginning of the experiments (see Figure 9, page 25). The orientations were used to explain experiment procedures, task flows, division of labor between crews, and milestone events in the scenario.

Daily orientations were conducted for all shifts to assure every participant attended. Orientations included a description of the overall study objectives as well as the actual experiments in which they would be involved. Per the requirements of NFPA 1403, full disclosure regarding the structure, the fire, and the tasks to be completed were provided. Crews were also oriented to the fireground props, instrumentation used for data collection, and the specific scenarios to be conducted. Every crew member was provided a walkthrough of the structure during the orientation and each day prior to the start of the experiments. 
Twenty-two fireground tasks were completed in each experiment. Meticulous procedures gathered data to measure key areas of focus, such as individual task start times, task completion times, and overall scenario performance times. Each task was assigned a standardized start and end marker, such as crossing the threshold to enter the building with a hose line or touching a ladder to raise it to a second story window. The 22 tasks, with the events for measuring start and stop times, are shown in Table 2 (page26). Figures $10-19$ illustrate firefighter activity in a number of the tasks to complete experiments or prepare for the next experiment.

For reasons of both safety and cost efficiency, two tasks forcible entry of the front door and ventilation of the windows on the first and second stories - required special procedures.

The study could not accommodate replacing the doors and windows daily for the fire suppression experiments. Before the start of experiments with the full sequence of tasks, these two tasks were measured in a realistic manner using training props constructed at the site of the fireground experiments. As with the overall experiments, these two tasks were repeated in triplicate and the times averaged. The average time to complete the tasks was then used in the larger scale experiment. As firefighters came to the point of breaching the door or windows, the timers would hold them for the time designated by the earlier experiments and then give them the approval to open the door or windows. The start and end times were then recorded just as other tasks were.
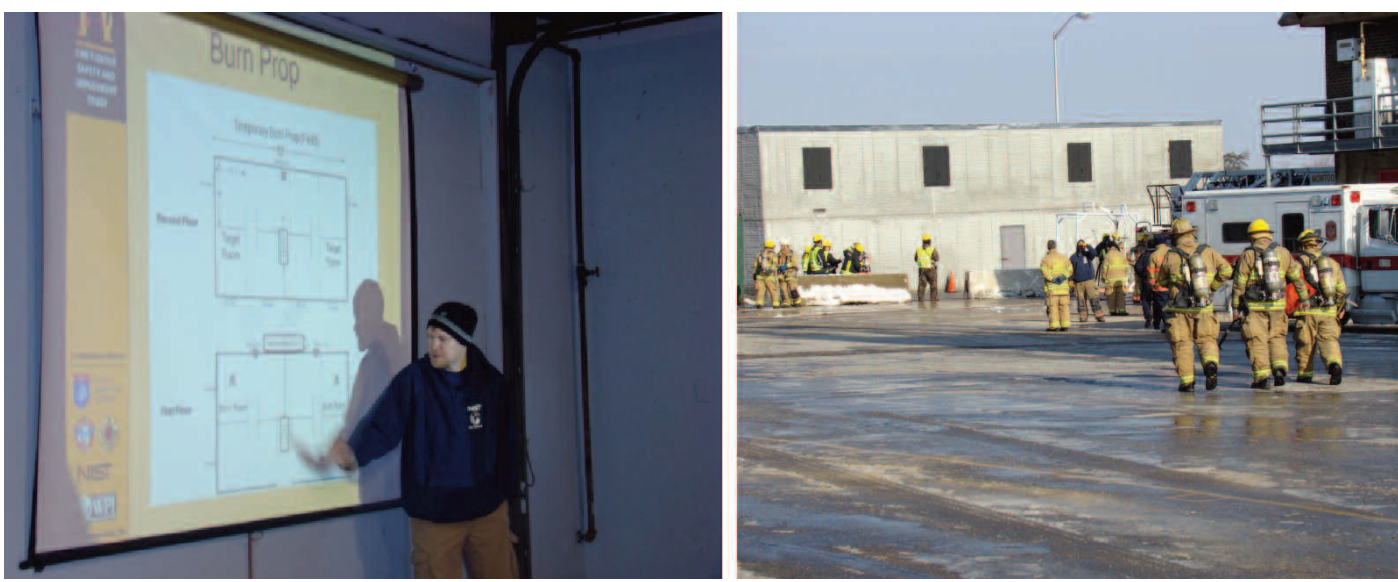

Figure 9: Crew Orientation and Walkthrough

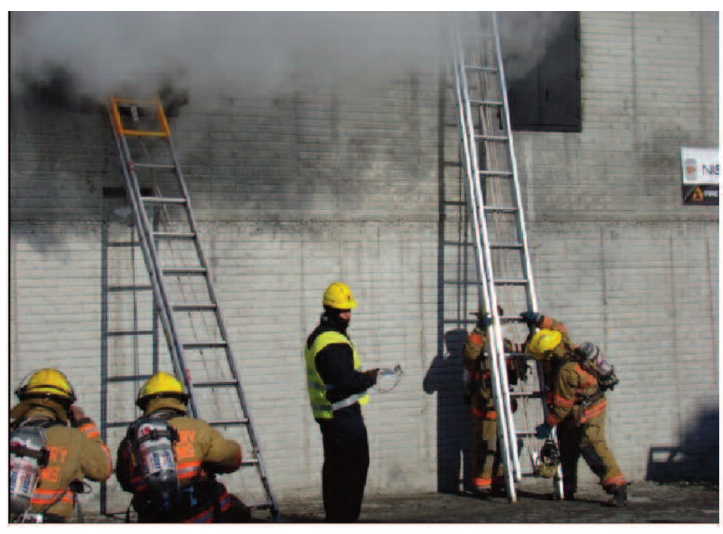

Figure 10: Ground Ladders

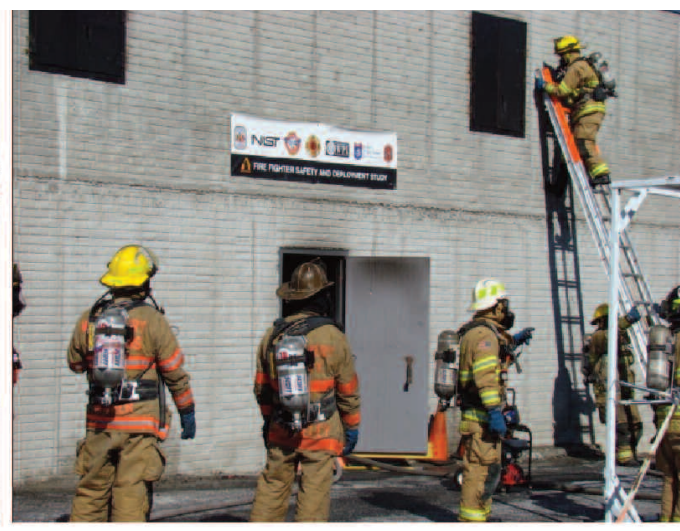

Figure 11: Ventilation

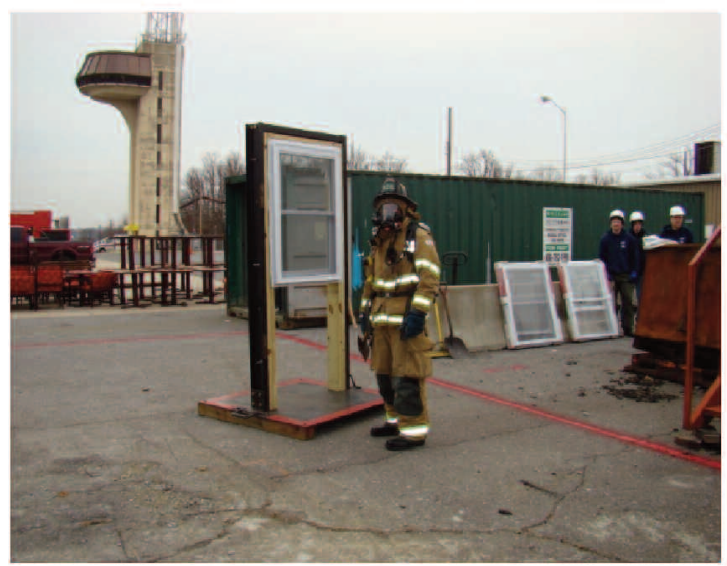

Figure 12: Ground Level Window Breakage Prop

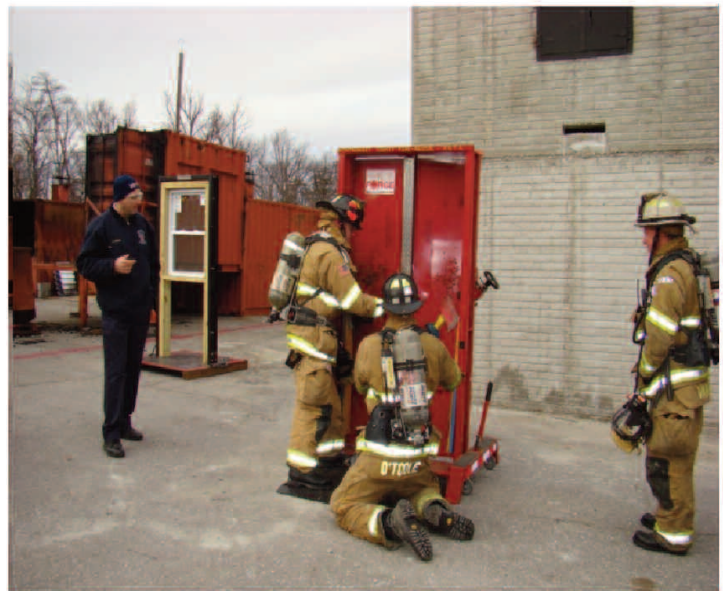

Figure 14: Door Forcible Entry Prop

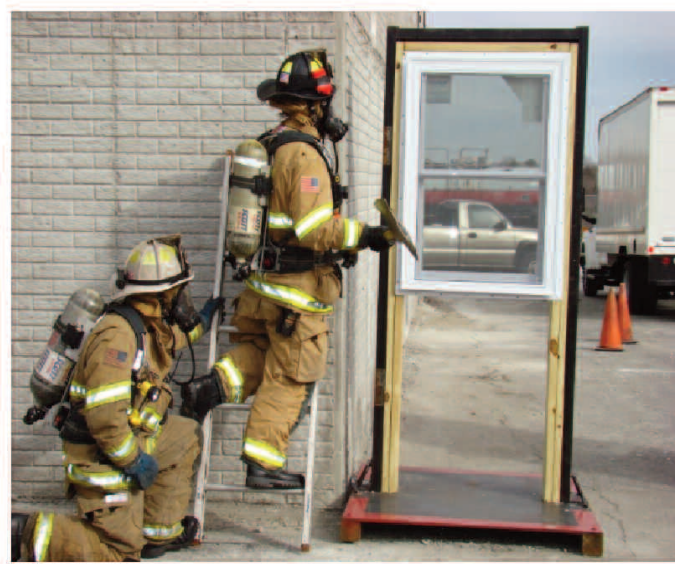

Figure 13: Second Story Window Breakage Prop

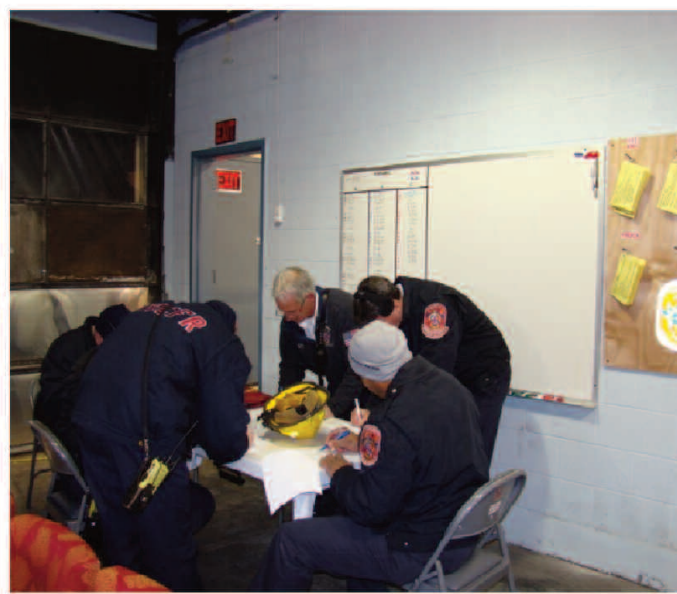

Figure 15: Crew Preparation and Cue Cards 
Table 2: Tasks and Measurement Parameters

\begin{tabular}{|c|c|c|c|}
\hline Tasks & Measurement Parameters & Tasks & Measurement Parameters \\
\hline 1. Stop at Hydrant, Wrap Hose & $\begin{array}{l}\text { START - Engine stopped at } \\
\text { hydrant } \\
\text { STOP - Firefighter back on engine } \\
\text { and wheels rolling }\end{array}$ & 13. Conduct Primary Search & $\begin{array}{l}\text { START - Firefighters enter front } \\
\text { door } \\
\text { STOP - Firefighters transmit } \\
\text { "search complete" }\end{array}$ \\
\hline 2. Position Engine 1 & $\begin{array}{l}\text { START - Wheels rolling from } \\
\text { hydrant } \\
\text { STOP - Wheels stopped at } \\
\text { structure }\end{array}$ & 14. Ground Ladders in Place & $\begin{array}{l}\text { START - Firefighter touches ladder } \\
\text { to pull it from truck } \\
\text { STOP - } 4 \text { Ladders thrown: } 3 \\
\text { ladders on the } 2^{\text {nd }- \text { story windows }} \\
\text { and } 1 \text { to the roof }\end{array}$ \\
\hline $\begin{array}{l}\text { 3. Conduct Size-up } \\
\text { (360-degree lap), transmit } \\
\text { report, establish command }\end{array}$ & $\begin{array}{l}\text { START - Officer off engine } \\
\text { STOP - Completes radio } \\
\text { transmission of report }\end{array}$ & $\begin{array}{l}\text { 15. Horizontal Ventilation } \\
\text { (Ground) }\end{array}$ & $\begin{array}{l}\text { START- Firefighter at } 1^{\text {st }} \text { window to } \\
\text { begin ventilation (HOLD for } 8 \\
\text { seconds) }\end{array}$ \\
\hline \multirow[t]{2}{*}{ 4. Engage Pump } & START - Driver off engine & & $\begin{array}{l}\text { STOP - Hold time complete - } \\
\text { window open }\end{array}$ \\
\hline & STOP - Driver throttles up pump & \multirow{2}{*}{$\begin{array}{l}\text { 16. Horizontal Ventilation } \\
\left(2^{\text {nd }} \text { Story }\right)\end{array}$} & \multirow{2}{*}{$\begin{array}{l}\text { START - Firefighter grabs ladder } \\
\text { for climb. (Firefighter must leg lock } \\
\text { for ventilation. HOLD time at each } \\
\text { window is } 10 \text { seconds) } \\
\text { STOP - All } 2^{\text {nd }-s t o r y ~ w i n d o w s ~ o p e n ~} \\
\text { - descend ladder - feet on ground. }\end{array}$} \\
\hline $\begin{array}{l}\text { 5. Position Attack Line } \\
\text { (Forward Lay) }\end{array}$ & $\begin{array}{l}\text { START - Firefighter touches hose } \\
\text { to pull it from engine } \\
\text { STOP - Flake, charge and bleed } \\
\text { complete (hose at front door } \\
\text { prepared to advance) }\end{array}$ & & \\
\hline 6. Establish 2 In/2 Out & $\begin{array}{l}\text { Company officer announces - "2 } \\
\text { In/2 Out established" ( } 4 \text { persons } \\
\text { assembled on scene OR at the } \\
\text { call of the Battalion } \\
\text { Chief/Company Officer) }\end{array}$ & 17. Control Utilities (Interior) & $\begin{array}{l}\text { START - Radio transmission to } \\
\text { control utilities } \\
\text { STOP - When firefighter } \\
\text { completes the task at the prop }\end{array}$ \\
\hline 7. Supply Attack Engine & $\begin{array}{l}\text { START - Firefighter touches } \\
\text { hydrant to attach line } \\
\text { STOP - Water supply to attack } \\
\text { engine }\end{array}$ & 18. Control Utilities (Exterior) & $\begin{array}{l}\text { START - Radio transmission to } \\
\text { control utilities } \\
\text { STOP - When firefighter } \\
\text { completes the task at the prop }\end{array}$ \\
\hline 9. Gain/Force Entry & $\begin{array}{l}\text { Time that Company Officer } \\
\text { announces RIT is established } \\
\text { START - Action started } \\
\text { (HOLD time }=10 \text { seconds) }\end{array}$ & 19. Conduct Secondary Search & $\begin{array}{l}\text { START - Firefighters enter front } \\
\text { door } \\
\text { STOP - Firefighters transmit } \\
\text { "secondary search complete" }\end{array}$ \\
\hline 10. Advance Attack Line & $\begin{array}{l}\text { STOP - Door opened for entry } \\
\text { START - Firefighter touches hose } \\
\text { STOP - Water on fire }\end{array}$ & $\begin{array}{l}\text { 20. Check for Fire Extension } \\
\text { (walls) }\end{array}$ & $\begin{array}{l}\text { START- Firefighters pick up } \\
\text { check-for-extension prop } \\
\text { STOP- Completion of } 4 \text { sets total } \\
\text { ( } 1 \text { set }=4 \text { in and } 4 \text { out) } \\
\text { This task may be done by more } \\
\text { than one person. }\end{array}$ \\
\hline $\begin{array}{l}\text { 11. Advance Backup Line } \\
\text { (stop time at front door) }\end{array}$ & $\begin{array}{l}\text { START - Firefighter touches hose } \\
\text { to pull from engine bed } \\
\text { STOP - Backup line charged to } \\
\text { nozzle }\end{array}$ & \multirow[t]{2}{*}{$\begin{array}{l}\text { 21. Check for Fire Extension } \\
\text { (ceilings) }\end{array}$} & \multirow{2}{*}{$\begin{array}{l}\text { START - Firefighters pick up } \\
\text { check-for-extension prop } \\
\text { STOP - Completion of } 4 \text { sets total } \\
\text { ( } 1 \text { set }=3 \text { up and } 5 \text { down) } \\
\text { This task may be done by more } \\
\text { than one person. }\end{array}$} \\
\hline \multirow{2}{*}{$\begin{array}{l}\text { 12. Advance Backup } \\
\text { Line/Protect Stairwell }\end{array}$} & \multirow[b]{2}{*}{$\begin{array}{l}\text { START - Firefighter crosses } \\
\text { threshold } \\
\text { STOP - Position line for attack at } \\
\text { stairwell }\end{array}$} & & \\
\hline & & 22. Mechanical Ventilation & $\begin{array}{l}\text { START - Firefighters touch fans to } \\
\text { remove from truck } \\
\text { STOP - Fans in place at front door } \\
\text { and started }\end{array}$ \\
\hline
\end{tabular}


Data Collection:

Standardized Control

Measures

Several control measures were used to collect data, including crew cue cards, radio communications, task timers, and video recording.

Performance was timed for each task in each scenario including selected milestone tasks such as door breach, water-on-fire, and individual window ventilation.

Data were collected for crew performance on each task, and individual firefighter

performance was not considered.

\section{Task Flow Charts and} Crew Cue Cards

Task procedures were standardized for each experiment/scenario. Technical experts worked with study investigators to break down crew tasks into individual tasks based on crew size. Task flow charts were created and then customized for the various crew sizes. The carefully designed task flow ensured that the same overall workload was maintained in each experiment, but was redistributed based on the number of personnel available for the work. See Appendix D for additional details.

All tasks were included in each scenario and cue cards were developed for each individual participant in each scenario. For example, a four-person crew would have a cue card for each person on the crew including the officer, the driver, and the two firefighters. Cards were color coded by crew size to assure proper use in each scenario.

\section{Radio communications}

Interoperability of radio equipment used by both participating departments made it possible to use regular duty radios for communication during the experiments. Company officers were instructed to use radios as they would in an actual incident. Montgomery County Fire and Rescue Communications recorded all radio interaction as a means of data backup. Once all data quality control measure were complete, the records were then overwritten as a routine procedure.

\section{Task Timers}

Ten observers/timers, trained in the use of a standard stop watch with split-time feature, recorded time-to-task data for each field experiment. To assure understanding of the observed tasks,

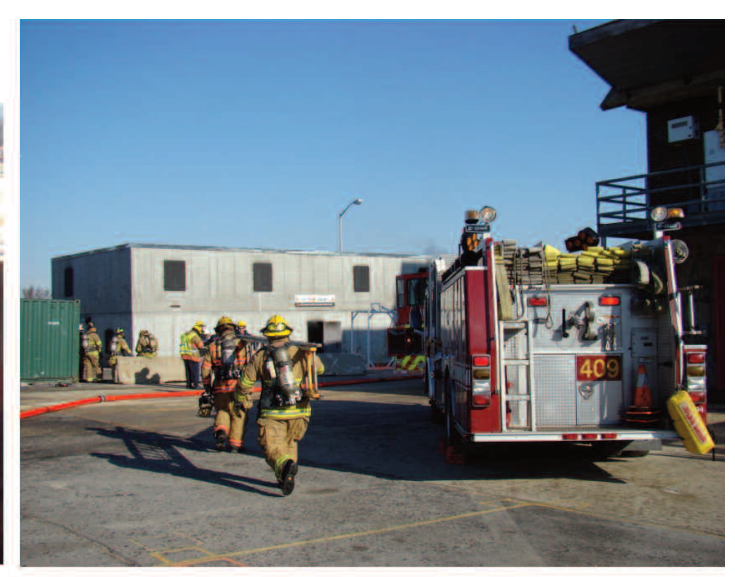

Figure 17: Crews Responding

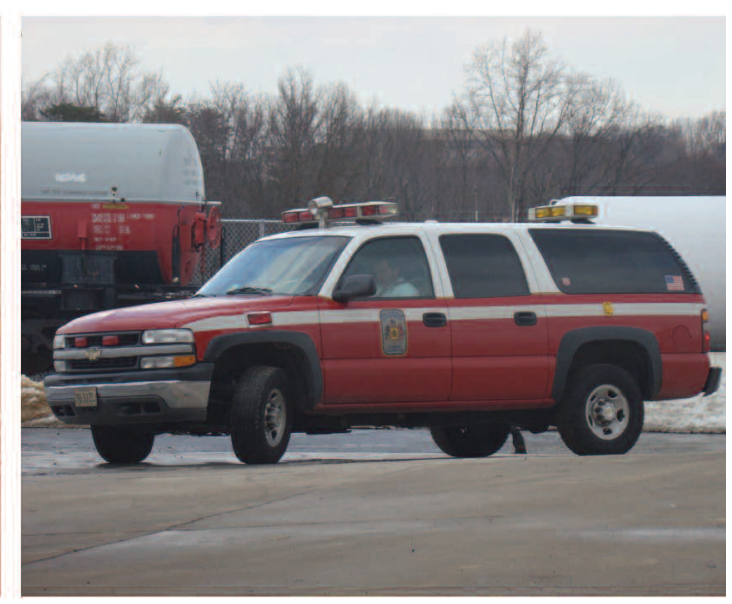

Figure 19: Incident Command

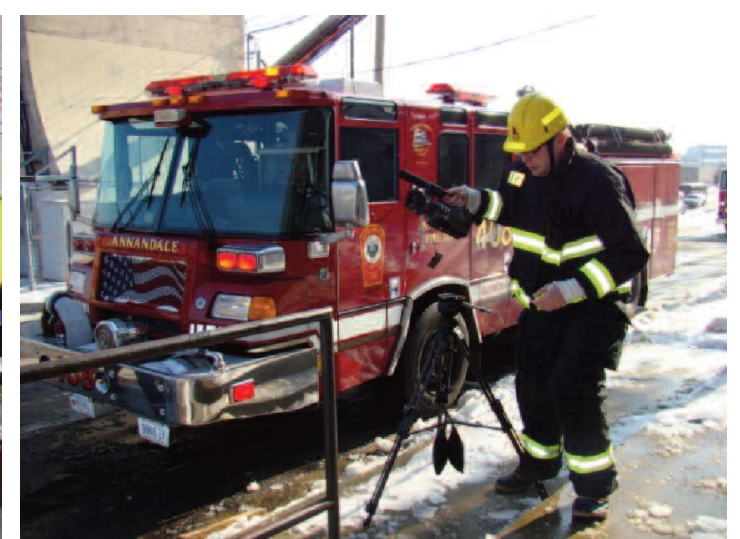

Figure 21: Video Recording for Quality Control

firefighters were used as timers, each assigned specific tasks to observe and to record the start and end times.

To enhance accuracy and consistency in recording times, the data recording sheets used several different colors for the tasks (see Appendix D). Each timer was assigned tasks that were coded in the same color as on the recording sheet. All timers wore high-visibility safety gear on the fireground (see Figure 20).

\section{Video records}

In addition to the timers, video documentation provided a backup for timed tasks and for quality control (see Figure 21). No less than six cameras were used to record fireground activity from varied vantage points. Observer/timer data were compared to video records as part of the quality control process. 


\section{Crew Assignment}

Crews from each department that regularly operated together were assigned to work as either engine or truck companies in each scenario. Both Fairfax County and Montgomery County crews participated in each experiment.

Crews assigned to each responding company position in one scenario were assigned to another responding company position in subsequent scenarios, with the objective of minimizing learning from one experiment to another. For example, crews in the role of engine 1 in a morning scenario might be assigned to the engine 3 position in the afternoon, thus eliminating learning from exact repetition of a task as a factor in time to completion. Additionally, participating crews from both Montgomery County and Fairfax County were from three different shifts, further reducing opportunities for participant repetition in any one position.

\section{Response Time Assumptions}

Response time assumptions were made based on time objectives set forth in the NFPA 1710. Time stagger allocations were set by the project technical advisors in order to assess the impact of arriving unit time separation on task start and completion times, as well as the overall scene time.
Below are the values assigned to the various time segments in the overall response time. The total of the response time segments may also be referred to as the total reflex time.

1. Fire ignition $=$ time zero

2. $60 \mathrm{~s}$ for recognition (detection of fire) and call to 9-1-1

3. $60 \mathrm{~s}$ for call processing/dispatch

4. $60 \mathrm{~s}$ for turnout ${ }^{10}$

5. Close Stagger $=240 \mathrm{~s}$ travel time FIRST engine with $60 \mathrm{~s}$ ladder-truck lag and $90 \mathrm{~s}$ lag for each subsequent engine

a. Truck arrives at $300 \mathrm{~s}$ from notification

b. Second engine at $330 \mathrm{~s}$ from notification

c. Third engine at 420 seconds from notification

6. Far Stagger $=240 \mathrm{~s}$ travel time FIRST engine with $120 \mathrm{~s}$ ladder-truck lag and $150 \mathrm{~s}$ lag for each subsequent engine a. Truck arrives at $360 \mathrm{~s}$ from notification

b. Second engine arrives at $390 \mathrm{~s}$ from notification

c. Third engine arrives at $540 \mathrm{~s}$ from notification.

The design of this part of the experiments allowed firefighter entry into the burn building. The next part of the experiments required a modified methodology. 


\section{Part 3: Room and Contents Fires}

A s previously discussed, NFPA 1403 prohibits firefighters in a training exercise from entering a structure with sufficient fuel load to result in room flashover. But the value of the data from the time-to-task experiments lies not just in the duration and time-of-completion statistics for tasks, but also in measuring the tenability of the atmosphere for occupants urgently needing firefighter assistance. Therefore Part 3 of the experiments (room and contents fires) used a larger fuel load to focus on the seven of the 22 tasks that cause a change in the fire behavior through ventilation or active suppression:

1. Forced entry of the front door

2. Water on fire

3. Second floor window \#1 ventilated (burn room window)

4. Second floor window \#2 ventilated (front window, near corner)

5. Second floor window \#3 ventilated (front window, near front door)

6. First floor window \#1 ventilated (window beside the fire room)

7. First floor window \#2 ventilated (self-ventilated at flashover)

Because the fuel load was sufficient for flashover, all firefighter activity was conducted outside the building. Tasks that in Part 3 required entry into the building, such as search or interior utility control, were factored into this part by delaying the next task for the average duration of the task from Part 2. Firefighters in full gear opened the door with a gloved hand or opened windows from the ground with a tool such as a pike pole or angle iron, again at the time specified by the averages from Part 2. Averages were derived from the three iterations of each scenario. The different number of iterations in Part 3 will be explained later in this report.

Because firefighters could not enter the building, a nozzle controlled from the instrumentation room was installed. The nozzle was placed in the room directly outside the burn room and oriented toward the burn room near the doorway in order to best emulate the nozzle location of live firefighter suppression (see Figure 22). The nozzle was encased with mineral wool and heavy-duty aluminum foil (bottom picture in Figure 22) to protect the electronics and wiring from the intense radiation energy emitted by the fire. Blocks were used to anchor the nozzle against the lateral forces exerted by the momentum of the water supply. The activation time for suppression was determined by the data from the time-to-task test results.

A $15^{\circ}$ spray pattern was directed toward the seat of the fire and swept horizontally from side to side. While the remotely controlled hose line knocked down the majority of the fire, it was

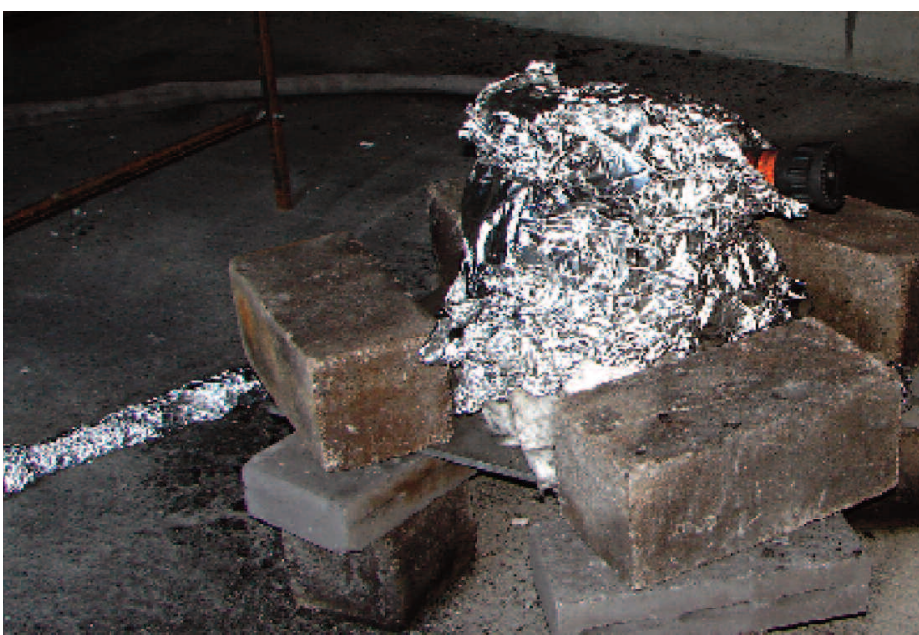

Figure 22: Remotely Controlled Fire Suppression Nozzle for Room and Contents Fires

not as effective as a live firefighter with a better view into the room of origin. Therefore, after the fire was diminished, a supplemental stream was applied through the burn room window in order to control the fire (see Figure 23). All personnel on the hose line were in full turnout gear and self-contained breathing apparatus during the exterior application of water.

\section{Fuel Packages for the Room and Contents Fires}

In order to maximize the repeatability of the fire development, nominally identical rooms of furniture of identical manufacturer, style, and age were used for each test. A plan-view schematic of the furniture is shown in Figure 24 and pictures of the burn room prior to testing are shown in Figure 25. Key dimensions, mass, and materials for combustible furnishings are detailed in Appendix C.

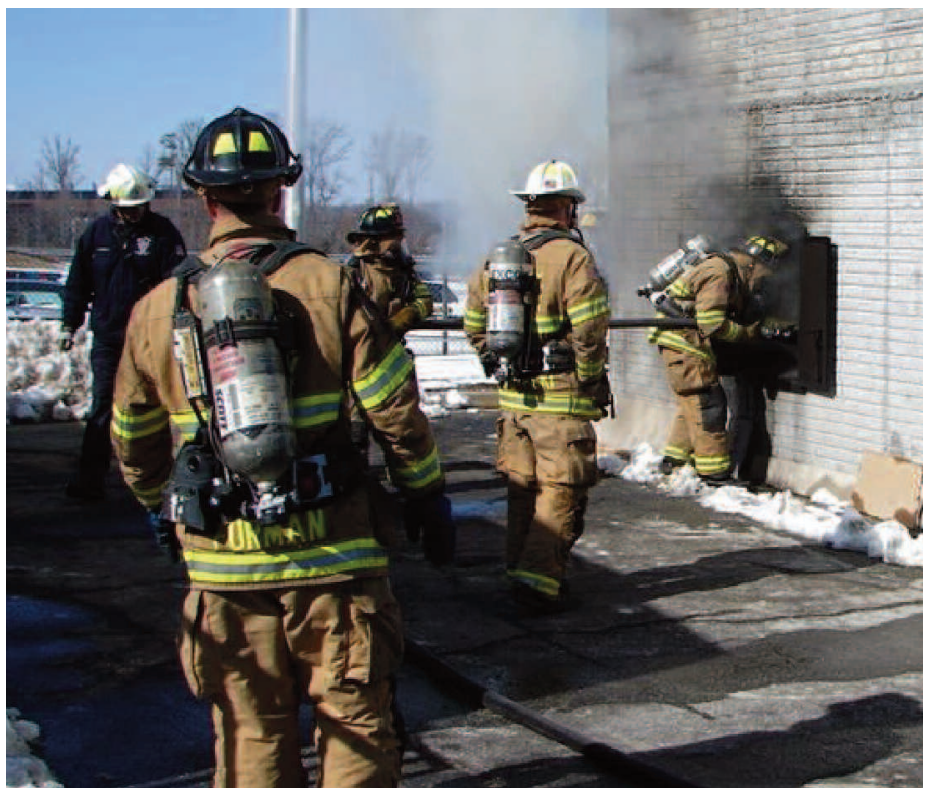

Figure 23: Supplemental Suppression Applied for Room and Contents Tests 


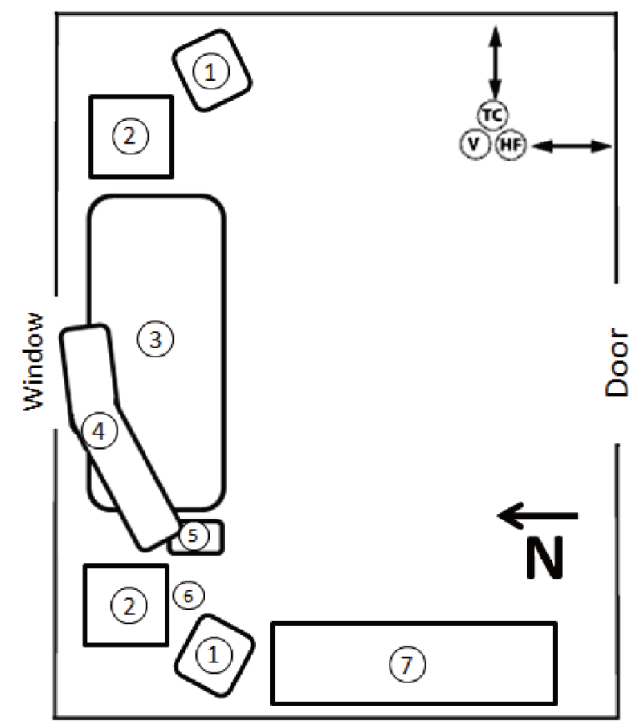

(1C) THERMOCOUPLE

$X=0.76 \mathrm{~m}, Y=0.51 \mathrm{~m}$,

$Z=0.3,0.61,0.91,1.22,1.52,1.83,2.13 m$

(Hi) HEAT FWX

HF1: $X=0.91 \mathrm{~m}, Y=0.91 \mathrm{~m}, Z=0.17 \mathrm{~m}$

$H F 2: X=0.5 \mathrm{~m}, Y=0.66 \mathrm{~m}, Z=1 \mathrm{~m}$

๖ำ

(v) VIDEO CAMERA

1: Red Upholstered Chair

2: Nightstand

3: Sleeper Sofa

4: Body Pillow

5:21 Quart Waste Basket

6: Twin Size 100\% Cotton Blanket

7:2 Drawer Dresser

Figure 24: Configuration of Furnishings in Burn Room (Room and Contents Fires)
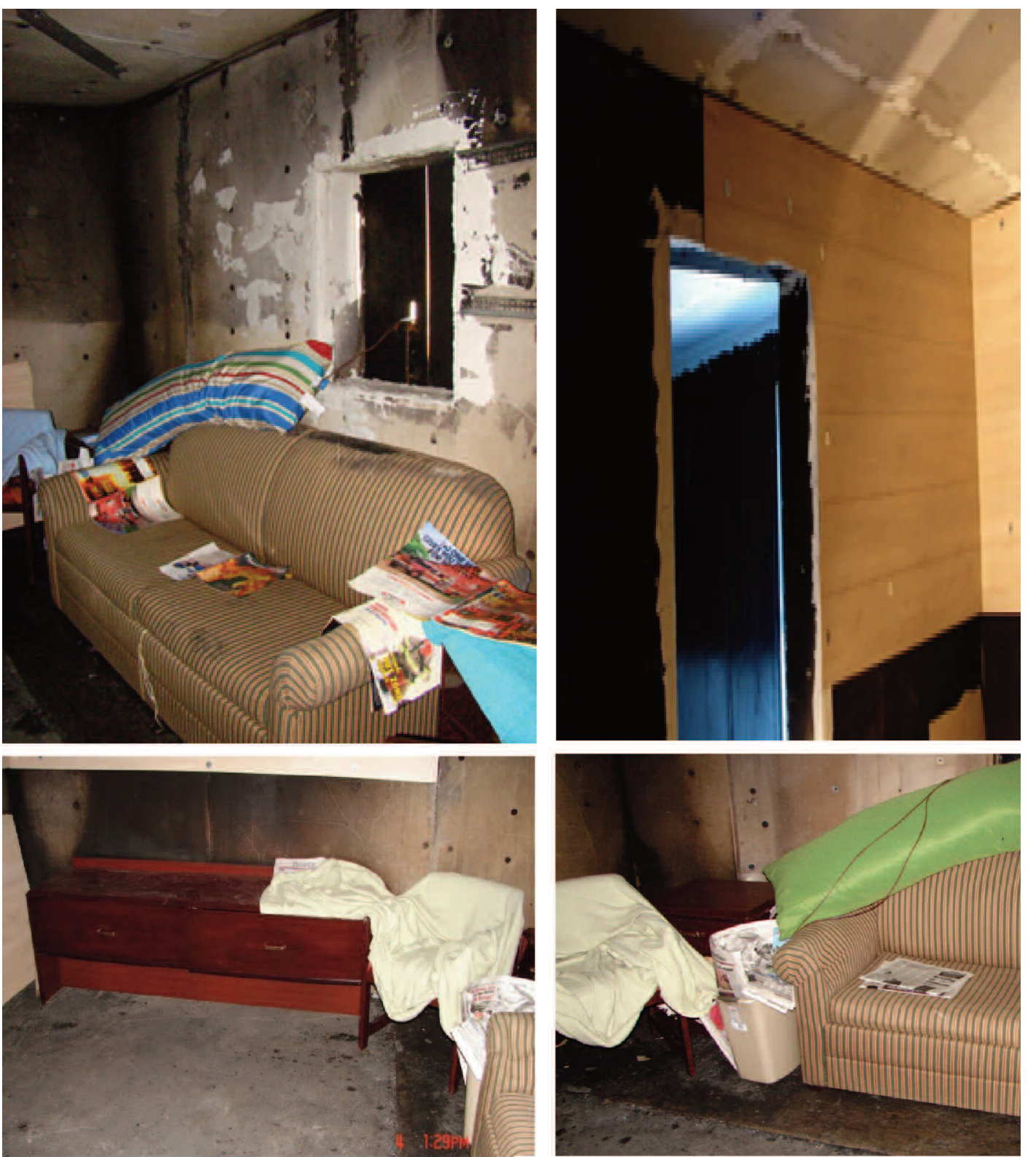

Figure 25: Pictures of the Room and Contents Furnishings
The ignition source consisted of a cardboard book of 20 matches that was ignited by an electrically heated wire, often referred to as an electric match. The electric match was placed near the bottom of a $21 \mathrm{qt}$ (19.9 L) polypropylene waste container. The height of the waste container was 15.5 in (394 $\mathrm{mm}$ ) with interior dimensions at the top opening of 14.5 in $(368 \mathrm{~mm})$ by 11.3 in (287 mm). Approximately 0.7 lbs $(0.3 \mathrm{~kg})$ of dry newspaper was added to the waste container. The majority of the newspaper was folded flat, and placed on edge along the sides of the waste container. Four sheets of newspaper, 22 in (559 $\mathrm{mm})$ by 25 in $(635 \mathrm{~mm})$ were crumpled into "balls" approximately 3.9 in (100 $\mathrm{mm})$ diameter and placed on top of the electric match in the center of the waste container.

\section{Experimental Matrix for}

Room and Contents Fires

Sufficient amounts of

furniture for 16 rooms were available for the room and contents fires, so eight experiment scenerios were conducted - each with a replicate. Because the time to untenable conditions was a primary variable of interest in the room and contents fires, the arrival time of the first due engine was a paramount consideration. Because the effects of the subsequent apparatus stagger were explored in the time-to-task tests, the stagger was fixed at the "close arrival" time. Additionally, a baseline measurement was required to compare the effectiveness of response to the absence of a fire department response. Therefore, a five-person, later arrival combination was eliminated in favor of a no-response scenario (with replicate). Table 3 summarizes the 16 tests conducted.

The first due engine arrival times were determined using the following assumptions: ignition of the fire occurs at 


\begin{tabular}{|ll|}
\hline 2-Person & Early Arrival of First Engine $(6.5 \mathrm{~min})$ - close stagger \\
\hline 3-Person & Early Arrival of First Engine $(6.5 \mathrm{~min})$ - close stagger \\
\hline 4-Person & Early Arrival of First Engine $(6.5 \mathrm{~min})$ - close stagger \\
\hline 5-Person & Early Arrival of First Engine $(6.5 \mathrm{~min})$ - close stagger \\
\hline 2-Person & Later Arrival of First Engine $(8.5 \mathrm{~min})$ - close stagger \\
\hline 3-Person & Later Arrival of First Engine $(8.5 \mathrm{~min})-$ close stagger \\
\hline 4-Person & Later Arrival of First Engine $(8.5 \mathrm{~min})-$ close stagger \\
\hline No Response (Baseline) & N/A \\
\hline
\end{tabular}

Table 3: Experimental Matrix for Room and Contents Tests (Each Conducted in Replicate) time zero. Smoke detector activation and a call to 9-1-1 occurs at 60 seconds after the fire starts. Call intake and processing requires an additional 90 seconds. The firefighters take 60 seconds to complete their turnout at the station and begin travel to the scene. Thus travel time begins 3.5 minutes into experiment. The two levels of arrival time are then determined by two different travel times: early arrival assumes a three-minute travel time, while later arrival assumes a five-minute travel time. For all scenarios in the room and contents experiments, the close stagger (60 seconds) between subsequent apparatus times was used.
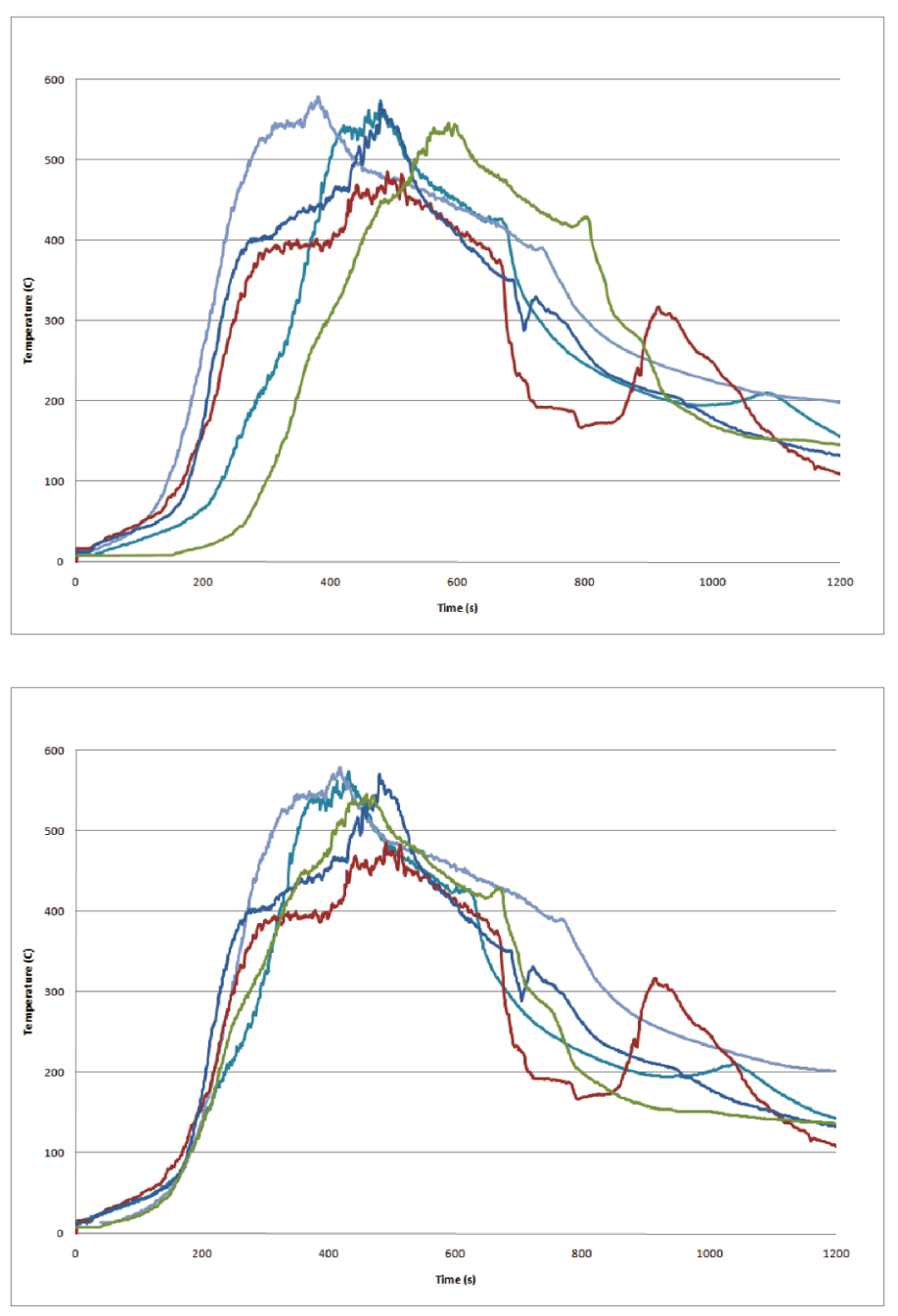

Figure 26: Direct Comparison of Temperatures, Before (Top) and After Adjustment (Bottom)
Procedure for Minimizing the Effect of Variance in Fire Growth Rate

Fires involving furnishings have inherent variance in burning behaviors. Factors such as humidity and minor variations in materials (particularly worn furnishings that may have different foam compression or fabric wear patterns), can result in uncertainty of $20 \%$ or more, despite significant efforts to enhance repeatability. The early growth period of fire development is often associated with the greatest variance, since minor factors (as discussed above) can influence the thermal environment more easily when the fire is small. Therefore, the room and contents fires were normalized to the $212^{\circ} \mathrm{F}\left(100^{\circ} \mathrm{C}\right)$ temperature near the ceiling in the burn room in order to minimize the variance of the room and contents fires. The time at which the burn room reached this temperature (usually in approximately 180 seconds) rather than the actual ignition time, was designated as the "zero time."

Figure 26 shows the time-temperature curves before and after normalizing at $100^{\circ} \mathrm{C}$. This approach was implemented during the experiments by watching the time temperature data in real-time from the instrumentation room and announcing the "zero-time" over the fireground radio system. The normalization procedure did not negatively affect tenability measurements in the target room because when the fire is small, products of combustion do not reach the room because of lack of momentum. Therefore, adjusting all room and contents tests to the same upper layer temperature was an appropriate way to minimize variance.

\section{Milestone Times for Critical Tasks}

As stated earlier, firefighters could not enter the burn building during the room and contents experiments because of the danger for potential flashover in an experimental scenario. Therefore, prescribed tasks were performed at specified times based on data from part 2. In this section we report on significant data gathered from instrumentation and describe an additional part of the experiments designed to extend our understanding of the effect of crew size and stagger on the tenability of the atmosphere in a burning structure.

Table 4 (page 32) identifies significant tasks selected as key milestones because of the way they affect fire behavior and atmospheric tenability inside the structure. 


\begin{tabular}{|c|c|}
\hline Milestone Tasks & 2-Person Close Stagger \\
\hline & Time from ignition ( $\min : \mathrm{s}$ ) \\
\hline Breached Door & $8: 44$ \\
\hline Water On Fire & 9:56 \\
\hline Upper Fire Window & 13:01 \\
\hline Ground Non-fire Window & $14: 51$ \\
\hline Upper Corner Window & $17: 55$ \\
\hline Upper Front Door Window & $19: 55$ \\
\hline Ground Fire Window & 4:30 \\
\hline \multirow[t]{2}{*}{ Milestone Tasks } & 3-Person Close Stagger \\
\hline & Time from ignition (min : s) \\
\hline Breached Door & $7: 48$ \\
\hline Water On Fire & $8: 54$ \\
\hline Upper Fire Window & $11: 26$ \\
\hline Ground Non-fire Window & $13: 31$ \\
\hline Upper Corner Window & $15: 54$ \\
\hline Upper Front Door Window & $17: 58$ \\
\hline Ground Fire Window & $4: 30$ \\
\hline \multirow[t]{2}{*}{ Milestone Tasks } & 4-Person Close Stagger \\
\hline & Time from ignition (min : s) \\
\hline Breached Door & $7: 46$ \\
\hline Water On Fire & $8: 41$ \\
\hline Upper Fire Window & $9: 23$ \\
\hline Ground Non-fire Window & 10:32 \\
\hline Upper Corner Window & $11: 46$ \\
\hline Upper Front Door Window & $13: 45$ \\
\hline Ground Fire Window & 4:30 \\
\hline \multirow[t]{2}{*}{ Milestone Tasks } & 5-Person Close Stagger \\
\hline & Time from ignition (min : s) \\
\hline Breached Door & $7: 35$ \\
\hline Water On Fire & 8:03 \\
\hline Upper Fire Window & 10:11 \\
\hline Ground Non-fire Window & $10: 54$ \\
\hline Upper Corner Window & $12: 31$ \\
\hline Upper Front Door Window & $12: 47$ \\
\hline Ground Fire Window & $04: 30$ \\
\hline
\end{tabular}




\section{Analysis of Experimental Results}

$\mathrm{T}$ his section describes the analytic approaches used to address the research objectives of the study. First the statistical methods used to analyze the fireground time-to-task observations are presented. Then the time-to-task data and the room and contents data were combined to assess crew performance in relation to tenability within the structure.

\section{Time-to-Task Analysis}

Time-to-task data were compiled into a database and assessed for outliers and missing entries. Because all time-to-task experiments were conducted in triplicate, missing data were apparent and were reviewed via video and radio tapes. Missing data attributable to timer error were replaced by a time observed in the video. Where video and/or radio documentation was not adequate, missing data were recoded to the mean of the task times from the other two experiments.

\section{Data Queries}

The statistical methods used to analyze the time-to-task data were driven by a principal goal of this research project - to assess the effect of crew size, first-due engine arrival time, and subsequent apparatus stagger on time-to-task for critical steps in response and fire fighting. This research goal motivated the development of four specific research questions (see Figure 27) that in turn pointed to specific statistical analyses for generating inference and insight.

\section{Statistical Methods - Time-to-Task}

The analysis of the time-to-task data involved a sequence of multiple linear regressions using Ordinary Least Squares to generate and test the effects of staffing and stagger on timings. The regressions were of the form:

$y_{i}=\beta_{0}+\beta_{1} x_{i 1}+\beta_{2} x_{i 2}+\ldots+\beta_{k} x_{i k}+\varepsilon_{i}$

where the $x_{i k}$ reflect factors such as stagger and crew size, and the $y$ represents our dependent/outcome variable.

Time-related outcomes (i.e., the dependent variables in the regression equations) could include task duration, elapsed time to start the task, and elapsed time until task completion, all measured in seconds. Table 5 (page 34) lists the time-related outcomes used to test the effect of crew size and stagger for the tasks in the field experiments.

The effects of crew size and stagger were explored using indicator variables in the regression analyses. The coefficient for a given indicator (for example, crew size of four relative to a crew size of two) indicated the number of seconds the larger crew size added or reduce the timing outcome of a task. Crew sizes were collapsed in some regressions to test whether the timings of "larger" crew sizes of four and five were significantly different than "smaller" crew sizes of two and three. Interaction terms were not assessed in these regression analyses because of the small number of experiments available for analysis.

Standard t-tests examined statistical significance (i.e., to see if the hypothesis of "no impact" could be rejected) to estimate the impact of several specific configurations:

\footnotetext{
crew sizes of three versus two

crew sizes of four versus three

crew sizes of five versus four
}

\section{Time-to-Task Research Questions}

1) How do crew size and stagger (i.e., timing of between first engine and subsequent apparatuses) affect overall (i.e., start to completion) response timing?

a. To what extent do variations in crew size affect overall response timing?

b. To what extent do variations in both crew size and stagger affect overall response timing?

2) How do crew size and stagger affect the timings of task initiation, task duration, and task completion for each of the tasks comprising the suite of 22 tasks?

a. To what extent do variations in crew size affect timings across the suite of tasks?

b. To what extent do variations in both crew size and stagger affect response timings across the suite of tasks?

3) How does crew size affect elapsed times to achieve three critical events known to change fire behavior or atmospheric tenability for occupants?
a. Entry into structure
b. Water on fire
c. Ventilation of each window (three upstairs and one downstairs window and the burn room window)

4) How does the elapsed time to achieve the national standard of assembling 15 firefighters at the scene (measured using "at hydrant" as the start time) vary by crew sizes of 4 and 5 ?

Figure 27: Research Questions for Time-to-Task Experiments
- (occasionally) five versus two, and four versus two
- larger (four \& five combined) versus smaller (two \& three combined) and
stagger

The specific tests for each task (regression analysis) are shown in the Appendix E. The actual coefficients of each regression and their corresponding standard errors are presented in Appendix F. To infer impact, significant tests were conducted at the 0.05 significance level. Only statistically significant contrasts of crew size and/or stagger are included in this section of the report. Graphic expositions of relevant time/task related findings are then presented as well. Where stagger was statistically significant, the effects are graphed separately. Where stagger was not statistically significant, the data for crew size were combined. 


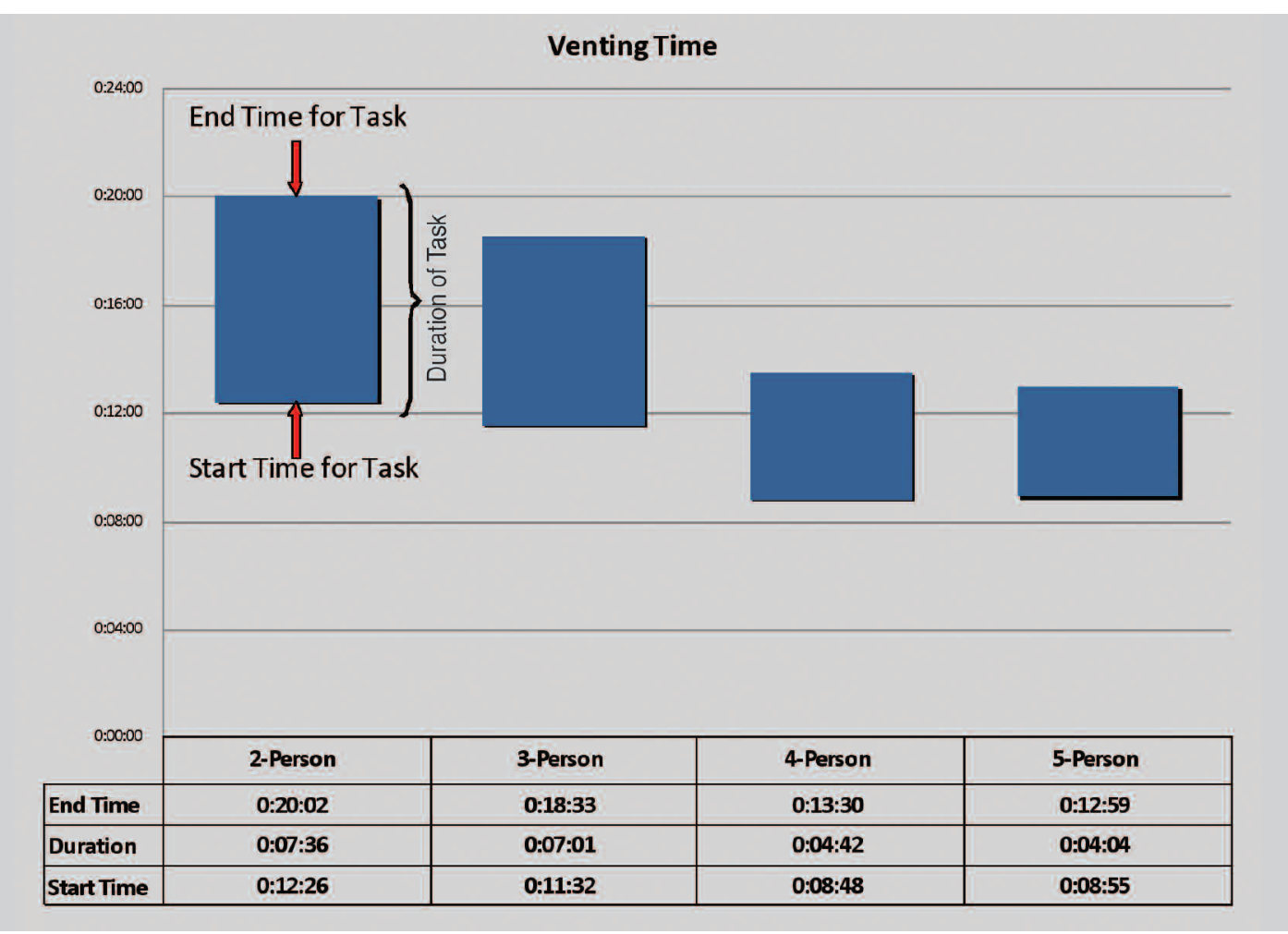

Figure 28: Example Time-to-Task Graph

\begin{tabular}{|c|c|c|c|}
\hline \multirow[b]{2}{*}{ Task: } & \multicolumn{3}{|c|}{ Time-to-Task Outcome Measures } \\
\hline & $\begin{array}{c}\text { Elapsed Time Until } \\
\text { Start* }\end{array}$ & $\begin{array}{l}\text { Elapsed Time for Task } \\
\text { Completion* }\end{array}$ & Duration* \\
\hline Conduct size-up & $\mathbf{x}$ & $\mathbf{x}$ & $\mathrm{x}$ \\
\hline Position attack line & $\mathbf{x}$ & & $\mathbf{x}$ \\
\hline Establish 2 in - 2 out & & $\mathbf{x}$ & \\
\hline Establish RIT & & $\mathbf{x}$ & \\
\hline Gain forced entry & $\mathbf{x}$ & & \\
\hline Advance line & $x$ & & \\
\hline Advance line & & $\mathrm{x}$ & \\
\hline Advance backup line to door & $\mathrm{x}$ & $\mathrm{x}$ & \\
\hline Advance backup line to stairwell & $\mathbf{x}$ & & \\
\hline Advance backup line 2 & & $\mathbf{x}$ & \\
\hline Conduct primary search 1 & $\mathbf{x}$ & & \\
\hline Ground ladders in place & & $\mathbf{x}$ & $x$ \\
\hline Horizontal ventilation, second story, window 3 & $\mathbf{x}$ & $\mathbf{x}$ & \\
\hline Horizontal ventilation, second story, window 2 & $\mathbf{x}$ & $\mathbf{x}$ & \\
\hline Horizontal ventilation, second story, window 1 & $\mathbf{x}$ & $\mathbf{x}$ & \\
\hline Horizontal ventilation, first story, window 2 & $\mathbf{x}$ & $\mathbf{x}$ & \\
\hline Control utilities interior & $x$ & & \\
\hline Control utilities exterior & $x$ & & \\
\hline Conduct secondary search & $x$ & & \\
\hline Check for fire extension walls & $x$ & & \\
\hline Check for fire extension ceiling & $x$ & & \\
\hline
\end{tabular}

Table 5: Dependent Variables Used in a Regression Analysis of the Effect of Crew Size and Stagger on Time-to-Task Outcomes
Regression analyses

Appendix F presents the regression results for each task and relevant outcome, along with their corresponding standard errors. The results of conducting significance tests at the 0.05 level of significance are shown in Appendix E. Rather than detailing each of the lengthy lists of coefficients found to be significant, only the answers to the primary research questions are presented for each task.

\section{Measurement Uncertainty}

The measurements of length, temperature, mass, moisture content, smoke obscuration, and stopwatch timing taken in these experiments have unique components of uncertainty that must be evaluated in order to determine the fidelity of the data. Appendix G summarizes the uncertainty of key measurements taken during the experiments. Importantly, the magnitudes of uncertainties associated with these measurements have no impact on the statistical inferences presented in this report.

\section{How to Interpret}

\section{Time-to-Task Graphs}

Figure 28 presents a sample time-to-task analysis, in this case results for venting time. Each crew size has a column graphic showing the start time and completion time for the task. Visually, columns starting lower on the graph depict deployment configurations that resulted in earlier start times. The height of the column graphic is a visualization of the duration of the task, taller columns indicating longer times to task completion. Time data are also shown in a table below the graph. Where stagger was statistically significant, the effects are graphed separately. Where stagger was not statistically significant, as in the illustration, the data for crew size were combined. 
Time-to-Task Graphs

Overall Scene Time (Time to Complete All 22 Tasks)

The four-person crews operating on a low-hazard structure fire completed the same number of tasks on the fireground (on average) 7 minutes faster than the two-person crews (see Figure 29). The four-person crews completed the same number of fireground tasks (on average) 5.1 minutes faster than the three-person crew. The four-person crews were able to complete necessary fireground tasks on a low-hazard residential structure fire nearly $30 \%$ faster than the two-person crews and nearly $25 \%$ faster than the three-person crews. Although on the low-hazard residential structure fire, adding a fifth person to the crews did not show any additional decrease in fireground task times, the benefits of a five-person vs. a four-person crew are significant in other measurements, particularly the "water-on-fire" time. Additionally, the greater need for five-person crews for medium- and high-hazard structures, particularly in urban settings, has been documented in other studies (Backoff et al., 1980; Cushman, 1982;

McManis Associates et al., 1984) and five-person crews are required for areas that contain medium and high-hazard structures in fire protection consensus standards. ${ }^{11}$

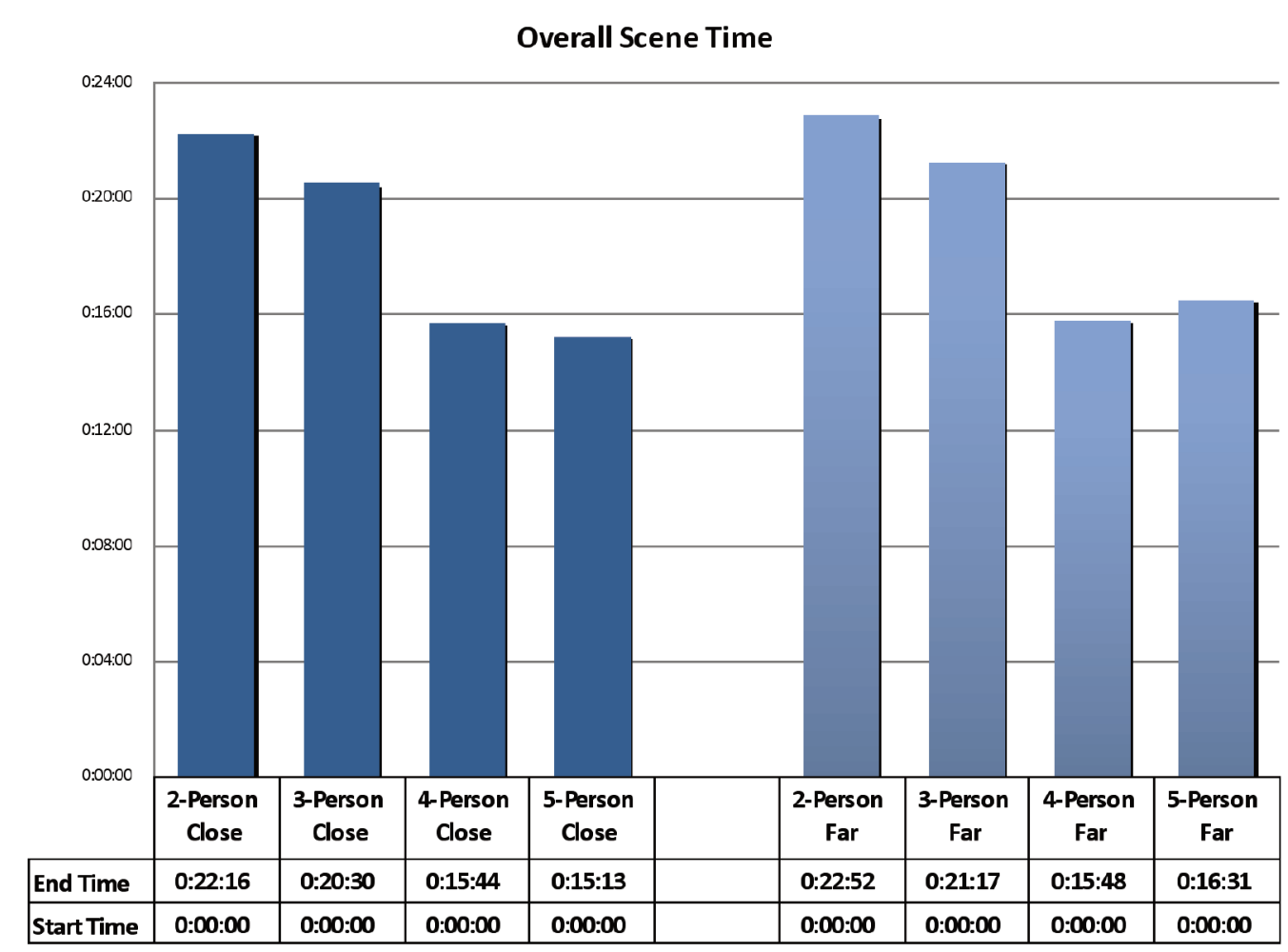

Figure 29: Overall Scene Time

11 NFPA 1710, Section 5.2.3.1.2 and Section 5.2.3.2.2: In jurisdictions with tactical hazards, high-hazard occupancies, high incident frequencies, geographical restrictions, or other pertinent factors as identified by the AHJ, these companies shall be staffed with a minimum of five or six on duty members. 
Overall Scene Time and Crew Sizes

The graphs in Figure 30 show average times for each task by crew size.

\section{Five-Person Crew \\ Replicate Average}

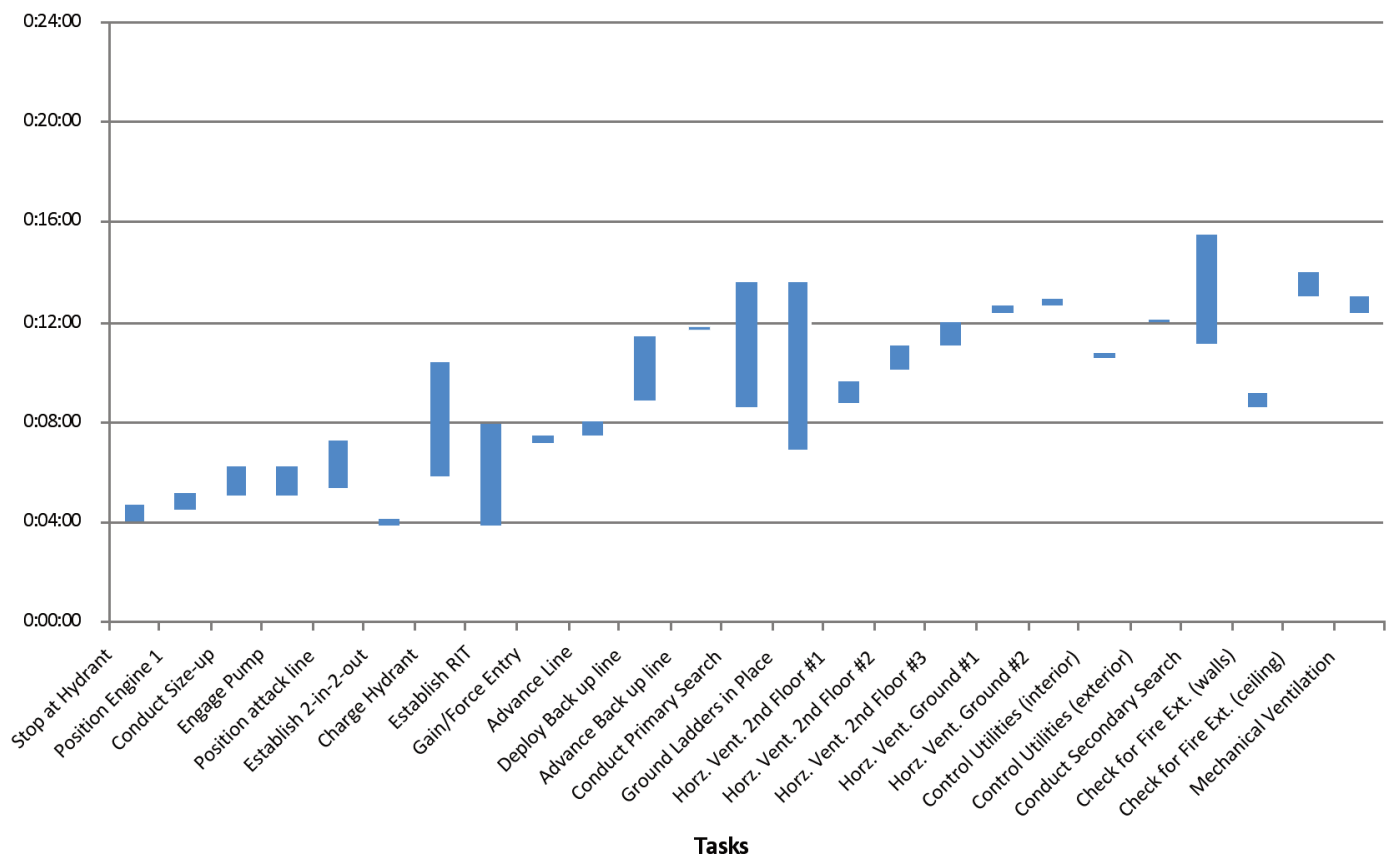

Figure 30 a: Overall Scene Time-Flve Person Crew

\begin{abstract}
Four-Person Crew
Replicate Average
\end{abstract}

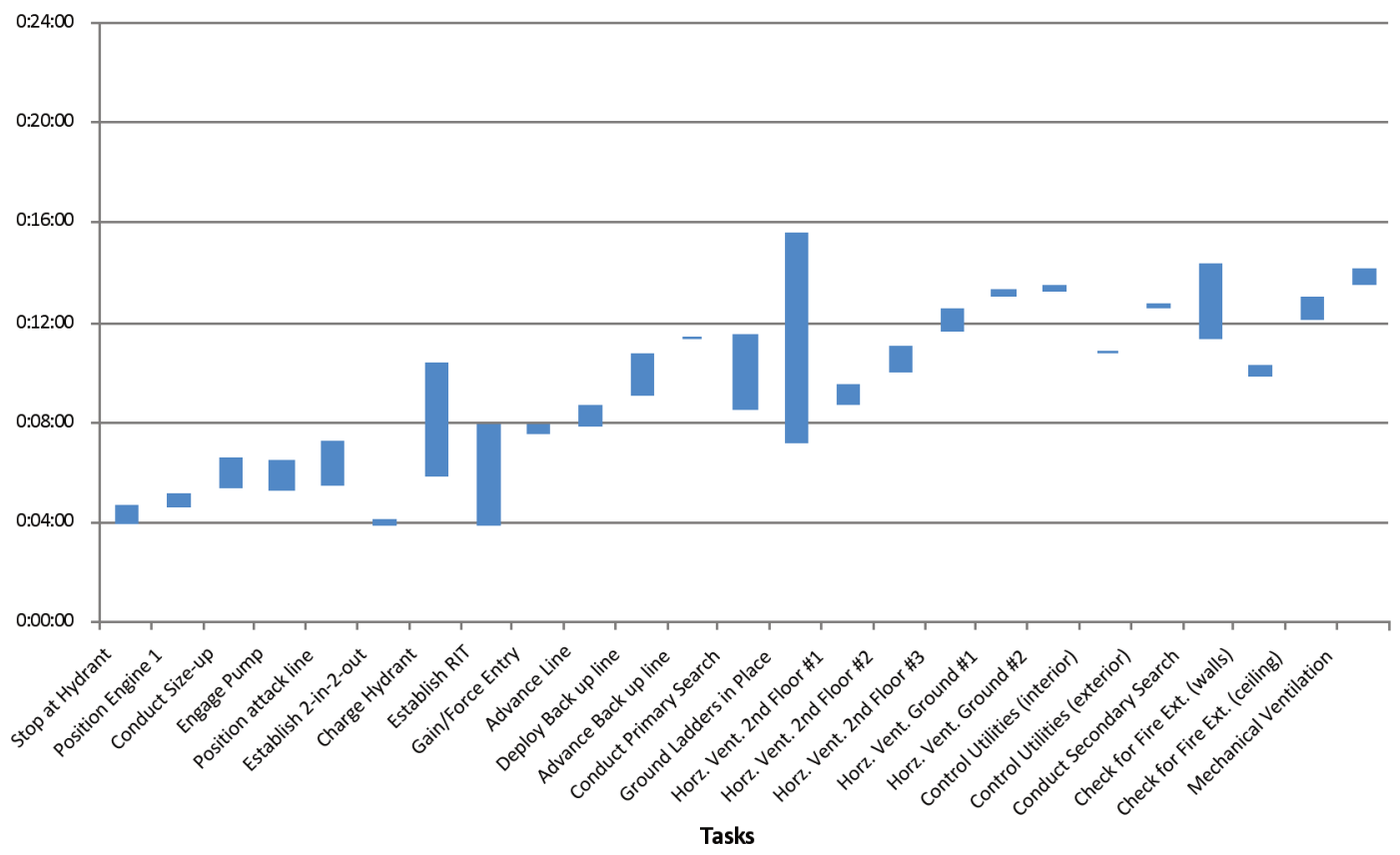

Figure 30 b: Overall Scene Time-Four Person Crew 


\section{Three-Person Crew}

\section{Replicate Average}

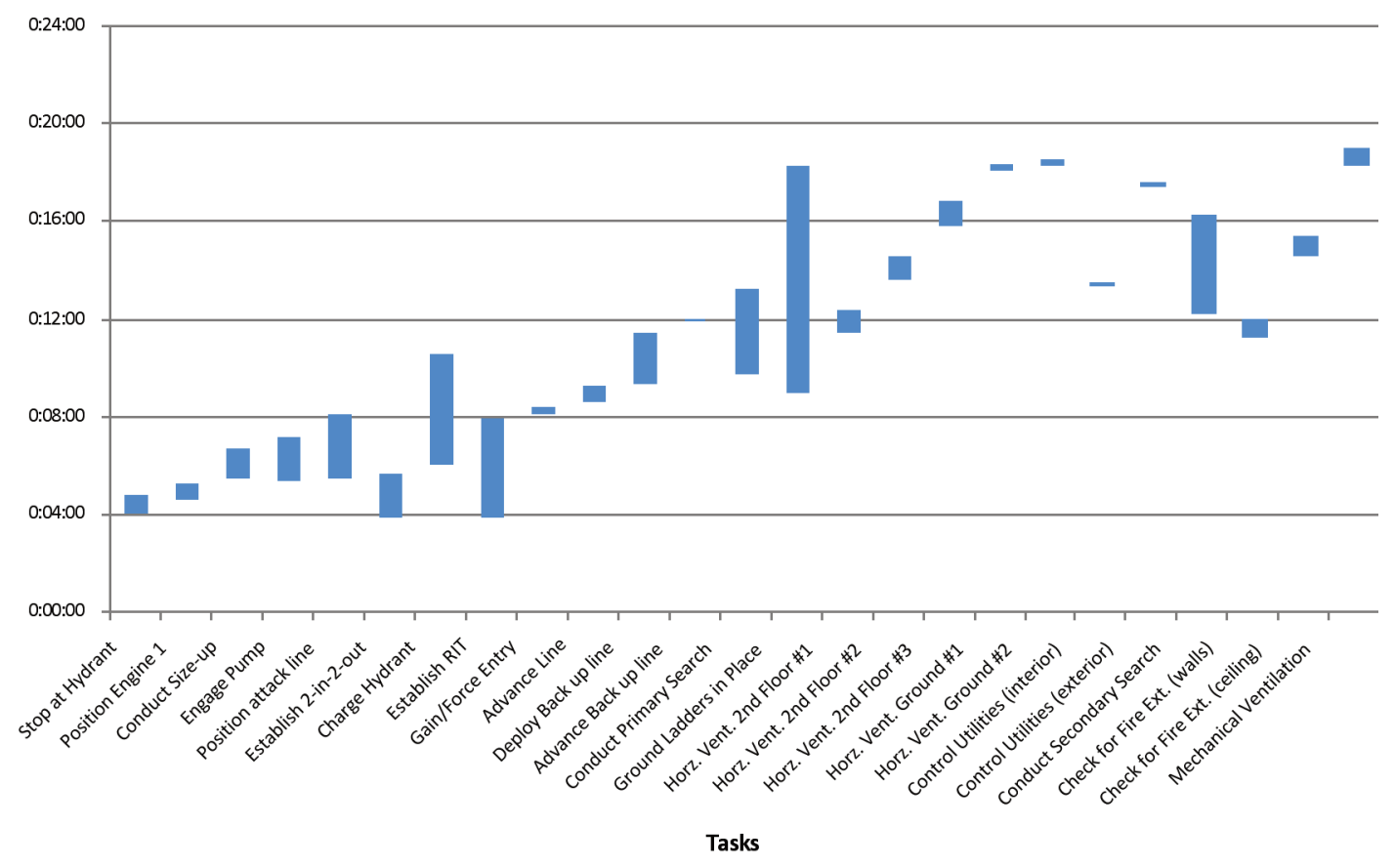

Figure 30 c: Overall Scene Time-Three Person Crew

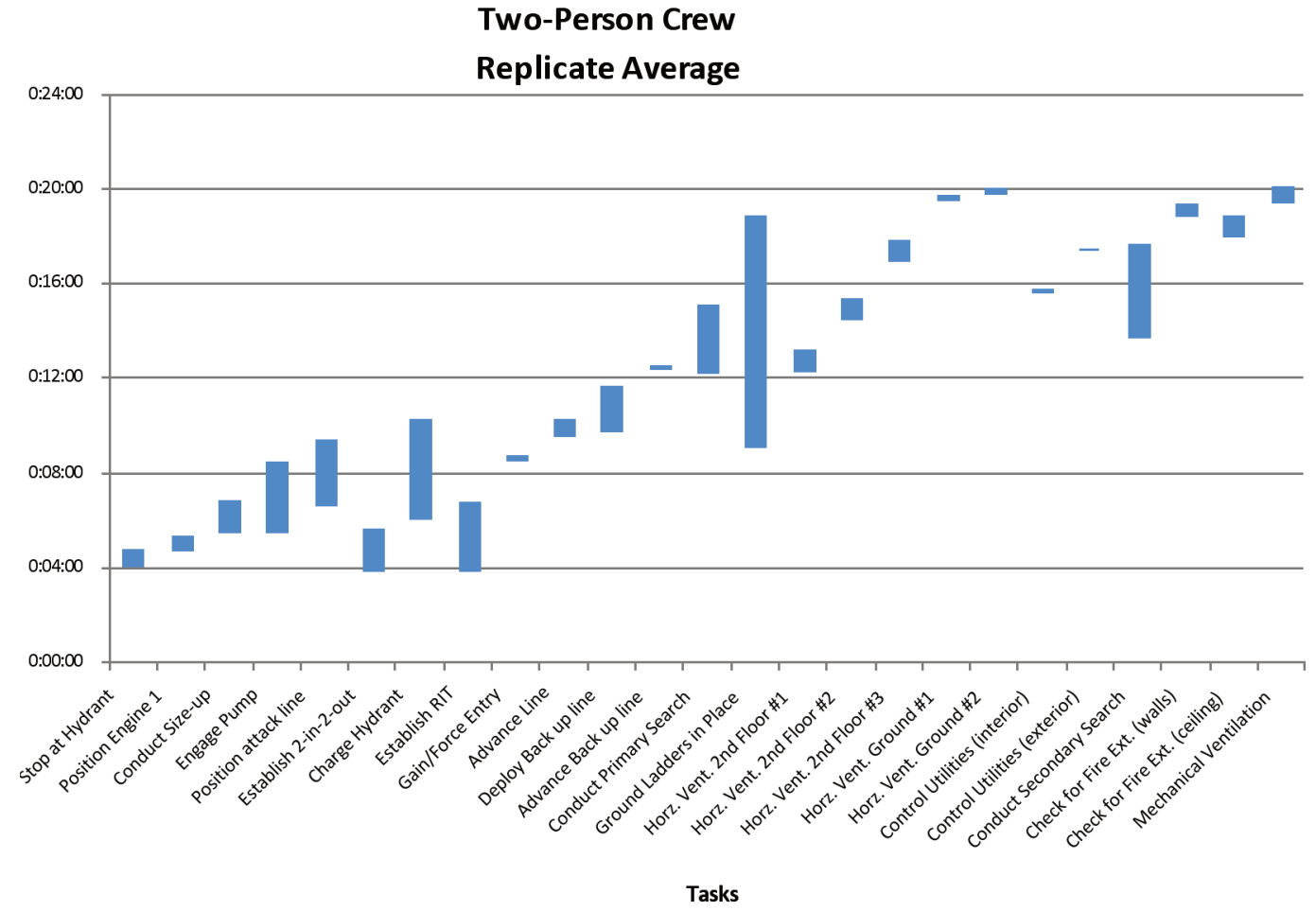

Figure 30 d: Overall Scene Time-Two Person Crew 


\section{Advance Attack Line} Time (Hose Stretch Time)

Figure 31 measures the interval from the start of the task "Position Attack Line" to the end of the task "Advance Attack Line.” In comparing four- and five-person crews to two and three-person crews collectively, the time difference for this measure was statistically significant at 76 seconds (1 minute 16 seconds). In conducting more specific analysis comparing all crew sizes to a two-person crew the differences are more distinct. A two-person crew took 57 seconds longer than a three-person crew to stretch a line. A two-person crew took 87 seconds longer than a four-person crew to complete the same task. Finally, the most notable comparison was between a two-person crew and a five-person crew, with a 122 -second difference in task completion time. ${ }^{12,13}$

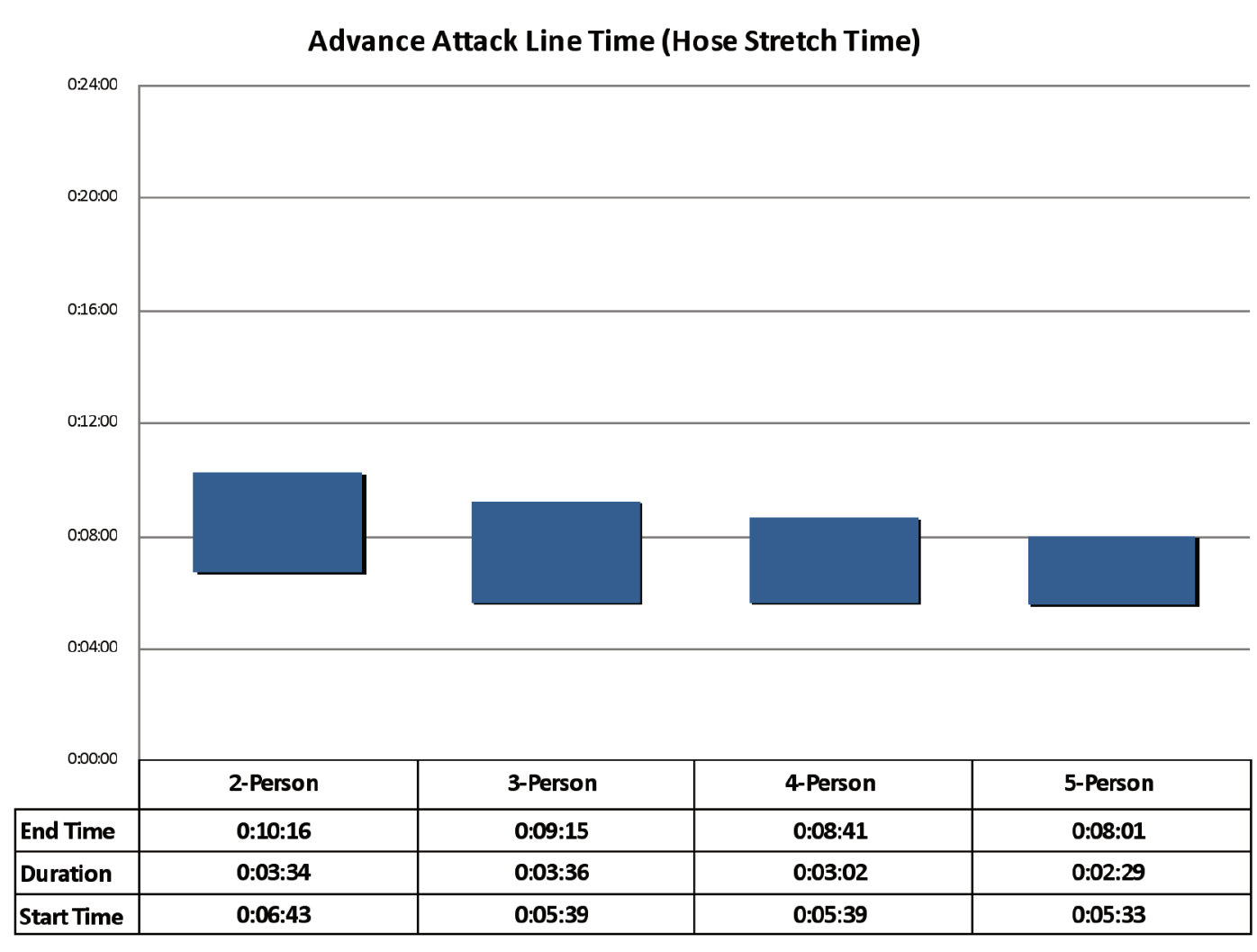

Figure 31: Advance Line Time (Hose Stretch Time) by Crew Size 
Water on Fire Time

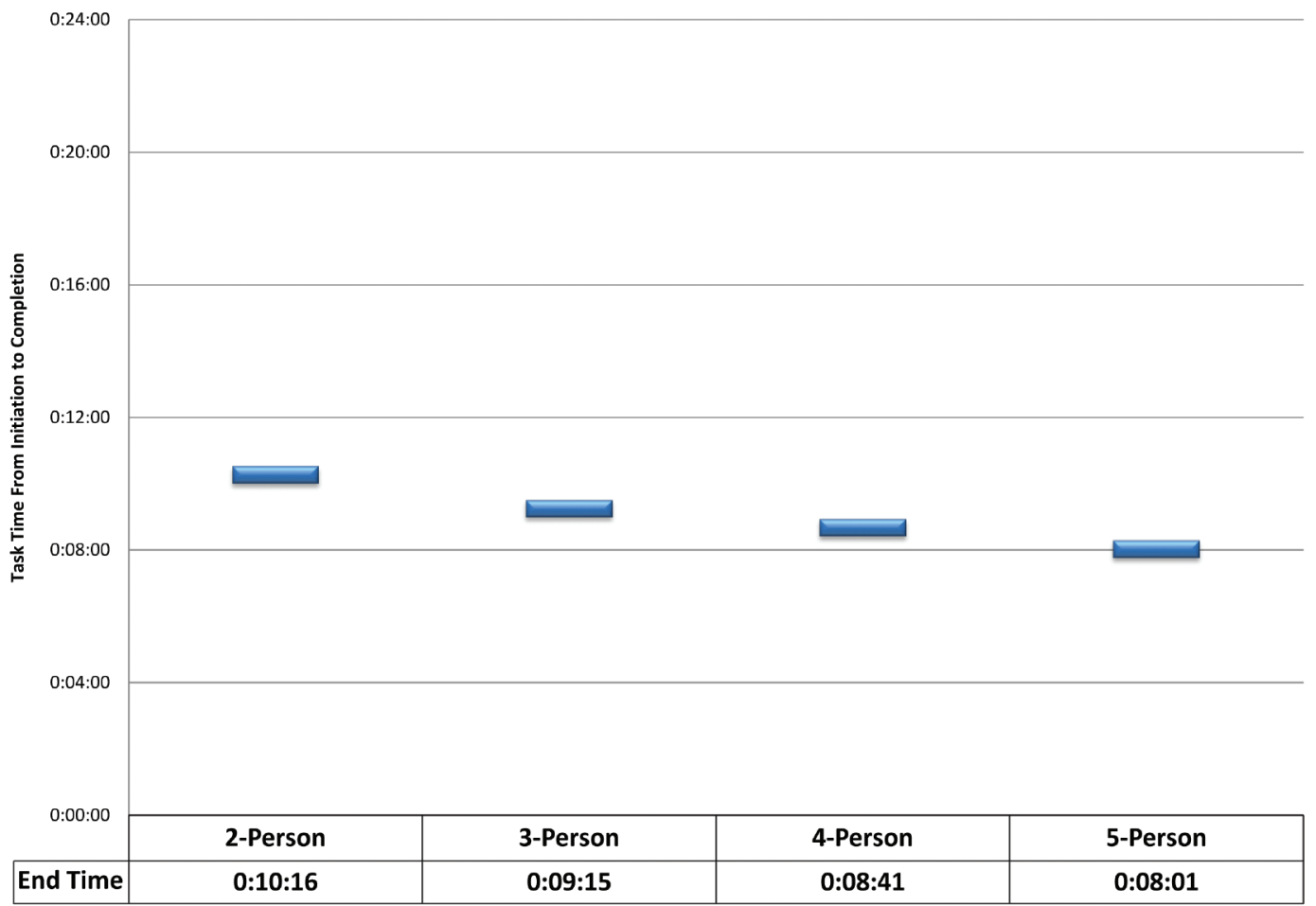

Figure 32: Water on Fire Time by Crew Size and Stagger

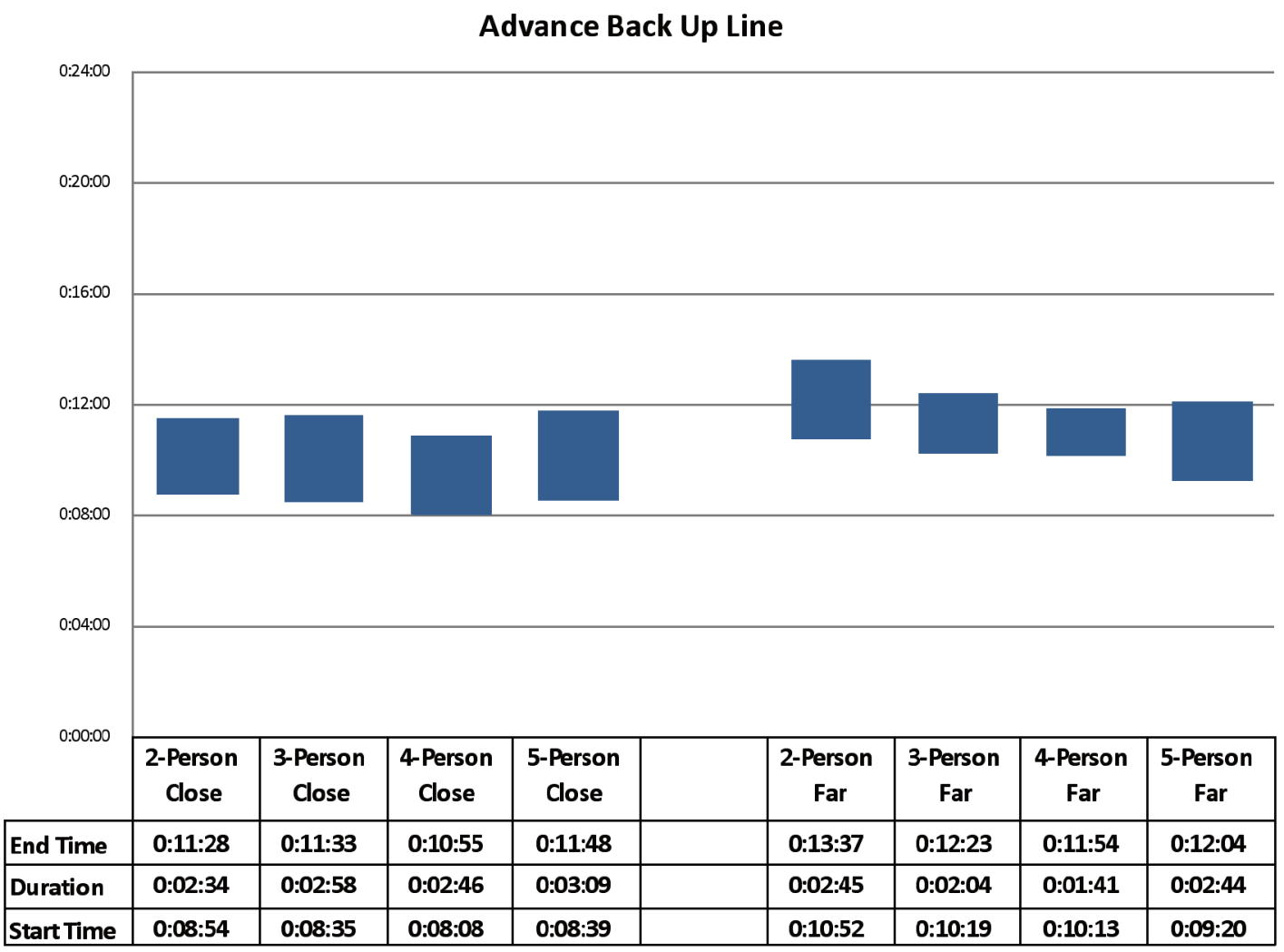

Time to Water on Fire

There was a $10 \%$ difference in the "water on fire" time between the two- and three-person crews. There was an additional $6 \%$ difference in the "water on fire" time between the three- and four-person crews. (i.e., four-person crews put water on the fire $16 \%$ faster than two person crews). There was an additional $6 \%$ difference in the "water on fire" time between the four- and five-person crews (i.e. five-person crews put water on the fire $22 \%$ faster than two-person crews).

\section{Advancing a Backup Line}

Advancing a backup line to the door and stairwell was started $16 \%$ faster and completed $9 \%$ for replicates with shorter staggers between company arrivals. Advancing a backup line is typically a task completed by the third arriving engine on a full alarm assignment and is critical to the safety of firefighters already in the building on the initial attack line. For this task, stagger of arrival was statistically significant and is an important consideration for overall station location and full alarm response capability. The differences can be seen in Figure 33, which shows the time from the start for the task "Deploy Backup Line" to the end of the task "Advance Backup Line.”

Figure 33: Times to Advance Backup Line by Crew Size and Stagger 


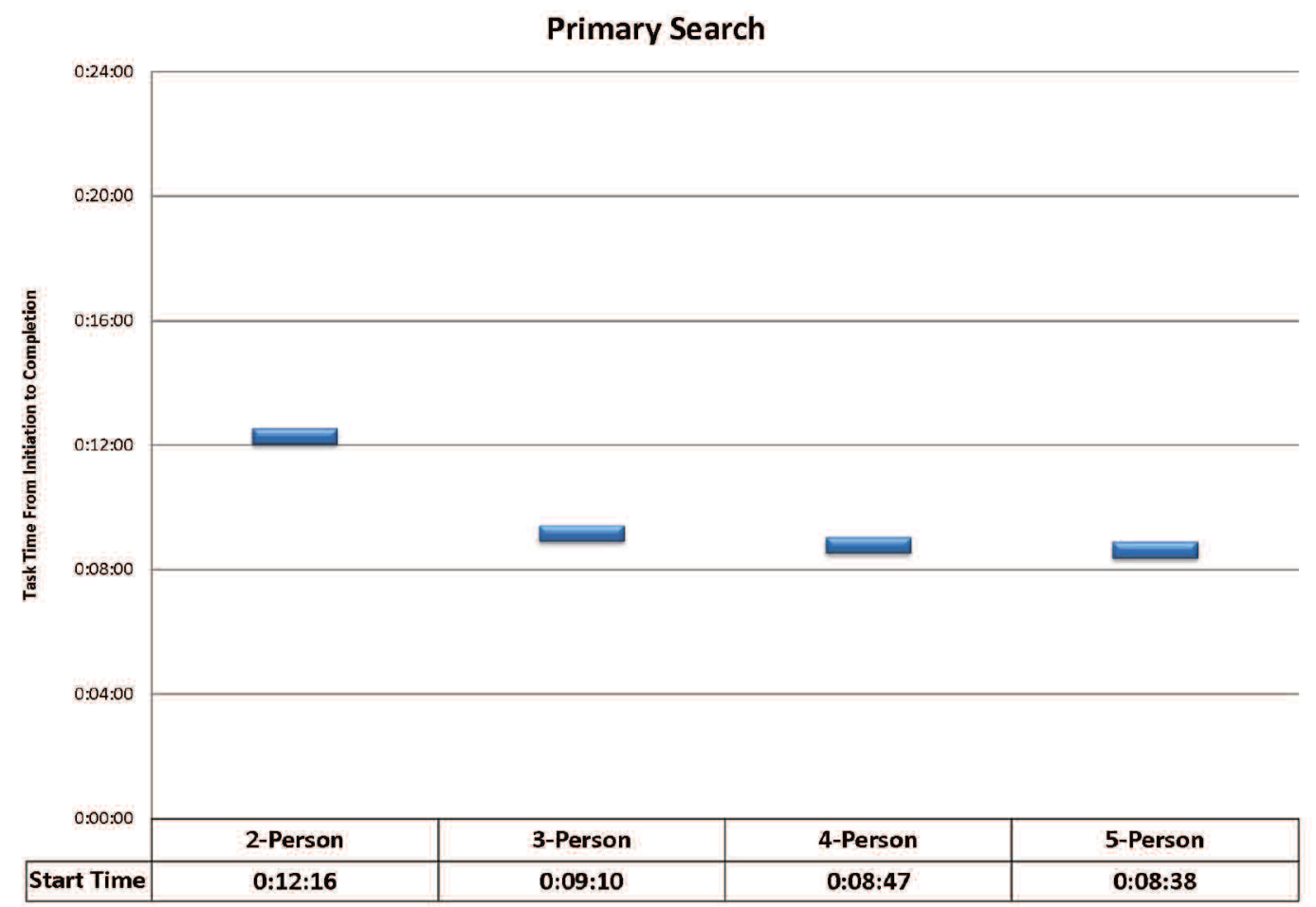

Figure 34: Times to Conduct Primary Search by Crew Size 


\section{Laddering Time}

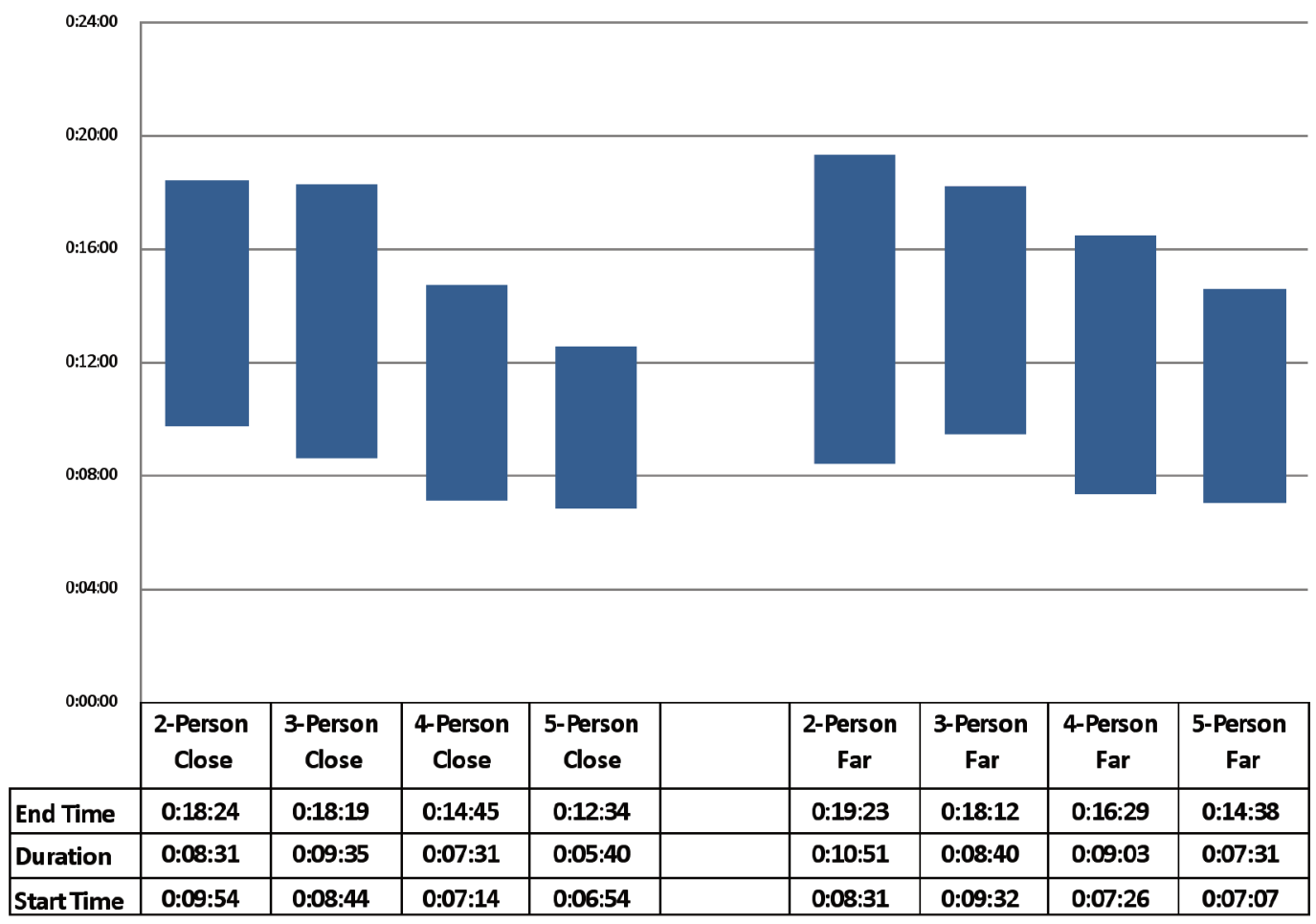

Figure 35: Laddering Time by Crew Size

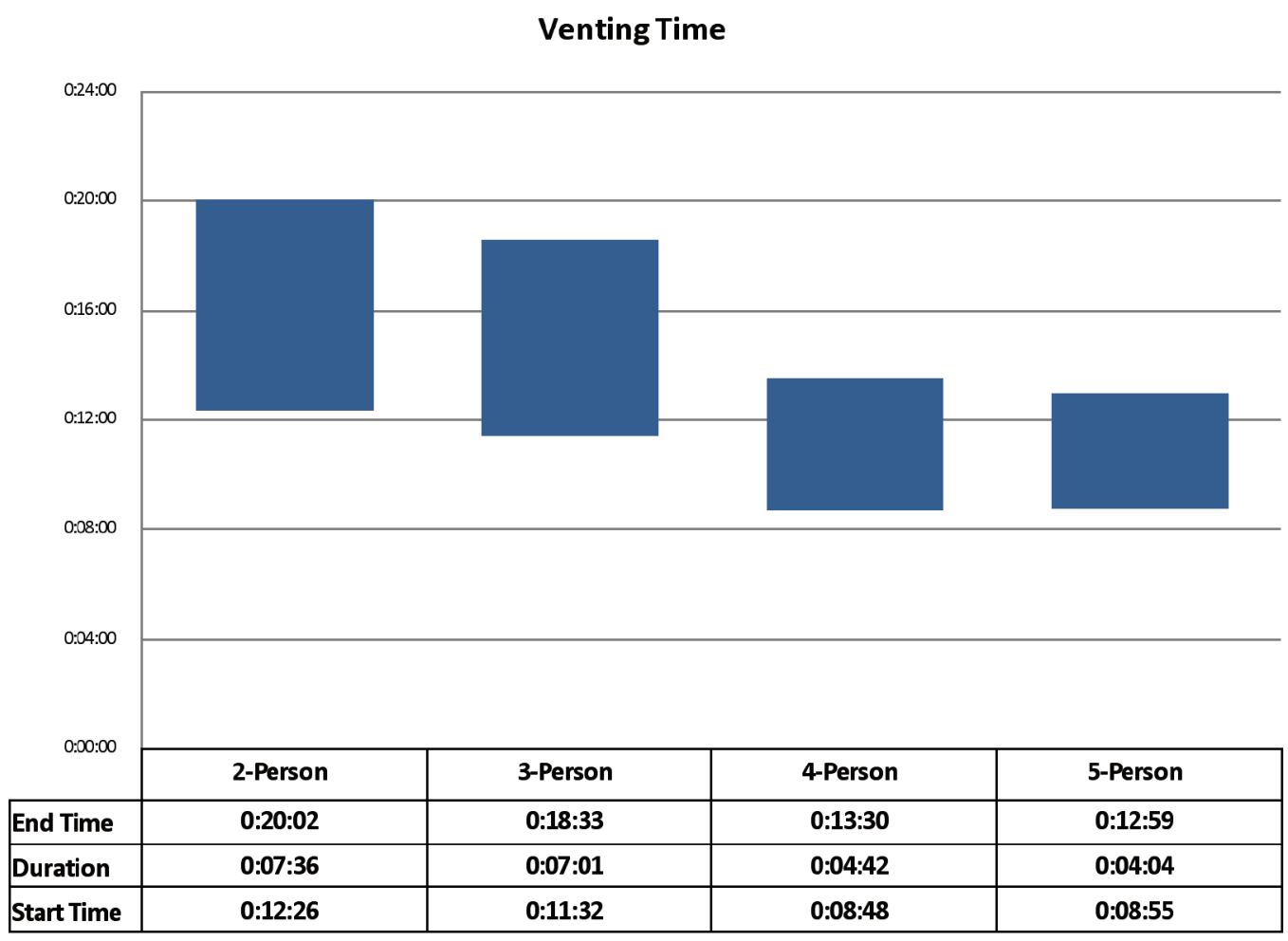

\section{Primary Search}

Figure 34 summarizes the times that crews took to start the primary search. On the low-hazard, two-story single-family dwelling 2,000 sq $\mathrm{ft}\left(186 \mathrm{~m}^{2}\right)$, the three-person crew started a primary search/rescue more than $25 \%$ faster than the two-person crew. In the same structure, the four- and five-person crews started a primary search $6 \%$ faster than the three-person crews and $30 \%$ faster than the two-person crew. Note that there is no end time included in this figure. Primary search end times were reliant upon radio communication by firefighters inside the structure. On occasion this communication did not occur or was delayed. Therefore data reliability was insufficient for analysis of task duration and end time. ${ }^{14}$

\section{Laddering and Venting Time}

A four-person crew operating on a low-hazard structure fire completed laddering and ventilation (for life safety and rescue) $30 \%$ faster than a two-person crew and $25 \%$ faster than a three-person crew. Ground laddering time started with the removal of the first ladder from the truck and stopped at end time of the last ladder put in place. A total of four ladders were raised on each experiment.

Truck operations ventilation time is the time from the start time of ventilation of the first window until the last window ventilation was complete.

The differences in start times and duration of the tasks can be seen in Figure 35 and Figure 36.

Figure 36: Ventilation Times by Crew Size ${ }^{15}$

15 Stagger was not statistically significant, so the data for crew size were combined. 
Industry Standard Effective Response Force Assembly Time

NFPA 1710 requires that a fire department have the capability to deploy an initial full-alarm assignment to a scene within eight-minutes (480 seconds). The number of people required falls between 15 and 17, depending on whether an aerial apparatus is used, and/or if two engines are being used to provide a continuous water supply. In these experiments, the measurement for an effective response force assembly time started from the first engine arrival at the hydrant and ended when 15 firefighters were assembled on scene. Figure 37 reveals the differences in assembly times between the four and five-person crews. An effective response force was assembled by the five-person crews a full three minutes faster than the four-person crews. It is important to note that (by definition), the two-and three-person crews were unable to meet this standard at any time during the experiments. ${ }^{16}$
Industry Standard Effective Response Force Assembly Time

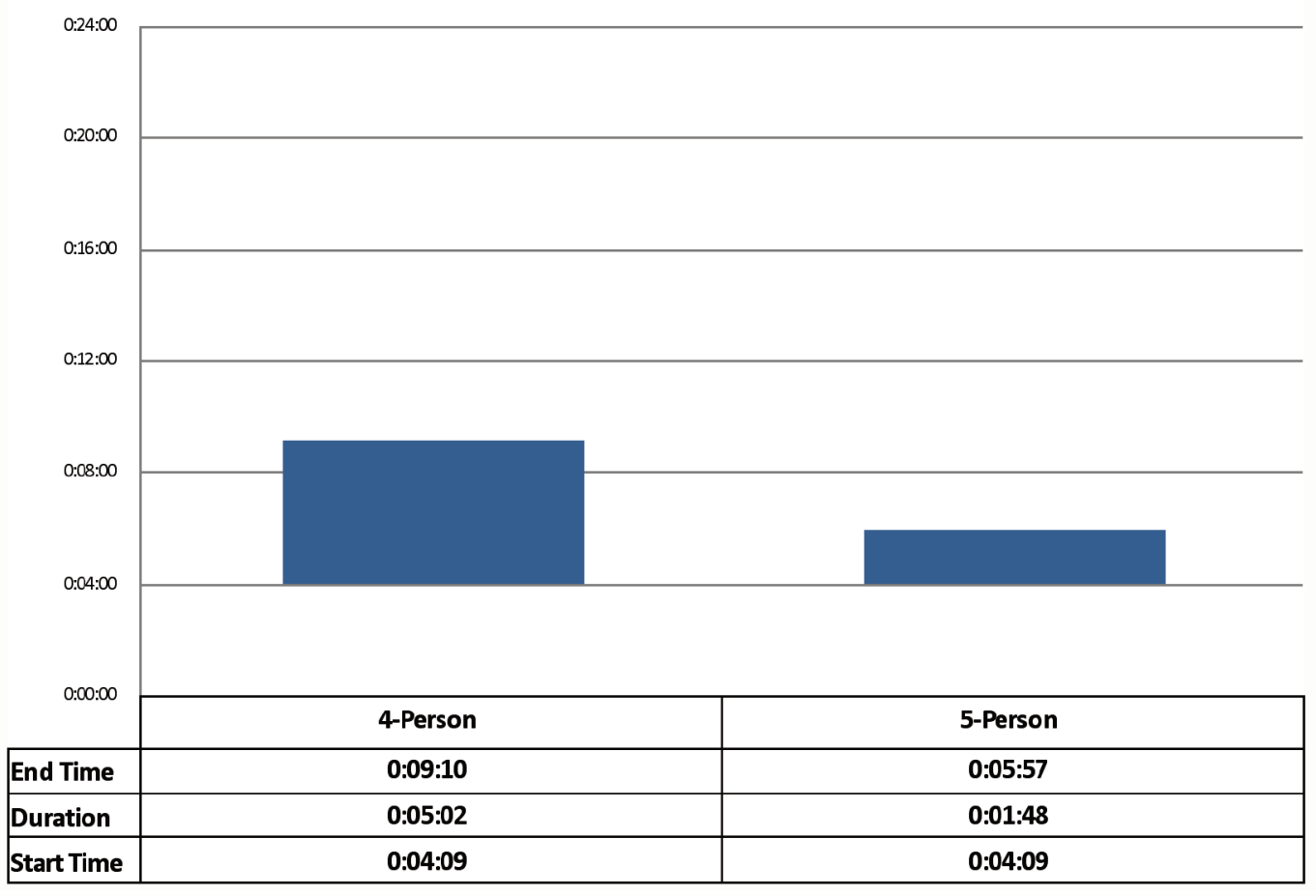

Figure 37: Industry Standard Effective Response Force Assembly Time

16 Stagger was not statistically significant, so the data for far and near stagger were combined. 


\section{Part 4: Fire Modeling}

$\mathrm{n}$ the room and contents experiments conducted in Part 3 of the study, instrumentation measured oxygen, carbon dioxide, and carbon monoxide concentrations. Data were grouped by the type of experiment conducted with respect to crew size and first due engine arrival time. As previously shown in the experimental matrix, each group contained two replicate tests. In each group of data the results of the replicates were averaged to simplify the data for further comparison. Figure 38 and Figure 39 show the typical concentration curves for the experiments.

These two graphs show the ranges representative of those found in the experiments. Charts of gas curves for the remainder of the experiments — for both the burn room and the target room - can be found in Appendix H.

Fire Modeling Methods A primary goal of fire department response is to prevent civilian injuries and deaths. Because the significant majority of fire deaths in the United States occur in residences, a rapid fire service response provides the last line-of-defense against civilian fire deaths. Further, because the fire service is less likely to rescue occupants intimate with the fire (i.e., inside the room of origin where conditions deteriorate rapidly), tenability measurements were taken in a remote bedroom on the second floor of the residential burn structure. The gas and temperature measurements were taken at the $5 \mathrm{ft}(1.5 \mathrm{~m})$ height above the floor, $3 \mathrm{ft}(0.9 \mathrm{~m})$ from the west wall in order to simulate a nonambulatory occupant (e.g, someone asleep, under the influence of alcohol or drugs, or otherwise mobility impaired).

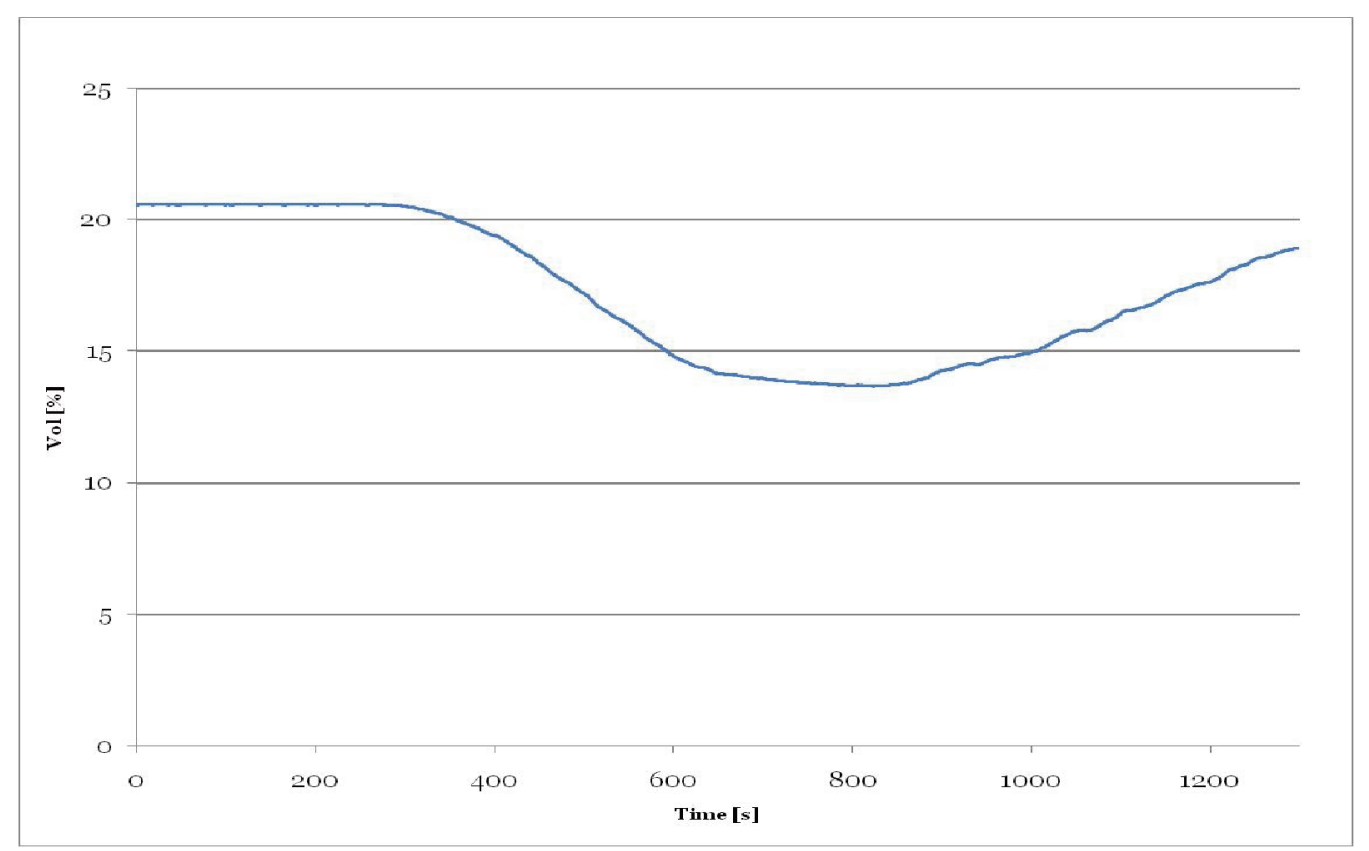

Figure 38: Representative Oxygen Concentration

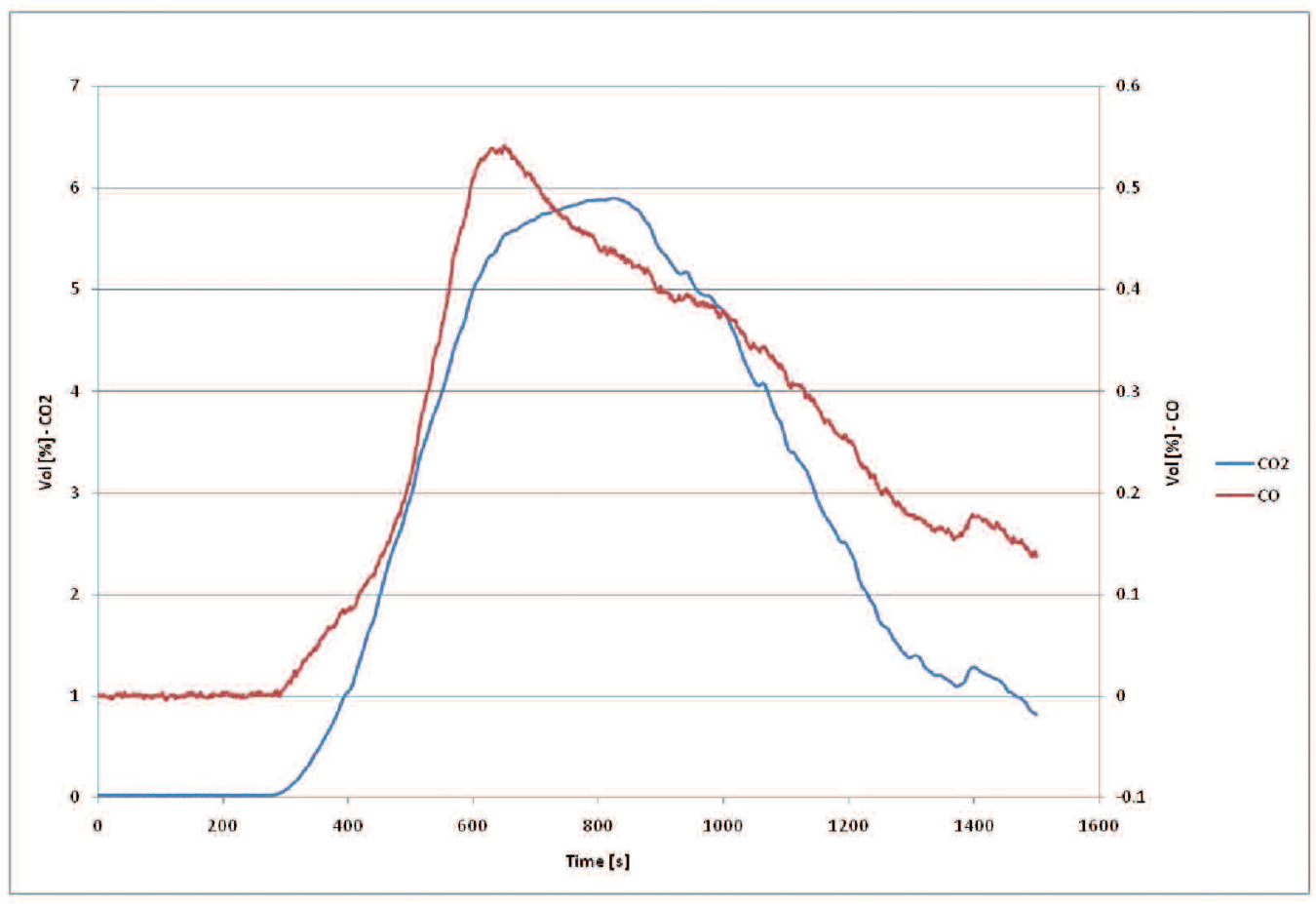

Figure 39: Representative Carbon Monoxide and Carbon Dioxide Concentrations 


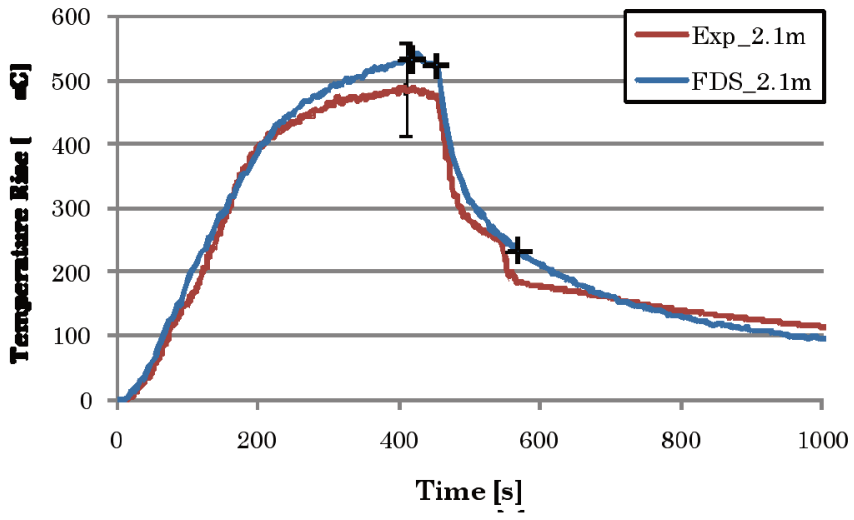

Figure 40: Measured vs. Predicted Temperature at the $2.1 \mathrm{~m}(6.9 \mathrm{ft})$ Thermocouple Location in the Burn Compartment

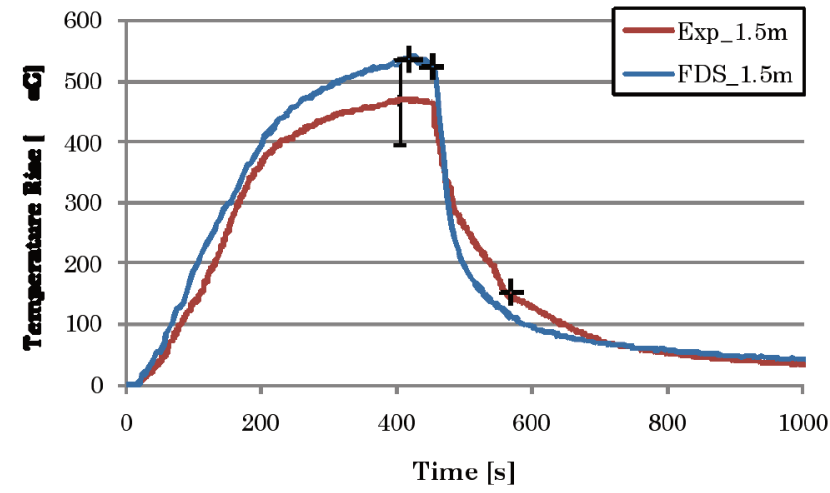

Figure 42: Measured vs. Predicted Temperature at the $1.5 \mathrm{~m} \mathrm{(4.9} \mathrm{ft})$ Thermocouple Location in the Burn Compartment

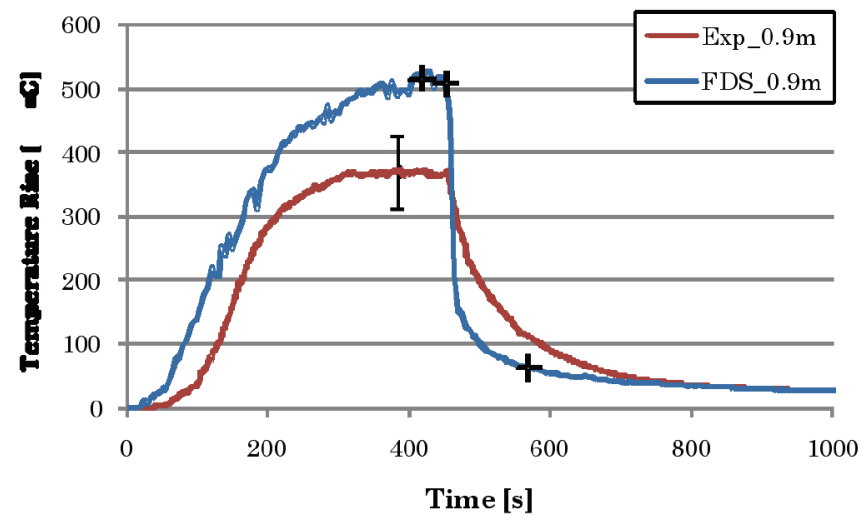

Figure 44: Measured vs. Predicted Temperature at the $0.9 \mathrm{~m}(2.9 \mathrm{ft})$ Thermocouple Location in the Burn Compartment

Computational fire models used the average suppression timings obtained from the time-to-task experiments under specific deployment configurations as inputs to the model. This quantitative approach eliminated the experimental variance of the fire. The resulting "computational" fire is repeatable, and therefore, any differences in occupant exposure to toxic gases will be due to the intervention times associated with a specific deployment configuration rather than the random variation that naturally occurs from fire to fire.

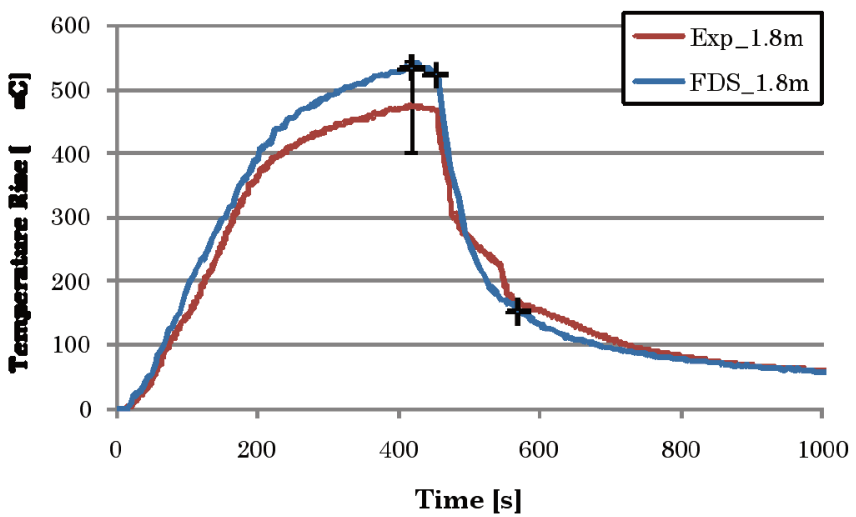

Figure 41: Measured vs. Predicted Temperature at the $1.8 \mathrm{~m}(5.9 \mathrm{ft})$ Thermocouple Location in the Burn Compartment

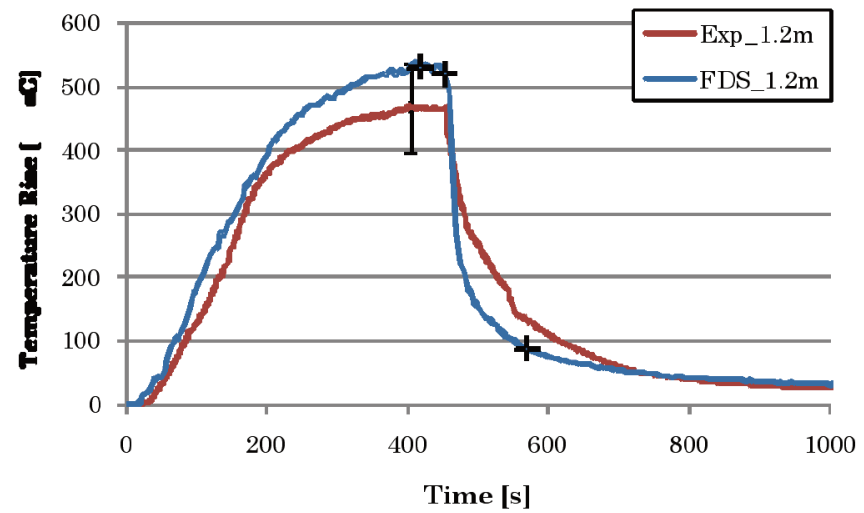

Figure 43: Measured vs. Predicted Temperature at the $1.2 \mathrm{~m} \mathrm{(3.9} \mathrm{ft)}$ Thermocouple Location in the Burn Compartment

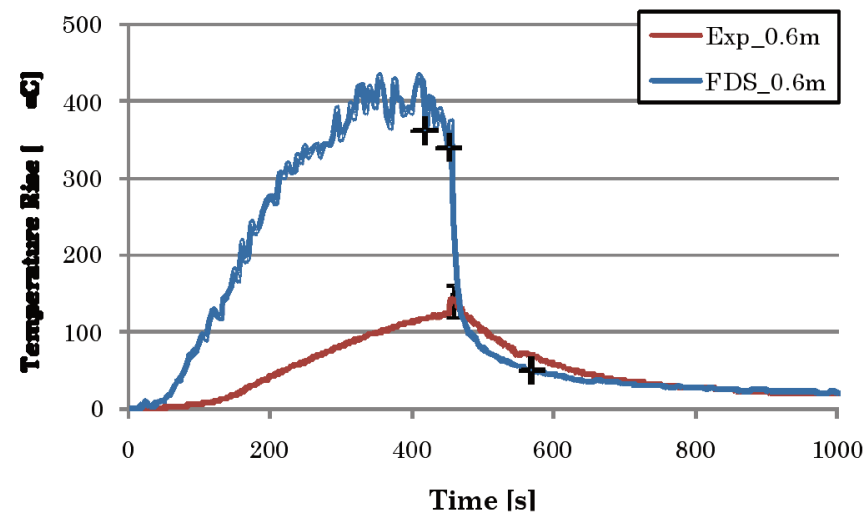

Figure 45: Measured vs. Predicted Temperature at the $0.6 \mathrm{~m} \mathrm{(1.9} \mathrm{ft)}$ Thermocouple Location in the Burn Compartment

Fire simulations were completed using the NIST Fire Dynamics Simulator (FDS). FDS is a computational fluid dynamics model of fire-driven fluid flow. The first version of the FDS was released in 2000. FDS has been extensively verified and validated (USNRC 2007). Since the initial release, numerous improvements have been made and new features added. This study used FDS version 5.4.2 (Sub-version \#4957), which was released on October 19, 2009. In order to calibrate the model, simulations were performed to replicate the experimental results observed in the 
room-and-contents fires. Once the ability of the model to replicate experimental results was established, the different fire growth rates and deployment configurations were simulated to characterize the effectiveness of different responses relative to different fire growth rates.

The occupant exposure to toxic gases was assumed to occur until the occupant is rescued by the truck crew (start time of primary search plus one minute). Table 6 shows the "rescue time" for the various crew sizes that correspond to the test matrix for the room and contents experiments.

Part 4 of the experiments used fire modeling to correlate response times to atmospheric tenability in a burning structure. In order to calibrate the computer fire model, simulations were performed to replicate the experimental results observed in the room-and-contents fires. Model inputs include building geometry and material properties, ventilation paths (doors, windows, leakage paths), and heat release rate of the fuel package. While the building geometry is easily measured and material properties (such as the thermal properties of drywall and concrete) are readily estimated, the heat release rate was not directly measured during the experiments. The heat release rate of the fuel package is the primary determinant of the production rate of heat, smoke, and gas species (e.g., carbon dioxide, carbon monoxide).

Figures 40 through 45 compare the experimental and simulated burn room temperatures using the burn room thermocouple tree. The tree contained thermocouples located at $0.6 \mathrm{~m}(1.9 \mathrm{ft})$, $0.9 \mathrm{~m}(2.9 \mathrm{ft}), 1.2 \mathrm{~m}(3.9 \mathrm{ft}), 1.5 \mathrm{~m}(4.9 \mathrm{ft}), 1.8 \mathrm{~m}(5.9 \mathrm{ft})$, and $2.1 \mathrm{~m}(6.9 \mathrm{ft})$ above the floor. For additional information about the instrumentation type location, see Appendix C. The results for thermocouples located in the hot gas layer show excellent agreement. The temperature at the lower two thermocouples show an overprediction of the hot gas layer depth in the computer simulation. A small difference in the location of the interface height (the steep temperature gradient between the relatively cool lower gas layer and the hot upper gas layer), can result in significant predicted temperature differences with relatively little effect on the bulk heat and mass transport accuracy. This explanation is supported by the agreement of the temperatures in the remote bedroom.

Figure 46 compares the experimental and predicted oxygen concentration levels in the upstairs bedroom (measured at $5 \mathrm{ft}$ $(1.5 \mathrm{~m})$ above the floor, centered above the bed). Figures 47 through 52 compare the experimental and simulated temperatures in the upstairs (target room) bedroom. As expected, the temperatures are moderated by mixing (cool ambient air mixes with hot combustion gases during transport between the burn room and the target room) and by thermal losses to the (cooler) surfaces between the two rooms.
Once the model inputs were determined to agree with the experimental results, the input heat release rate was changed to represent three fire growth rates representative of a range of fire hazard development - slow, medium, and fast, which are described in greater detail in the following sections.

\section{Time to Untenable Conditions: Research Questions}

In the real world, fires grow at many different rates - from very slow, smoldering fires all the way to ultra-fast, liquid fuel or spray fires. In order to extend the applicability of the findings of this report beyond the one fire growth rate observed in part 3 of this report (residential room and contents fires), computer fire modeling was used to quantify the effectiveness of fire department operations in response to an idealized range of fire growth rates (characterized as slow, medium, and fast). Based on the research questions shown in Figure 53, fire modeling methods were then selected to maximize the applicability of the times to task results.

1) How do performance times relate to fire growth as projected by standard fire time/temperature curves?

2) How do these performance times vary by crew size, first due arrival time, and stagger?

3) How do crew size, stagger, and arrival time affect occupant tenability within the structure?

Figure 53: Research Questions for Time to Untenable Conditions 


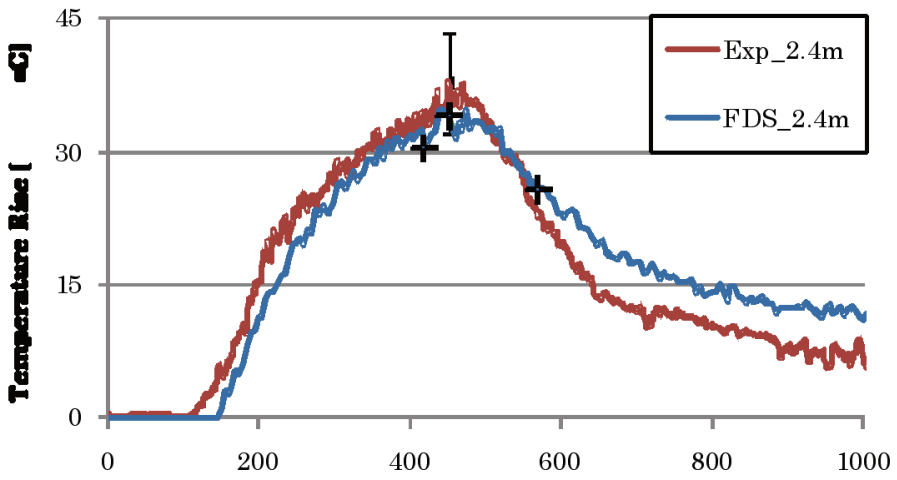

Time [s]

Figure 47: Measured vs. Predicted Temperature at the $2.4 \mathrm{~m}(7.8 \mathrm{ft})$ Thermocouple Location in the Bedroom

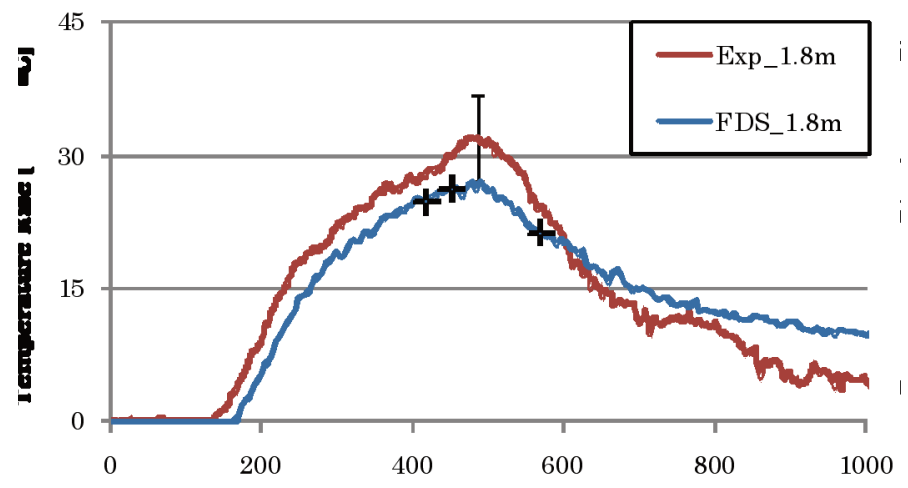

Time [s]

Figure 49: Measured vs. Predicted Temperature at the $1.8 \mathrm{~m}$ (5.9 ft) Thermocouple Location in the Bedroom

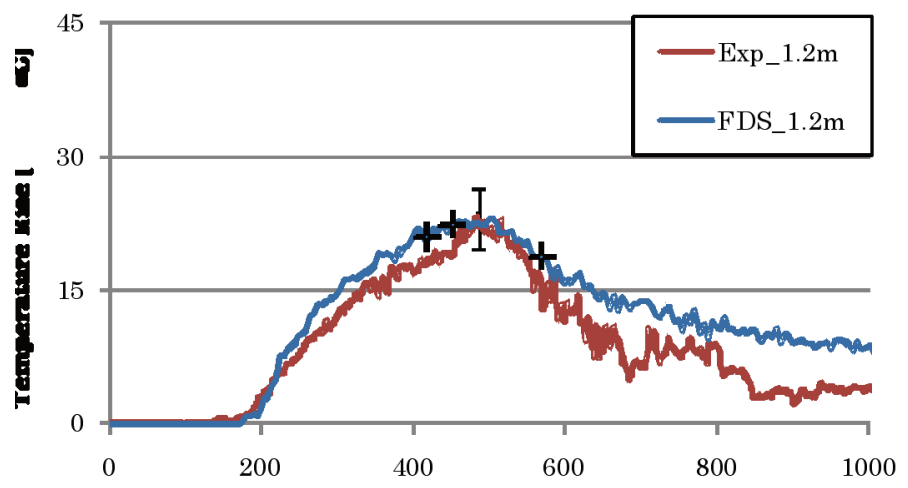

Time [s]

Figure 51: Measured vs. Predicted Temperature at the $1.2 \mathrm{~m}$ (3.9 ft) Thermocouple Location in the Bedroom

\section{Fire Growth Rates}

Three fire growth rates were used in the computer fire modeling to assess the effectiveness of different fire department deployment configurations in response to fires that were similar to, faster growing, and slower growing than the fires observed in the room-and-contents fires. The slow, medium, and fast fire growth rates are defined by the Society of Fire Protection Engineers according to the time at which they reach 1 megawatt (MW). A typical upholstered chair burning at its peak would produce a 1-MW fire, while a large sofa at its burning peak would produce roughly a 2-MW fire.

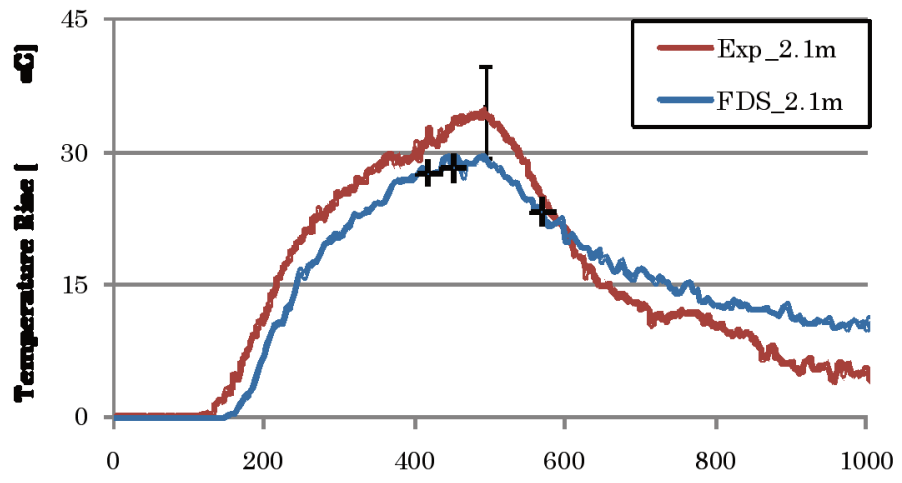

Time [s]

Figure 48: Measured vs. Predicted Temperature at the $2.1 \mathrm{~m}(6.8 \mathrm{ft})$ Thermocouple Location in the Bedroom

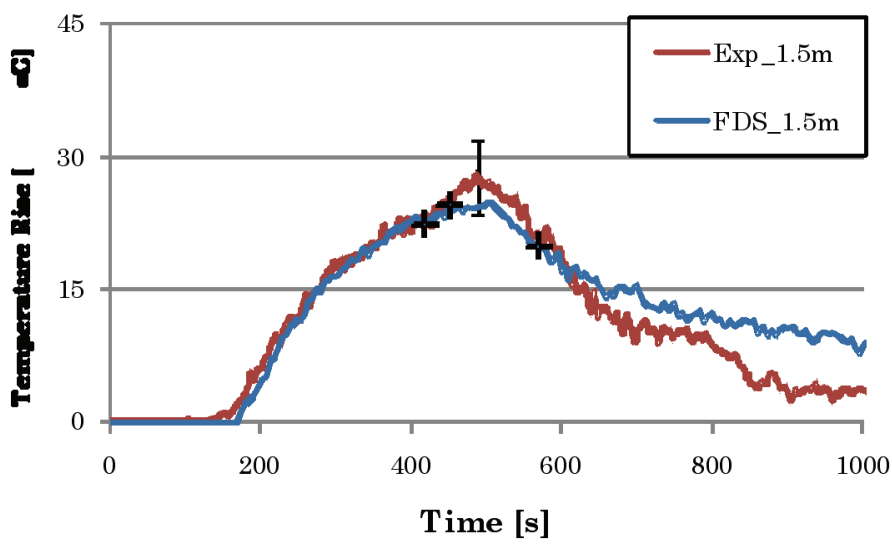

Figure 50: Measured vs. Predicted Temperature at the $1.5 \mathrm{~m} \mathrm{(4.9} \mathrm{ft)}$ Thermocouple Location in the Bedroom

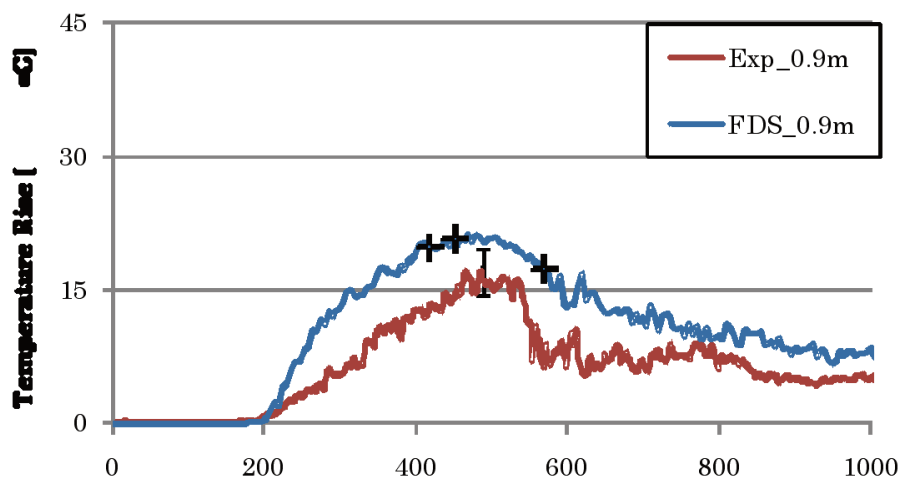

Time [s]

Figure 52: Measured vs. Predicted Temperature at the $0.9 \mathrm{~m}(2.9 \mathrm{ft})$ Thermocouple Location in the Bedroom

The growth rate of fires is often approximated by simple correlation of heat release rate to the square of time. If a fire is not suppressed before full-room involvement, the probability of spread beyond the room of origin increases dramatically if there is nearby fuel load to support fire spread. If a nearby fuel load is available, the $12 \mathrm{ft}(3.7 \mathrm{~m})$ by $16 \mathrm{ft}(4.9 \mathrm{~m})$ compartment used in the fire experiments would become fully involved at approximately 2 MW. Table 7 shows the time in seconds at which 1-MW and 2-MW (fully involved) fires in this compartment would be reached in the absence of suppression. 
A fire department rescue operation is a race between the deteriorating interior conditions inside the structure and the rescue and suppression activities of the fire department. Each fire growth rate was used as a baseline heat release rate for the simulation. Intervention times (window and door opening times and suppression time) from the time-to-task tests were systematically input into the model to evaluate the effects on interior tenability conditions. The interior tenability conditions were calculated in a remote upstairs bedroom (above the room of fire origin on the first floor) in order to maximize the opportunity for differentiation among different crew configurations.

\section{Fractional Effective Dose (FED)}

In order to convert instantaneous measurements of local gas conditions, the fractional effective dose (FED) formulation published by the International Standards Organization (ISO) in document 13571 Life-threatening Components of Fire-Guidelines for the Estimation of Time Available for Escape Using Fire Data (ISO 2007) were used. FED is a probabilistic estimate of the effects of toxic gases on humans exposed to fire effluent. The formulation used in the

\begin{tabular}{|c|c|}
\hline $\begin{array}{c}\text { Deployment } \\
\text { Conflguration } \\
\text { (All times with } \\
\text { fose stagger adjusted } \\
\text { of first due engine) }\end{array}$ & $\begin{array}{c}\text { Rescue Time for } \\
\text { Deployment } \\
\text { Conflguration } \\
\text { (Min : Sec) }\end{array}$ \\
\hline 2-Person Early & $12: 47$ \\
\hline 3-Person Early & $9: 03$ \\
\hline 4-Person Early & $9: 10$ \\
\hline 5-Person Early & $8: 57$ \\
\hline 2-Person Late & $14: 47$ \\
\hline 3-Person Late & $11: 03$ \\
\hline 4-Person Late & $11: 10$ \\
\hline Resurival & \\
\hline
\end{tabular}

Table 6: Rescue Time for Different Deployment Configurations
Time in Seconds Reach 1 MW

Time in Seconds to Reach to 2 MW

\begin{tabular}{|c|c|}
\hline 600 & 848 \\
\hline 300 & 424 \\
\hline 150 & 212 \\
\hline
\end{tabular}

Table 7: Time to Reach 1 MW and 2 MW by Fire Growth Rate In the Absence of Suppression simulations accounts for carbon monoxide (CO), carbon dioxide $\left(\mathrm{CO}_{2}\right)$, and oxygen $\left(\mathrm{O}_{2}\right)$ depletion. Other gases, including hydrogen cyanide $(\mathrm{HCN})$ and hydrogen chloride $(\mathrm{HCl})$, were not accounted for in this analysis and may alter FED for an actual occupant.

$$
F E D=\sum_{i=1}^{n} \frac{C_{i}}{\left(C_{t}\right)_{i}} \Delta t
$$

Where $\mathrm{C}_{\mathrm{i}}$ is the concentration of the ith gas and $\left(\mathrm{C}_{\mathrm{t}}\right)_{\mathrm{i}}$ is the toxic concentration of ith gas and $\Delta \mathrm{t}$ is the time increment.

There are three FED thresholds generally representative of different exposure sensitivities of the general population. An FED value of 0.3 indicates the potential for certain sensitive populations to become incapacitated as a result of exposure to toxic combustion products. Sensitive populations may include elderly, young, or individuals with compromised immune systems. Incapacitation is the point at which occupants can no longer effect their own escape. An FED value of 1.0 represents the median incapacitating exposure. In other words, $50 \%$ of the general population will be incapacitated at that exposure level. Finally, an FED value of 3.0 represents the value where occupants who are particularly tolerant of combustion gas exposure (extremely fit persons, for example) are likely to become incapacitated.

These thresholds are statistical probabilities, not exact measurements. There is variability in the way individuals respond to toxic atmospheric conditions. FED values above 2.0 are often fatal doses for so-called typical occupants. There is no threshold so low that it can be said to be safe for every exposed occupant. ${ }^{17}$

17 See the following sections of ISO Document 13571:

5.2 Given the scope of this Technical Specification, FED and/or FEC values of 1,0 are associated, by definition, with sublethal effects that would render occupants of average susceptibility incapable of effecting their own escape. The variability of human responses to toxicological insults is best represented by a distribution that takes into account varying susceptibility to the insult. Some people are more sensitive than the average, while others may be more resistant (see Annex A.1.5). The traditional approach in toxicology is to employ a safety factor to take into consideration the variability among humans, serving to protect the more susceptible subpopulations. 5.2.1 As an example, within the context of reasonable fire scenarios FED and/or FEC threshold criteria of 0,3 could be used for most general occupancies in order to provide for escape by the more sensitive subpopulations. However, the user of this Technical Specification has the flexibility to choose other FED and/or FEC threshold criteria as may be appropriate for chosen fire safety objectives. More conservative FED and/or FEC threshold criteria may be employed for those occupancies that are intended for use by especially susceptible subpopulations. By whatever rationale FED and FEC threshold criteria are chosen, a single value for both FED and FEC must be used in a given calculation of the time available for escape. 


\section{Results from Modeling Methods}

Table 8 shows the FED for slow-, medium-, and fast-growth rate fires correlated to rescue times based on crew size and arrival time in the study. As with the room-and-contents fire in part 3, results in Table 8 included only the close-stagger rescue time data. The effect of far-stagger rescue times on occupant tenability should be investigated in future studies. Values above 0.3 are shown in yellow, and those above the median incapacitating exposure of 1.0 are shown in red.

Figure 54 shows that with slow-growth fires in the experimental residential structure, all crew configurations could achieve rescue time before FED reached incapacitating levels. Figure 55

illustrates the greater danger of medium-growth fires, where the FED at rescue time for two-person crews is well above the 0.3 level, and almost to that level for the other crews.

Figure 56 (page 49) vividly illustrates the extreme danger of fast-growth fires. By the time a two-person crew is able to facilitate a rescue, the FED has far exceeded the median 1.0 level. For other crew sizes, the FED has exceeded 0.3, which is a threshold level for vulnerable populations.

Table 8: FED as a Function of Deployment Configuration and Fire Growth Rate

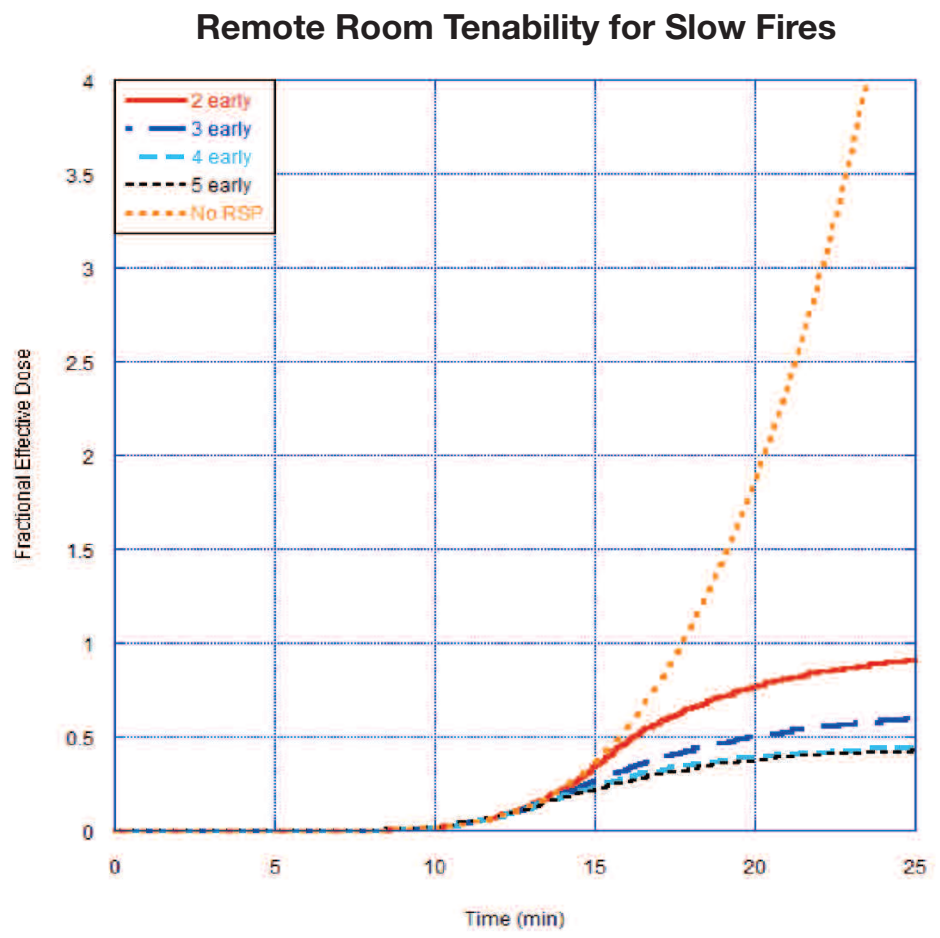

Figure 54: FED Curves for Early Arrival for All Crew Sizes at Slow-Growth Fires

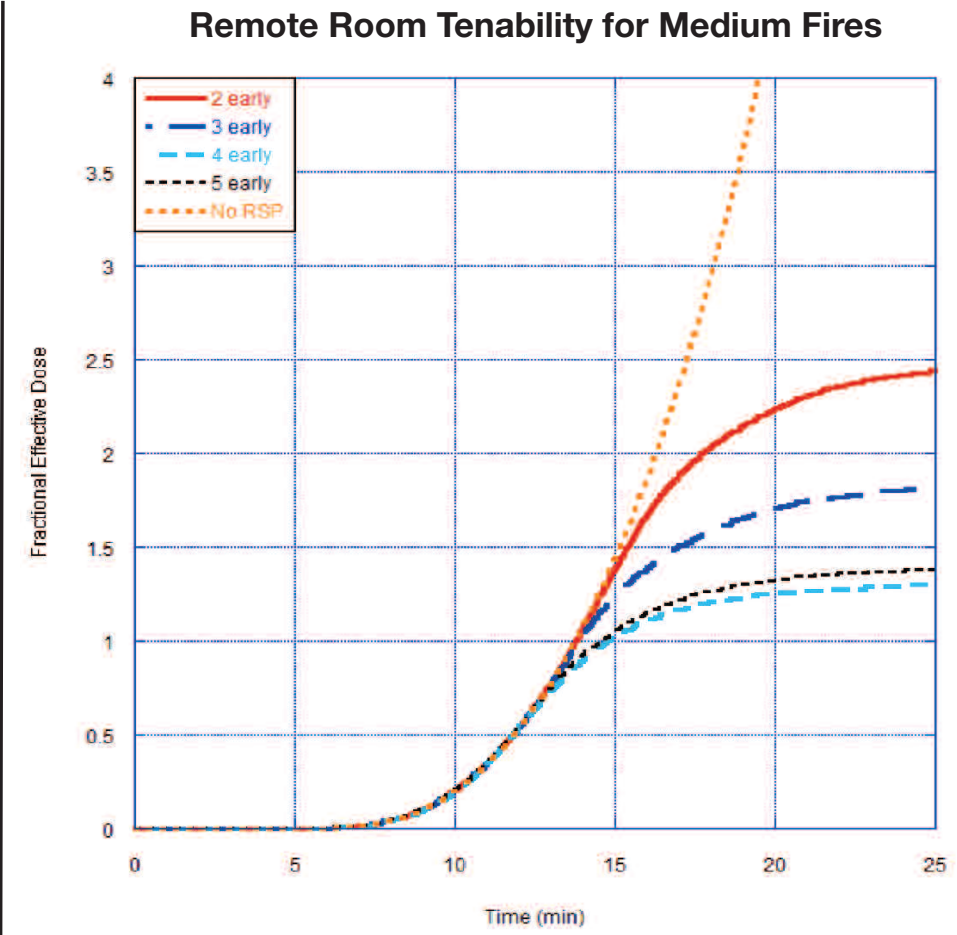

Figure 55: Average FED Curves for Early Arrival for All Crew Sizes at Medium-Growth Fires 


\section{Remote Room Tenability for Fast Fires}

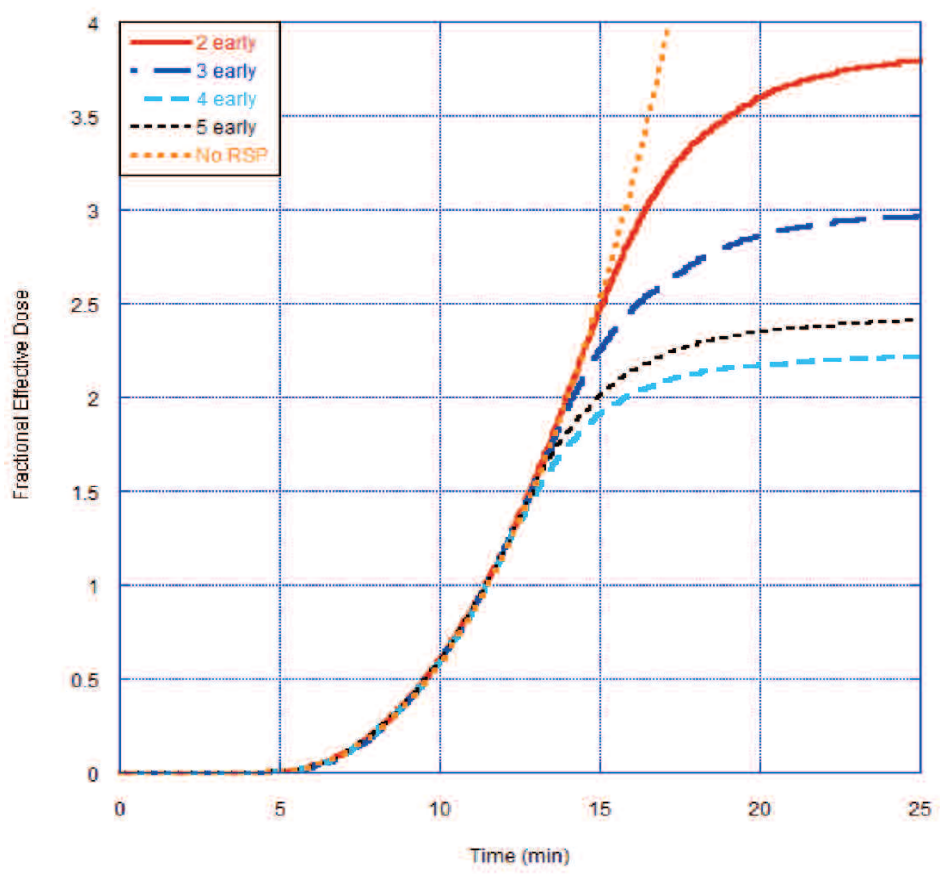

Figure 56: Average FED Curves for Early Arrival for All Crew Sizes at Fast-Growth Fires

\section{Interior Firefighting Conditions and Deployment Configuration}

The available time to control a fire can be quite small. Risks to firefighters are lower for smaller fires than larger fires because smaller fires are easier to suppress and produce less heat and fewer toxic gases. Therefore, firefighter deployment configurations that can attack fires earlier in the fire development process present lower risk to firefighters. The longer the duration of the fire development process without intervention, the greater the increase in risk for occupants and responding firefighters. Therefore, time is critical.

Stopping the escalation of the event involves firefighter intervention via critical tasks performed on the fireground. Critical tasks, as described previously, include those tasks that directly affect the spread of fire as well as the associated structural tenability.

There are windows of opportunity to complete critical tasks. A fire in a structure with a typical residential fuel load at six minutes post-ignition is very different from the same fire at eight minutes or at ten minutes post-ignition. Some tasks that are deemed "important" (e.g., scene size-up) for a fire in early stages of growth become critical if intervention tasks are delayed. Time can take away opportunities. If too much time passes, then the window of opportunity to affect successful outcomes (e.g., rescue victim or stop fire spread) closes.

For a typical structure fire event involving a fire department response, there is an incident commander on the scene who determines both the strategy and tactics that will be employed to stop the spread of the fire, rescue occupants, ventilate the structure, and ultimately extinguish the fire. Incident commanders must deal with the fire in the present and make intelligent command decisions based on the circumstances at hand upon arrival. Additionally, arrival time and crew size are factors that contribute to the incident commander's decisions and affect the capability of the firefighters to accomplish necessary tasks on scene in a safe, efficient, and effective manner.

Table 9 illustrates vividly the more dangerous conditions small crews face because of the extra time it takes to begin and complete critical tasks (particularly fire suppression). In the two minutes more it took for the two-person crew (early arrival) than the five-person crew (early arrival) to get water on the fire, a slow growth rate fire would have increased from 1.1 MW to 1.5 MW. This growth would have been even more extreme for a medium-or fast-growth rate fire. The difference is even more substantial for the two-person crew with late arrival as the fire almost doubled in size in the time difference between this crew and the five-person crew.

Based on fire modeling for the low hazard structure studied with a typical residential fuel load, it is likely that medium- and fast-growth rate fires will move beyond the room of origin prior to the arrival of firefighters for all crew sizes. Note that results in Table 8 included only the close-stagger rescue time data. The effect of far-stagger rescue times on occupant tenability should be investigated in future studies. Therefore, the risk level of the event upon arrival will be higher for all crews which must be considered by the incident commander when assigning firefighters to on-scene tasks.

\begin{tabular}{|l|c|c|}
\hline \multicolumn{1}{c|}{$\begin{array}{c}\text { Deployment } \\
\text { Configuration }\end{array}$} & $\begin{array}{c}\text { Time to Water } \\
\text { on Fire } \\
\text { (Min : Sec) }\end{array}$ & $\begin{array}{c}\text { Fire Size at Time of } \\
\text { Suppression for } \\
\text { Slow-Growth Fires }\end{array}$ \\
\hline 2-Person, Late Arrival & $14: 26$ & $2.1 \mathrm{MW}$ \\
\hline 2-Person, Early Arrival & $12: 26$ & $1.5 \mathrm{MW}$ \\
\hline 3-Person, Late Arrival & $13: 24$ & $1.8 \mathrm{MW}$ \\
\hline 3-Person, Early Arrival & $11: 24$ & $1.3 \mathrm{MW}$ \\
\hline 4-Person, Late Arrival & $13: 11$ & $1.7 \mathrm{MW}$ \\
\hline 4-Person, Early Arrival & $11: 11$ & $1.3 \mathrm{MW}$ \\
\hline 5-Person, Late Arrival & $12: 33$ & $1.6 \mathrm{MW}$ \\
\hline 5-Person, Early Arrival & $10: 33$ & $1.1 \mathrm{MW}$ \\
\hline
\end{tabular}

Table 9: Fire Size at Time of Fire Suppression 


\section{Physiological Effects of Crew Size on Firefighters}

eports on firefighter fatalities consistently document overexertion/overstrain as the leading cause of line-of-duty fatalities. There is strong epidemiological evidence that heavy physical exertion can trigger sudden cardiac events (Mittleman et al. 1993; Albert et al. 2000). Therefore, information about the effect of crew size on physiological strain is very valuable.

During the planning of the fireground experiments, investigators at Skidmore College recognized the opportunity to conduct an independent study on the relationship between firefighter deployment configurations and firefighter heart rates. With the approval of the Institutional Review Board of Skidmore College, they were able to leverage the resources of the field experiments to conduct a separate analysis of the cardiac strain on fire fighters on the fireground.
For details, consult the complete report (Smith 2009). Two important conclusions from the report reinforce the importance of crew size:

Average heart rates were higher for members of small crews, particularly two-person crews.

- Danger is increased for small crews because the stress of fire fighting keeps heart rates elevated beyond the maximum heart rate for the duration of a fire response, and so the higher heart rates were maintained for sustained time intervals. 
T he scope of this study is limited to understanding the relative influence of deployment variables to low-hazard, residential structure fires, similar in magnitude to the hazards described in NFPA 1710. The applicability of the conclusions from this report to commercial structure fires, high-rise fires, outside fires, terrorism/natural disaster response, HAZMAT or other technical responses has not been assessed and should not be extrapolated from this report.

Every attempt was made to ensure the highest possible degree of realism in the experiments while complying with the requirements of NFPA 1403, but the dynamic environment on the fireground cannot be fully reproduced in a controlled experiment. For example, NFPA 1403 required a daily walkthrough of the burn prop (including identifying the location of the fire) before ignition of a fire that would produce an Immediately Dangerous to Life and Health (IDLH) atmosphere, a precaution not available to responders dispatched to a live fire.

The number of responding apparatus for each fireground response was held constant (three engines and one truck, plus the battalion chief and aide) for all crew size configurations. The effect of deploying either more or fewer apparatus to the scene was not evaluated.

The fire crews who participated in the experiments typically operate using three-person and four-person staffing. Therefore, the effectiveness of the two-person and five-person operations may have been influenced by a lack of experience in operating at those staffing levels. Standardizing assigned tasks on the fireground was intended to minimize the impact of this factor, which has an unknown influence on the results.

The design of the experiments controlled for variance in performance of the incident commander. In other words, a more-or less-effective incident commander may have a significant influence on the outcome of a residential structure fire.

Although efforts were made to minimize the effect of learning across experiments, some participants took part in more than one experiment, and others did not.

The weather conditions for the experiments were moderate to cold. Frozen equipment such as hydrants and pumps was not a factor. However, the effect of very hot weather conditions on firefighter performance was not measured.

All experiments were conducted during the daylight hours. Nighttime operations could pose additional challenges.

Fire spread beyond the room of origin was not considered in the room and contents tests or in the fire modeling. Therefore, the size of the fire and the risk to the firefighter may be somewhat underestimated for fast-growing fires or slower-response configurations.

There is more than one effective way to perform many of the required tasks on the fireground. Attempts to generalize the results from these experiments to individual departments must take into account tactics and equipment that vary from those used in the experiments. 


\section{Conclusions}

$\mathrm{M}$ ore than 60 laboratory and full-scale fire experiments were conducted to determine the impact of crew size, first-due engine arrival time, and subsequent apparatus arrival times on firefighter safety and effectiveness at a low-hazard residential structure fire. This report quantifies the effects of changes to staffing and arrival times for low-hazard residential firefighting operations. While resource deployment is addressed in the context of a single structure type and risk level, it is recognized that public policy decisions regarding the cost-benefit of specific deployment decisions are a function of many factors including geography, available resources, community expectations, as well as all local hazards and risks. Though this report contributes significant knowledge to community and fire service leaders in regard to effective resource deployment for fire suppression, other factors contributing to policy decisions are not addressed.

The objective of the experiments was to determine the relative effects of crew size, first-due engine arrival time, and stagger time for subsequent apparatus on the effectiveness of the firefighting crews relative to intervention times and the likelihood of occupant rescue using a parametric design. Therefore, the experimental results for each of these factors are discussed below.

Of the 22 fireground tasks measured during the experiments, the following were determined to have especially significant impact on the success of fire fighting operations. Their differential outcomes based on variation of crew size and/or apparatus arrival times are statistically significant at the $95 \%$ confidence level or better.

\section{Overall Scene Time:}

The four-person crews operating on a low-hazard structure fire completed all the tasks on the fireground (on average) seven minutes faster - nearly $30 \%$ - than the two-person crews. The four-person crews completed the same number of fireground tasks (on average) 5.1 minutes faster - nearly $25 \%$ - than the three-person crew. For the low-hazard residential structure fire, adding a fifth person to the crews did not decrease overall fireground task times. However, it should be noted that the benefit of five-person crews has been documented in other evaluations to be significant for medium- and high-hazard structures, particularly in urban settings, and should be addressed according to industry standards. ${ }^{18}$

\section{Time to Water on Fire:}

There was a nearly $10 \%$ difference in the "water on fire time" between the two and three-person crews and an additional $6 \%$ difference in the "water on fire time" between the three- and four-person crews (i.e., $16 \%$ difference between the four and two-person crews). There was an additional $6 \%$ difference in the "water on fire" time between the four- and five-person crews (i.e., $22 \%$ difference between the five and two-person crews).

\section{Ground Ladders and Ventilation:}

The four-person crew operating on a low-hazard structure fire can complete laddering and ventilation (for life safety and rescue) $30 \%$ faster than the two-person crew and $25 \%$ faster than the three-person crew.

\section{Primary Search:}

The three-person crew started and completed a primary search and rescue $25 \%$ faster than the two-person crew. In the same structure, the four- and five-person crews started and completed a primary search $6 \%$ faster than the three-person crews and $30 \%$ faster than the two-person crew. A $10 \%$ difference was equivalent to just over one minute.

\section{Hose Stretch Time:}

In comparing four-and five-person crews to two-and three-person crews collectively, the time difference to stretch a line was 76 seconds. In conducting more specific analysis comparing all crew sizes to a two-person crew the differences are more distinct. A two-person crew took 57 seconds longer than a three-person crew to stretch a line. A two-person crew took 87 seconds longer than a four-person crew to complete the same tasks. Finally, the most notable comparison was between a two-person crew and a five-person crew - more than 2 minutes (122 seconds) difference in task completion time.

\section{Industry Standard Achieved:}

The "industry standard achieved" time started from the first engine arrival at the hydrant and ended when 15 firefighters were assembled on scene. ${ }^{19}$ An effective response force was assembled by the five-person crews three minutes faster than the four-person crews. According to study deployment protocal, the two- and three-person crews were unable to assemble enough personnel to meet this standard.

\section{Occupant Rescue:}

Three different "standard" fires (slow-, medium-, and fast-growth rate) were simulated using the Fire Dynamics Simulator (FDS) model. The fires grew exponentially with time. The fire modeling simulations demonstrated that two-person, late arriving crews can face a fire that is twice the intensity of the fire faced by five-person, early arriving crews. The rescue scenario was based on a nonambulatory occupant in an upstairs bedroom with the bedroom door open.

Independent of fire size, there was a significant difference between the toxicity, expressed as fractional effective dose (FED), for occupants at the time of rescue depending on arrival times for all crew sizes. Occupants rescued by crews starting tasks two minutes earlier had lesser exposure to combustion products.

The fire modeling showed clearly that two-person crews cannot complete essential fireground tasks in time to rescue occupants without subjecting either firefighters or occupants to an increasingly hazardous atmosphere. Even for a slow-growth rate fire, the FED was approaching the level at which sensitive populations, such as children and the elderly are threatened. For a medium-growth rate fire with two-person crews, the FED was far above that threshold and approached the level affecting the median sensitivity in general population. For a fast-growth rate fire, the FED was well above the median level at which $50 \%$ of the general population would be incapacitated. Larger crews responding to slow-growth rate fires can rescue most occupants prior to incapacitation along with early-arriving larger crews responding to medium-growth rate fires. The result for late-arriving (two minutes later than early-arriving) larger crews may result in a threat to sensitive populations for medium-growth rate fires." The new sentence is consistent with our previous description for two-person crews where we identify a threat to sensitive populations..

Statistical averages should not, however, mask the fact that there is no FED level so low that every occupant in every situation is safe.

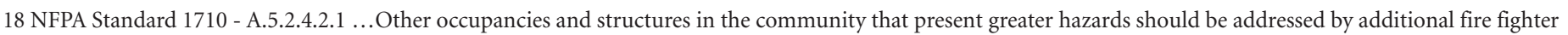
functions and additional responding personnel on the initial full alarm assignment.

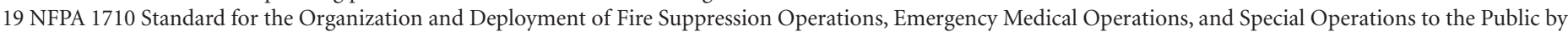
Career Fire Departments. Section 5.2.1 - Fire Suppression Capability and Section 5.2.2 Staffing. 


\section{Summary:}

The results of these field experiments contribute significant knowledge to the fire service industry. First, the results establish a technical basis for the effectiveness of company crew size and arrival time in NFPA 1710. The results also provide valid measures of total effective response force assembly on scene for fireground operations, as well as the expected performance of time-to-critical-task

measures for a low-hazard structure fires. Additionally, the results provide tenability measures associated with the occupant exposure rates to the range of fires considered by the fire model. 
$\mathrm{n}$ order to realize a significant reduction in firefighter

line-of-duty death (LODD) and injury, fire service leaders must

focus directly on resource allocation and the deployment of resources, both contributing factors to LODD and injury. Future research should use similar methods to evaluate firefighter resource deployment to fires in medium- and high-hazard structures, including multiple-family residences and commercial properties. Additionally, resource deployment to

multiple-casualty disasters or terrorism events should be studied to provide insight into levels of risks specific to individual communities and to recommend resource deployment proportionate to such risk. Future studies should continue to investigate the effects of resource deployment on the safety of both firefighters and the civilian population to better inform public policy. 


\section{Acknowledgements}

A project of this magnitude extends significantly beyond the capabilities and expertise of the report authors. The following individuals were instrumental in the success of the experiments:

- Technical Experts - Dennis Compton, Retired Chief from Mesa, AZ and consultant, IFSTA; Russell Sanders, Retired Chief from Louisville, KY and staff, NFPA; William "Shorty" Bryson, Retired Chief of Miami, FL and Past President of Metropolitan Fire Chiefs; David Rohr, Operations Chief from Fairfax County Fire and Rescue; Richard Bowers, Chief from Montgomery County Fire and Rescue Department; Vincent Dunn, Retired from Fire Department of New York; Michael Clemens, Chief of Training from Montgomery County Fire and Rescue Department; James Walsh, Battalion Chief from Fairfax County Fire and Rescue; Larry Jenkins, Captain I from Fairfax County Fire and Rescue; Doug Hinkle, Training Captain from Montgomery County Fire and Rescue Department; and Paul Neal, Safety Officer for Montgomery County Fire and Rescue Department.

Montgomery County Fire Department - Former Chief Tom Carr and Chief Richard Bowers - AND Fairfax County Fire and Rescue Services - Chief Ronald Mastin for supporting this study over a period of years to an unprecedented degree.

- NIST experimental and modeling personnel - Michael Selepak, Roy McLane, Anthony Chakalis, Andrew Lock, Marco Fernandez, Ed Hnetkovsky, Jay McElroy, Lauren DeLauter, Glenn Forney, Dan Murphy, and Craig van Norman.

IAFF Staff/ Data Entry/ Timer Supervision/Heart Rate Monitors- Nicole Taylor, Randy Goldstein, and Ron Benedict

Skidmore College - Denise Smith and Polar Heart Rate Monitors for supplemental study to bolster the significance of the main study results.

Timers - DeWayne Dutrow — Lead, Cliff Berner, Michael Fleming, Colby Poore, Chris Maple, Michael Thornton, Robert Daley, Ryan Loher

Montgomery County Support Services - Joey Fuller III Lead, Chris Hinkle, Doug Dyer, Joey Fuller IV

The dedicated Fire Officers and Firefighters from Montgomery County Fire \& Rescue and Fairfax County Fire $\&$ Rescue, who performed the difficult work of structural fire fighting safely and courageously. 
- Albert CM, Mittleman MA, Chae CU, Lee IM, Hennekens CH, Manson JE (2000). Triggering of sudden death from cardiac causes by vigorous exertion. N Engl J Med 343(19):1355-1361.

- Backoff, R. W.; et al. (1980). Firefighter Effectiveness - A Preliminary Report. Columbus Fire Division, The Ohio State University.

- Barnard RJ, Duncan HW [1975]. Heart rate and ECG responses of firefighters. J Occup Med 17: 247-250.

Blevins, L. G. and Pitts, W. M. (1999). Modeling of Bare and Aspirated Thermocouples in Compartment Fires. Fire Safety Journal, Vol. 33, 239-259.

Bryant, R. A., et al. (2004). The NIST 3 Megawatt Quantitative Heat Release Rate Facility - Description and Procedure. Natl. Inst. Stand. Technol. NIST IR 7052

- Centaur Associates. (1982). Report on the Survey of Fire Suppression Crew Size Practices.

Center for Public Safety Excellence. (2008.) CFAI: STANDARDS OF COVER, FIFTH EDITION. Chantilly, Va.

- Center for Public Safety Excellence. (2009.) FIRE \& EMERGENCY SERVICE SELF-ASSESSMENT MANUAL. Chantilly, VA.

Chang, C. Huang, H. (2005). A Water Requirements Estimation Model for Fire Suppression: A Study Based on Integrated Uncertainty Analysis, Fire Technology, Vol. 41, NO. 1, Pg. 5.

Coleman, Ronny J. (1988). MANAGING FIRE SERVICES, 2nd Edition, International City/County Management Association, Washington, DC.

Cushman, J. (1982). Report to Executive Board, Minimum Manning as Health \& Safety Issue. Seattle, WA Fire Department, Seattle, WA.

Gerard, J.C. and Jacobsen, A.T. (1981). Reduced Staffing: At What Cost?, Fire Service Today, Pg. 15.

Fahy R (2005). U.S. Firefighter Fatalities Due to Sudden Cardiac Death 1995-2004. NFPA Journal. 99(4): 44-47.

Hall, John R. Jr. (2006). U.S Unintentional Fire Death Rates by State. National Fire Protection Association, Quincy, MA.

Huggett, C. (1980). Estimation of the Rate of Heat Release by Means of Oxygen Consumption. J. of Fire and Flammability, Vol. 12, pp. 61-65.

- International Association of Fire Fighters/John's Hopkins University. (1991). "Analysis of Fire Fighter Injuries and
Minimum Staffing Per Piece of Apparatus in Cities With Populations of 150,000 or More," December 1991.

ISO (2007). ISO 13571: Life-threatening Components of Fire - Guidelines for the Estimation of Time Available for Escape Using Fire Data, International Standards Organization, Geneva.

- Janssens, M. L. (1991). Measuring Rate of Heat Release by Oxygen Consumption., Fire Technology, Vol. 27, pp. 234-249.

Jones, W. W. (2000). Forney, G. P.; Peacock, R. D.; Reneke, P. A. Technical Reference for CFAST: An Engineering Tool for Estimating Fire and Smoke Transport. National Institute of Standards and Technology, Gaithersburg, MD. NIST TN 1431; 190 p. March 2000.

Karter, M.J. Jr. (2008). U.S. Fire Loss for 2007. NFPA Journal, September/October 2008.

McGrattan, K. B. (2006). Fire Dynamics Simulator (Version 4): Technical Reference Guide. NIST Gaithersburg, MD. NIST SP 1018; NIST Special Publication 1018; 109 p. March 2006.

- McManis Associates and John T. O’Hagan and Associates (1984). “Dallas Fire Department Staffing Level Study," June 1984; pp. I-2 \& II-1 through II-7.

Menker, W.K. (1994). Predicting Effectiveness of Manual Suppression, MS Thesis, Worcester Polytechnic Institute.

- Metro Chiefs/International Association of Fire Chiefs (1992) "Metro Fire Chiefs - Minimum Staffing Position," May 1992.

Mittleman MA, Maclure M, Tofler GH, Sherwood JB, Goldberg RJ, Muller JE (1993). Triggering of acute myocardial infarction by heavy physical exertion. $N$ Engl J Med 329(23):1677-1683.

Morrison, R. C. (1990). Manning Levels for Engine and Ladder Companies in Small Fire Departments National Fire Academy, Emmitsburg, MD.

NFA (1981). Fire Engines are Becoming Expensive Taxi Cabs: Inadequate Manning. National Fire Academy, United States Fire Administration, Emmitsburg, MD.

NFPA (2007). NFPA 1403: Standard on Live Fire Training Evolutions. National Fire Protection Association, Quincy, MA.

NFPA (2004). NFPA 1710: Standard for the Organization and Deployment of Fire Suppression Operations, Emergency Medical Operations, and Special Operations to the Public by Career Fire Departments. National Fire Protection Association, Quincy, MA.

NFPA (2008). Fire Protection Handbook, $20^{\text {th }}$ Edition. National Fire Protection Association, Quincy, MA. 
Office of the Fire Marshal of Ontario. (1993). Fire Ground Staffing and Delivery Systems Within a Comprehensive Fire Safety Effectiveness Model. Ministry of the Solicitor General, Toronto, Ontario, Canada.

Omega Engineering, Inc. (2004). The Temperature Handbook. 5th Edition.

Parker, W. J. (1984). Calculations of the Heat Release Rate by Oxygen-Consumption for Various Applications., Journal of Fire Sciences, Vol. 4, pp. 380-395.

Phoenix, AZ Fire Department," Fire Department Evaluation System (FIREDAP)," December 1991; p. 1.

Purser, D. (2002). “Toxicity Assessment of Combustion Products." In The SFPE Handbook of Fire Protection Engineering, 3rd Edition. DiNenno (Editor). National Fire Protection Association, Quincy, MA.

Rand Institute. (1978). Fire Severity and Response Distance: Initial Findings. Santa Monica, CA.Roberts, B.

Romet TT, Frim J (1987). Physiological responses to firefighting activities. Eur J Appl Physiol 56: 633-638.

Sardqvist, S; Holmsted, G., Correlation Between Firefighting Operation and Fire Area: Analysis of Statistics, Fire Technology, Vol. 36, No. 2, Pg. 109, 2000

Smith DL, Petruzzello SJ, Kramer JM, Warner SE, Bone BG, Misner JE (1995). Selected physiological and psychobiological responses of physical activity in different configurations of firefighting gear. Ergonomics 38(10): 2065-2077

Smith, D. Effect of Deployment of Resources on Cardiovascular Strain of Firefighters.” DHS, 2009.

Thornton, W. (1917). The Relation of Oxygen to the Heat of Combustion of Organic Compounds., Philosophical Magazine and J. of Science, Vol. 33.

TriData Corporation. The Economic Consequences of Firefighter Injuries and Their Prevention, Final Report. National Institute of Standards and Technology, U.S. Department of Commerce, Gaithersburg, MD. 2005.

USFA (2002). Firefighter Fatality Retrospective Study. United States Fire Administration

USFA (2008). Fatal Fires, Vol. 5-Issue 1, March 2005. USFA, Firefighter Fatalities in the United States in 2007. June 2008. Prepared by C2 Technologies, Inc., for U.S. Fire Administration, Contract Number EME-2003-CO-0282.
USNRC (2007). Verification and Validation of Selected Fire Models for Nuclear Power Plant Applications. Volume 2: Experimental Uncertainty. Washington, DC : United States Nuclear Regulatory Commission. 1824. 
$\mathrm{T}$ he fire suppression and resource deployment experiments consisted of four distinct parts: laboratory experiments, time-to-task experiments, room and contents experiments and fire modeling. The purpose of the laboratory experiments was to assure a fire in the field experiments that would consistently meet NFPA 1403 requirements for live fire training exercises. The laboratory experiments enabled investigators to characterize the burning behavior of the wood pallets as a function of:

number of pallets and the subsequent peak heat release rate

compartment effects on burning of wood pallets

effect of window ventilation on the fire

effect on fire growth rate of the loading configuration of excelsior (slender wood shavings typically used as packing material)

\section{Design and Construction}

Figure A-1 shows the experimental configuration for the compartment pallet burns. Two identically sized compartments (3.66 m x $4.88 \mathrm{~m} \times 2.44 \mathrm{~m}$ ) were connected by a hallway ( $4 \mathrm{~m} \mathrm{x} 1 \mathrm{~m}$ $\mathrm{x} 2.4 \mathrm{~m}$ ). At each end of the hallway, a single door connected the hallway to each of the compartments. In the burn compartment, a single window ( $3 \mathrm{~m} \times 2 \mathrm{~m}$ ) was covered with noncombustible board that was opened for some experiments and closed for others. At the end of test, it was opened to extinguish the remaining burning material and to remove any debris prior to the next test. In the second compartment, a single doorway connected the compartment to the rest of the test laboratory. It was kept open throughout the tests allowing the exhaust to flow into the main collection hood for measurement of heat release rate.

The structure was constructed of two layer of gypsum wallboard over steel studs. The floor of the structure was lined with two layers of gypsum wallboard directly over the concrete floor of the test facility. In the burn compartment, an additional lining of cement board was placed over the gypsum walls and ceiling surfaces near the fire source to minimize fire damage to the structure after multiple fire experiments. A doorway $0.91 \mathrm{~m}$ wide by $1.92 \mathrm{~m}$ tall connected the burn compartment to the hallway and an opening $1 \mathrm{~m}$ by $2 \mathrm{~m}$ connected the hallway to the target compartment. Ceiling height was $2.41 \mathrm{~m}$ throughout the structure, except for the slight variation in the burn room.

\section{Fuel Source}

The fuel source for all of the tests was recycled hardwood pallets constructed of several lengths of hardwood boards nominally 83 $\mathrm{mm}$ wide by $12.7 \mathrm{~mm}$ thick. Lengths of the individual boards ranged from nominally $1 \mathrm{~m}$ to $1.3 \mathrm{~m}$. The finished size of a single pallet was approximately $1 \mathrm{~m}$ by $1.3 \mathrm{~m}$ by $0.11 \mathrm{~m}$. Figure A-2 shows the fuel source for one of the tests including six stacked pallets and excelsior ignition source. For an ignition source, excelsior was placed within the pallets, with the amount and location depending on the ignition scenario. Figure A-3 shows the pallets prior to a slow and a fast ignition scenario fire. Table A-1 details the total mass of pallets and excelsior for each of the free burn and compartment tests.

\section{Experimental Conditions}

The experiments were conducted in two series. In the first series, heat release measurements were made under free burn conditions beneath a $6 \mathrm{~m}$ by $6 \mathrm{~m}$ hood used to collect combustion gases and provide the heat release rate (HRR) measurement. A second series of tests was conducted with the fire in a compartmented structure to assess environmental conditions within the structure during the fires and determine the effect of the compartment enclosure on the fire growth. Table A-1 presents a summary of the tests conducted.

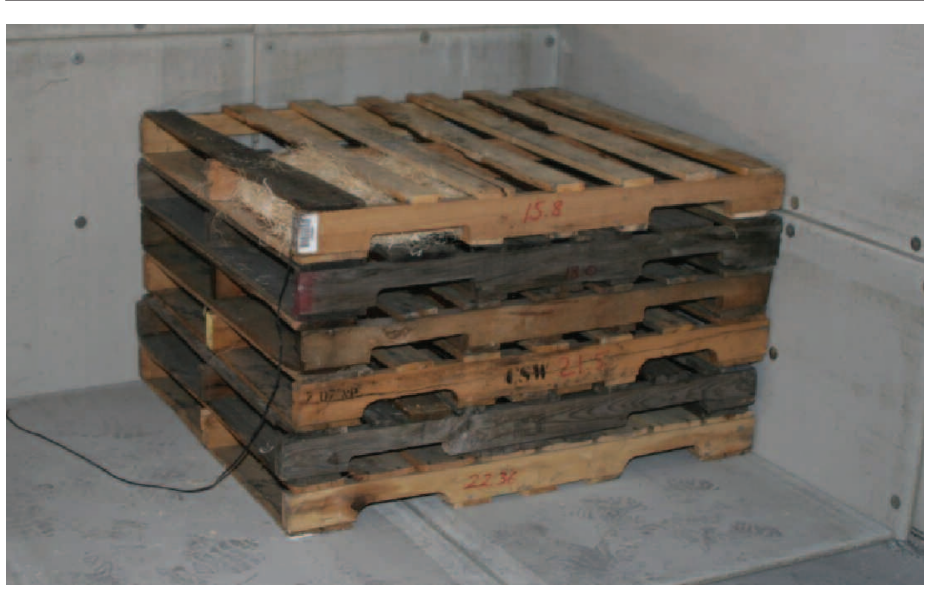

Figure A-2. Pallets and Excelsior Ignition Source Used as a Fuel Source 
Table A-1. Tests Conducted and Ambient Conditions at Beginning of Each Test

\begin{tabular}{|l|c|c|c|c|c|}
\hline Test & Test Type & $\begin{array}{c}\text { Number } \\
\text { of } \\
\text { Pallets }\end{array}$ & $\begin{array}{c}\text { Ignition } \\
\text { Scenario }\end{array}$ & $\begin{array}{c}\text { Total } \\
\text { Pallet } \\
\text { Mass } \\
\text { (kg) }\end{array}$ & $\begin{array}{c}\text { Excelsior } \\
\text { Mass } \\
\text { (kg) }\end{array}$ \\
\hline PAL 1 & Free burn & 4 & Fast & 79.3 & 8.1 \\
\hline PAL 2 & Free burn & 6 & Fast & 118.8 & 15.1 \\
\hline PAL 3 & Free burn & 8 & Fast & 146.7 & 16.2 \\
\hline PAL 4 & Free burn & 4 & Slow & 51.0 & 1.65 \\
\hline PAL 5 & Free burn & 6 & Slow & 160.3 & 0.85 \\
\hline CRA 1 & Compartment & 6 & Slow & 114.0 & 0.83 \\
\hline CRA 2 & Compartment & 4 & Slow & 69.7 & \\
\hline CRA 3 & Compartment & 4 & Fast & 71.1 & 0.8 \\
\hline CRA 4 & Compartment & 4 & Slow & 73.9 & 0.83 \\
\hline CRA 5 & Compartment & 4 & Slow & 73.8 & 0.85 \\
\hline
\end{tabular}

Notes: PAL stands for "pallet" and CRA ("Community Risk Assessment") is the designator for the configuration of pallets burned in the compartment. Efforts were made to use the same amount of excelsior mass for CRA $2(\sim 0.8 \mathrm{~kg})$, but the value was not measured.
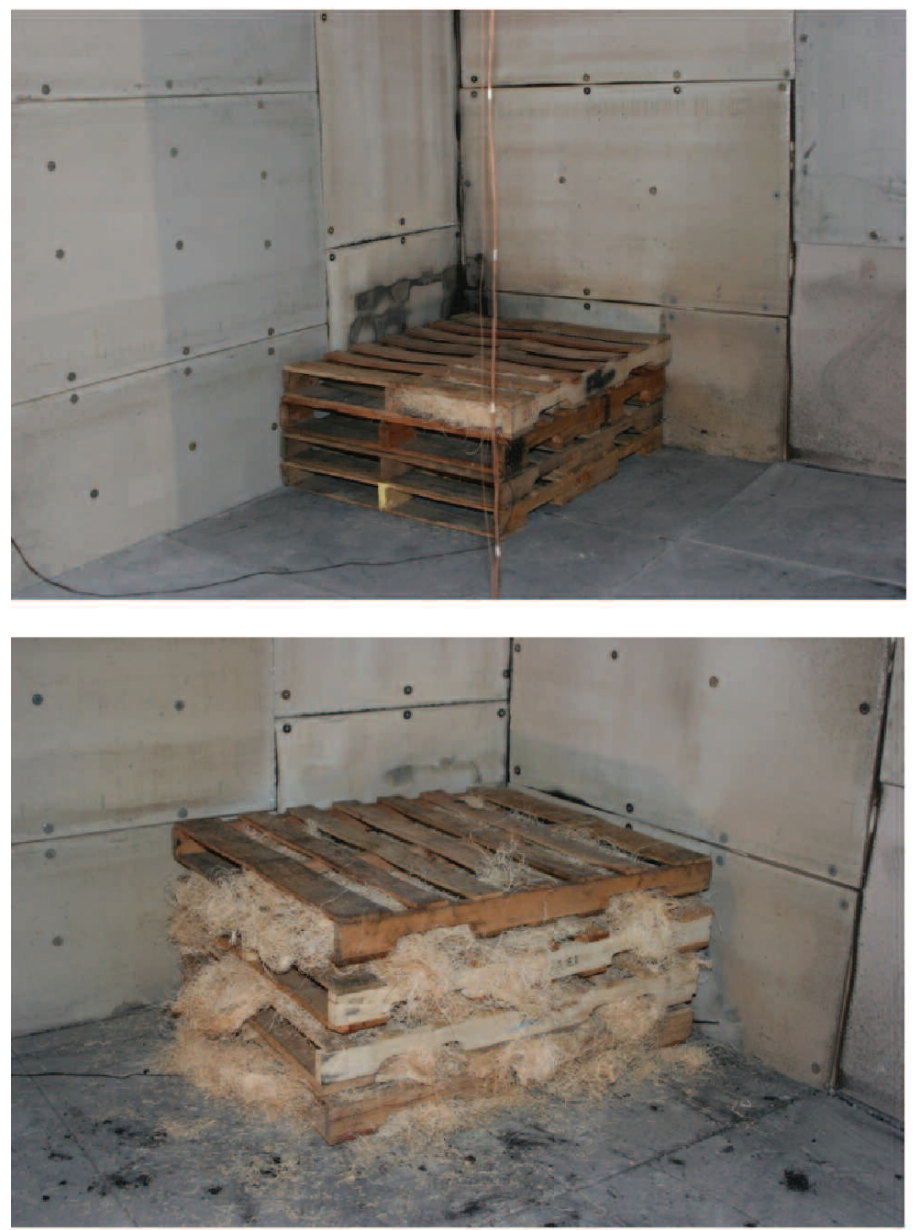

Figure A-3. Fuel and Excelsior Source for Slow (top) and Fast (bottom) Ignition Scenarios

\section{Measurements Conducted}

Heat release rate (HRR) was measured in all tests. HRR measurements were conducted under the $3 \mathrm{~m}$ by $3 \mathrm{~m}$ calorimeter at the NIST Large Fire Research Laboratory. The HRR measurement was based on the oxygen consumption calorimetry principle first proposed by Thornton (Thornton 1917) and developed further by Huggett (Huggett 1980) and Parker (Parker 1984). This method assumes that a known amount of heat is released for each gram of oxygen consumed by a fire. The measurement of exhaust flow velocity and gas volume fractions $\left(\mathrm{O}_{2}, \mathrm{CO}_{2}\right.$ and $\left.\mathrm{CO}\right)$ were used to determine the HRR based on the formulation derived by Parker (Parker 1984) and Janssens (Janssens 1981). The combined expanded relative uncertainty of the HRR measurements was estimated at $\pm 14 \%$, based on a propagation of uncertainty analysis (Bryant 2004).

For the compartment fire tests, gas temperature measurements were made in the burn compartment and in the target compartment connected by a hallway to the burn compartment using 24 gauge bare-bead chromel-alumel (type K)

thermocouples positioned in vertical array. Thermocouples were located at the center of each compartment at locations $0.03 \mathrm{~m}$, $0.30 \mathrm{~m}, 0.61 \mathrm{~m}, 0.91 \mathrm{~m}, 1.22 \mathrm{~m}, 1.52 \mathrm{~m}, 1.83 \mathrm{~m}$, and $2.13 \mathrm{~m}$ from the ceiling. The expanded uncertainty associated with a type $\mathrm{K}$ thermocouple is approximately $\pm 4.4^{\circ} \mathrm{C}$. (Omega 2004)

Gas species were continuously monitored in the burn compartment at a level $0.91 \mathrm{~m}$ from the ceiling at a location centered on the side wall of the compartment, $0.91 \mathrm{~m}$ from the wall. Oxygen was measured using paramagnetic analyzers. Carbon monoxide and carbon dioxide were measured using non-dispersive infrared (NDIR) analyzers. All analyzers were calibrated with nitrogen and a known concentration of gas prior to each test for a zero and span concentration calibration. The expanded relative uncertainty of each of the span gas molar fractions is estimated to be $\pm 1 \%$.

Total heat flux was measured on the side wall of the enclosure at a location centered on the side wall, $0.61 \mathrm{~m}$ from the ceiling level. The heat flux gauges were $6.4 \mathrm{~mm}$ diameter Schmidt-Boelter type, water cooled gauges with embedded type-K thermocouples (see Figure A-4). The manufacturer reports a $\pm 3 \%$ expanded uncertainty in the response calibration (the slope in $\mathrm{kW} / \mathrm{m}^{2} / \mathrm{mV}$ ). Calibrations at the NIST facility have varied within an additional $\pm 3 \%$ of manufacturer's calibration. For this study, an uncertainty of $\pm 6 \%$ is estimated.

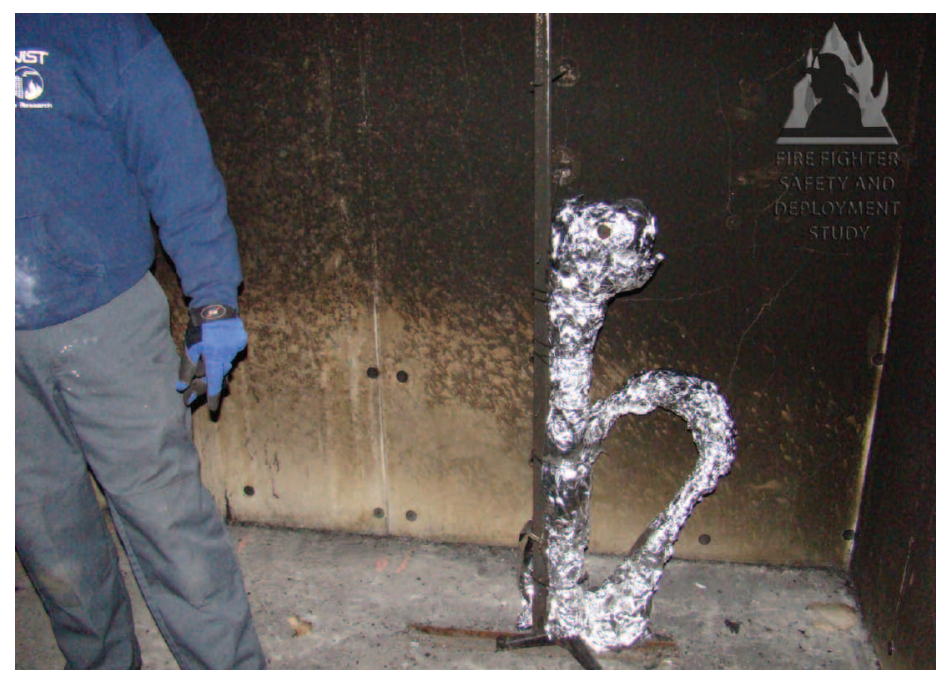

Figure A-4: Heat Flux Gauge with Radiation Shielding 


\begin{tabular}{|c|c|c|c|c|c|}
\hline Test & Test Type & $\begin{array}{c}\text { Number } \\
\text { of } \\
\text { Pallets }\end{array}$ & $\begin{array}{c}\text { Ignition } \\
\text { Scenario }\end{array}$ & $\begin{array}{c}\text { Peak } \\
\text { HRR } \\
(\mathrm{kW})\end{array}$ & $\begin{array}{c}\text { Time to } \\
\text { Peak } \\
\text { HRR (s) }\end{array}$ \\
\hline $\begin{array}{c}\text { PAL } \\
1\end{array}$ & Free burn & 4 & Fast & 2144 & 205 \\
\hline $\begin{array}{c}\text { PAL } \\
2\end{array}$ & Free burn & 6 & Fast & 2961 & 320 \\
\hline $\begin{array}{c}\text { PAL } \\
3\end{array}$ & Free burn & 8 & Fast & 3551 & 301 \\
\hline $\begin{array}{c}\text { PAL } \\
4\end{array}$ & Free burn & 4 & Slow & 1889 & 385 \\
\hline $\begin{array}{c}\text { PAL } \\
5\end{array}$ & Free burn & 6 & Slow & 2410 & 986 \\
\hline $\begin{array}{c}\text { CRA } \\
1\end{array}$ & Compartment & 6 & Slow & 1705 & 1102 \\
\hline $\begin{array}{c}\text { CRA } \\
2\end{array}$ & Compartment & 4 & Slow & 1583 & 649 \\
\hline $\begin{array}{c}\text { CRA } \\
3\end{array}$ & Compartment & 4 & Fast & 1959 & 159 \\
\hline $\begin{array}{c}\text { CRA } \\
4\end{array}$ & Compartment & 4 & Slow & 1620 & 775 \\
\hline $\begin{array}{c}\text { CRA } \\
5\end{array}$ & Compartment & 4 & Slow & 1390 & 927 \\
\hline
\end{tabular}

\section{Results}

Table A-2 shows the peak HRR and time to peak HRR for the free burn tests and for the compartment tests. Figure A-5 includes images from the free burn experiments near the time of peak HRR for each of the experiments. Figure A-6 illustrates the progression of the fire from the exit doorway looking down the hallway to the burn compartment for one of the tests. Figure A-7 to Figure A-10 present graphs of the heat release rate for all of the tests. Figure A-11 through Figure A-15 shows the gas temperature, major gas species concentrations, and heat flux in the burn compartment and target compartment in the five compartment tests.

Table A-2. Peak Heat Release Rate During Several Pallet Tests in Free-burn and in a Compartment

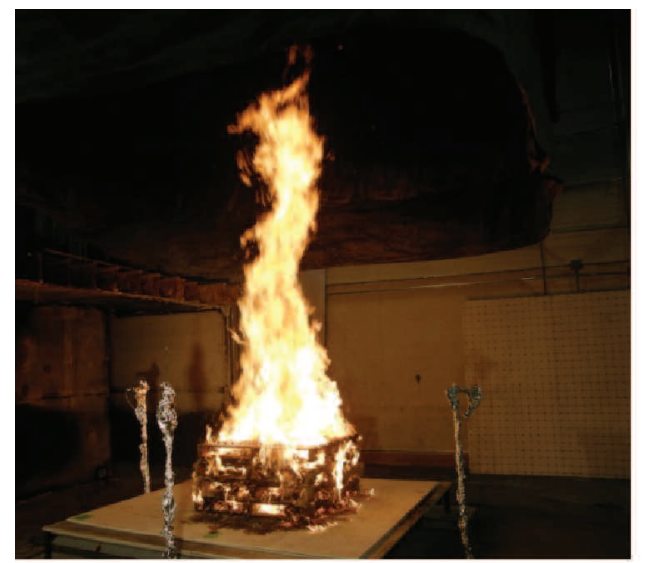

PAL 1

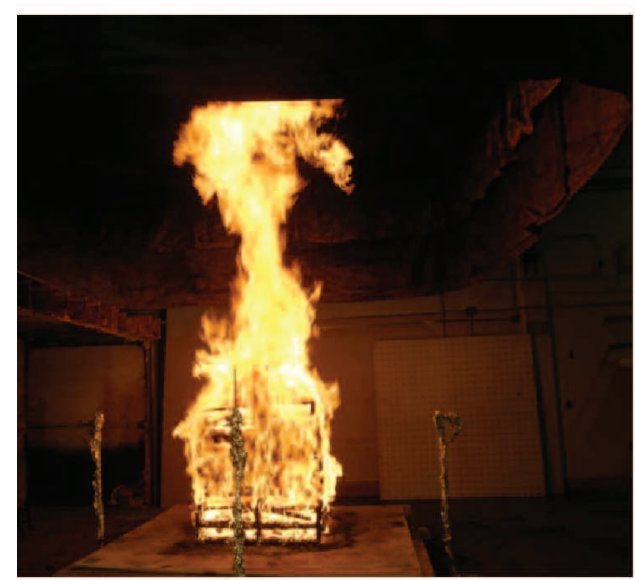

PAL 3

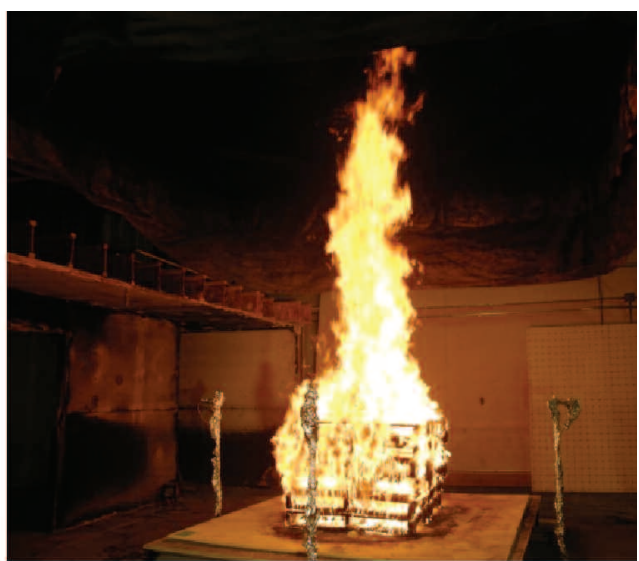

PAL 2

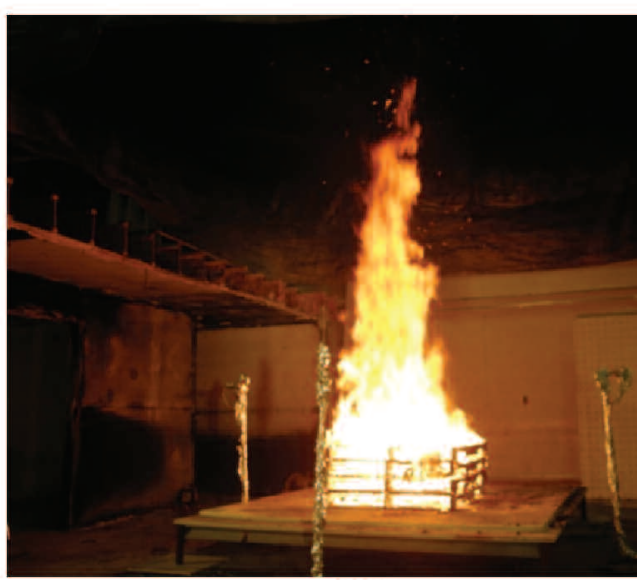

PAL 4

Figure A-5. Free-Burn Experiments Near Time of Peak Burning 

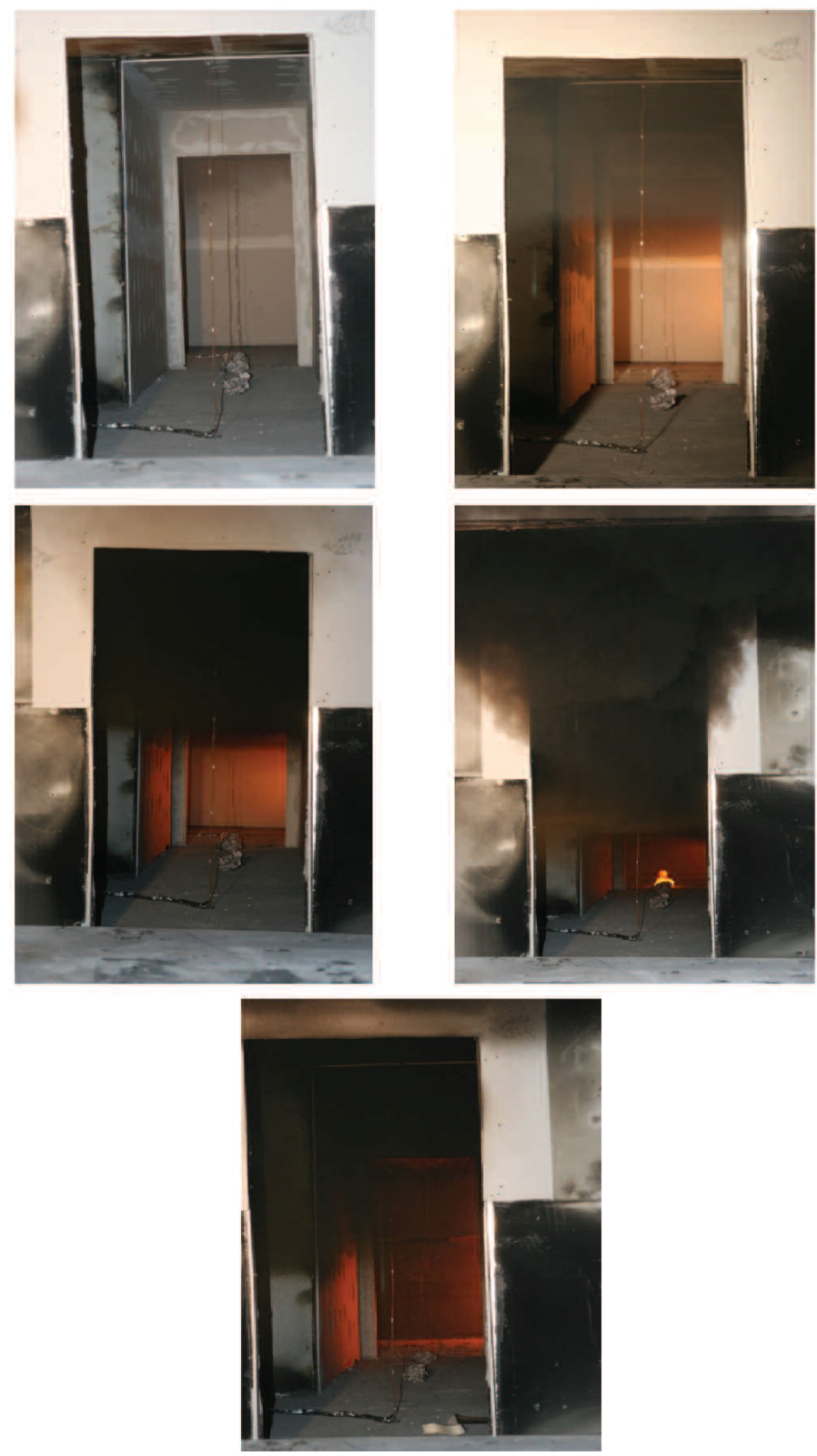

Figure A-6. Example Fire Progression from Test CRA 1

Slow Ignition Scenario

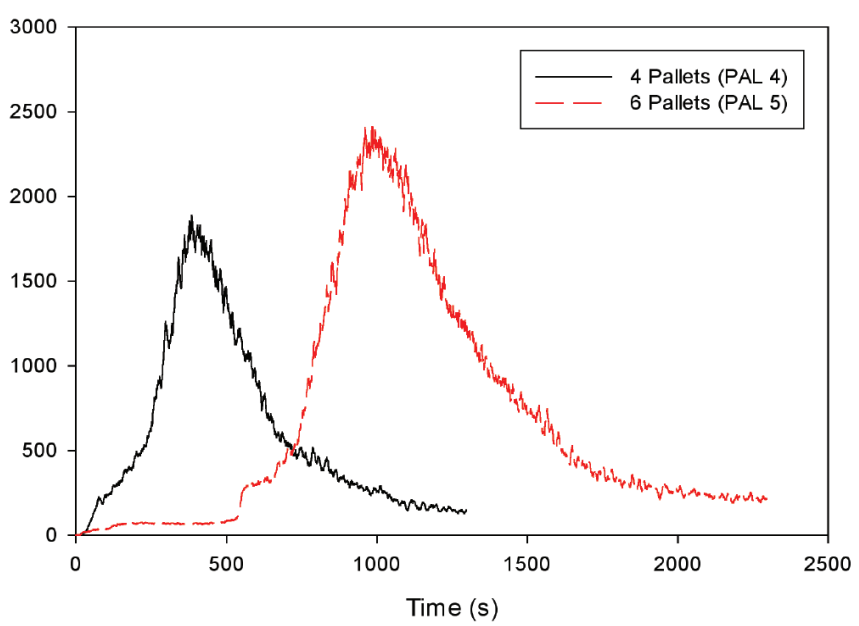

Figure A-7. HRR, Slow Ignition, Free Burn Scenario
Fast Ignition Scenario

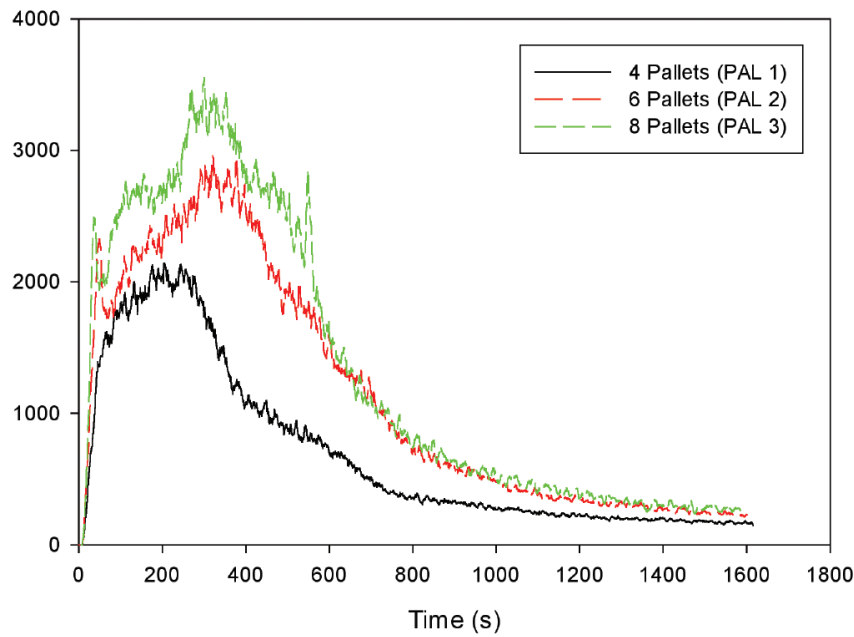

Figure A-8. HRR, Fast Igntion, Free Burn Scenario

Slow Ignition Scenario

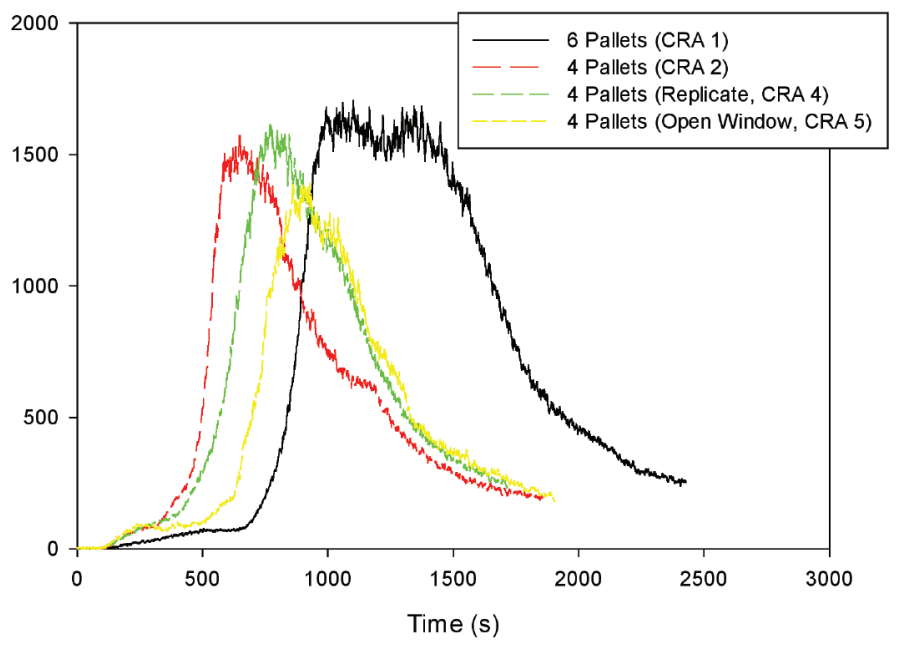

Figure A-9. HRR, Slow Ignition, Compartment Test

Fast Ignition Scenario

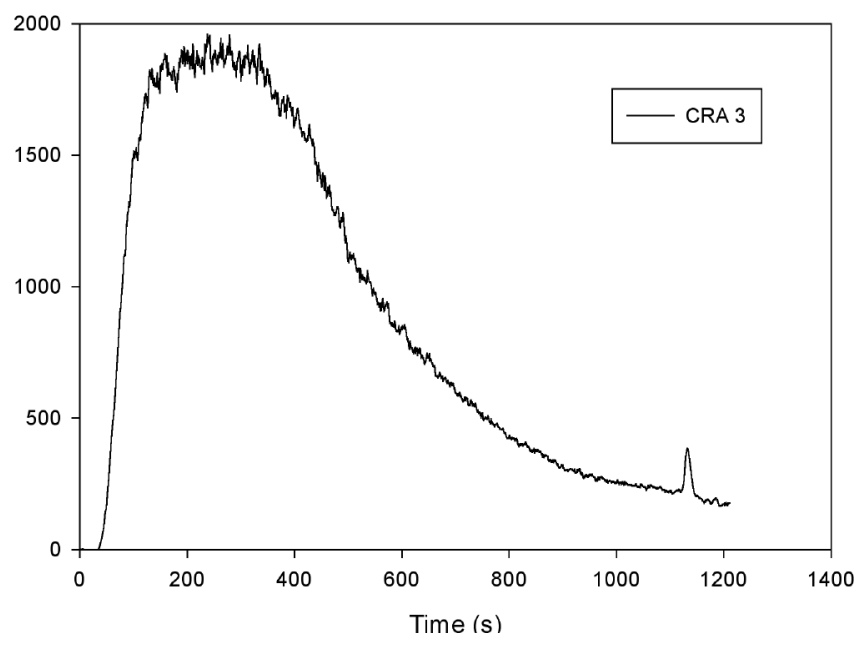

Figure A-10. HRR, Fast Ignition, Compartment Test 


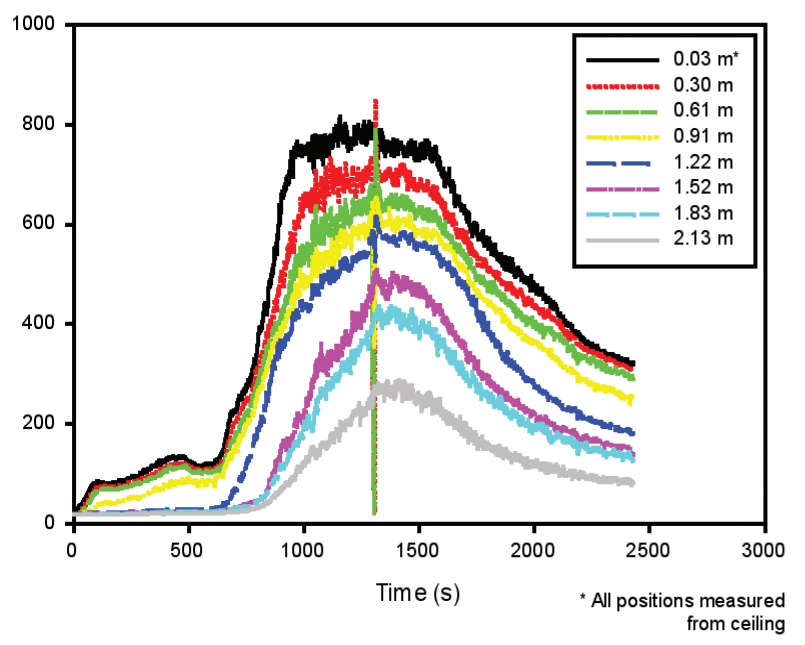

6 Pallets, Slow Ignition Scenario, Burn Room

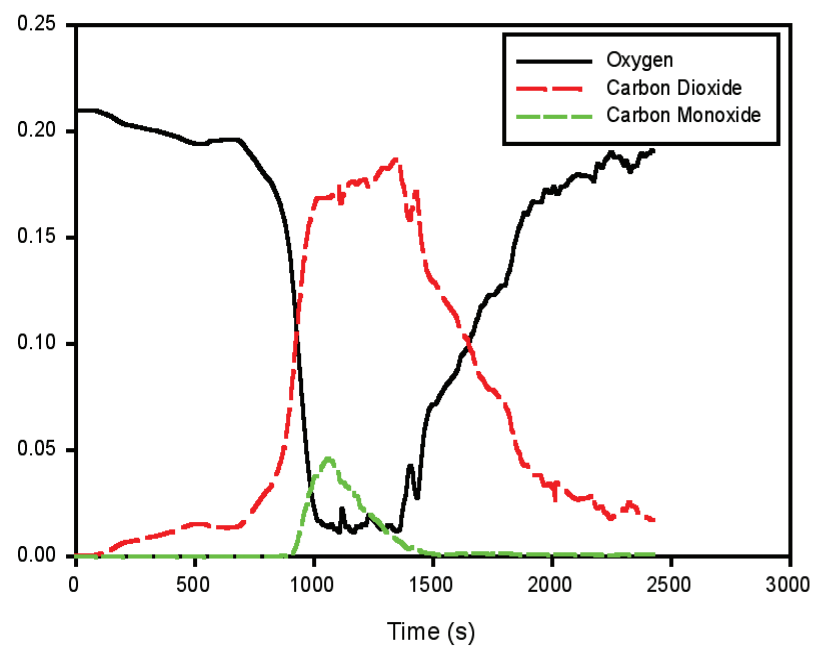

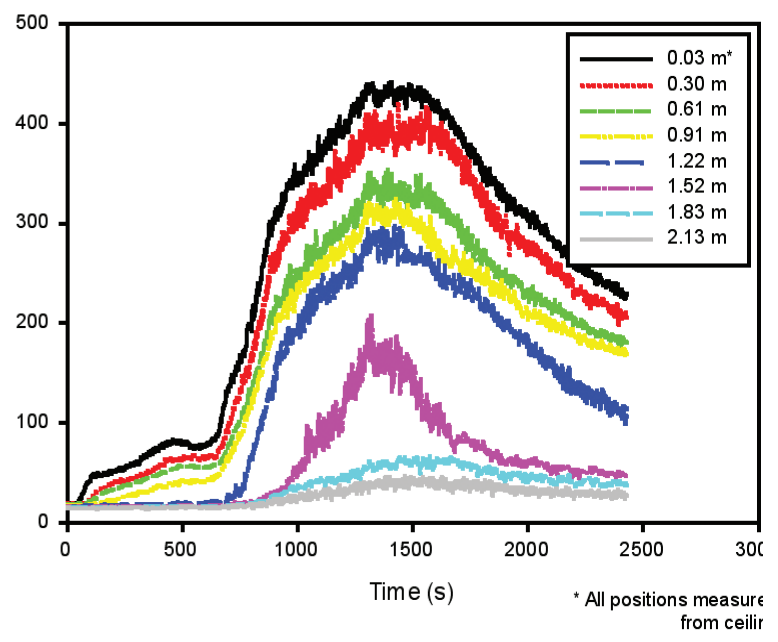

6 Pallets, Slow Ignition Scenario, Target Room

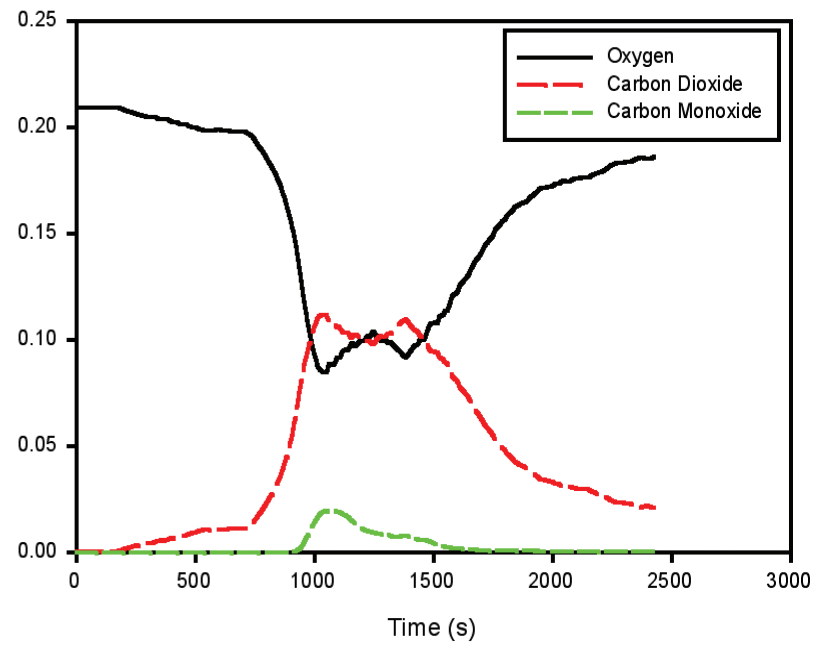

6 Pallets, Slow Ignition Scenario, Burn Room

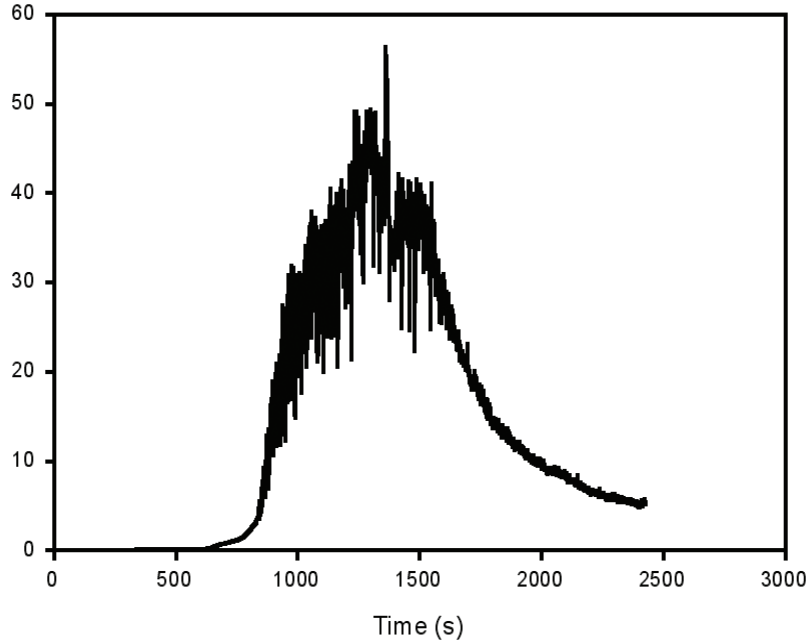

Figure A-11. Temperature, Gas Concentration, and Heat Flux During Test CRA 1, 6 Pallets, Slow Ignition Scenario 


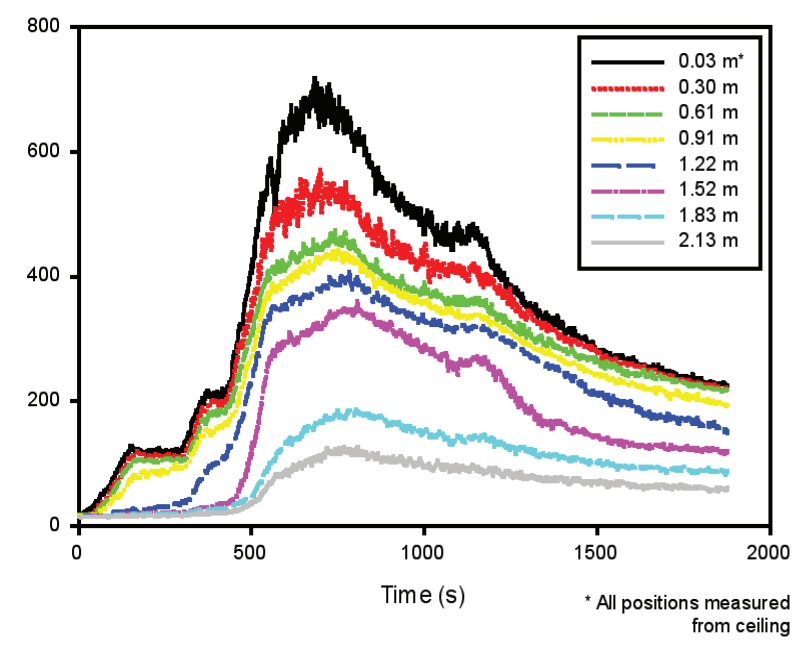

4 Pallets, Slow Ignition Scenario, Burn Room

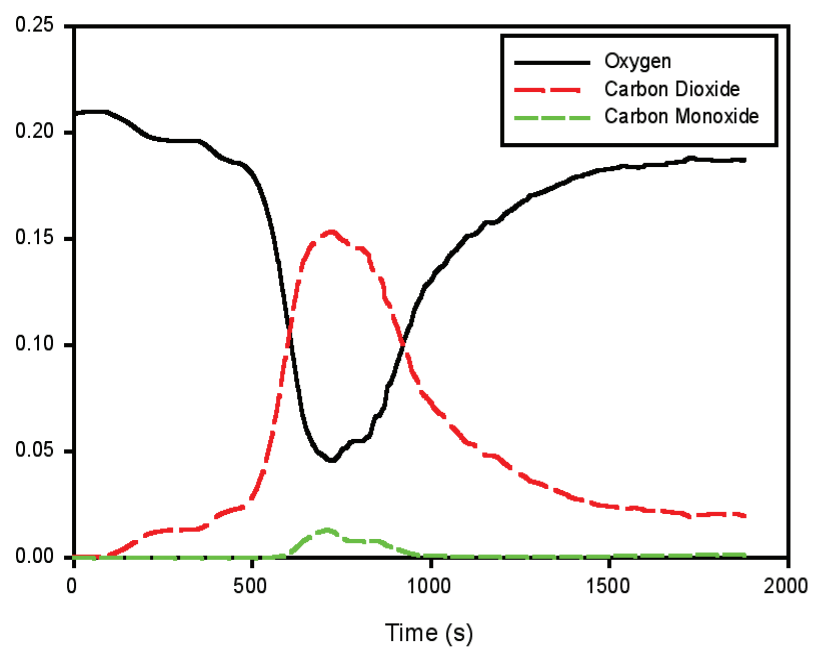

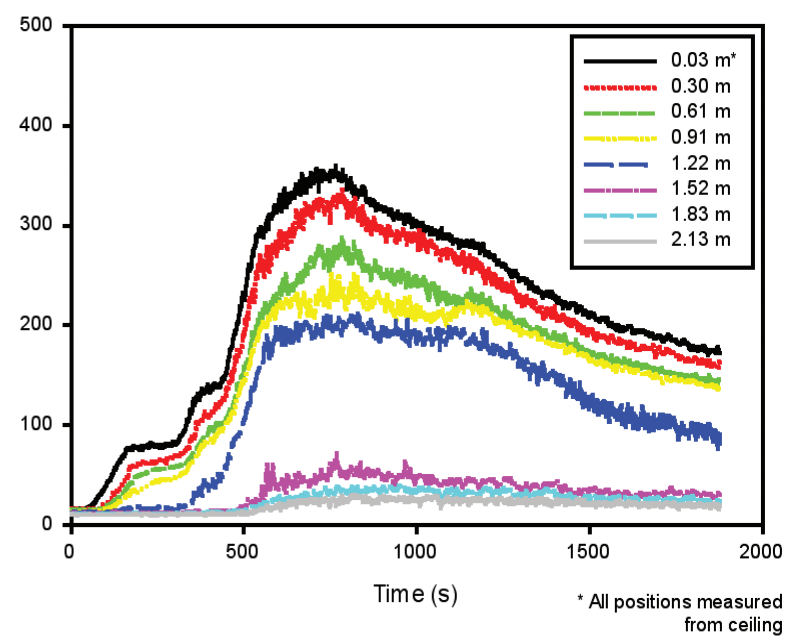

4 Pallets, Slow Ignition Scenario, Target Room

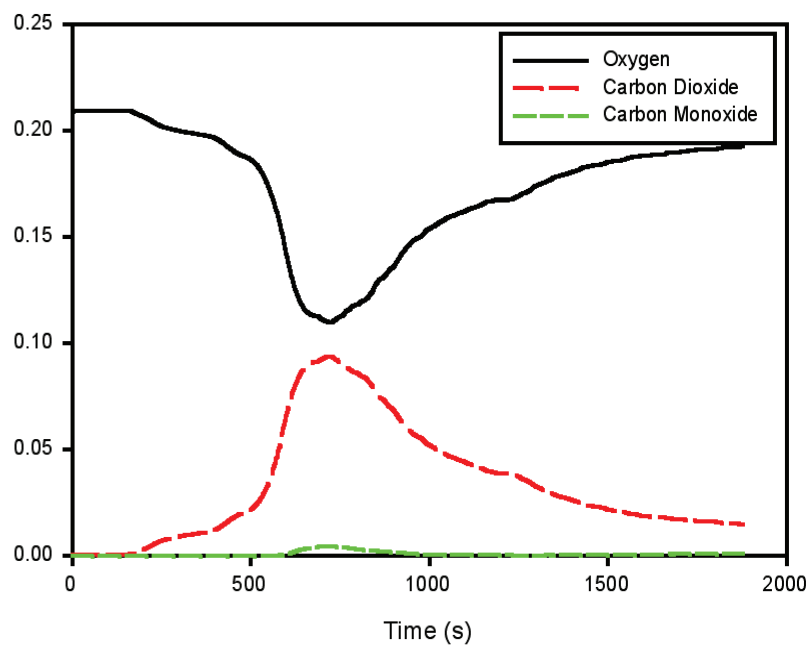

4 Pallets, Slow Ignition Scenario, Burn Room

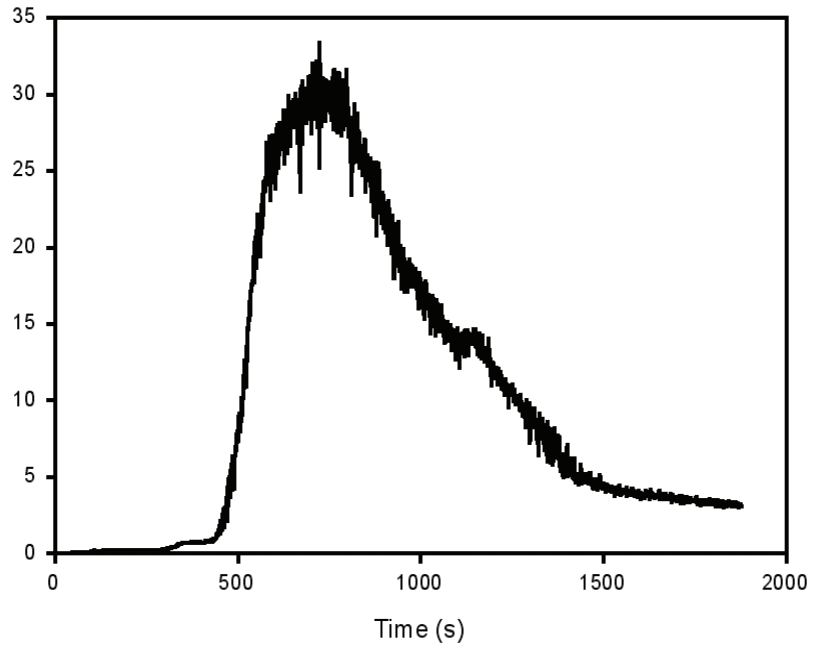

Figure A-12. Temperature, Gas Concentration, and Heat Flux During Test CRA 2, 4 Pallets, Slow Ignition Scenario 


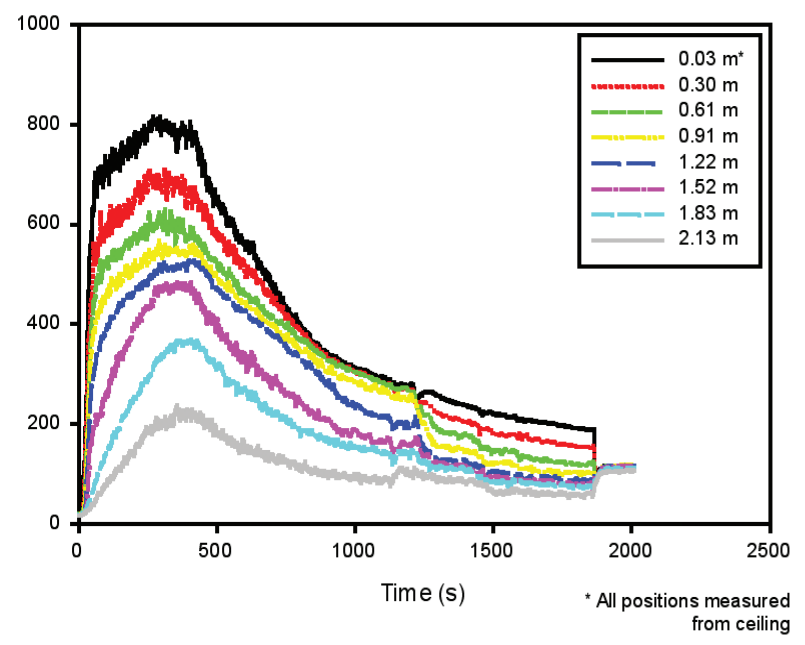

4 Pallets, Fast Ignition Scenario, Burn Room

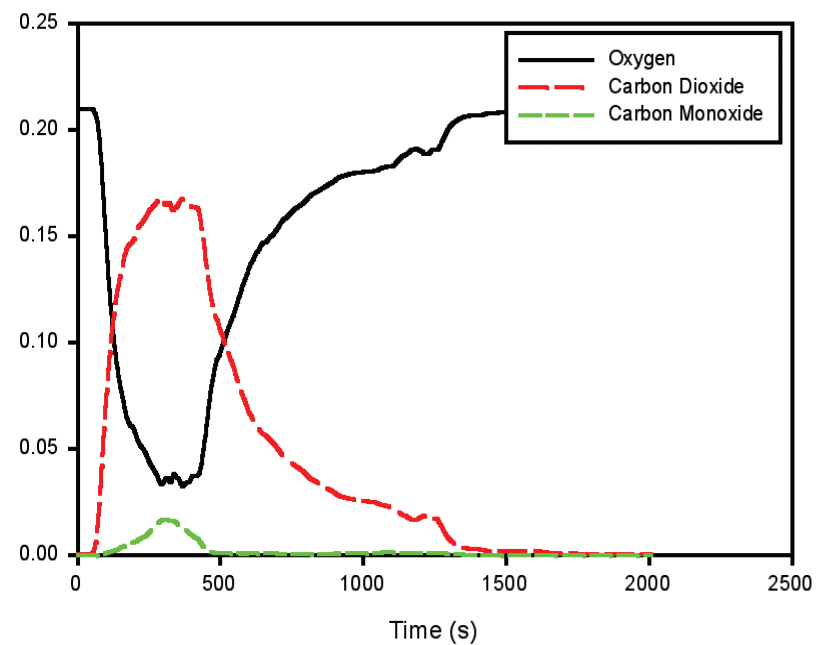

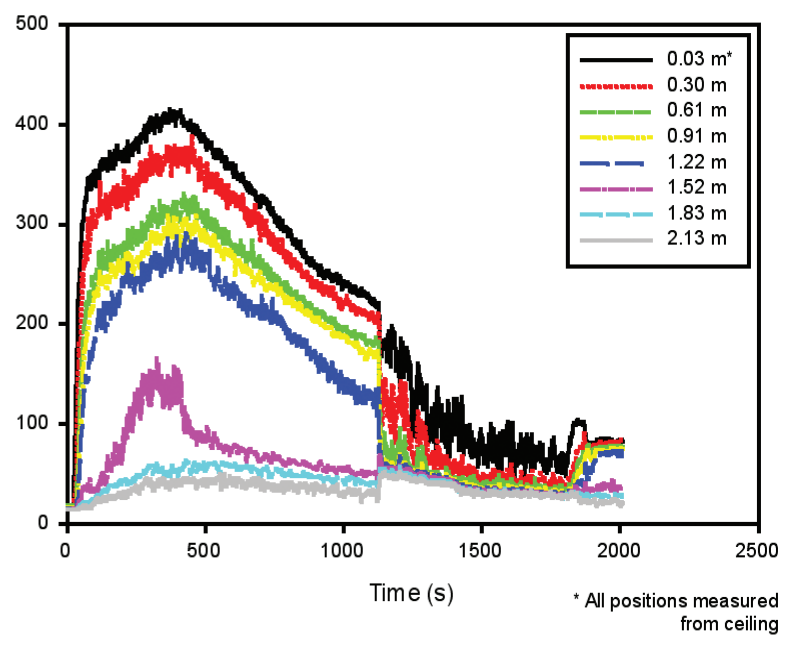

4 Pallets, Fast Ignition Scenario, Target Room

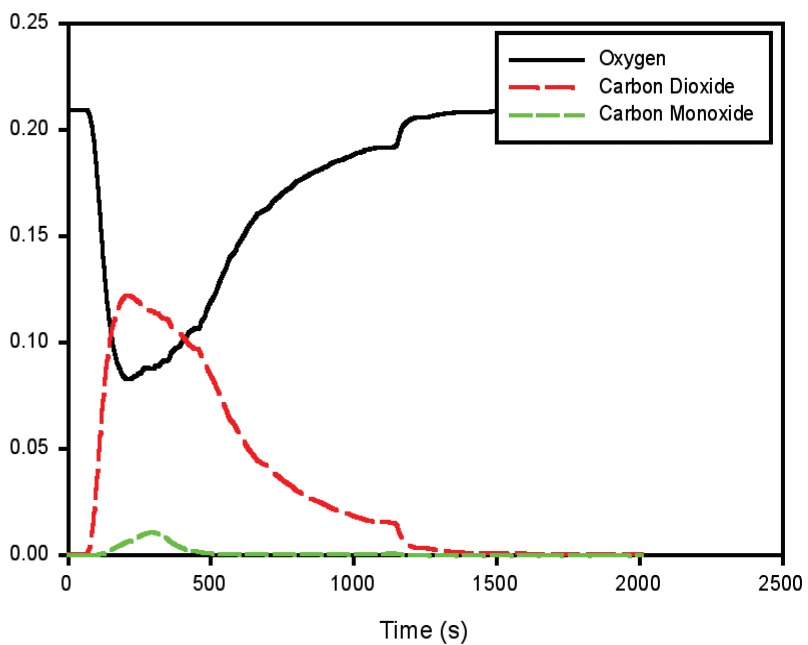

4 Pallets, Fast Ignition Scenario, Burn Room

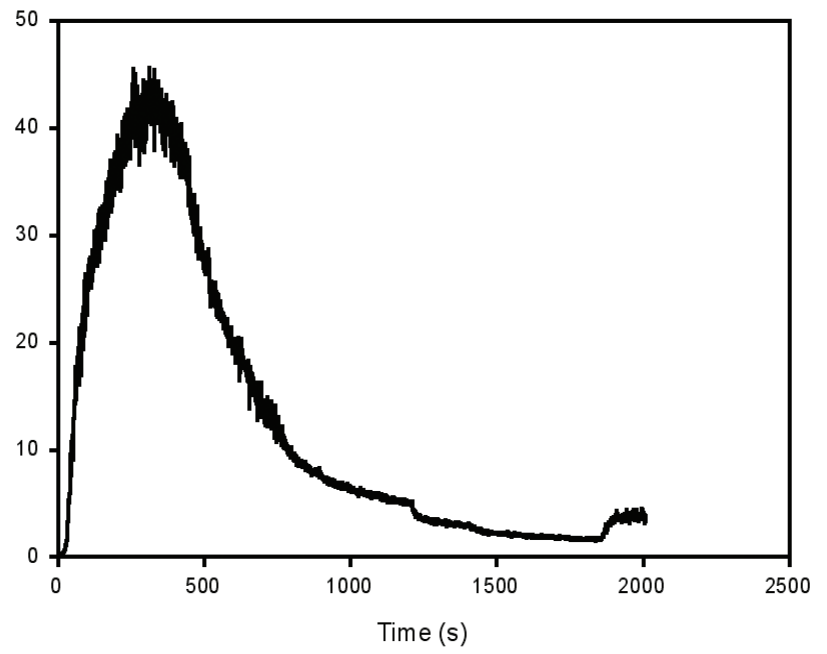

Figure A-13. Temperature, Gas Concentration, and Heat Flux During Test CRA 3, 4 Pallets, Fast Ignition Scenario 


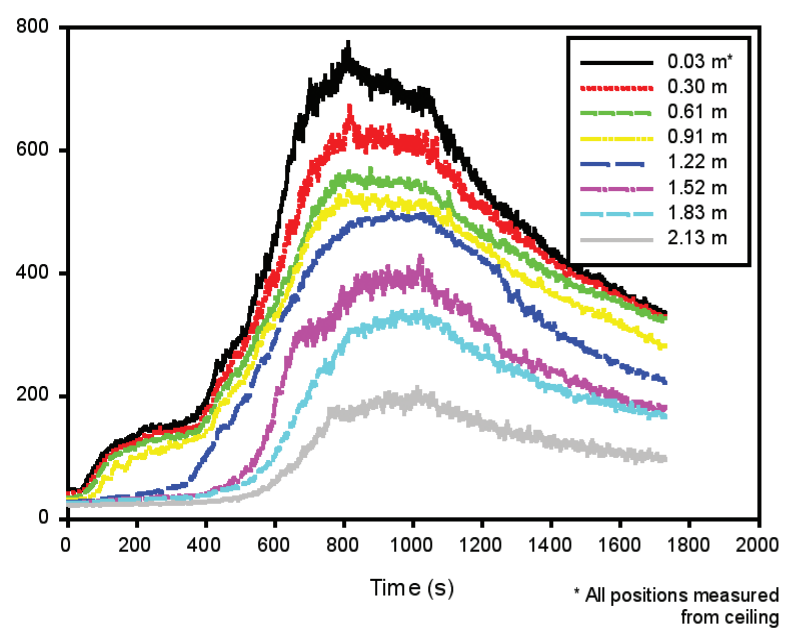

4 Pallets, Slow Ignition Scenario, Burn Room

(Replicate)

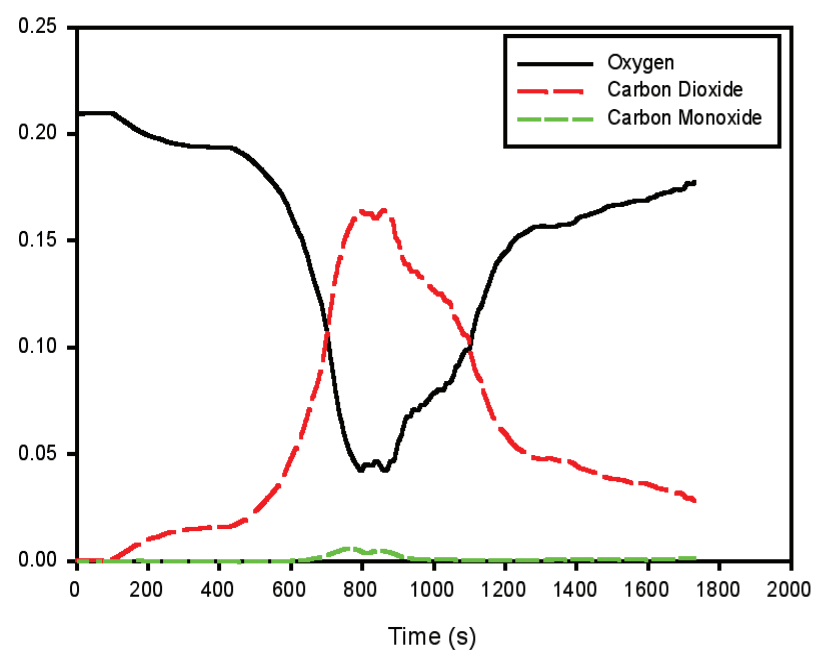

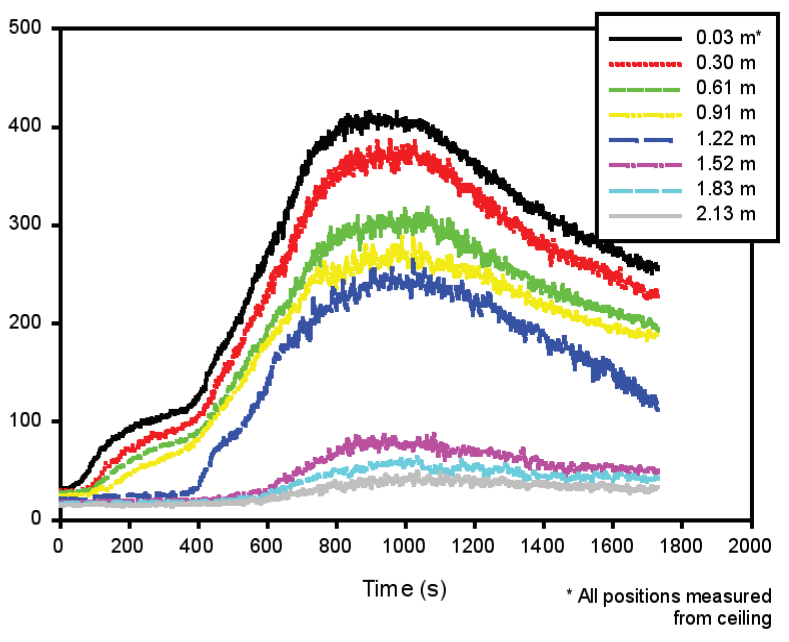

4 Pallets, Slow Ignition Scenario, Target Room (Replicate)

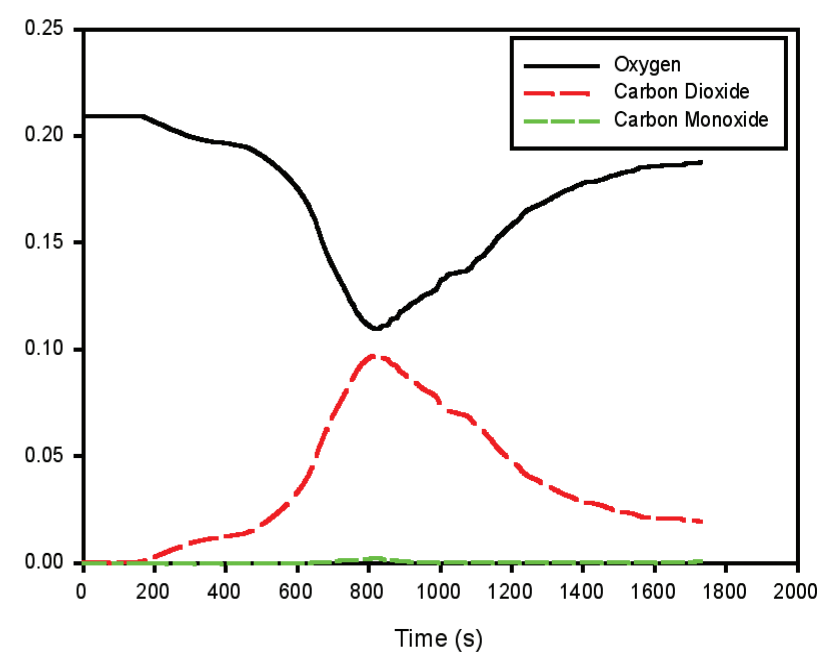

4 Pallets, Slow Ignition Scenario, Burn Room

(Replicate)

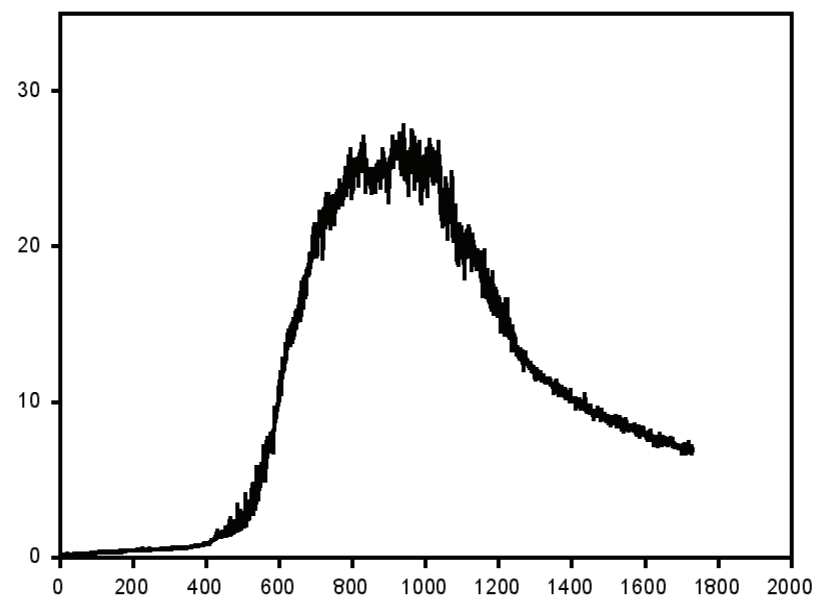

Figure A-14. Temperature, Gas Concentration, and Heat Flux During Test CRA 4, 4 Pallets, Slow Ignition Scenario (Replicate) 


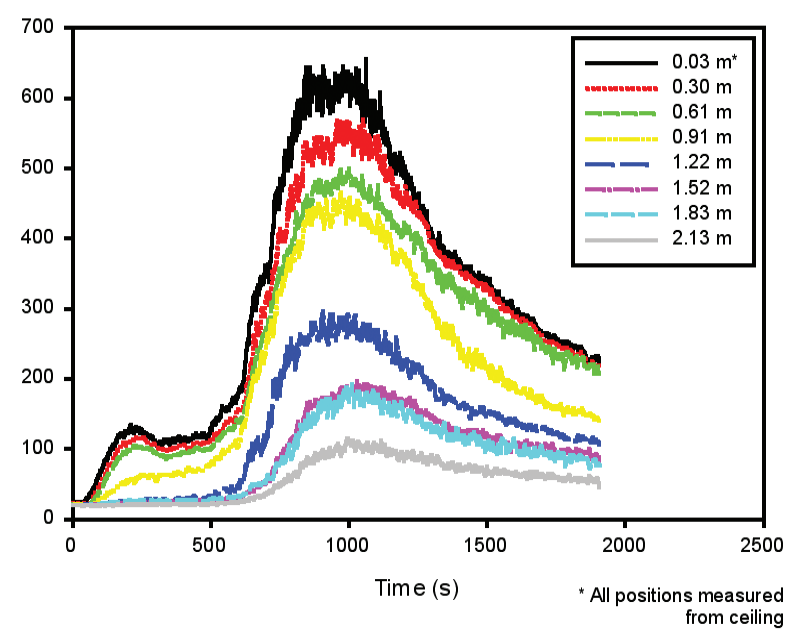

4 Pallets, Slow Ignition Scenario, Burn Room (Open Window Venting)

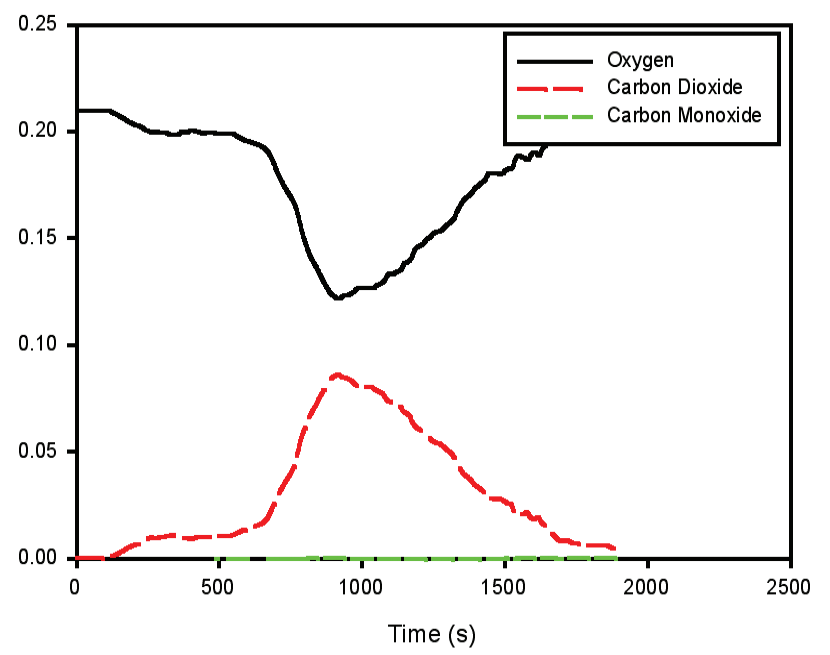

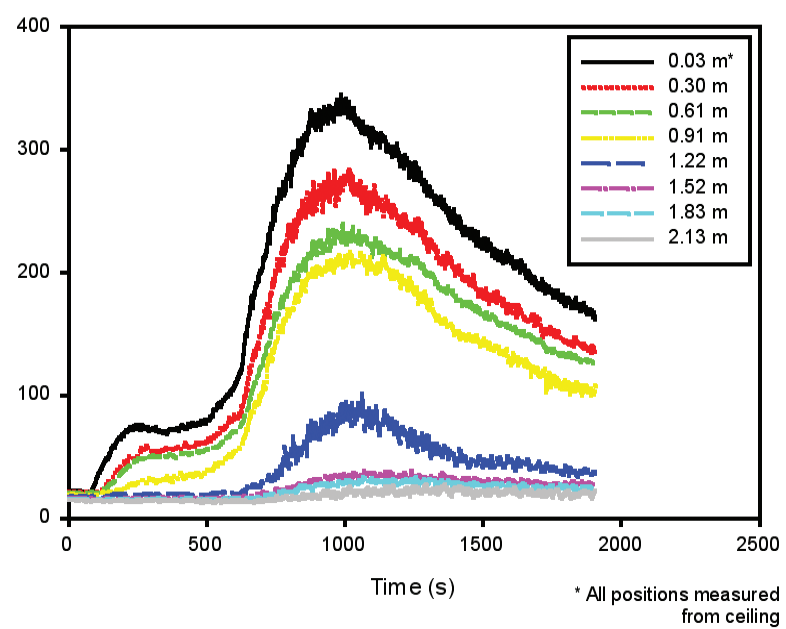

4 Pallets, Slow Ignition Scenario, Target Room (Open Window Venting)

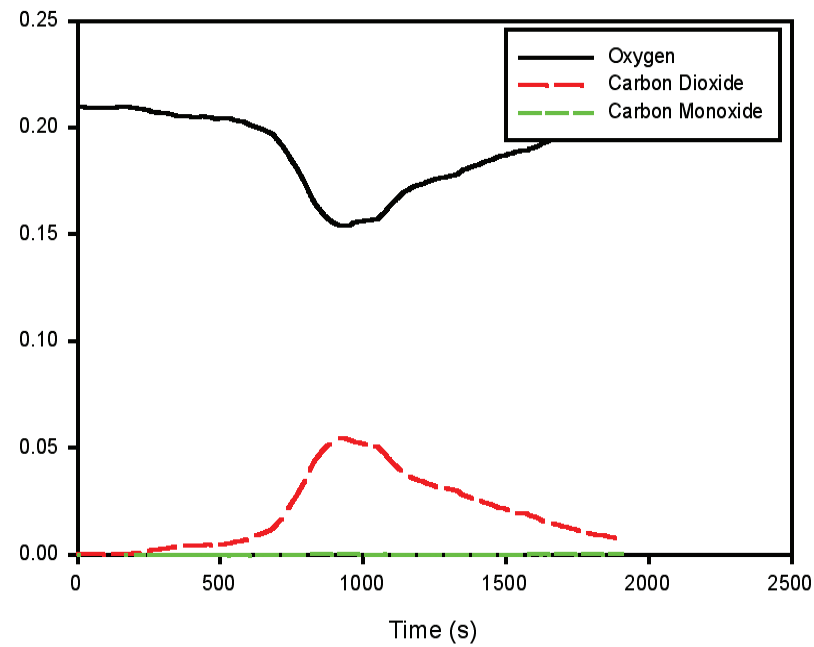

4 Pallets, Slow Ignition Scenario, Burn Room (Open Window Venting)

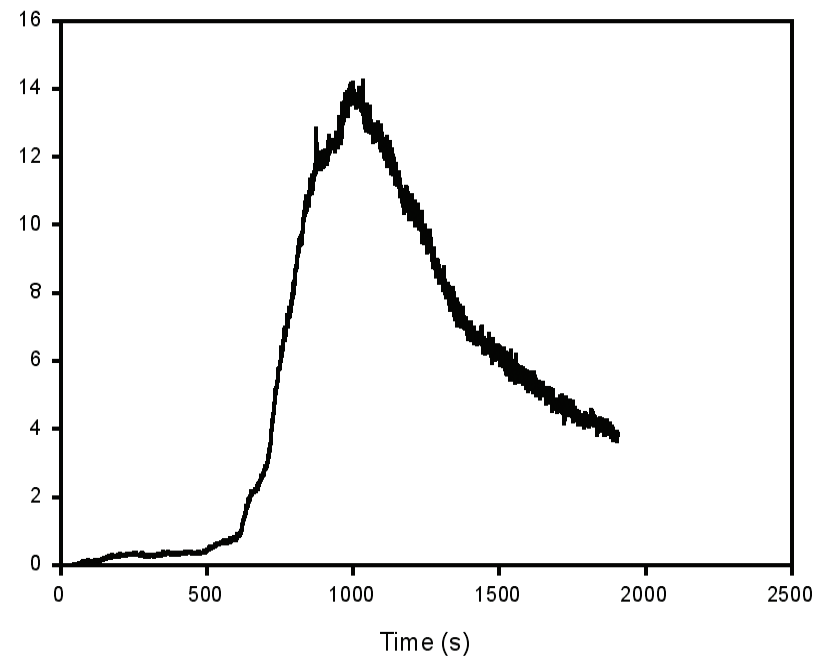

Figure A-15. Temperature, Gas Concentration, and Heat Flux During Test CRA 5, 4 Pallets, Slow Ignition Scenario (Open Window Venting) 
ased upon the results of the laboratory experiments, the project team determined that four pallets would provide both a realistic fire scenario, as well as a repeatable and well-characterized fuel source. Varying the placement and quantity of excelsior provided significant variance in the rate of fire growth. Prior to finalization of the fuel package and construction specifications, modeling was used to ensure that the combination of fuel and residential geometry would result in untenable conditions throughout the structure without subjecting the firefighters to unsafe testing conditions. Therefore, CFAST (the consolidated fire and smoke transport model (Jones 2000)) and FDS (fire dynamics simulator model (McGrattan 2006)) were used to predict the temperatures and toxic species within the structure as a function of the experimentally determined heat release rates. The results summarized below confirmed that the building geometry and fuel package produced adequate variation in tenability conditions in the residential structure and ensured that the room of origin would not reach flashover conditions (a key provision of NFPA 1403). Meeting these conditions provided the foundation for experiments to meet the two primary objectives of fire department response: preservation of life and property.

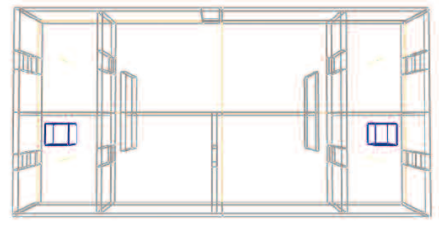

$\operatorname{Tin}: \mathrm{n} 2$

Temperature at $\mathrm{t}=0.2 \mathrm{~s}$

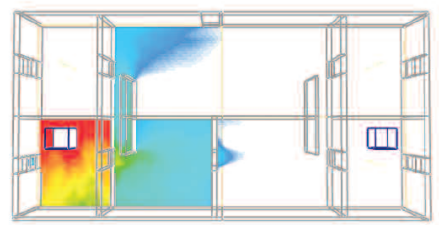

The resn $=2$

Temperature at $\mathrm{t}=\mathbf{1 2 0} \mathrm{s}$
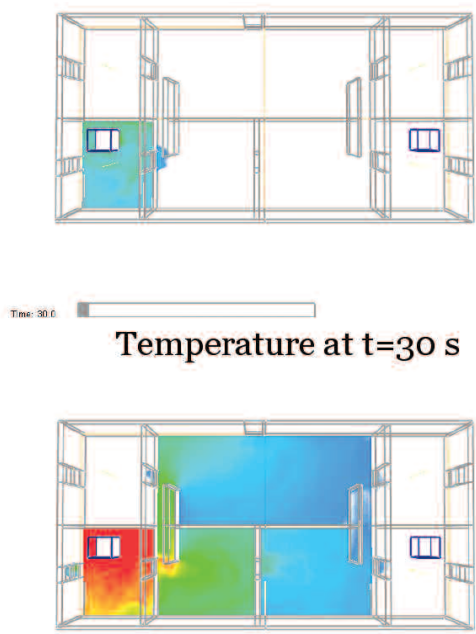

Temperature at $\mathrm{t}=240 \mathrm{~s}$

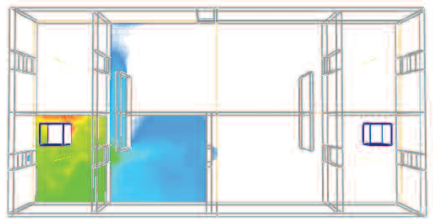

The an

Figure B-1 and B-2 show the thermal and smoke conditions in the residential structure at different time periods using the fast growth, four pallet fuel package.

The results of the fire modeling indicated development of untenable conditions in the field experiments between 5 and 15 minutes, depending upon several factors: fire growth rate, ventilation conditions, the total leakage of heat into the building and through leakage paths, and firefighter intervention. This time frame allowed for differentiation of the effectiveness of various fire department deployment models.

Figure B-1: Time-dependent temperature contours in field structure with fast growth fire

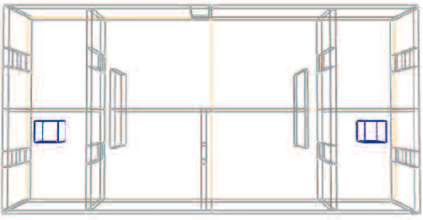

Time 42

Smoke density at $\mathrm{t}=0.2 \mathrm{~s}$

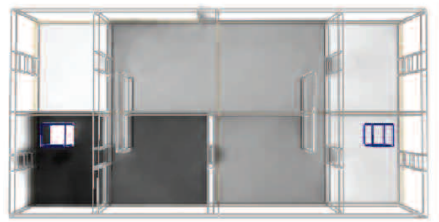

Smoke density at $\mathrm{t}=\mathbf{1 2 0} \mathrm{s}$
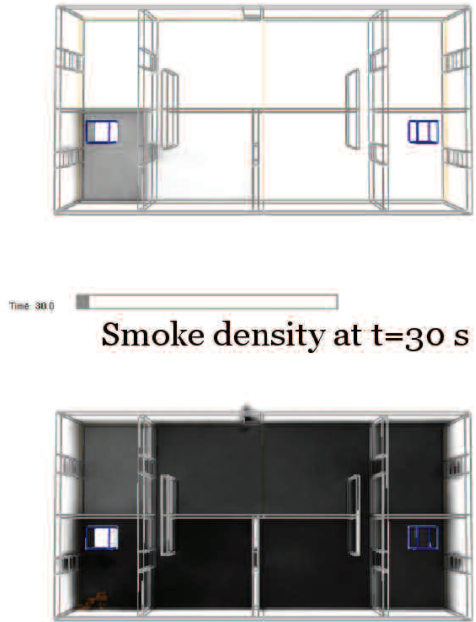

Smoke density at $\mathrm{t}=240 \mathrm{~s}$

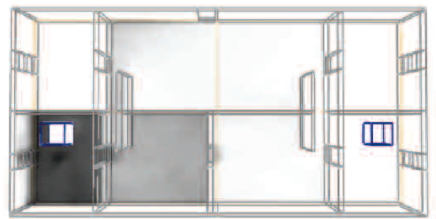

The nat

Smoke density at $\mathrm{t}=60 \mathrm{~s}$

Figure B-2: Time-dependent smoke density contours in field structure with fast growth fire 
$\mathrm{T}$ hrough the generosity of the Montgomery County (MD), an open space was provided to construct a temporary burn prop at the Montgomery County Fire and Rescue Training Facility in Rockville, MD. The area had ready access to water and electrical utilities. A licensed general contractor was retained, including a structural engineer for the design of critical ceiling members, and the burn prop was constructed over a several month period in late 2008 .

The burn prop consisted of two 2,000 ft. ${ }^{2}\left(186 \mathrm{~m}^{2}\right)$ floors totaling $4,000 \mathrm{ft}^{2}\left(372 \mathrm{~m}^{2}\right)$. An exterior view of two sides of the burn prop is shown in Figure C-1.

Additional partitions were installed by NIST staff to create a floor plan representative of a two-story, $186 \mathrm{~m}^{2}\left(2,000 \mathrm{ft}^{2}{ }^{2}\right)$ single family residence. Note that the structure does not have a basement and includes no exposures. The overall dimensions are consistent with the general specifications of a typical low hazard residential structure that many fire departments respond to on a regular basis, as described in NFPA 1710.

Further details about typical single family home designs are not provided in the standard. Therefore, a floor plan representative of a typical single family home was created by the project team. Details and floor plan dimensions are shown in Figure C-2.

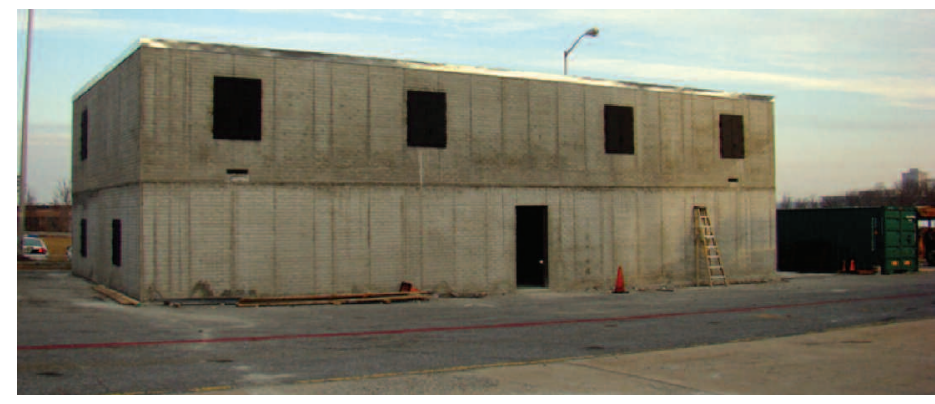

Figure C-1: View of two sides of the burn prop

The black lines indicate load-bearing reinforced concrete walls and red lines indicate the gypsum over steel stud partition walls. The ceiling height, not shown in Figure C-2, is 94 in. (2.4 m) throughout the entire structure except in the burn compartments, where the ceiling height is 93 in. $(2.4 \mathrm{~m})$. The purpose of the partition walls was to symmetrically divide the structure about the short axis in order to allow one side of the test structure to cool down and dry-out after a fire test with suppression while conducting experiments on the other side.

The concrete walls original to the burn prop were 8 in. $(204 \mathrm{~mm}$ ) thick steel reinforced poured concrete and the floors on the first level and second levels were 4 in. $(102 \mathrm{~mm})$ thick poured concrete. The support structure for the second floor and the roof consisted of corrugated metal pan welded to open web steel joists. The dimensions of the joists are shown in Figure C-3. The ceiling was constructed from $1 / 2$ in. ( 13 $\mathrm{mm}$ ) thick cement board fastened to the bottom chord of the steel joists. Partition walls were constructed from 5/8 in. (17 mm) thick gypsum panels attached to 20 gauge steel studs fastened to steel track, spaced 16 in. (407 $\mathrm{mm}$ ) on center.

Additional construction was implemented in the burn compartments to address thermal loading and hose stream impingement concerns. Spray-on fireproofing was applied to the steel joists prior to fastening the ceiling, as shown in Figure C-4. The ceilings were constructed with three layers of $1 / 2$ in. $(13 \mathrm{~mm})$ cement board, as opposed to one layer construction in the rest of the building. Each layer was fastened in a different direction so that seams of adjacent layers ran orthogonally. The difference in ceiling heights previously 

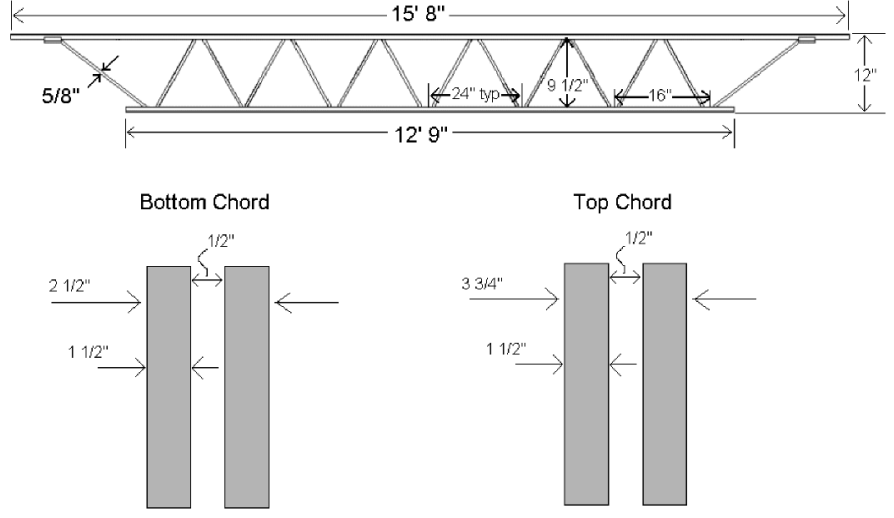

Figure C-3: Structural Steel Dimensions

mentioned is the result of the two additional sheets of cement board. The burn compartment walls were constructed from a single layer of $1 / 2$ in. $(13 \mathrm{~mm}$ ) cement board over a single layer of $5 / 8$ in. $(16 \mathrm{~mm})$ gypsum board, attached to $7 / 8 \mathrm{in}$. $(22 \mathrm{~mm})$ offset metal furring strips. Particular care was taken so that all ceiling and partition wall seams were filled with chemically-setting type joint compound to prevent leakage into the interstitial space between the ceiling and the floor above. After construction of the ceiling was complete, a dry-standpipe deluge system was installed with one head in each burn room to provide emergency suppression. During an experiment, a $2.5 \mathrm{in}$. (104 mm) ball valve fitting was attached and charged from a nearby hydrant. Figure

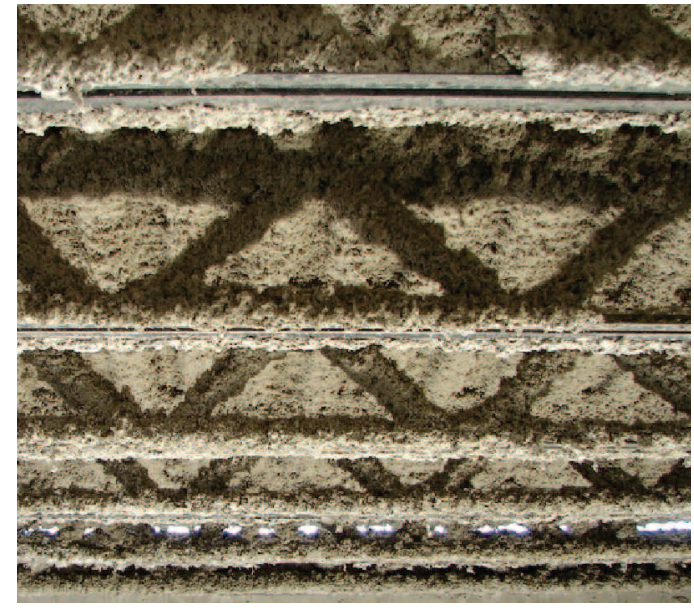

Figure C-4: Fireproofing added to structural steel

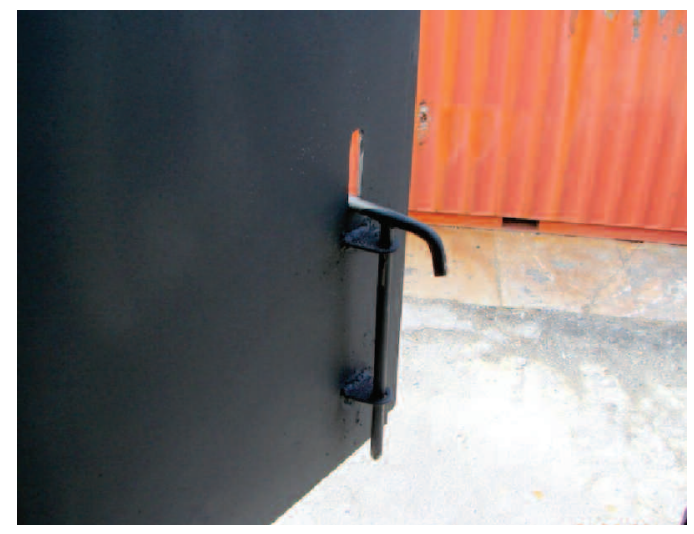

Figure C-6: Window \& Latch Construction

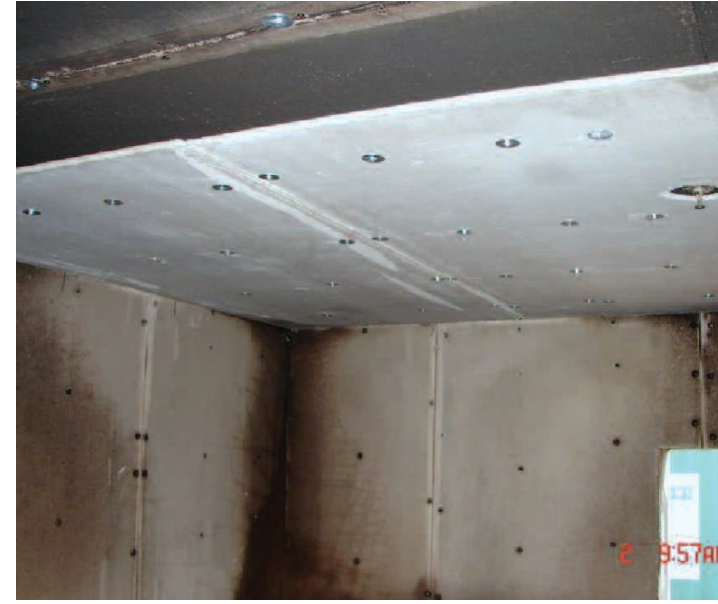

Figure C-5: Additional construction of burn room walls and ceiling and deluge sprinkler head.

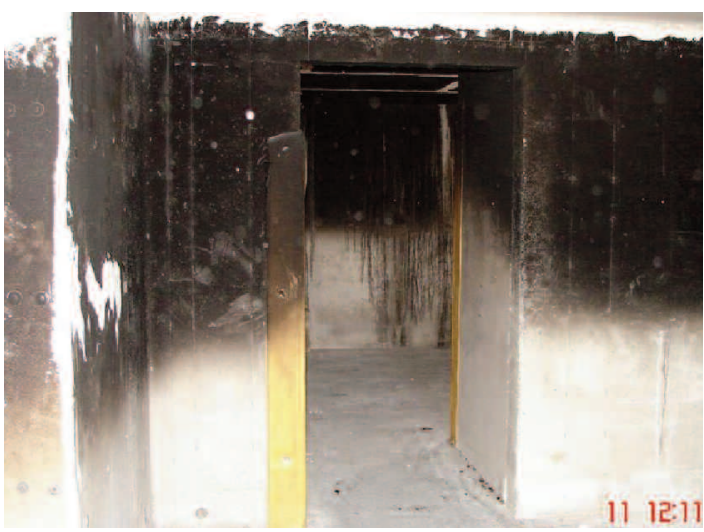

Figure C-7: Interior View of Burn Prop
C-5 was taken during the process of replacing "worn out" ceiling panels and shows the additional construction implemented in the burn room as well as the deluge sprinkler head.

Windows and exterior doors were constructed to be non-combustible. Windows were fabricated from $0.25 \mathrm{in}$. (10 $\mathrm{mm}$ ) thick steel plate and the exterior doors were of prefabricated hollow-core steel design. The windows on the first floor were 30 in. $(0.76 \mathrm{~m})$ width $x 36$ in. $(0.91 \mathrm{~m})$ height and 36 in. $(0.91 \mathrm{~m})$ width $\mathrm{x} 40$ in. $(1.02 \mathrm{~m})$ height on the second floor. Exterior doors were 35.8 in. $(0.88 \mathrm{~m})$ width $x 80.5$ in. $(2.03 \mathrm{~m})$ height. There were no doors attached to the doorways inside the structure. Figure C-6 shows the construction of the burn prop windows as well as the NFPA 1403-compliant latch mechanism. Figure C-7 is a picture of the interior of the burn prop taken just outside the burn compartment, showing the construction of the ceiling, interior doorway construction, gypsum wing wall and the joint compound used to seal seams in the ceiling and walls.

\section{Instrumentation}

After construction, the instrumentation to measure the propagation of products of combustion was installed throughout the burn prop. The instrumentation plan was designed to measure gas temperature, gas concentrations, heat flux, visual obscuration, video, and time during the experiments. The data were recorded at intervals of $1 \mathrm{~s}$ on a computer based data acquisition system. A schematic plan view of the instrumentation arrangement is shown in Figure C-8.

Table C-1 gives the locations of all of the instruments.

Measurements taken prior to the compartment fire experiments were length, wood moisture content, fuel mass and weather conditions (relative humidity, temperature, wind speed and direction). Gas temperatures were measured with two different constructs of type $\mathrm{K}$ (Chromel-Alumel) thermocouples. All thermocouples outside the burn compartments were fabricated from 30 gauge glass-wrapped thermocouple wire. Vertical arrays of three thermocouples were placed near the front door on the north side and south sides of the stairwell on the first floor. On the second floor, vertical arrays of eight thermocouples were placed near the center of each target room. Inside the burn compartments, seven 3.2 $\mathrm{mm}(0.125$ in.) exposed junction thermocouples and $0.76 \mathrm{~m}$ (30 in.) SUPER OMEGACLAD XL ${ }^{\circledR}$ sheathed thermocouple probes were arranged in a floor-to-ceiling array. Figure C-9 shows the vertical array in the burn 

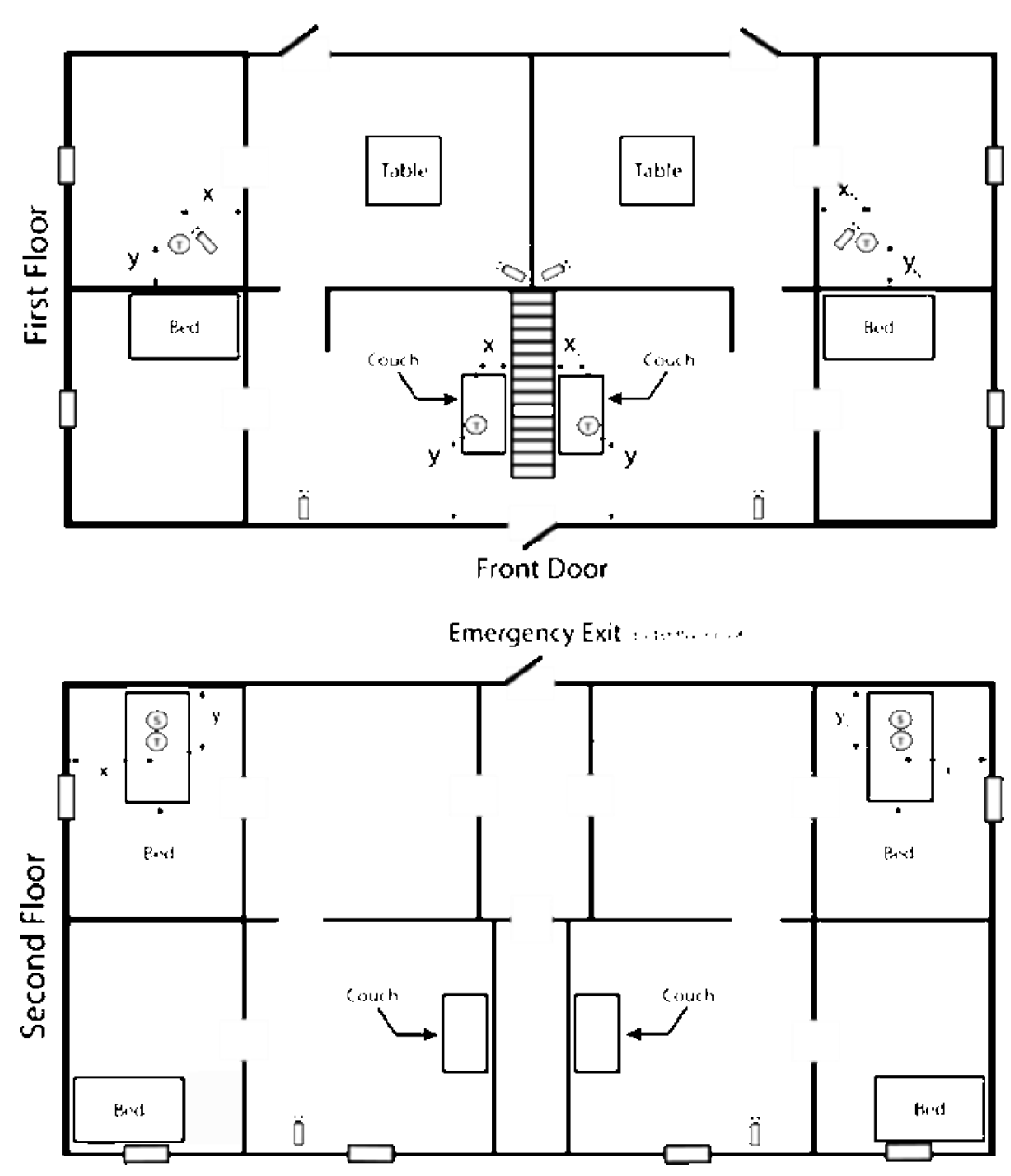

Figure C-8: Instrumentation \& Furniture Prop Layout compartment. Type K thermocouple probes were chosen because of their ability to withstand high temperature, moisture and physical abuse resulting from physical contact with hose streams and firefighters. To protect the extension wire and connectors from the effects of heat and water, through-holes were drilled in the burn compartment walls and the sheaths were passed through from the adjacent

(T) Thermocouple

(G) Gas Probe

(s) Smoke Meter $\partial$ video

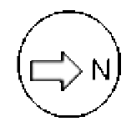
compartment. To prevent leakage through the holes, all void spaces were tightly packed with mineral wool. Inside the burn compartment the end of each probe was passed through an angle iron stand, and fastened to the floor and ceiling to provide additional protection from physical contact with firefighters and to ensure that the measurement location remained fixed throughout the experiments. In consideration of the risk associated with heating the open web steel joists, additional thermocouples were placed above each burn compartment to monitor the temperature of the interstitial space.

Table C-1: Detailed locations of instruments within respective rooms

\begin{tabular}{|c|c|c|c|c|c|c|c|c|c|c|}
\hline Floor & Instrument & $\mathbf{X}_{\mathrm{S}}[\mathbf{m}]$ & $\mathbf{Y}_{\mathrm{S}}[\mathbf{m}]$ & $\mathbf{Z}_{\mathbf{S}}[\mathbf{m}]$ & $\mathbf{X}_{\mathrm{N}}[\mathbf{m}]$ & $\mathbf{Y}_{\mathrm{N}}[\mathbf{m}]$ & $\mathbf{Z}_{\mathrm{N}}[\mathbf{m}]$ & $\mathbf{X}_{\mathbf{C}}[\mathbf{m}]$ & $\mathbf{Y}_{\mathbf{C}}[\mathbf{m}]$ & $\mathbf{Z}_{\mathbf{C}}[\mathbf{m}]$ \\
\hline 1 & Thermocouple & 0.76 & 0.51 & $\begin{array}{c}0.3,0.61 \\
0.91,1.22 \\
1.52,1.83 \\
2.13\end{array}$ & 0.76 & 0.51 & $\begin{array}{c}0.3,0.61 \\
0.91,1.22 \\
1.52,1.83 \\
2.13\end{array}$ & Find & Find & $\begin{array}{l}0.91 \\
1.52 \\
2.41\end{array}$ \\
\hline & HF Gauge 1 & & N/A & & 0.91 & 0.91 & 0.17 & & & \\
\hline & HF Gauge 2 & & & & 0.5 & 0.66 & 1 & & & \\
\hline 2 & Thermocouple & 1.83 & 0.91 & $\begin{array}{l}0.3,0.61 \\
0.91,1.22 \\
1.52,1.83 \\
2.13,2.41\end{array}$ & 1.83 & 0.91 & $\begin{array}{l}0.3,0.61 \\
0.91,1.22 \\
1.52,1.83 \\
2.13,2.41\end{array}$ & & N/A & \\
\hline & Smoke Meter & 1.7 & 0.49 & 1.52 & 1.64 & 0.43 & 1.5 & & & \\
\hline & Gas Probe & 1.83 & 0.91 & 1.7 & 1.83 & 0.91 & 1.52 & & & \\
\hline
\end{tabular}



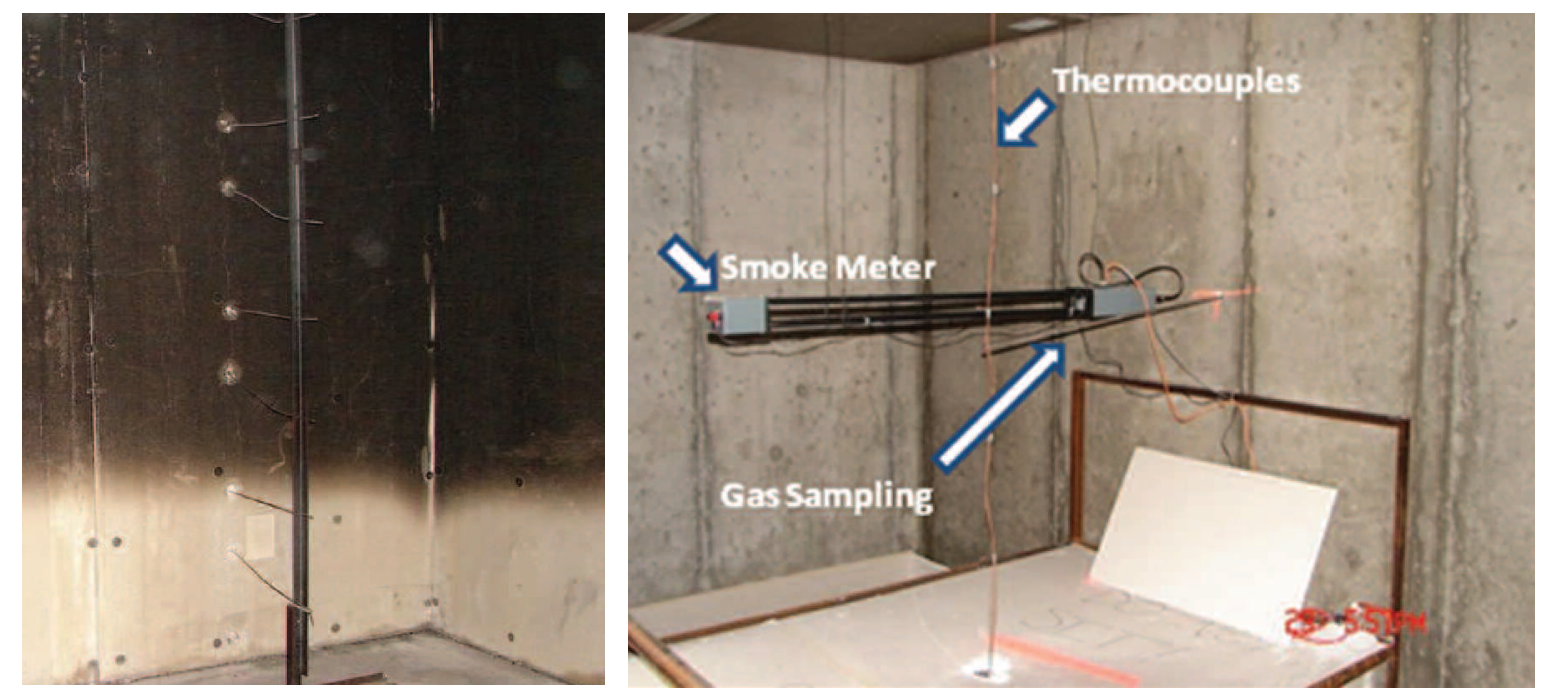

Figure C-9: Burn Room Thermocouple Array

Figure C-10: Target Room Instrument Cluster

Gas concentrations were sampled at the same location in each target room. Both gas probes were plumbed to the same analyzer and isolated using a switch valve; gas was only sampled at one location during any given test. The gas sampling points were located in the center of the West wall (C Side) of both rooms, 1.5 $\mathrm{m}(5 \mathrm{ft}$.) above the floor. The sampling tubes were connected to a diaphragm pump which pulled the gas samples through stainless steel probes into a sample conditioning system designed to eliminate moisture in the gas sample. The dry gas sample was then piped to the gas analyzer setup. In all of the experiments, oxygen was measured using a paramagnetic analyzer and carbon monoxide and carbon dioxide were measured using a

non-dispersive infrared (NDIR) analyzer. One floor-to-ceiling thermocouple array was also co-located with each sample port inlet.

Schmidt-Boelter heat flux gauges were placed in the North burn room. One gauge was located $1.0 \mathrm{~m}$ (3.3 ft.) above the floor and was oriented towards the fire origin (waste basket). This heat flux gauge was placed to characterize the radiative heat flux at the face piece level that would be experienced by a firefighter inside the room. A second flux gauge was placed on the floor in order to characterize the radiative heat flux from the upper layer and to make an estimate of how close the room was to flashing over with respect to time from ignition (using the common criteria of flashover occurring at $\sim 20 \mathrm{~kW} / \mathrm{m}^{2}$ at the floor level). The heat flux gauges were co-located with the thermocouple probe array.

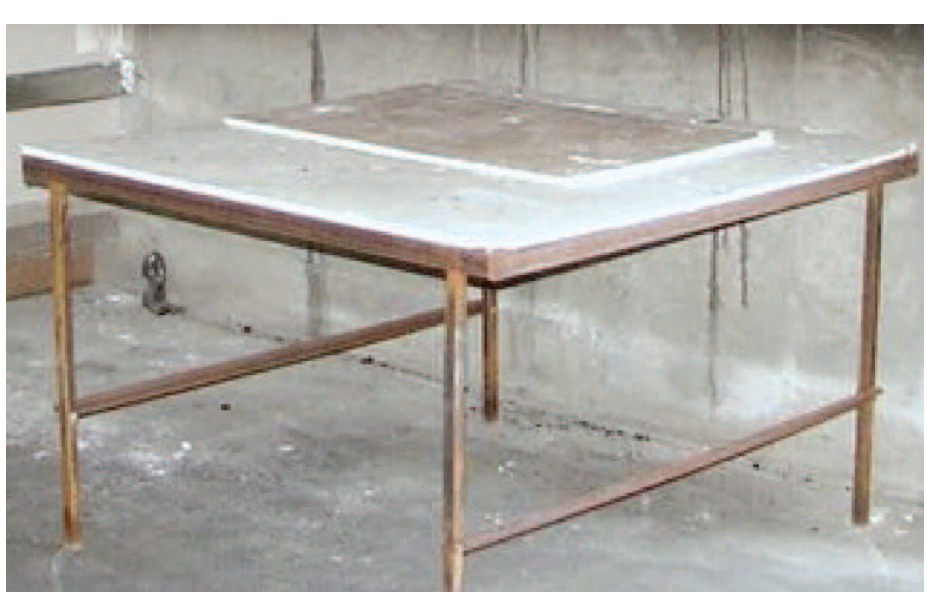

Figure C-11: Non-combustible "Prop" Table
All length measurements were made using a steel measuring tape. Wood moisture content measurements were taken using a non-insulated-pin type wood moisture meter. Fuel mass was measured prior to each experiment using a platform-style heavy duty industrial scale. Mass was not measured after each experiment because of the absorption of fire suppression water. Publicly accessible Davis Vantage Pro2 weather instrumentation (available via http://www.wunderground.com) located approximately two miles from the experimentation site was used to collect weather data in five minute intervals for the each day that the experiments were conducted. Figure C-10 is a photograph of the West wall of the North target room, showing the thermocouple array, the smoke obscuration meter, and a gas sampling probe used during the phase two experiments. The layout is identical to that in the South target room.

Non-combustible "prop" furniture was fabricated from angle iron stock and gypsum wallboard. The purpose of the furniture was twofold. The furniture was placed inside the burn prop to simulate realistic obstacles which obscure the search paths and hose stream advancement. The second use for the furniture was so that measurement instrumentation could be strategically placed within the frame of the furniture. This served to protect instrumentation from physical damage as a result of contact with firefighters and their tools. Figure $\mathrm{C}-11$ shows an example of a table placed outside the burn room.

All instruments were wired to a centralized data collection room, shown in Figure C-12, which was attached as a separate space on one side of the building. This ensured physical separation for the data collection personnel from the effects of the fire, while minimizing the wire and tube lengths to the data logging equipment. Note that the roof of the instrument room was designed to serve as an additional means of escape for personnel from the second floor of the burn prop through a metal door. A railing was installed in order to minimize the fall risk in the event that the emergency exit was required. 


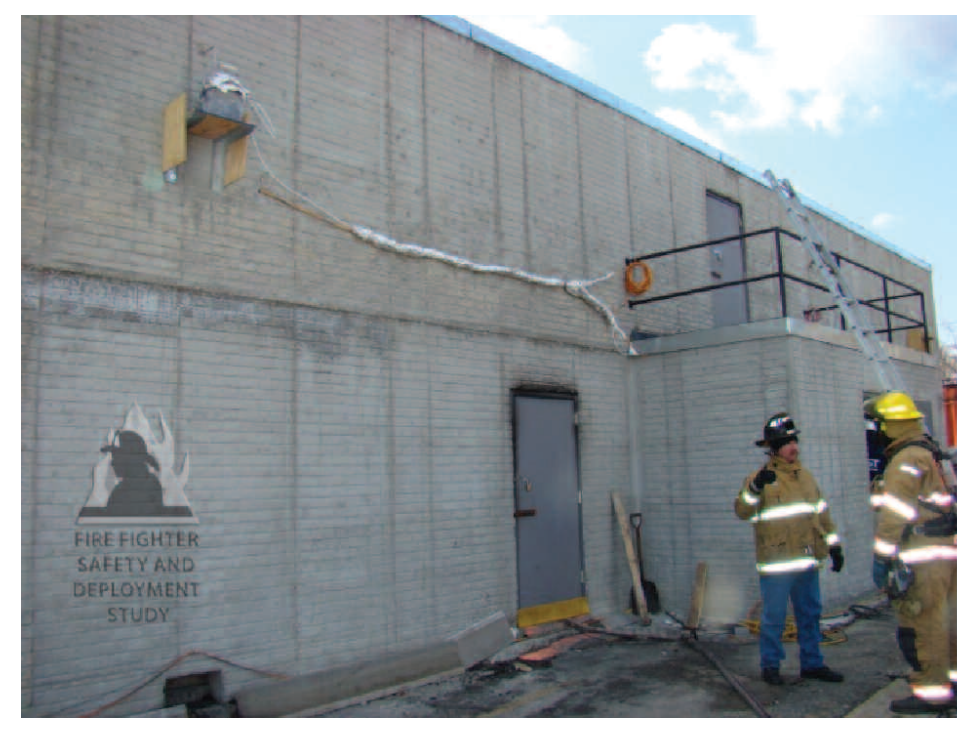

Figure C-12: Instrumentation Room

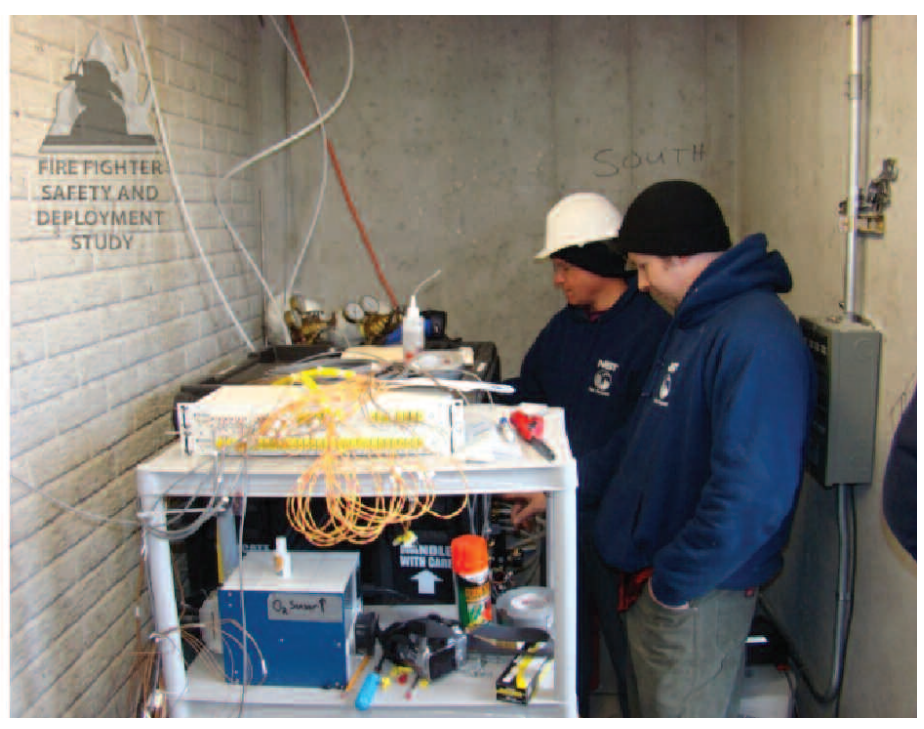

Inside

Table C-2: Dimensions and Mass of Furniture for Room and Contents Tests

\begin{tabular}{|c|c|c|c|c|c|}
\hline Furniture & Width $[\mathrm{m}]$ & $\begin{array}{c}\text { Depth } \\
{[\mathrm{m}]}\end{array}$ & Height $[\mathrm{m}]$ & Mass $[\mathrm{kg}]$ & Material \\
\hline Couch & 1.8 & 0.8 & 0.9 & 58.1 & See D-3 \\
\hline Dresser & 1.8 & 0.5 & 0.6 & 72.3 & $\begin{array}{c}\text { Laminated Particle } \\
\text { Board }\end{array}$ \\
\hline Nightstand & 0.5 & 0.6 & 0.61 & 22.7 & $\begin{array}{c}\text { Laminated Particle } \\
\text { Board }\end{array}$ \\
\hline \multirow[t]{2}{*}{ Chair } & 0.5 & 0.7 & 0.6 & 9.2 & $\begin{array}{l}\text { Wood, Fabric, and } \\
\text { Polyurethane Foam }\end{array}$ \\
\hline & \multicolumn{4}{|c|}{ Back cushion $=0.1 \mathrm{~m}$, Bottom cushion $=0.07 \mathrm{~m}$} & \\
\hline Blanket & 1.8 & - & 2.4 & 1.3 & $100 \%$ Cotton \\
\hline Body Pillow & 0.5 & - & 1.4 & 1.3 & $\begin{array}{c}100 \% \text { cotton cover, } \\
\text { polyester fill }\end{array}$ \\
\hline Trash Can & 0.4 & 0.3 & 0.4 & 1.3 & Polypropylene \\
\hline Towel & 0.8 & - & 1.4 & 0.4 & $100 \%$ Cotton \\
\hline Wallboard & 1.2 & 0.003 & 2.4 & 9.0 & MDF \\
\hline
\end{tabular}

\section{Table C-3: Materials in Couch}

\begin{tabular}{|l|l|}
\hline Body: & Resinated dyed fiber (unknown material) $3 \%$ \\
\hline & PU foam pad 46\% \\
\hline & Waste fiber batting (unknown material) $26 \%$ \\
\hline & Polyester fiber batting $25 \%$ \\
\hline & \\
\hline Cushions: & PU foam pad $86 \%$ \\
\hline & Polyester fiber batting 14\% \\
\hline
\end{tabular}




\section{APPENDIX D: Data Collection and Company Protocols for Time-to-Task Tests}

\section{Time-to-Task Data Collection Chart}

Date

Start Time

End Time (all task complete)

Timer Name

\begin{tabular}{|c|c|c|c|}
\hline Task & $\begin{array}{l}\text { Start } \\
\text { Time }\end{array}$ & $\begin{array}{l}\text { Completion } \\
\text { Time }\end{array}$ & Duration \\
\hline Stop at Hydrant-- Wrap Hose & & & \\
\hline Position Engine 1 & & & \\
\hline $\begin{array}{l}\text { Conduct Size-up } \\
\begin{array}{c}-\quad 360 \text { o lap } \\
-\quad \text { Transmit report } \\
-\quad \text { establish command }\end{array}\end{array}$ & & & \\
\hline Engage Pump & & & \\
\hline Position attack line (stop time - at front door) & & & \\
\hline Establish 2-in-2-out & & & \\
\hline $\begin{array}{l}\text { Charge Hydrant - supply attack } \\
\text { Engine }\end{array}$ & & & \\
\hline Establish RIT & & & \\
\hline Gain/Force Entry & & & \\
\hline Advance Line (stop time -water on fire) & & & \\
\hline Deploy Back up line (stop time at front door) & & & \\
\hline $\begin{array}{l}\text { Advance Back up line/protect stairwell (start } \\
\text { time at front door - Stop at stairwell) }\end{array}$ & & & \\
\hline Conduct Primary Search & & & \\
\hline Ground Ladders in Place & & & \\
\hline Horizontal Ventilation (ground) & & & \\
\hline Horizontal Ventilation ( $2^{\text {nd }}$ story) & & & \\
\hline Control Utilities (interior) & & & \\
\hline Control Utilities (exterior) & & & \\
\hline Conduct Secondary Search & & & \\
\hline Check for Fire Extension (walls) & & & \\
\hline Check for Fire Extension (ceiling) & & & \\
\hline Mechanical Ventilation & & & \\
\hline
\end{tabular}




\section{Company Protocols: Crew Size of 2}

\section{(10 total personnel on scene)}

\section{PLUS 4 RIC $-1403=$ total 14 needed}

\section{Tasks/Company \\ Engine 1/2 \\ Truck $1 / 2$ \\ Engine 2/2 \\ \begin{tabular}{|l|l} 
Battalion Chief/ Aide & Engine 3/2
\end{tabular}}

Arrive on Scene

- Arrive/ stop at hydrant

- Position engine

\section{Driver}

- Layout report

- On-scene report

- Conduct size-up $-360^{\circ}$

lap - incident action plan - offensive

- detail incident (situation report)

- Transmit size-up to responding units

- Transfer command to chief

\section{Officer}

-
-Arrive

$-360^{\circ}$ lap
- Arrives

- Assumes Command

- Evaluates Resources

- Establishes

Command post

- Evaluates exposure problems

- Directs hose positioning

- Coordinates Units

- Transmits

Progress reports

- Changes strategy

- Orders, records, and transmits results of primary and secondary searches

- Declares fire under control
Establish Supply line

- Hydrant-Drop line (wrap)

- Position engine

- Pump engaged

- 4" straight lay
Driver/O

Driver/O

Driver/O
-Dry Lay - 2nd

engine takes hydrant

- Charged

hydrant

- Supply attack engine

- Supply attack engine

Position attack line

- Flake

Officer - (Not

interior-just

- Charge

front door)

- Bleed

- -------------

- Advance

Officer

Establish - 2 in -2 out

(Initial RIT)

Establish RIT

(Dedicated)

Driver

Officer

all RIT duties) 


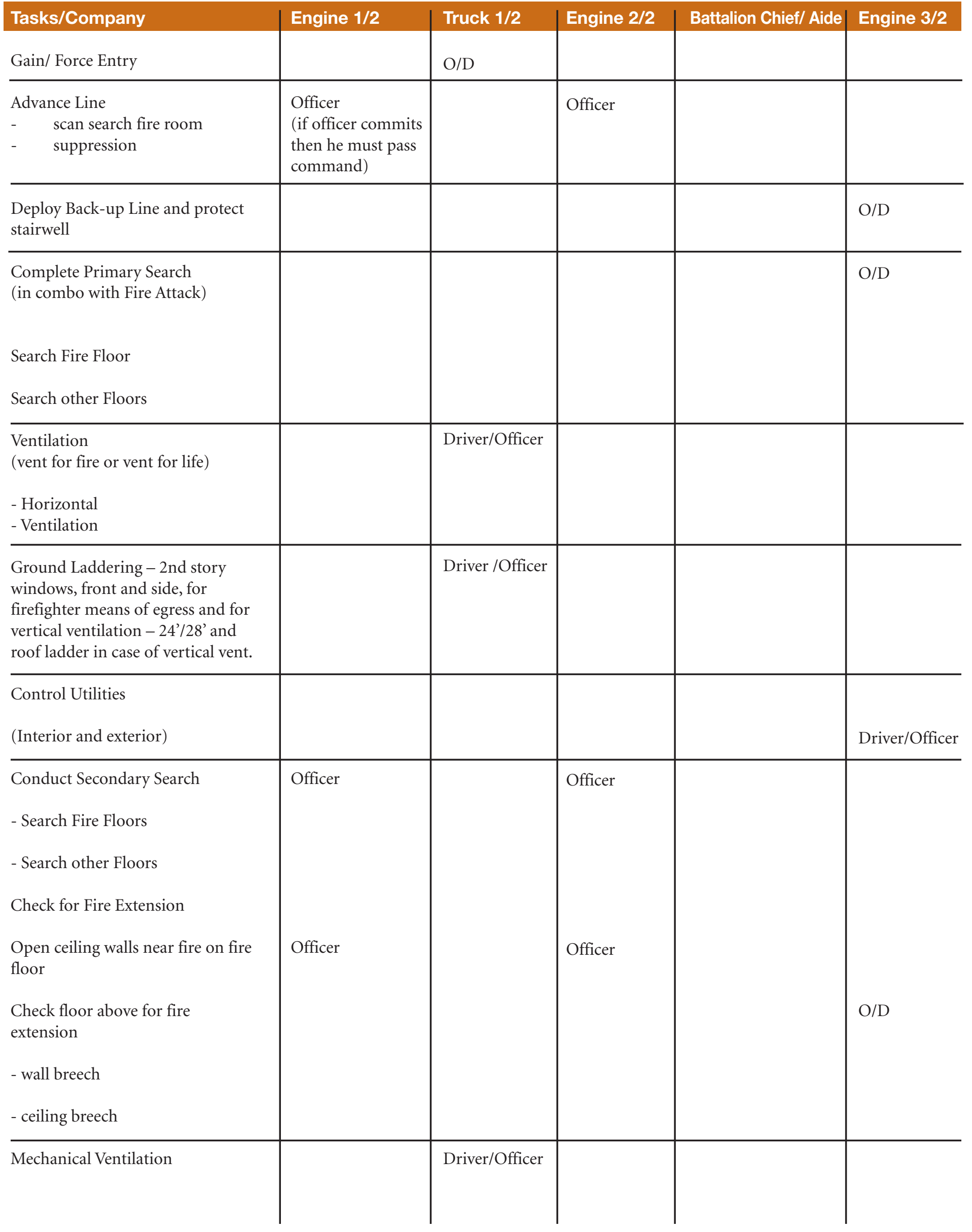




\section{Company Protocols: Crew Size of 3}

\section{(14 total personnel on scene)}

\section{PLUS 4 RIC $-1403=$ total 18 needed}

\section{Tasks/Company \\ Engine 1/3 \\ Truck 1/3 \\ Engine 2/3 \\ Battalion Chief/ Aide $\quad$ Engine 3/2}

Arrive on Scene

- Arrive/ stop at hydrant

Driver

-Arrive

- 360 degree lap

- Position engine

- Layout report

- On-scene report

- Conduct size-up - $360^{\circ}$

lap - incident action plan - offensive

- detail incident (situation report)

- Transmit size-up to responding units

- Transfer command to chief
Officer

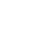

- Arrives

- Assumes Command

- Evaluates Resources

- Establishes

Command post

- Evaluates exposure problems

- Directs hose positioning

- Coordinates Units

- Transmits

Progress reports

- Changes strategy

- Orders, records, and transmits results of primary and secondary searches

- Declares fire under control
Establish Supply line

- Hydrant-Drop line (wrap)

- Position engine

- Pump engaged

- 4" straight lay

- Supply attack engine

Position attack line

- Flake

- Charge

- Bleed

- Advance

Establish - 2 in -2 out

(Initial RIT)

Establish RIT

(Dedicated) 


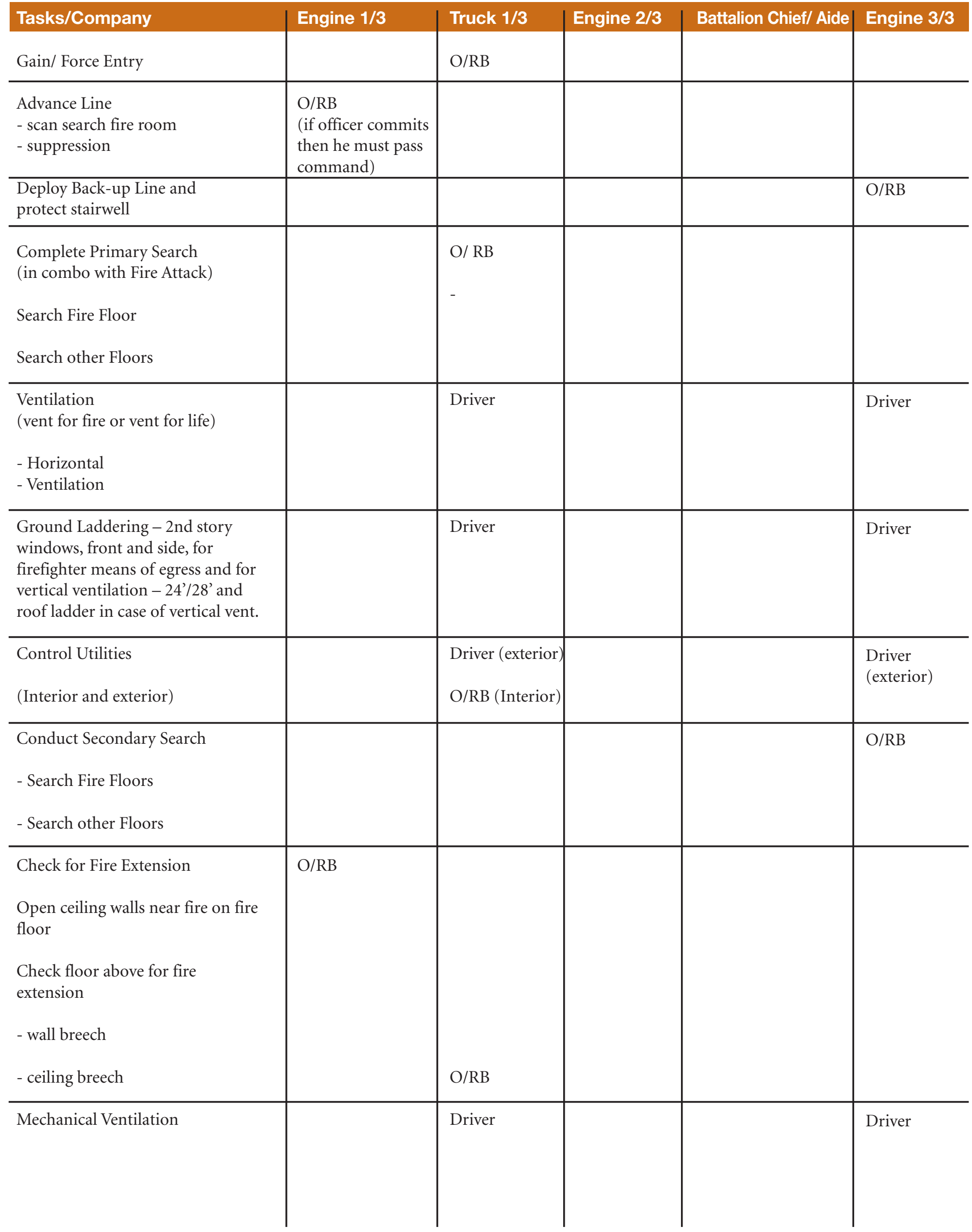




\section{Company Protocols: Crew Size of 4}

\section{Total on scene $=18$}

\section{PLUS 4 RIC $-1403=$ total 22 needed}

\section{Tasks/Company \\ Engine 1/4 \\ Truck $1 / 4$ \\ Engine 2/4 \\ \begin{tabular}{|l|l} 
Battalion Chief/ Aide & Engine 3/4
\end{tabular}}

Arrive on Scene

Driver

-Arrive

- Arrive/ stop at hydrant

- Position engine

- Layout report

- On-scene report

- Conduct size-up - $360^{\circ}$

lap - incident action plan - offensive

- detail incident (situation report)

- Transmit size-up to responding units

- Transfer command to chief

Establish Supply line

- Hydrant-Drop line (wrap)

- Position engine

- Pump engaged

- 4" straight lay

- Supply attack engine (1 3/4")

Position attack line

- Flake

- Charge

- Bleed

- Advance

Establish - 2 in -2 out

(Initial RIT)

Establish RIT

(Dedicated)
Officer

- 360 degree lap

Position Truck

-Dry Lay - 2nd

engine takes

hydrant

Charged

hydrant -

Supply attack

engine

Driver
- Arrives

- Assumes Command

- Evaluates Resources

- Establishes

Command post

- Evaluates exposure problems

- Directs hose positioning

- Coordinates Units

- Transmits

Progress reports

- Changes strategy

- Orders, records, and transmits results of primary and secondary searches

- Declares fire under control
$\mathrm{O} / \mathrm{LB} / \mathrm{RB}$

advance by foot to get to point of entry-performs all RIT duties 


\begin{tabular}{|c|c|c|c|c|}
\hline Tasks/Company & Engine 1/4 & Truck 1/4 & Battalion Chief/ Aide & Engine $3 / 4$ \\
\hline Gain/ Force Entry & & $\mathrm{O} / \mathrm{RB}$ & & \\
\hline $\begin{array}{l}\text { Advance Line } \\
\text { - scan search fire room } \\
\text { - suppression }\end{array}$ & $\begin{array}{l}\mathrm{RB} / \mathrm{LB} \\
\text { Officer - not on line } \\
\text { (if officer commits } \\
\text { then he must pass } \\
\text { command) }\end{array}$ & & & \\
\hline $\begin{array}{l}\text { Deploy Back-up Line and } \\
\text { protect stairwell }\end{array}$ & & & & $\mathrm{O} / \mathrm{RB}$ \\
\hline $\begin{array}{l}\text { Complete Primary Search } \\
\text { (in combo with Fire Attack) } \\
\text { Search Fire Floor }\end{array}$ & & $\begin{array}{l}\text { Officer and RB } \\
\text { - }\end{array}$ & & \\
\hline Search other Floors & & & & \\
\hline $\begin{array}{l}\text { Ventilation } \\
\text { - Horizontal } \\
\text { - Ventilation }\end{array}$ & & Driver and LB & & \\
\hline $\begin{array}{l}\text { Ground Laddering - } 2 \text { nd story } \\
\text { windows, front and side, for } \\
\text { firefighter means of egress and for } \\
\text { vertical ventilation }-24^{\prime} / 28^{\prime} \text { and } \\
\text { roof ladder in case of vertical vent. }\end{array}$ & & Driver /LB & & \\
\hline $\begin{array}{l}\text { Control Utilities } \\
\text { (Interior and exterior) } \\
\text { Conduct Secondary Search } \\
\text { - Search Fire Floors } \\
\text { - Search other Floors }\end{array}$ & & $\begin{array}{l}\begin{array}{l}\text { Driver/LB } \\
\text { (control exterior) }\end{array} \\
\mathrm{O} / \mathrm{RB} \\
\text { (control interior) }\end{array}$ & & $\mathrm{D} / \mathrm{LB}$ \\
\hline $\begin{array}{l}\text { Check for Fire Extension } \\
\text { Open ceiling walls near fire on fire } \\
\text { floor } \\
\text { Check floor above for fire } \\
\text { extension } \\
\text { - wall breech } \\
\text { - ceiling breech }\end{array}$ & $\mathrm{O} / \mathrm{RB}$ & $\mathrm{O} / \mathrm{RB}$ & & \\
\hline Mechanical Ventilation & & $\mathrm{D} / \mathrm{LB}$ & & \\
\hline
\end{tabular}


Company Protocols: Crew Size of 5

D/O/LB/RB/CB Total on scene $=22$

PLUS 4 RIC $-1403=$ total 26 needed

\section{Tasks/Company}

Engine 1/5

Truck $1 / 5$

Engine 2/5

\begin{tabular}{|l|l|} 
Battalion Chief/ Aide & Engine 3/4
\end{tabular}

Arrive on Scene

- Arrive/ stop at hydrant

- Position engine

- Layout report

- On-scene report

- Locate Fire

- Conduct size-up - $360^{\circ}$

lap - incident action plan - offensive

- detail incident (situation report)

- Transmit size-up to responding units

- Transfer command to chief



Establish Supply line

- Hydrant-Drop line (wrap)

- Position engine

- Pump engaged

- 4" straight lay

- Supply attack engine (1 3/4”)

Position attack line

- Flake

- Charge

- Bleed

- Advance

Establish - 2 in -2 out

Driver

Driver

Driver

Driver

Officer

-Arrive

- 360 degree

Size up.

-
- Arrives

- Assumes Command

- Evaluates Resources

- Establishes

Command post

- Evaluates exposure

problems

- Directs hose

positioning

- Coordinates Units

- Transmits

Progress reports

- Changes strategy

- Orders, records, and transmits results of primary and secondary searches

- Declares fire under control

(Initial RIT)

RB/Nozzle

LB/Flake

$\mathrm{CB} /$ Control

Advance line for fire attack

The Officer responsibility is

to supervise hose

stretch /monitor

safety and

continually survey

the scene

Position Truck $\quad$-Dry Lay - 2nd

engine takes

hydrant

Charged

hydrant -

Supply attack

engine 


\begin{tabular}{|c|c|c|c|c|c|}
\hline Tasks/Company & Engine 1/5 & Truck 1/5 & Engine 2/5 & Battalion Chief/ Aide & Engine $3 / 5$ \\
\hline $\begin{array}{l}\text { Establish RIT } \\
\text { (Dedicated) }\end{array}$ & & & $\begin{array}{l}\mathrm{O} / \mathrm{LB} / \mathrm{RB}- \\
\text { advance by foo } \\
\text { to get to point } \\
\text { of entry- } \\
\text { performs all } \\
\text { RIT duties } \\
\end{array}$ & & \\
\hline Gain/ Force Entry & & $\mathrm{O} / \mathrm{RB} / \mathrm{CB}$ & & & \\
\hline $\begin{array}{l}\text { Advance Line } \\
\text { - scan search fire room } \\
\text { - suppression }\end{array}$ & $\begin{array}{l}\mathrm{RB} / \mathrm{LB} / \mathrm{CB} \\
\text { Officer - not on } \\
\text { line (if officer } \\
\text { commits then he } \\
\text { must pass } \\
\text { command) }\end{array}$ & & & & \\
\hline $\begin{array}{l}\text { Insures first line flowing water- } \\
\text { Deploy Back-up Line and protect } \\
\text { stairwell ( }\left(13 / 4^{\prime \prime}\right)\end{array}$ & & & & & $\mathrm{O} / \mathrm{RB} / \mathrm{CB}$ \\
\hline $\begin{array}{l}\text { Complete Primary Search } \\
\text { (in combo with Fire Attack) } \\
\text { Search Fire Floor - } \\
\text { Search other floors- }\end{array}$ & & $\begin{array}{l}\text { Officer and } \\
\mathrm{RB} / \mathrm{CB}\end{array}$ & & & \\
\hline \begin{tabular}{ll}
\multicolumn{2}{l}{ Ventilation (vent for fire or vent for life) } \\
- & Horizontal \\
- & Vertical
\end{tabular} & & Driver and LB & & & \\
\hline $\begin{array}{l}\text { Ground Laddering - 2nd story } \\
\text { windows, front and side, for } \\
\text { firefighter means of egress and for } \\
\text { vertical ventilation }-24 \text { ' } / 28^{\prime} \text { and roof } \\
\text { ladder in case of vertical vent. }\end{array}$ & & Driver /LB & & & \\
\hline $\begin{array}{l}\text { Control Utilities after search, force } \\
\text { entry, venting and fire extinguished } \\
\text { (Interior and exterior) }\end{array}$ & & $\begin{array}{l}\text { Driver/LB } \\
\text { (control exterior) } \\
\mathrm{O} / \mathrm{RB} / \mathrm{CB} \\
\text { (control interior) }\end{array}$ & & & \\
\hline $\begin{array}{l}\text { Conduct Secondary Search } \\
\text {-Fire Floor } \\
\text {-Primary and secondary search of } \\
\text { entire floor above }\end{array}$ & & $\mathrm{D} / \mathrm{LB}$ & & & $\begin{array}{l}\mathrm{D} / \mathrm{LB} \\
\mathrm{O} / \mathrm{RB} / \mathrm{CB}\end{array}$ \\
\hline $\begin{array}{l}\text { Check for Fire Extension } \\
\text { Open ceiling walls near fire on fire } \\
\text { floor } \\
\text { Check floor above for fire } \\
\text { extension } \\
\text { wall breech } \\
\text { ceiling breech- }\end{array}$ & $\mathrm{O} / \mathrm{RB}$ & & & & $\mathrm{O} / \mathrm{RB} / \mathrm{CB}$ \\
\hline Mechanical Ventilation & & & & & \\
\hline
\end{tabular}




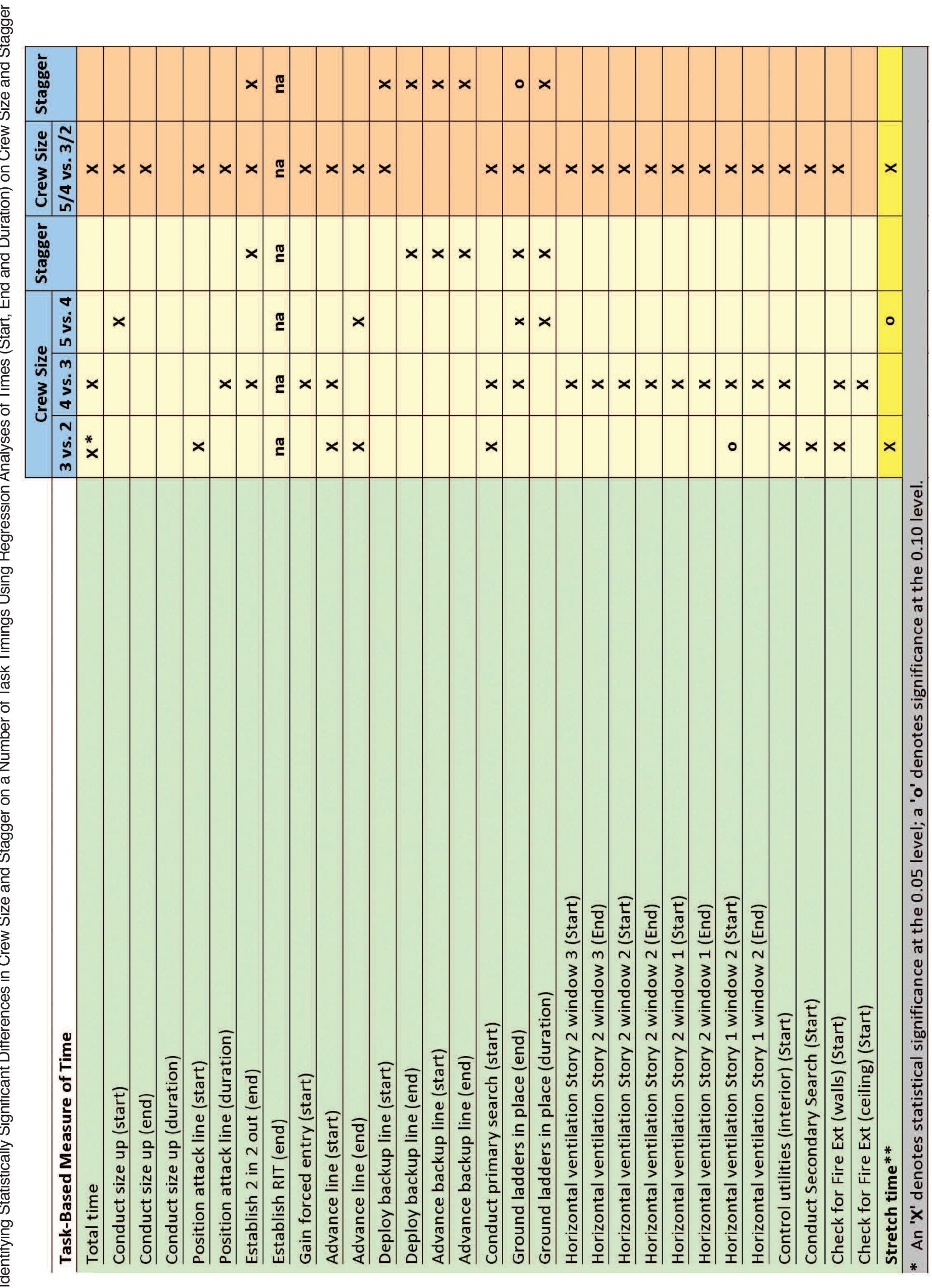




\section{Appendix F: All Regression Coefficients}

\section{Regression Models of Time to Task (in Seconds) as a Function of Crew Size and Stagger (Standard Errors are in Parentheses underneath coefficients)}

\begin{tabular}{|c|c|c|c|c|c|c|}
\hline \multirow{3}{*}{ Measure of Task Time } & \multirow{2}{*}{\multicolumn{6}{|c|}{ Coefficients }} \\
\hline & & & & & & \\
\hline & $\begin{array}{c}\text { Time } \\
\text { measured }\end{array}$ & $\begin{array}{c}\text { Crew } \\
\text { size of } 3\end{array}$ & $\begin{array}{c}\text { Crew } \\
\text { size of } 4\end{array}$ & $\begin{array}{c}\text { Crew } \\
\text { size of } 5\end{array}$ & $\begin{array}{c}\text { Close } \\
\text { Stagger }\end{array}$ & Constant \\
\hline \multirow[t]{2}{*}{ Total time } & & -100.5 & -408.33 & -402.17 & -40.83 & 1374.42 \\
\hline & & (50.29) & $(50.29)$ & $(50.29)$ & $(35.56)$ & (39.77) \\
\hline \multirow[t]{2}{*}{ Conduct size up } & Start & 2.5 & -5.167 & -18.17 & -1.25 & 335 \\
\hline & & $(5.97)$ & $(5.97)$ & $(5.97)$ & $(4.22)$ & $(4.72)$ \\
\hline \multirow[t]{2}{*}{ Conduct size up } & Complete & -5.167 & -13.17 & -38.33 & -12 & 416 \\
\hline & & $(13.60)$ & $(13.60)$ & $(13.60)$ & $(9.62)$ & $(10.75)$ \\
\hline \multirow[t]{2}{*}{ Conduct size up } & Duration & -7.667 & -8 & -20.17 & -10.75 & 81.04 \\
\hline & & $(12.10)$ & $(12.10)$ & $(12.10)$ & $(8.56)$ & (9.57) \\
\hline \multirow[t]{2}{*}{ Position attack line } & Start & -63.5 & -63.5 & -69.67 & -11.17 & 408.1 \\
\hline & & (14.09) & $(14.09)$ & (14.09) & $(9.96)$ & (11.14) \\
\hline \multirow[t]{2}{*}{ Position attack line } & Duration & -16 & -63.67 & -61.67 & 5.167 & 160.6 \\
\hline & & (13.79) & $(13.79)$ & (13.79) & (9.75) & $(10.90)$ \\
\hline \multirow[t]{2}{*}{ Establish 2in - 2 out } & Complete & $-6.7 E-15$ & -90 & -90 & -30 & 355 \\
\hline & & $(9.73)$ & (9.73) & $(9.73)$ & $(6.88)$ & (7.69) \\
\hline \multirow[t]{2}{*}{ Establish RIT } & Complete & 70 & 70 & 70 & -60 & 435 \\
\hline & & 0.00 & 0.00 & 0.00 & 0.00 & 0.00 \\
\hline \multirow[t]{2}{*}{ Gain forced entry } & Start & -23.5 & -54 & -80.83 & -20.83 & 528.6 \\
\hline & & $(19.66)$ & $(19.66)$ & $(19.66)$ & $(13.90)$ & (15.54) \\
\hline \multirow[t]{2}{*}{ Advance line } & Start & -54 & -97.83 & -123.5 & -17.5 & 586.3 \\
\hline & & $(18.83)$ & $(18.83)$ & $(18.83)$ & $(13.31)$ & $(14.88)$ \\
\hline \multirow[t]{2}{*}{ Advance line } & Complete & -61 & -95.5 & -134.7 & -19.08 & 625.5 \\
\hline & & $(20.35)$ & $(20.35)$ & $(20.35)$ & $(14.39)$ & $(16.08)$ \\
\hline \multirow[t]{2}{*}{ Deploy backup line } & Start & -26 & -42.67 & -53.5 & -96.75 & 641.5 \\
\hline & & (17.11) & $(17.11)$ & $(17.11)$ & $(12.10)$ & $(13.53)$ \\
\hline \multirow[t]{2}{*}{ Deploy backup line } & Complete & -15.83 & -56.17 & -17.5 & -53.75 & 728.9 \\
\hline & & (33.49) & $(33.49)$ & $(33.49)$ & $(23.68)$ & $(26.48)$ \\
\hline \multirow[t]{2}{*}{ Advance backup line } & Start & -33 & -66.83 & -34.83 & -63 & 779.7 \\
\hline & & $(29.65)$ & $(29.65)$ & $(29.65)$ & $(20.97)$ & $(23.44)$ \\
\hline \multirow[t]{2}{*}{ advancebackupline 2} & Complete & -34.5 & -68.17 & -36.17 & -63.75 & 784.4 \\
\hline & & $(29.73)$ & $(29.73)$ & $(29.73)$ & $(21.02)$ & $(23.50)$ \\
\hline \multirow[t]{2}{*}{ conductprimarysearch1 } & Start & -147 & -215.8 & -211.5 & 0.1667 & 736.1 \\
\hline & & $(25.08)$ & $(25.08)$ & $(25.08)$ & $(17.74)$ & $(19.83)$ \\
\hline \multirow[t]{2}{*}{ Ground ladders in place } & Complete & -38 & -196.5 & -317.8 & -69.83 & 1168 \\
\hline & & (48.38) & $(48.38)$ & $(48.38)$ & $(34.21)$ & $(38.24)$ \\
\hline \multirow[t]{2}{*}{ Ground ladders in place } & Duration & -33.83 & -83.67 & -185.7 & -72.08 & 617 \\
\hline & & $(48.12)$ & $(48.12)$ & $(48.12)$ & (34.03) & $(38.04)$ \\
\hline \multirow[t]{2}{*}{ Horizontal ventilation, second story, window 3} & Start & -53.67 & -217.8 & -211 & -26.59 & 759.1 \\
\hline & & (30.75) & $(30.75)$ & $(30.75)$ & $(21.75)$ & $(24.31)$ \\
\hline \multirow[t]{2}{*}{ Horizontal ventilation, second story, window 3} & Complete & -64.83 & -316 & -353 & -33.58 & 1088 \\
\hline & & $(49.74)$ & $(49.74)$ & $(49.74)$ & $(35.17)$ & $(39.32)$ \\
\hline \multirow[t]{2}{*}{ Horizontal ventilation, second story, window 2} & Start & -51.67 & -265.8 & -261.2 & -18.83 & 885.1 \\
\hline & & $(37.20)$ & $(37.20)$ & $(37.20)$ & $(26.30)$ & $(29.41)$ \\
\hline
\end{tabular}


All Regression Coefficients (CONTINUED)

Regression Models of Time to Task (in Seconds) as a Function of Crew Size and Stagger (Standard Errors are in Parentheses underneath coefficients)

\begin{tabular}{|c|c|c|c|c|c|c|}
\hline Horizontal ventilation, second story, window 2 & Complete & -53.5 & -259.8 & -262.3 & -13.33 & 931.3 \\
\hline & & $(39.97)$ & $(39.97)$ & $(39.97)$ & $(28.26)$ & $(31.60)$ \\
\hline \multirow[t]{2}{*}{ Horizontal ventilation, second story, window 1} & Start & -70 & -316.3 & -348.8 & -31.08 & 1038 \\
\hline & & $(48.37)$ & $(48.37)$ & $(48.37)$ & $(34.20)$ & $(38.24)$ \\
\hline \multirow[t]{2}{*}{ Horizontal ventilation, second story, window 1} & Complete & -51.83 & -219 & -214.8 & -24 & 805.7 \\
\hline & & $(33.71)$ & $(33.71)$ & $(33.71)$ & $(23.83)$ & $(26.65)$ \\
\hline \multirow[t]{2}{*}{ Horizontal ventilation, first story, window 2} & Start & -87.17 & -386.3 & -428.5 & -44.67 & 1200 \\
\hline & & $(45.13)$ & $(45.13)$ & $(45.13)$ & $(31.91)$ & $(35.68)$ \\
\hline \multirow[t]{2}{*}{ Horizontal ventilation, first story, window 2} & Complete & -88.5 & -391.5 & -423.3 & -44.17 & 1224 \\
\hline & & $(47.02)$ & $(47.02)$ & $(47.02)$ & $(33.25)$ & $(37.17)$ \\
\hline \multirow[t]{2}{*}{ Control utilities interior } & Start & -136.5 & -287.8 & -300 & -6.333 & 946.3 \\
\hline & & $(45.57)$ & $(45.57)$ & $(45.57)$ & $(32.22)$ & $(36.02)$ \\
\hline \multirow[t]{2}{*}{ Control utilities exterior } & Start & 6.667 & -281.8 & -312.8 & -38.17 & 1063 \\
\hline & & $(70.21)$ & $(70.21)$ & $(70.21)$ & $(49.65)$ & $(55.51)$ \\
\hline \multirow[t]{2}{*}{ Conduct secondary search } & Start & -92.5 & -143 & -152.7 & -28.25 & 846 \\
\hline & & $(38.97)$ & $(38.97)$ & $(38.97)$ & $(27.56)$ & $(30.81)$ \\
\hline \multirow[t]{2}{*}{ Check for fire extension walls } & Start & -453.8 & -535.3 & -608.7 & -38.25 & 1155 \\
\hline & & $(38.28)$ & $(38.28)$ & $(38.28)$ & $(27.07)$ & $(30.26)$ \\
\hline \multirow[t]{2}{*}{ Check for fire extension ceiling } & Start & -206.3 & -349.7 & -292.7 & -2.833 & 1086 \\
\hline & & $(48.29)$ & $(48.29)$ & $(48.29)$ & (34.14) & (38.17) \\
\hline
\end{tabular}


Regression Models of Time to Task (in Seconds) as a Function of Combined Crew Size and Stagger (Standard Errors appear in Parentheses)

\begin{tabular}{|c|c|c|c|c|}
\hline & & & oefficient & \\
\hline Measure of Task Time* & $\begin{array}{c}\text { Time } \\
\text { measured }\end{array}$ & $\begin{array}{c}\text { Crew } \\
\text { size of } \\
4 / 5 \text { vs. } \\
3 / 2 \\
\end{array}$ & $\begin{array}{c}\text { Close } \\
\text { Stagger }\end{array}$ & Constant \\
\hline Total time & & $\begin{array}{c}-355 \\
(37.23)\end{array}$ & $\begin{array}{l}-40.83 \\
(37.23)\end{array}$ & $\begin{array}{c}1324.00 \\
(32.24)\end{array}$ \\
\hline Conduct size up & Start & $\begin{array}{r}-12.92 \\
(4.50) \\
\end{array}$ & $\begin{array}{l}-1.25 \\
(4.50) \\
\end{array}$ & $\begin{array}{l}336.2 \\
(3.90) \\
\end{array}$ \\
\hline Conduct size up & Complete & $\begin{array}{r}-23.17 \\
(9.97) \\
\end{array}$ & $\begin{array}{c}-12 \\
(9.97) \\
\end{array}$ & $\begin{array}{l}413.4 \\
(8.64) \\
\end{array}$ \\
\hline Conduct size up & Duration & $\begin{array}{r}-10.25 \\
(8.44)\end{array}$ & $\begin{array}{r}-10.75 \\
(8.44) \\
\end{array}$ & $\begin{array}{l}77.21 \\
(7.31)\end{array}$ \\
\hline Position attack line & Start & $\begin{array}{l}-34.83 \\
(13.66)\end{array}$ & $\begin{array}{l}-11.17 \\
(13.66)\end{array}$ & $\begin{array}{c}376.3 \\
(11.83)\end{array}$ \\
\hline Position attack line & Duration & $\begin{array}{r}-54.67 \\
(9.60) \\
\end{array}$ & $\begin{array}{l}5.167 \\
(9.60) \\
\end{array}$ & $\begin{array}{l}152.6 \\
(8.31) \\
\end{array}$ \\
\hline Establish 2 in - 2 out & Complete & $\begin{array}{c}-90 \\
(6.55) \\
\end{array}$ & $\begin{array}{c}-30 \\
(6.55) \\
\end{array}$ & $\begin{array}{c}355 \\
(5.67) \\
\end{array}$ \\
\hline Establish RIT & Complete & $\begin{array}{c}35 \\
(10.80) \\
\end{array}$ & $\begin{array}{c}-60 \\
(10.80) \\
\end{array}$ & $\begin{array}{c}470 \\
(9.35) \\
\end{array}$ \\
\hline Gain forced entry & Start & $\begin{array}{l}-55.67 \\
(14.32)\end{array}$ & $\begin{array}{l}-20.83 \\
(14.32)\end{array}$ & $\begin{array}{c}\mathbf{5 1 6 . 8} \\
(12.40) \\
\end{array}$ \\
\hline Advance line & Start & $\begin{array}{l}-83.67 \\
(15.67) \\
\end{array}$ & $\begin{array}{c}-17.5 \\
(15.67) \\
\end{array}$ & $\begin{array}{c}\mathbf{5 5 9 . 3} \\
(13.57) \\
\end{array}$ \\
\hline Advance line & Complete & $\begin{array}{l}-84.58 \\
(17.67) \\
\end{array}$ & $\begin{array}{r}-19.08 \\
(17.67) \\
\end{array}$ & $\begin{array}{c}595 \\
(15.31) \\
\end{array}$ \\
\hline Deploy backup line & Start & $\begin{array}{l}-35.08 \\
(12.30)\end{array}$ & $\begin{array}{l}-96.75 \\
(12.30)\end{array}$ & $\begin{array}{c}628.5 \\
(10.65)\end{array}$ \\
\hline Deploy backup line & Complete & $\begin{array}{l}-28.92 \\
(23.43)\end{array}$ & $\begin{array}{l}-53.75 \\
(23.43)\end{array}$ & $\begin{array}{c}721 \\
(20.29) \\
\end{array}$ \\
\hline Advance backup line & Start & $\begin{array}{l}-34.33 \\
(21.17)\end{array}$ & $\begin{array}{c}-63 \\
(21.17)\end{array}$ & $\begin{array}{c}763.2 \\
(18.33)\end{array}$ \\
\hline advancebackupline2 & Complete & $\begin{array}{l}-34.92 \\
(21.27)\end{array}$ & $\begin{array}{l}-63.75 \\
(21.27) \\
\end{array}$ & $\begin{array}{c}767.1 \\
(18.42) \\
\end{array}$ \\
\hline conductprimarysearch1 & Start & $\begin{array}{c}-140.2 \\
(28.28)\end{array}$ & $\begin{array}{l}0.1667 \\
(28.28)\end{array}$ & $\begin{array}{c}662.6 \\
(24.49)\end{array}$ \\
\hline Ground ladders in place & Complete & $\begin{array}{l}-238.2 \\
(37.99)\end{array}$ & $\begin{array}{l}-69.83 \\
(37.99) \\
\end{array}$ & $\begin{array}{c}1149 \\
(32.90)\end{array}$ \\
\hline Ground ladders in place & Duration & $\begin{array}{l}\mathbf{- 1 1 7 . 7} \\
(36.37) \\
\end{array}$ & $\begin{array}{l}-72.08 \\
(36.37) \\
\end{array}$ & $\begin{array}{c}600.1 \\
(31.49)\end{array}$ \\
\hline Horizontal ventilation, second story, window 3 & Start & $\begin{array}{l}-187.6 \\
(22.31)\end{array}$ & $\begin{array}{l}-26.59 \\
(22.31)\end{array}$ & $\begin{array}{c}732.3 \\
(19.32)\end{array}$ \\
\hline Horizontal ventilation, second story, window 3 & Complete & $\begin{array}{l}-302.1 \\
(35.38)\end{array}$ & $\begin{array}{l}-33.58 \\
(35.38)\end{array}$ & $\begin{array}{c}1056 \\
(30.64)\end{array}$ \\
\hline
\end{tabular}


Regression Models of Time to Task (in Seconds) as a Function of Combined Crew Size and Stagger (CONTINUED) (Standard Errors appear in Parentheses)

\begin{tabular}{|c|c|c|c|c|c|c|}
\hline Horizontal ventilation, second story, window 2 & Start & & $\begin{array}{l}-237.7 \\
(26.27) \\
\end{array}$ & $\begin{array}{l}-18.83 \\
(26.27) \\
\end{array}$ & $\begin{array}{c}859.3 \\
(22.75) \\
\end{array}$ & \\
\hline Horizontal ventilation, second story, window 2 & Complete & & $\begin{array}{l}-234.3 \\
(28.12) \\
\end{array}$ & $\begin{array}{l}-13.33 \\
(28.12) \\
\end{array}$ & $\begin{array}{c}904.6 \\
(24.36)\end{array}$ & \\
\hline Horizontal ventilation, second story, window 1 & Start & & $\begin{array}{l}-297.6 \\
(34.64)\end{array}$ & $\begin{array}{l}-31.08 \\
(34.64)\end{array}$ & $\begin{array}{c}1003 \\
(30.00)\end{array}$ & \\
\hline Horizontal ventilation, second story, window 1 & Complete & & $\begin{array}{c}-191 \\
(24.05)\end{array}$ & $\begin{array}{c}-24 \\
(24.05) \\
\end{array}$ & $\begin{array}{c}779.8 \\
(20.83)\end{array}$ & \\
\hline Horizontal ventilation, first story, window 2 & Start & & $\begin{array}{l}-363.8 \\
(33.83) \\
\end{array}$ & $\begin{array}{c}-44.67 \\
(33.83) \\
\end{array}$ & $\begin{array}{c}1156 \\
(29.30) \\
\end{array}$ & \\
\hline Horizontal ventilation, first story, window 2 & Complete & & $\begin{array}{c}-363.2 \\
(34.80) \\
\end{array}$ & $\begin{array}{l}-44.17 \\
(34.80) \\
\end{array}$ & $\begin{array}{c}1180 \\
(30.14)\end{array}$ & \\
\hline Control utilities interior & Start & & $\begin{array}{l}-225.7 \\
(37.23) \\
\end{array}$ & $\begin{array}{r}-6.333 \\
(37.23) \\
\end{array}$ & $\begin{array}{c}878.1 \\
(32.25)\end{array}$ & \\
\hline Control utilities exterior & Start & & $\begin{array}{l}-300.7 \\
(47.48) \\
\end{array}$ & $\begin{array}{l}-38.17 \\
(47.48) \\
\end{array}$ & $\begin{array}{c}1066 \\
(41.12) \\
\end{array}$ & \\
\hline Conduct secondary search & Start & & $\begin{array}{l}-101.6 \\
(29.88) \\
\end{array}$ & $\begin{array}{l}-28.25 \\
(29.88) \\
\end{array}$ & $\begin{array}{c}799.7 \\
(25.88) \\
\end{array}$ & \\
\hline Check for fire extension walls & Start & & $\begin{array}{c}-345.1 \\
(75.46)\end{array}$ & $\begin{array}{r}-38.25 \\
(75.46)\end{array}$ & $\begin{array}{c}927.9 \\
(65.35)\end{array}$ & \\
\hline Check for fire extension ceiling & Start & & $\begin{array}{c}-218 \\
(46.32) \\
\end{array}$ & $\begin{array}{l}-2.833 \\
(46.32) \\
\end{array}$ & $\begin{array}{c}983.1 \\
(40.12) \\
\end{array}$ & \\
\hline $\begin{array}{l}\text { Stretch time = advance line minus position } \\
\text { engine }\end{array}$ & Duration & & $\begin{array}{c}-75.7 \\
(16.68)\end{array}$ & $\begin{array}{c}-17.2 \\
(16.68)\end{array}$ & $\begin{array}{c}273.3 \\
(14.44)\end{array}$ & \\
\hline \multicolumn{7}{|c|}{ * Standard errors are in parentheses below coefficient value } \\
\hline & & $\begin{array}{c}\text { Crew } \\
\text { size of } 3\end{array}$ & $\begin{array}{c}\text { Crew } \\
\text { size of } 4\end{array}$ & $\begin{array}{c}\text { Crew } \\
\text { size of } 5\end{array}$ & $\begin{array}{c}\text { Close } \\
\text { Stagger }\end{array}$ & Constant \\
\hline $\begin{array}{l}\text { Stretch time = advance line minus position } \\
\text { engine }\end{array}$ & Duration & $\begin{array}{c}-57.3 \\
(19.39)\end{array}$ & $\begin{array}{c}-86.7 \\
(19.39)\end{array}$ & $\begin{array}{l}-122.0 \\
(19.39)\end{array}$ & $\begin{array}{c}-17.2 \\
(13.71)\end{array}$ & $\begin{array}{c}301.9 \\
(15.33)\end{array}$ \\
\hline
\end{tabular}


$\mathrm{T}$ he measurements of length, temperature, mass, moisture content, smoke obscuration, and time taken in these experiments have unique components of uncertainty that must be evaluated in order to determine the fidelity of the data. These components of uncertainty can be grouped into two categories: Type A and Type B. Type A uncertainties are those evaluated by statistical methods, such as calculating the standard deviation of the mean of a set of measurements. Type B uncertainties are based on scientific judgment using all available and relevant information. Using relevant information, the upper and lower limits of the expected value are estimated so that the probability that the measurement falls within these limits is essentially $100 \%$. After all the component uncertainties of a measurement have been identified and evaluated it is necessary to use them to compute the combined standard uncertainty using the law of propagation of uncertainty (the "root sum of squares"). Although this expresses the uncertainty of a given measurement, it is more useful in a fire model validation exercise to define an interval for which the measurement will fall within a certain level of statistical confidence. This is known as the expanded uncertainty. The current international practice is to multiply the combined standard uncertainty by a factor of two $(\mathrm{k}=2)$, giving a confidence of $95 \%$.

Length measurements of room dimensions, openings and instrument locations were taken using a steel measuring tape with a resolution of 0.02 in $(0.5 \mathrm{~mm})$. However, measurement error due to uneven and unlevel surfaces results in an estimated uncertainty of \pm $0.5 \%$ for length measurements taken on the scale of room dimensions. The estimated total expanded uncertainty for length measurements is $\pm 1.0 \%$.

The standard uncertainty of the thermocouple wire itself is $1.1^{\circ} \mathrm{C}$ or $0.4 \%$ of the measured value, whichever is greater (Omega 2004). The estimated total expanded uncertainty associated with type $\mathrm{K}$ thermocouples is approximately $\pm 15 \%$. Previous work done at NIST has shown that the uncertainty of the environment surrounding thermocouples in a full-scale fire experiment has a significantly greater uncertainty (Blevins 1999) than the uncertainty inherent with thermocouple design. Furthermore, while a vertical thermocouple array gives a good approximation of the temperature gradient with respect to height, temperatures cannot be expected to be uniform across a plane at any height because of the dynamic environment in a compartment fire. Inaccuracies of thermocouple measurements in a fire environment can be caused by:

n Radiative heating or cooling of the thermocouple bead

- Soot deposition on the thermocouple bead which change its mass, emissivity, and thermal conductivity

- Heat conduction along thermocouple wires

- Flow velocity over the thermocouple bead

To reduce these effects, particularly radiative heating and cooling, thermocouples with smaller diameter beads were chosen. This is particularly important for thermocouples below the interface because the radiative transfer between the surrounding room surfaces will be significantly less uniform than if the thermocouple were in the hot gas layer. It is suggested in [Pitts] that it may be possible to correct for radiative transfer given enough sufficient knowledge about thermocouple properties and the environment. However, measurements of local velocity and the radiative environment were not taken. Additionally, the probes were located away from the burn compartment walls in order to avoid the effects of walls and corners.

The gas measurement instruments and sampling system used in this series of experiments have been demonstrated to have an expanded $(\mathrm{k}=2)$ relative uncertainty of $\pm 1 \%$ when compared with span gas volume fractions (Matheson). Given the limited set of sampling points in these experiments, an estimated uncertainty of $\pm 10 \%$ is being applied to the results.

The potential for soot deposition on the face of the water-cooled total heat flux gauges contributes significant uncertainty to the heat flux measurements. Calibration of heat flux gauges was completed at lower fluxes and then extrapolated to higher values and this resulted in a higher uncertainty in the flux measurement. Combining all of component uncertainties for total heat flux resulted in a total expanded uncertainty of $-24 \%$ to $+13 \%$ for the flux measurements.

Prior to experimentation, ten of the wooden pallets used in the fuel packages were randomly selected for measurement. Two measurements were taken, moisture content and mass. Moisture content was measured using a pin-type moisture meter with a moisture measurement range of $6 \%$ to $40 \%$ and an accuracy of $<0.5 \%$ of the measured value between $6 \%$ and $12 \%$ moisture content. Mass measurements were made with an industrial bench scale having a range of $0 \mathrm{~kg}$ to $100 \mathrm{~kg}$, a resolution of $0.1 \mathrm{~kg}$ and an uncertainty of $\pm 0.1 \mathrm{~kg}$.

All timing staff were equipped with the same model of digital stopwatch with a resolution of 0.01 seconds and an uncertainty of \pm 3 seconds per 24 hours; the uncertainty of the timing mechanism in the stopwatches is small enough over the duration of an experiment that it can be neglected. There are three components of uncertainty when using people to time fire fighting tasks. First, timers may have a bias depending on whether they record the time in anticipation of, or reaction to an event. A second component exists because multiple timers were used to record all tasks. The third component is the mode of the stimulus to which the staff is reacting: audible (firefighters announcing task updates over the radio) or visual (timing staff sees a task start or stop).

Milestone events in these experiments were recorded both audibly and visually. A test series described in the NIST Recommended Practice Guide for Stopwatch and Timer Calibrations found the reaction times for the two modes of stimulus to be approximately the same, so this component can be neglected. Because of the lack of knowledge regarding the mean bias of the timers, a rectangular distribution was assumed and the worst case reaction time bias of $120 \mathrm{~ms}$ was used, giving a standard deviation of $69 \mathrm{~ms}$. The standard deviation of the reaction time was assumed to be the worst case of $230 \mathrm{~ms}$. The estimated total expanded uncertainty of task times measured in these experiments is $240 \mathrm{~ms}$.

An additional component of uncertainty exists for the time measurement of the application of water on the fire. In order to measure this time, timing staff were required to listen for radio confirmation that suppressing water had been applied by the interior attack crew. This process required a member of the interior crew to find and manipulate their microphone, wait for the radio to access a repeater, and transmit the message. Because of the lack of 
knowledge about the distributions of time it takes for each part of this process, all parts are lumped into a single estimate of

uncertainty and a rectangular distribution is assumed. This is most

reasonably estimated to be 2.5 seconds with a standard deviation of

\pm 2.89 seconds and an expanded uncertainty of \pm 5.78 seconds.

Weather measurement uncertainty was referenced to the published user's manual for the instrumentation used. The weather instrumentation has calibration certificates that are traceable to

NIST standards. A summary of experimental measurement

uncertainty is given in Table G-1.

Table G-1: Summary of Measurement Uncertainty

\begin{tabular}{|c|c|c|c|}
\hline Measurement & $\begin{array}{l}\text { Component Standard } \\
\text { Uncertainty }\end{array}$ & $\begin{array}{l}\text { Combined Standard } \\
\text { Uncertainty }\end{array}$ & $\begin{array}{l}\text { Total Expanded } \\
\text { Uncertainty }\end{array}$ \\
\hline \multicolumn{4}{|l|}{ Length Measurements } \\
\hline Instrumentation Locations & $\pm 1 \%$ & $\pm 3 \%$ & $\pm 6 \%$ \\
\hline Building Dimensions & $\pm 1 \%$ & & \\
\hline Repeatability $^{1}$ & $\pm 2 \%$ & & \\
\hline Random $^{1}$ & $\pm 2 \%$ & & \\
\hline \multicolumn{4}{|l|}{ Gas Temperature - Lower Layer } \\
\hline Calibration & $\pm 1 \%$ & $\pm 8 \%$ & $\pm 15 \%$ \\
\hline Radiative Cooling & $-5 \%$ to $+0 \%$ & & \\
\hline Radiative Heating & $0 \%$ to $+5 \%$ & & \\
\hline Repeatability $^{1}$ & $\pm 5 \%$ & & \\
\hline Random $^{1}$ & $\pm 3 \%$ & & \\
\hline \multicolumn{4}{|l|}{ Wood Moisture Content } \\
\hline & $\pm 0.5 \%$ & $\pm 0.5 \%$ & $\pm 1 \%$ \\
\hline \multicolumn{4}{|l|}{ Wood Pallet Mass } \\
\hline & $\pm 0.2 \%$ & $\pm 0.1 \%$ & $\pm 0.1 \%$ \\
\hline \multicolumn{4}{|l|}{ Weather } \\
\hline Relative Humidity & $\pm 3 \%$ & & \\
\hline Barometric Pressure & $\pm 0.03^{\prime \prime ~} \mathrm{Hg}$ & & \\
\hline Wind Speed & $\pm 5 \%$ & & \\
\hline Wind Direction & $\pm 5 \%$ & & \\
\hline Outside Temperature & $\pm 0.5^{\circ} \mathrm{C}$ & & \\
\hline \multicolumn{4}{|l|}{ Time } \\
\hline Timer Bias & $\pm 0.069 \mathrm{~s}$ & $\pm 2.90 \mathrm{~s}$ & \\
\hline Reaction Time & $\pm 0.230 \mathrm{~s}$ & & $\pm 5.80 \mathrm{~s}$ \\
\hline Radio Operation & $\pm 2.890 \mathrm{~s}$ & & \\
\hline
\end{tabular}


Examples of Gas and Temperature Data for Time-to-Task Tests

\section{Burn Room Data}

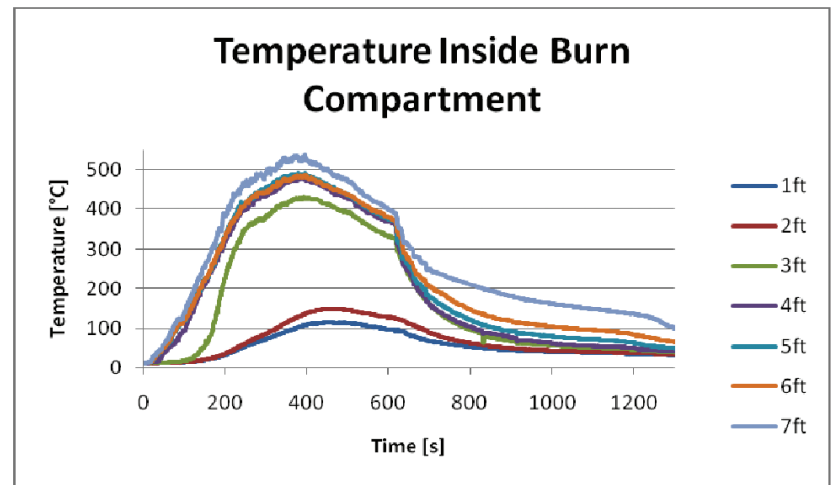

2 Person, Close Stagger

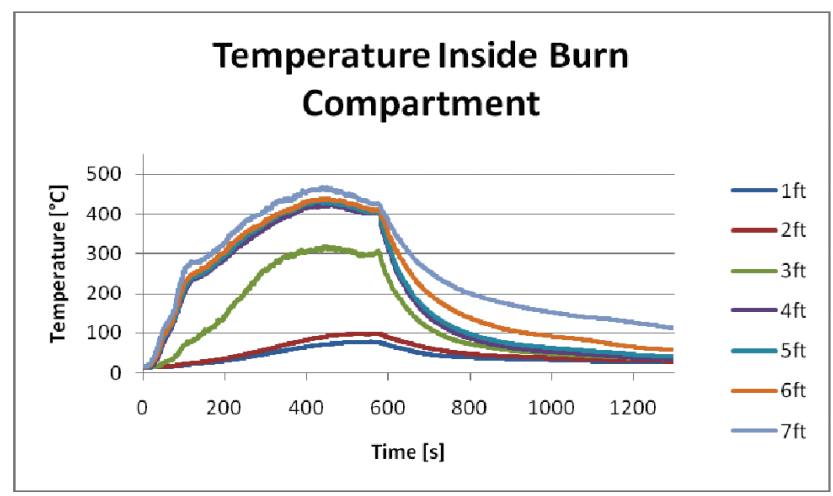

3 Person, Close Stagger

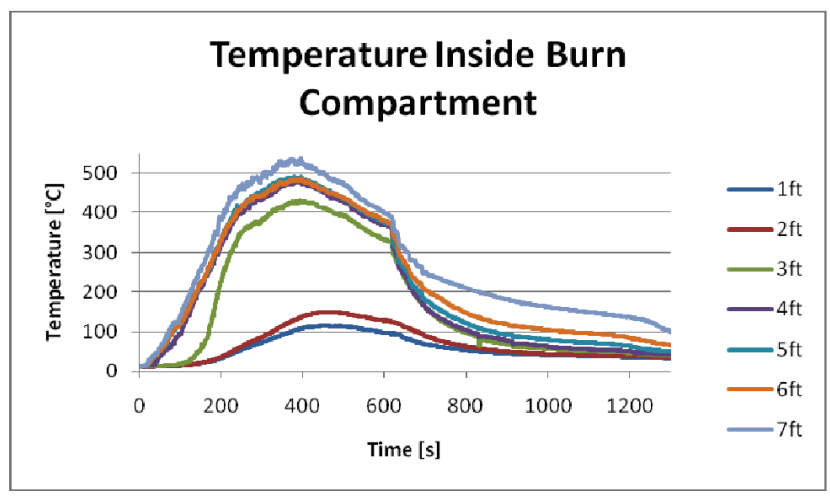

2 Person, Close Stagger

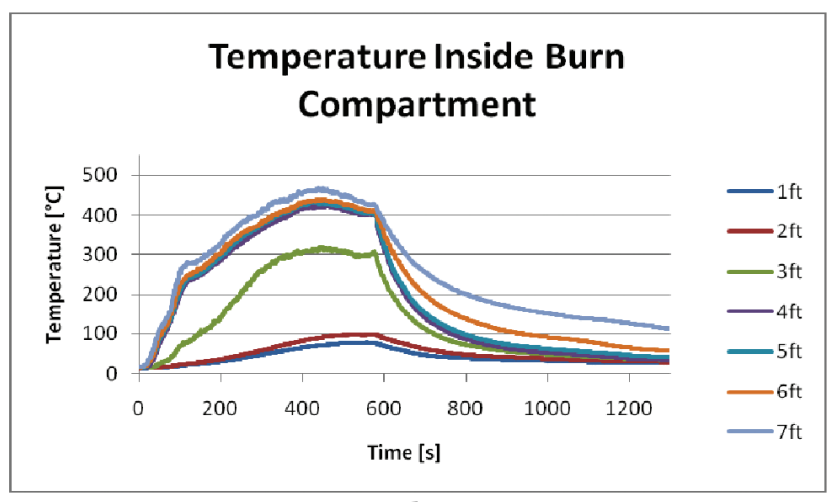

3 Person, Close Stagger

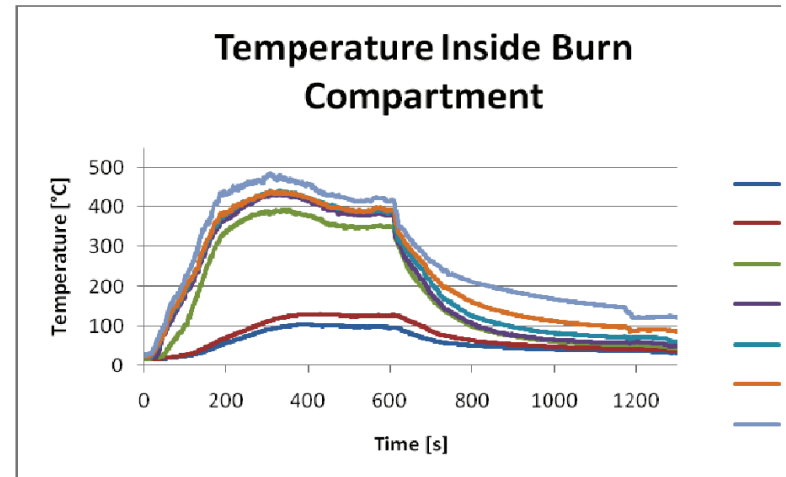

2 Person, Far Stagger

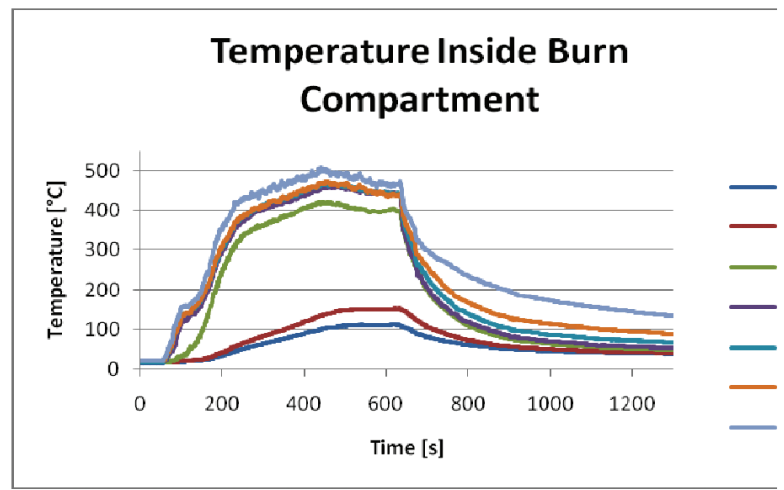

3 Person, Far Stagger

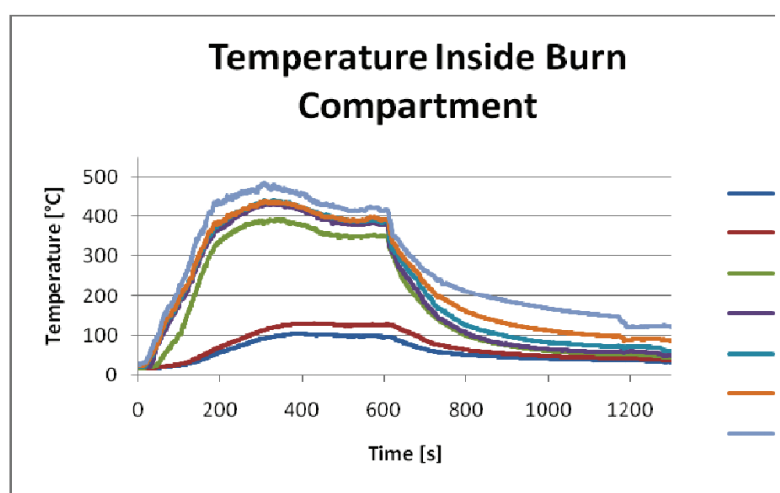

2 Person, Far Stagger

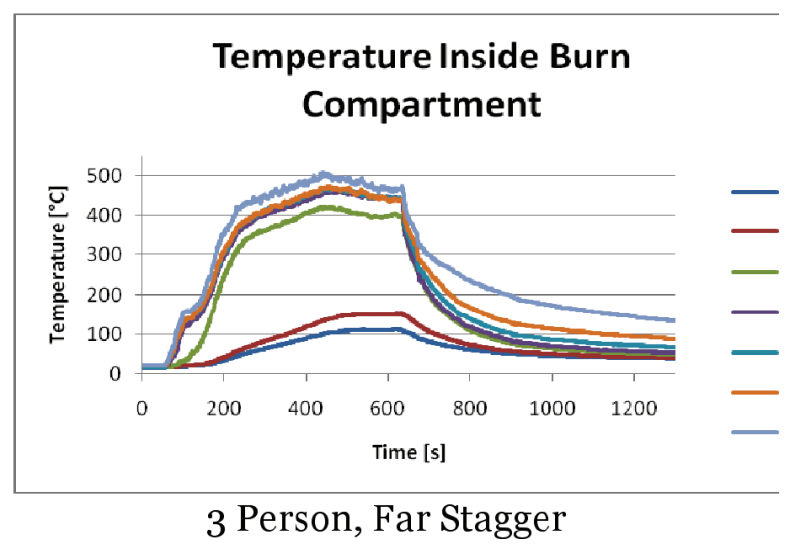




\section{Target Room Data}

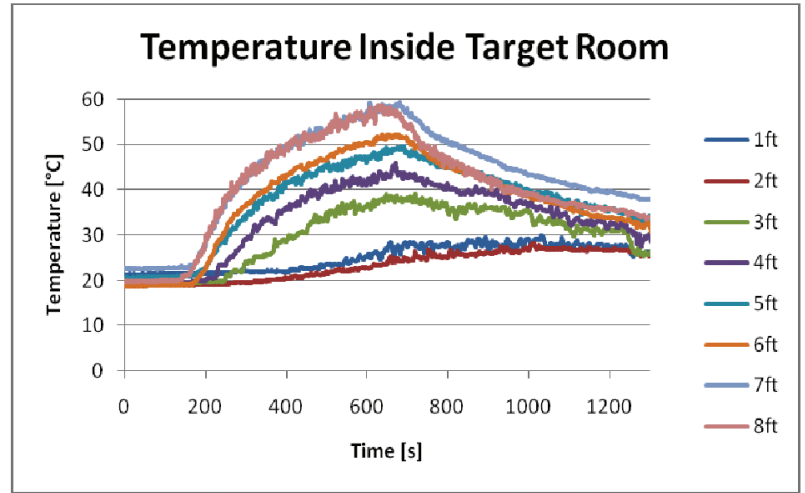

2 Person, Close Stagger

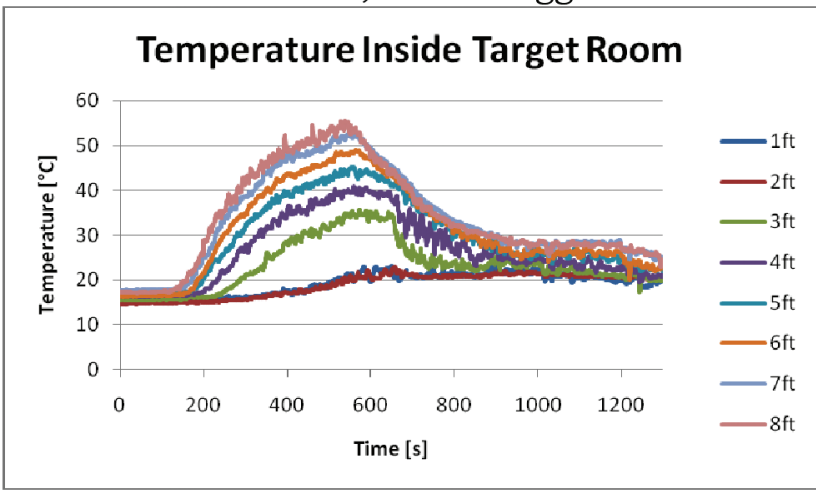

3 Person, Close Stagger
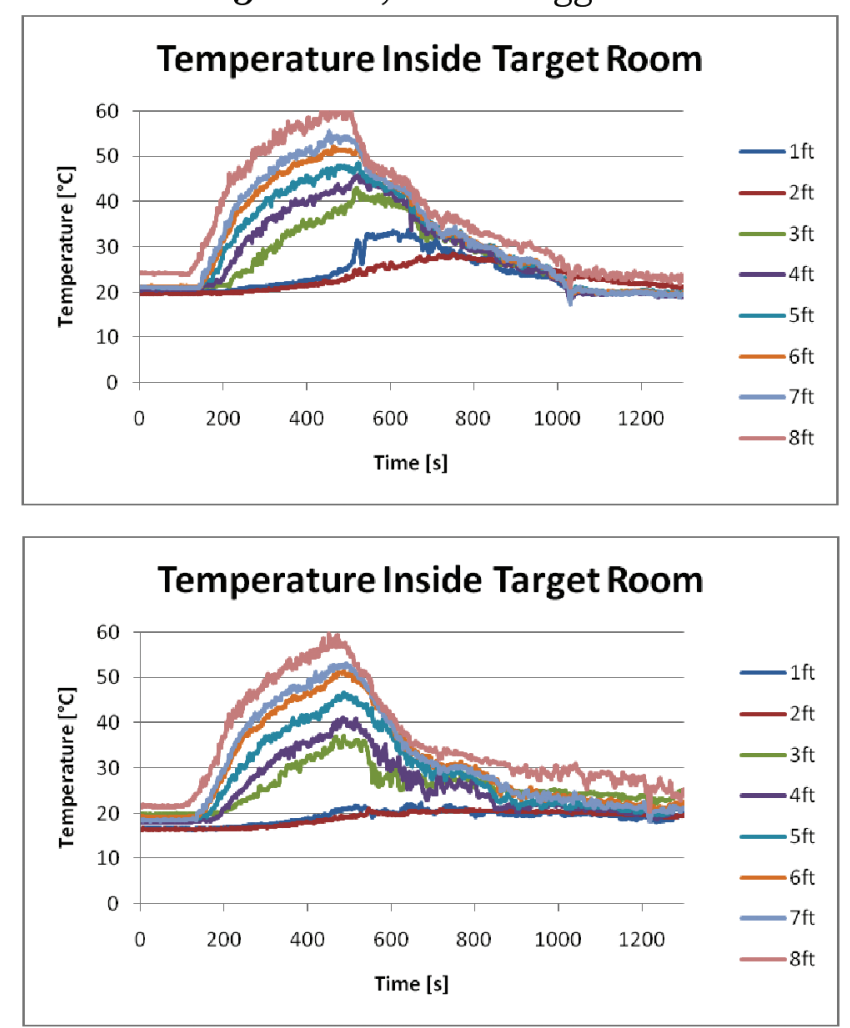

5 Person, Close Stagger

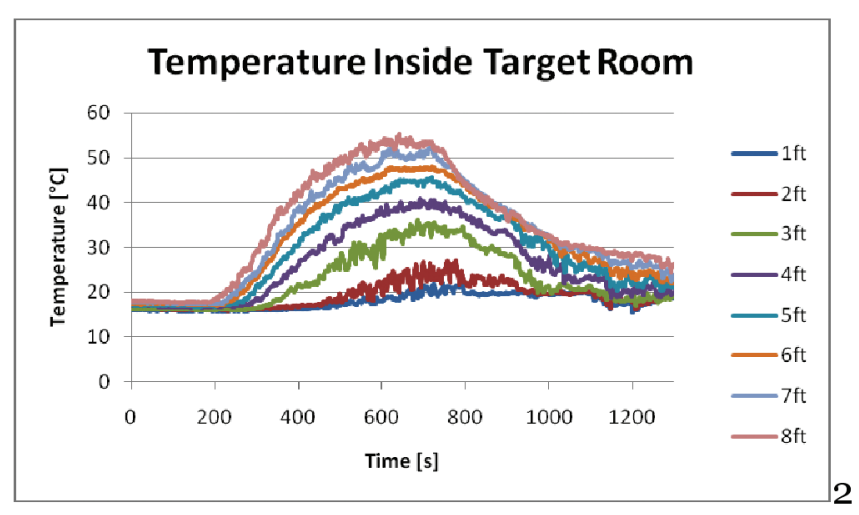

Person, Far Stagger

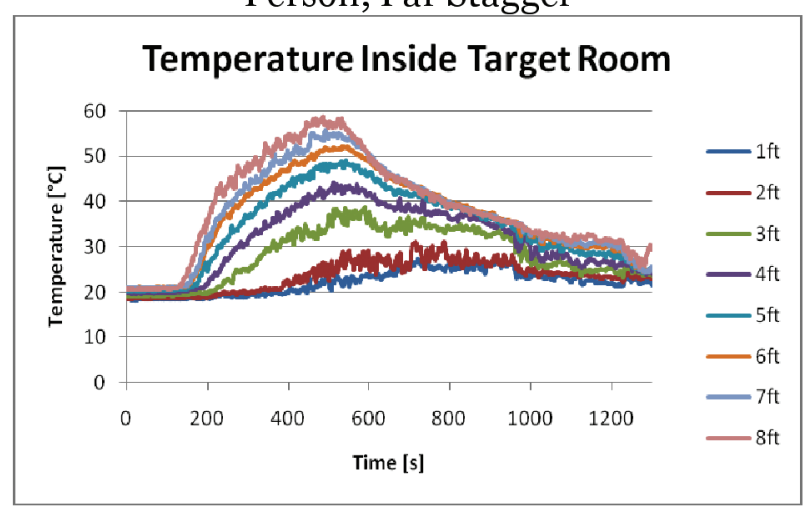

3 Person, Far Stagger
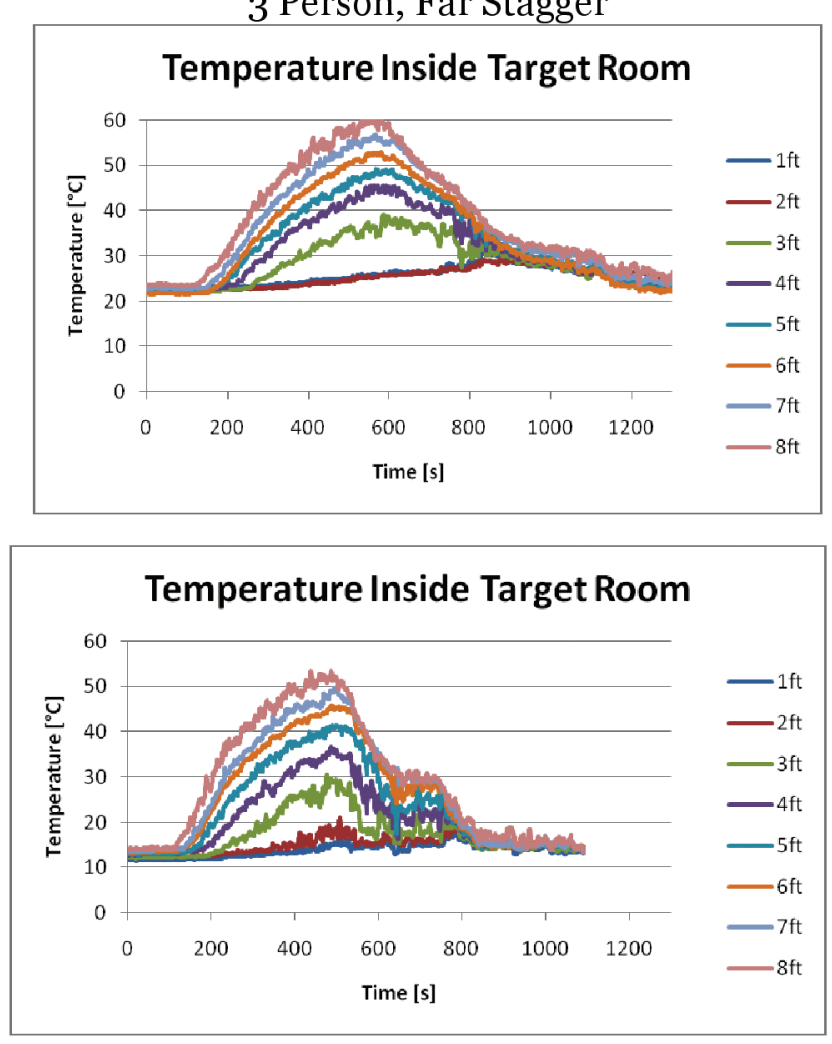

5 Person, Far Stagger 


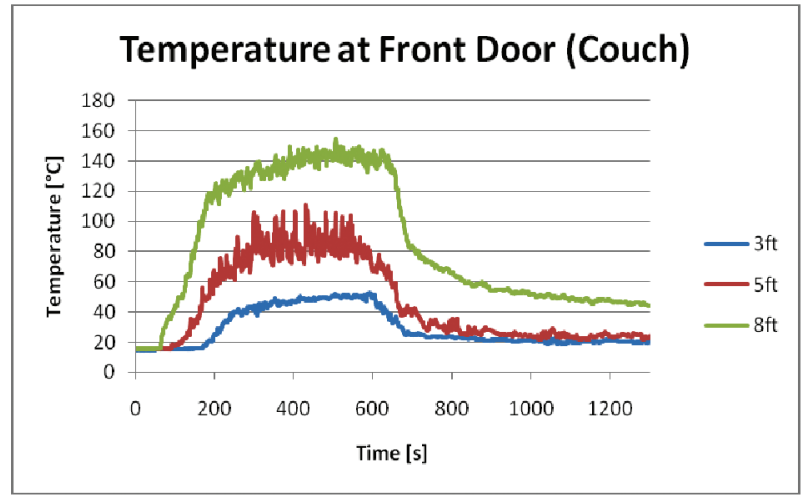

2 Person, Close Stagger

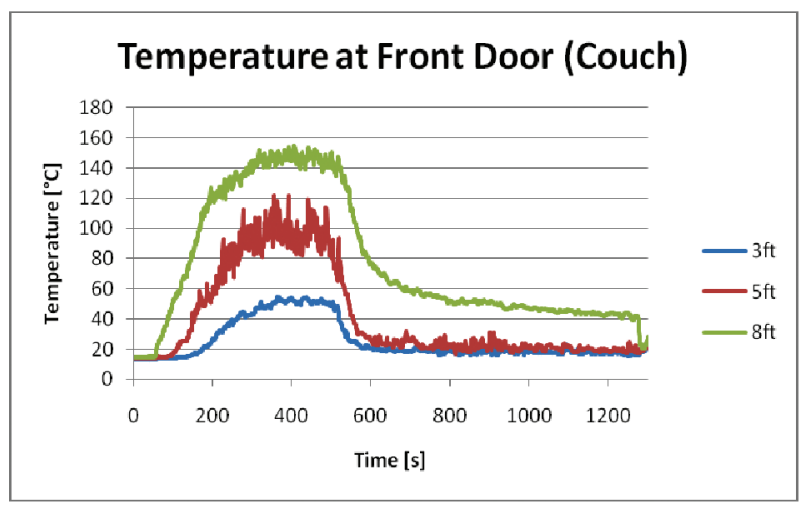

3 Person, Close Stagger

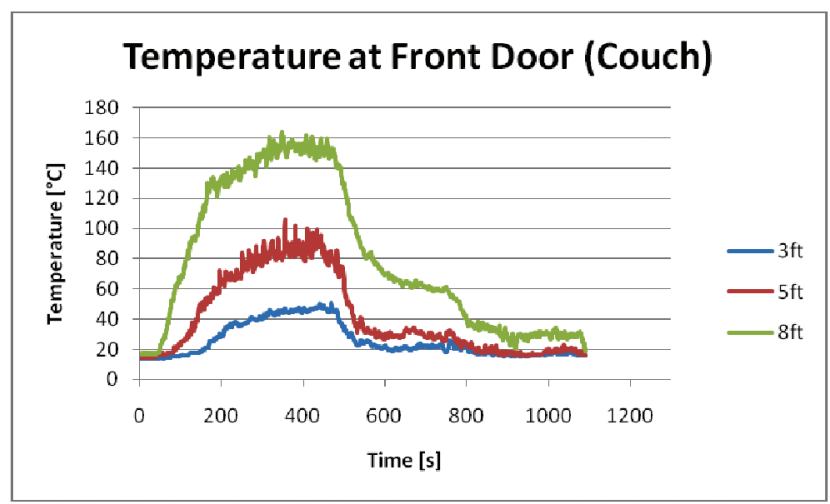

4 Person, Close Stagger

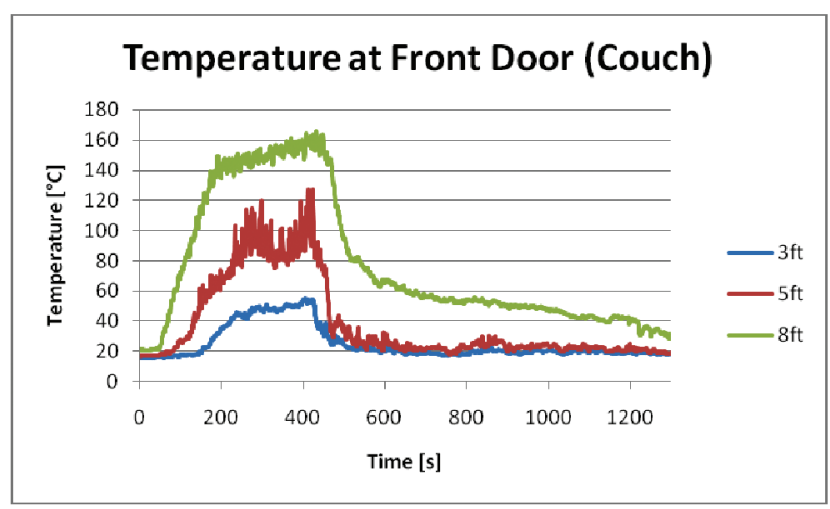

5 Person, Close Stagger

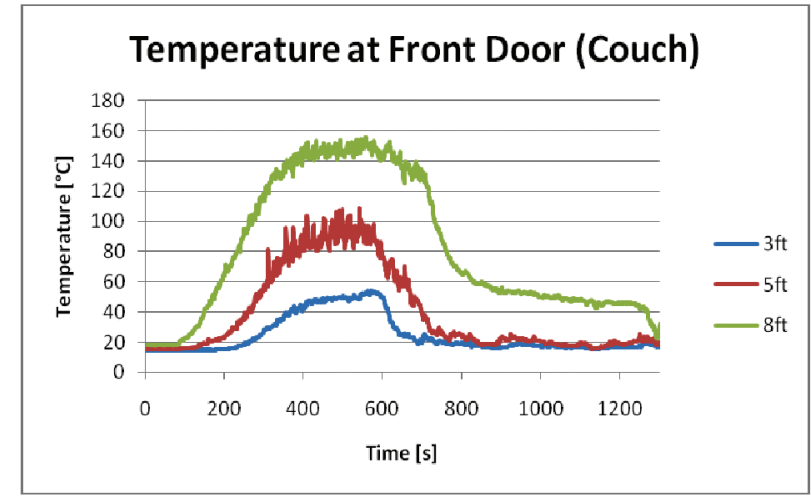

2 Person, Far Stagger

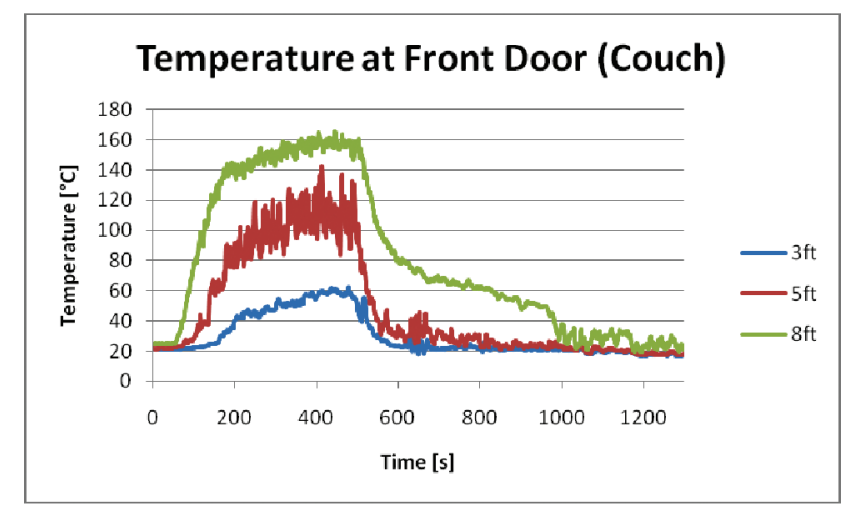

3 Person, Far Stagger

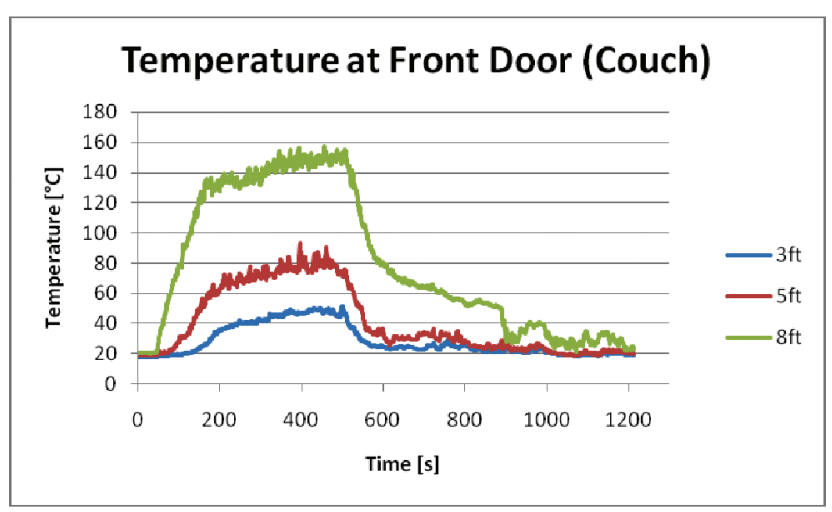

4 Person, Far Stagger

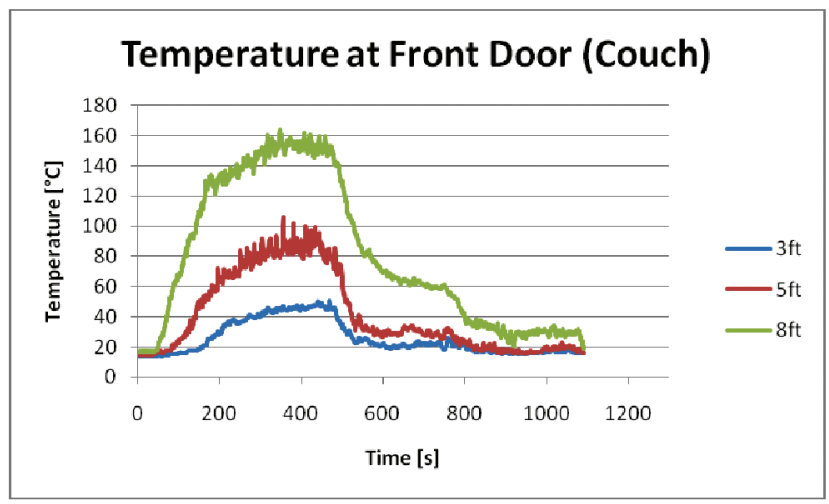

5 Person, Far Stagger 


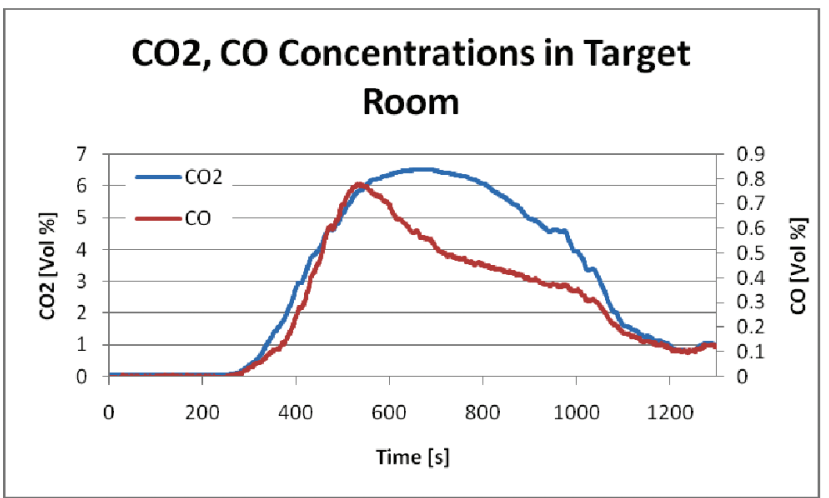

2-Person, Early Arrival

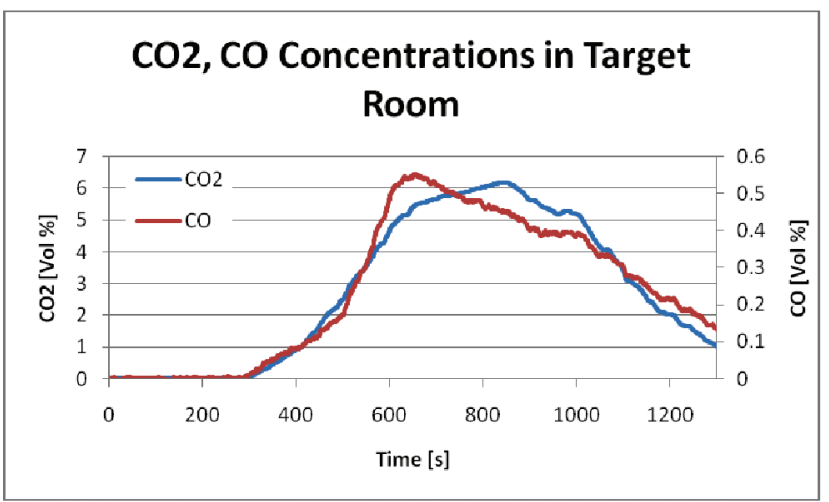

2-Person, Late Arrival

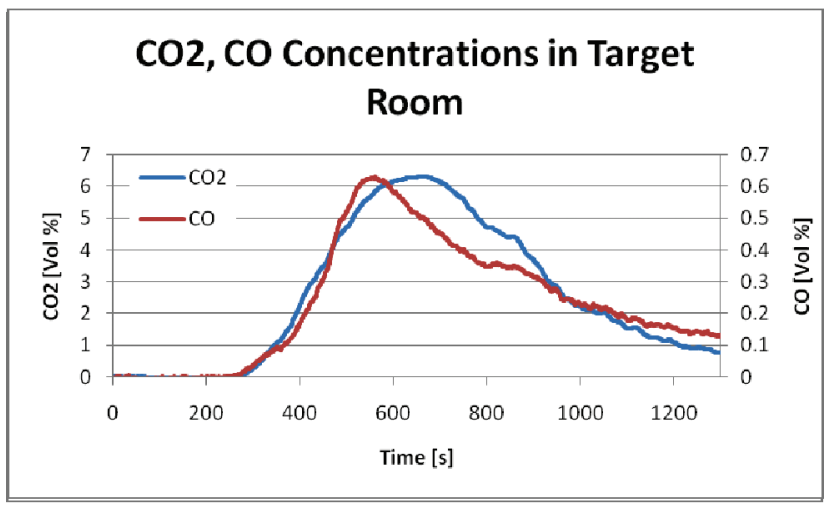

3-Person, Early Arrival

\section{O2 Concentration in Target Room}

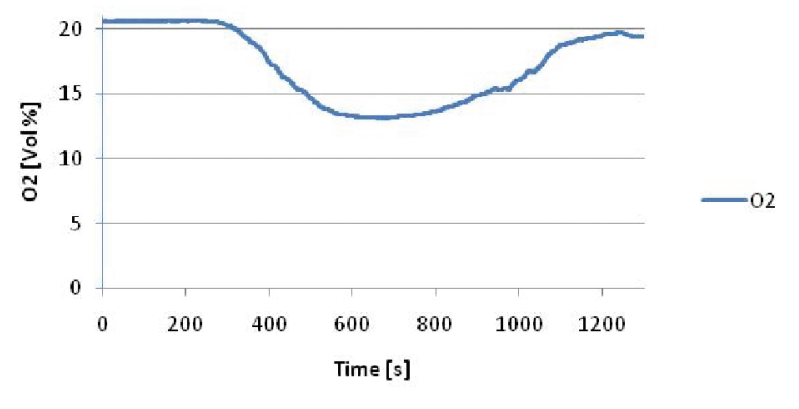

2-Person, Early Arrival

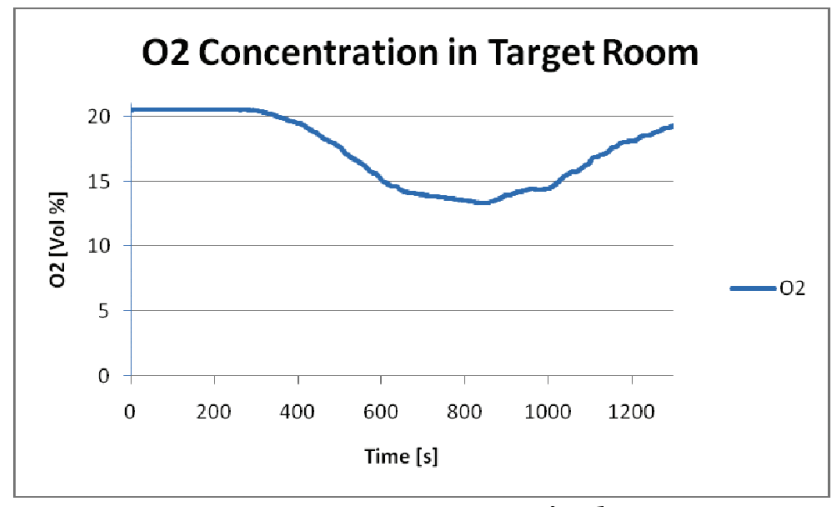

2-Person, Late Arrival

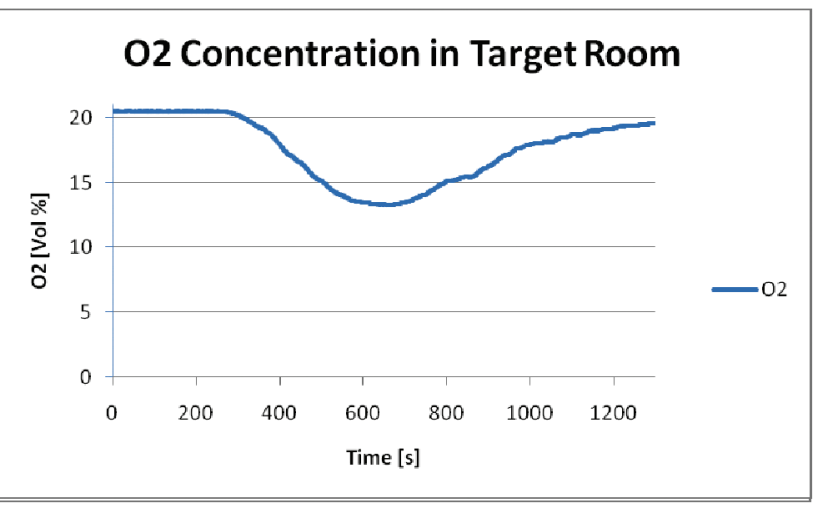

3-Person, Early Arrival 


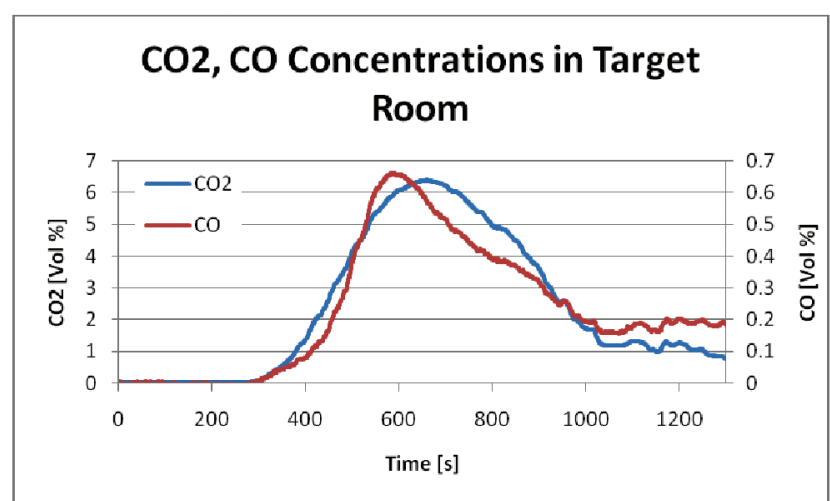

3-Person, Late Arrival

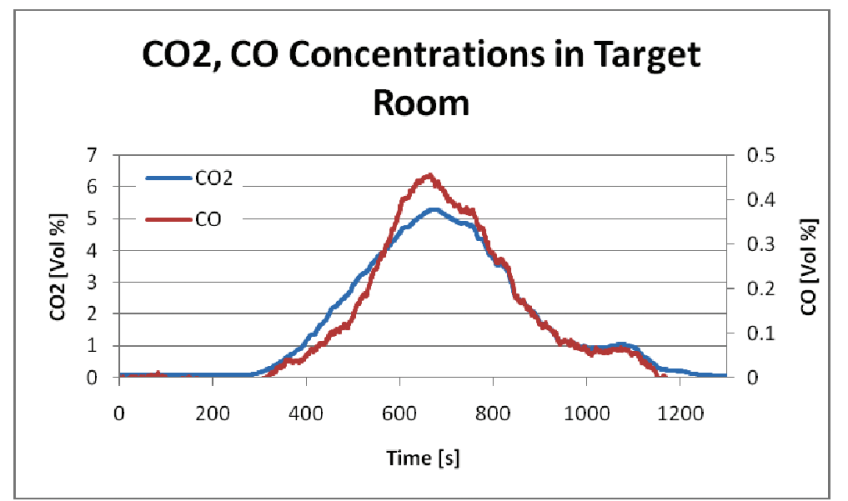

4-Person, Early Arrival

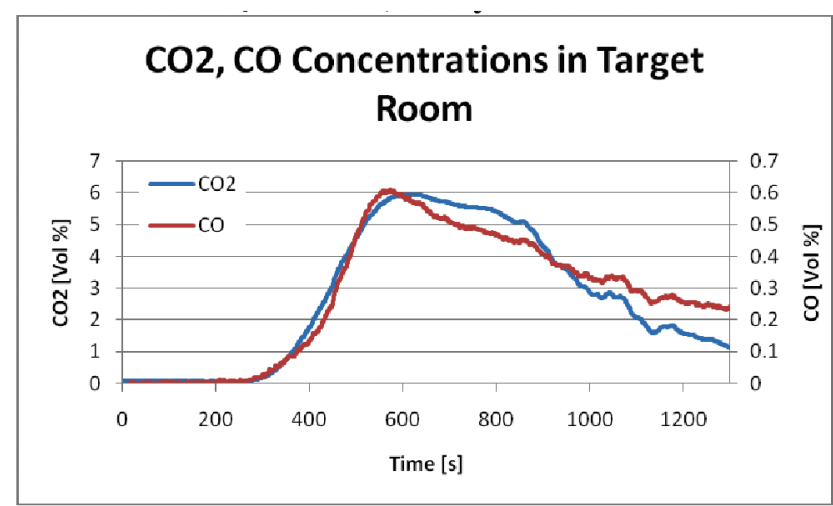

4-Person, Late Arrival

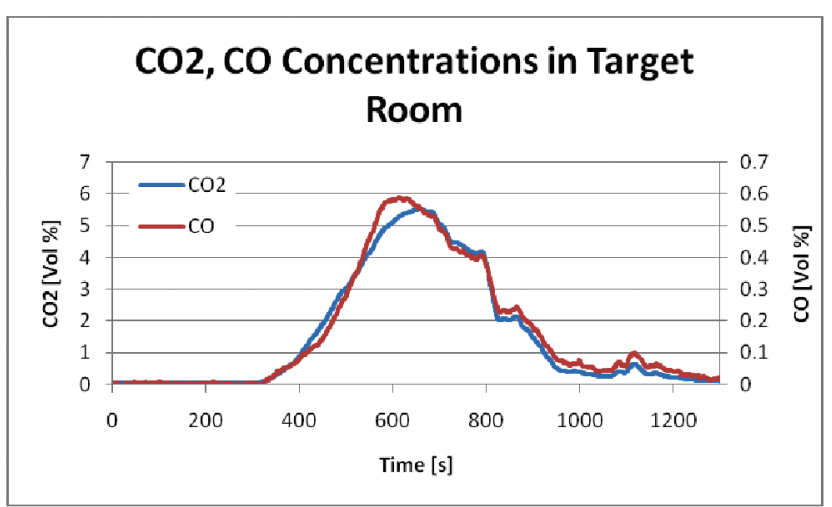

5-Person, Early Arrival

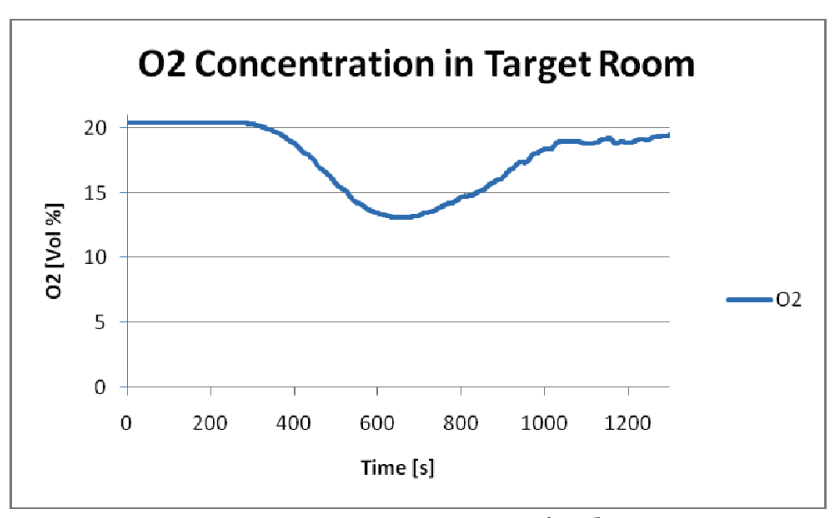

3-Person, Late Arrival

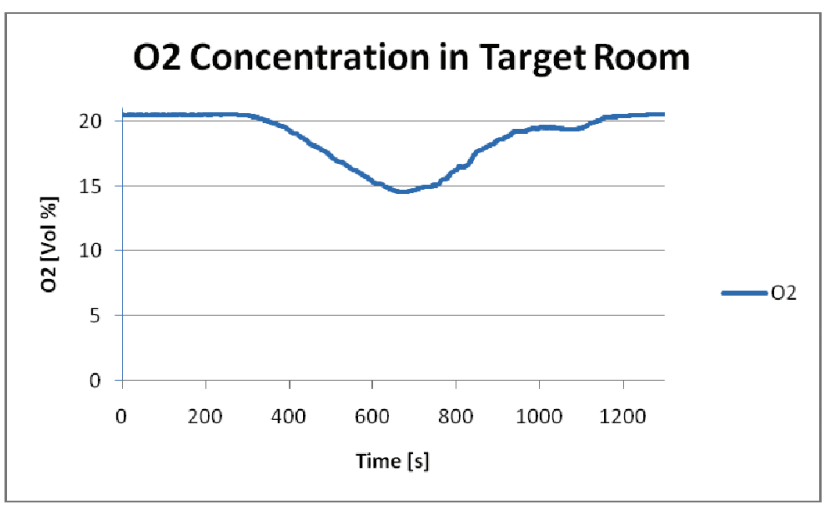

4-Person, Early Arrival

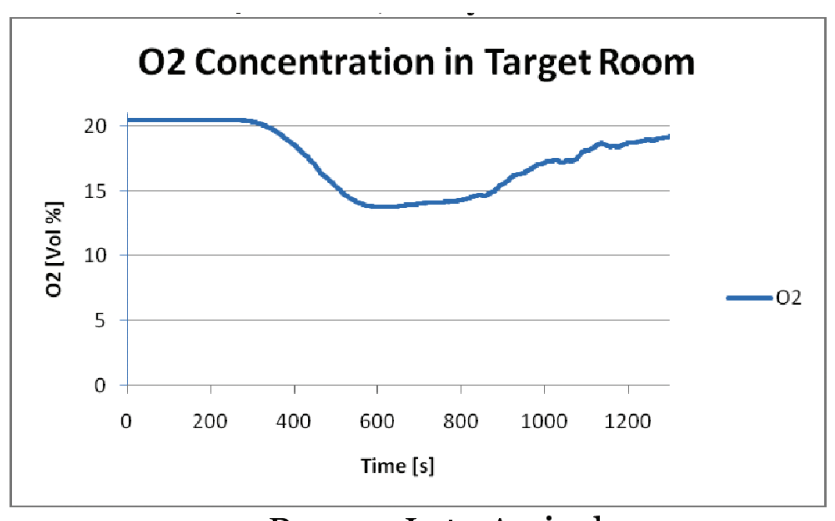

4-Person, Late Arrival

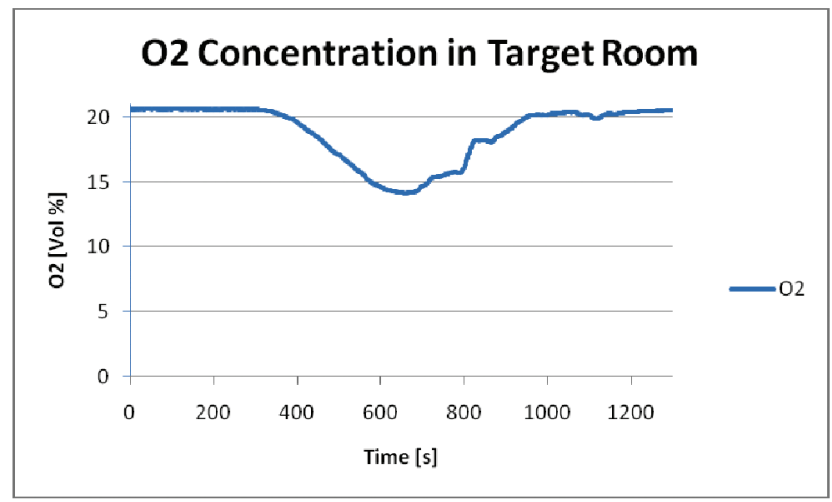

5-Person, Early Arrival 


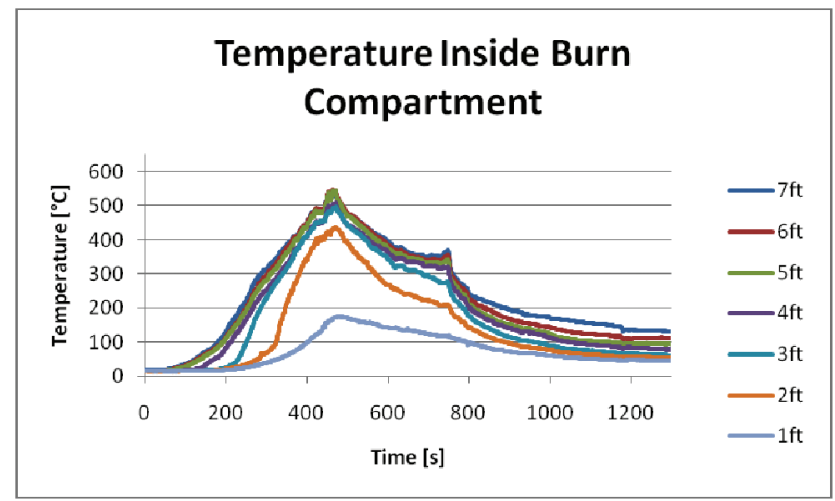

2-Person, Early Arrival

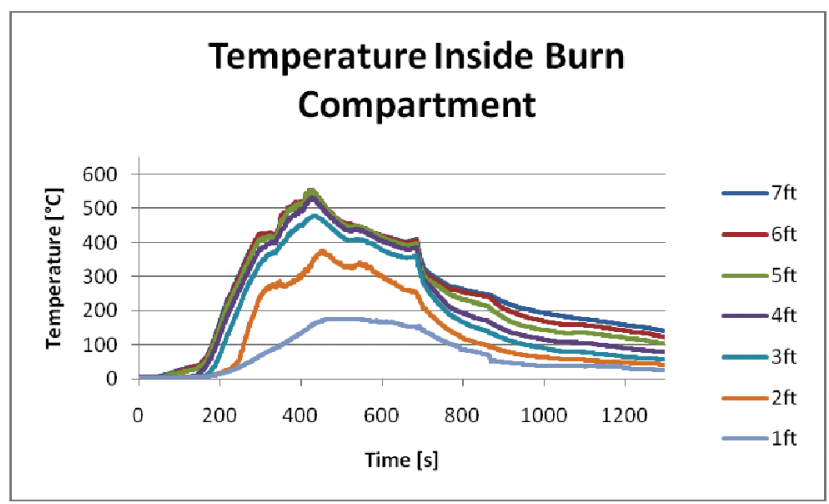

3-Person, Early Arrival

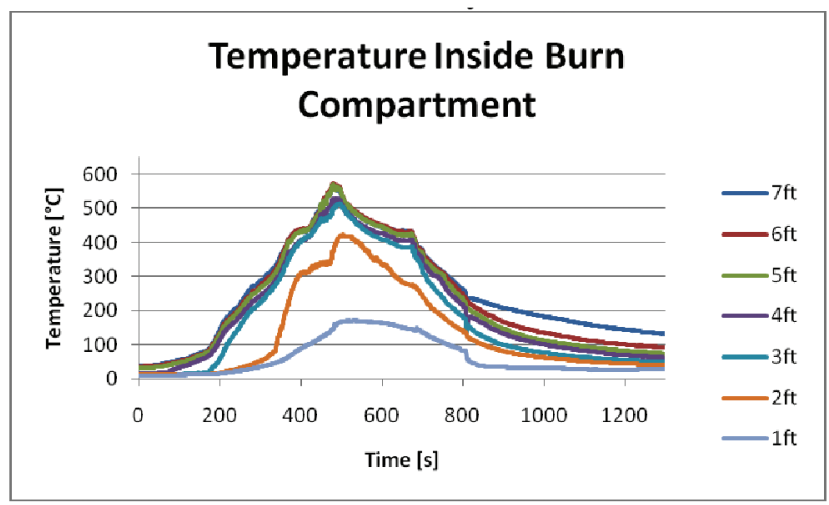

4-Person, Early Arrival

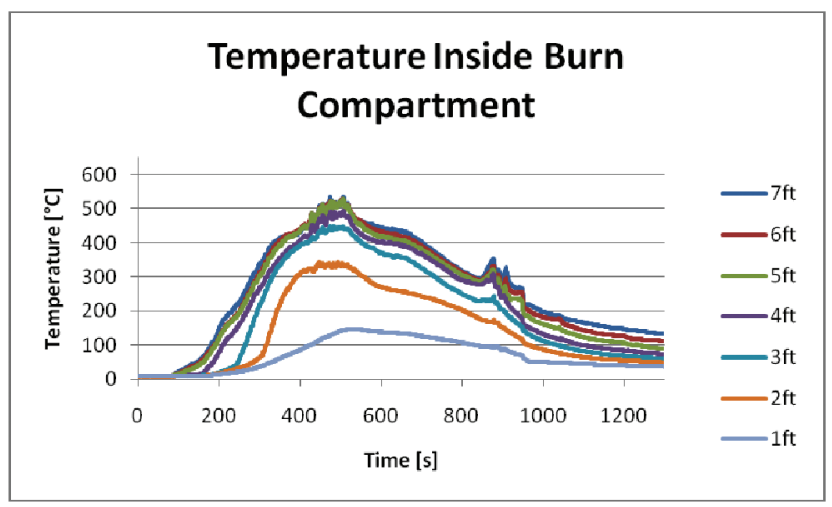

2-Person, Late Arrival

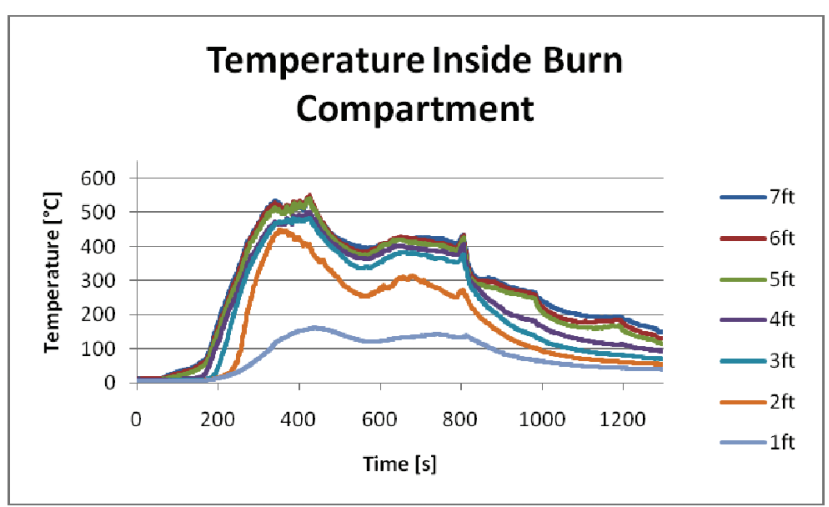

3-Person, Late Arrival

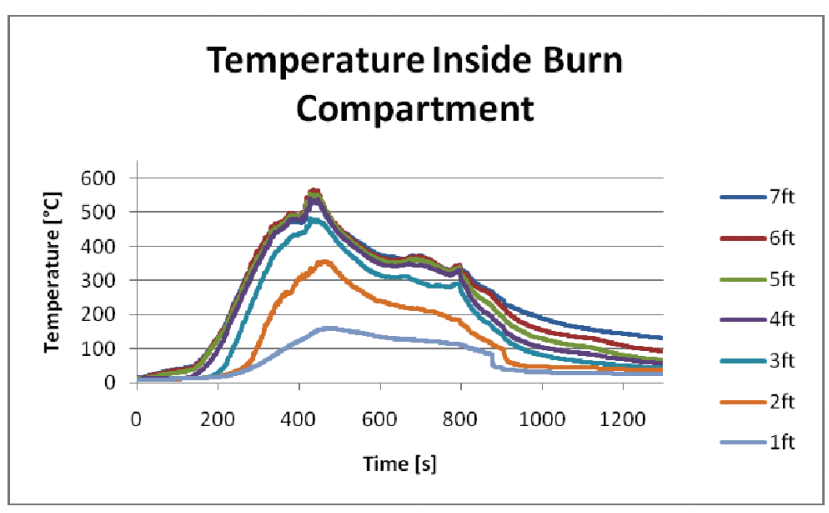

4-Person, Late Arrival

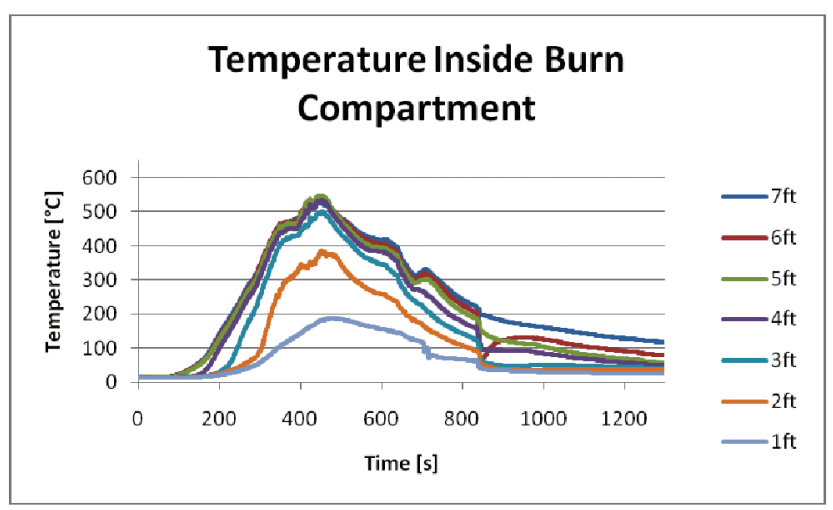

5-Person, Early Arrival 


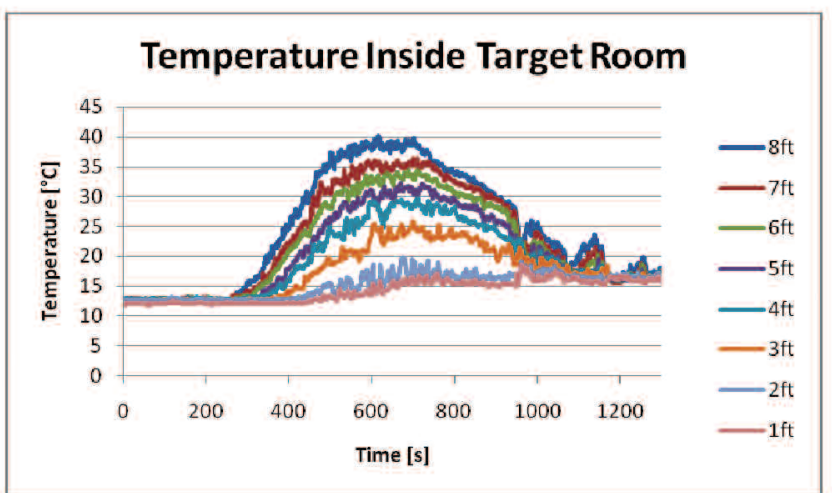

2-Person, Early Arrival

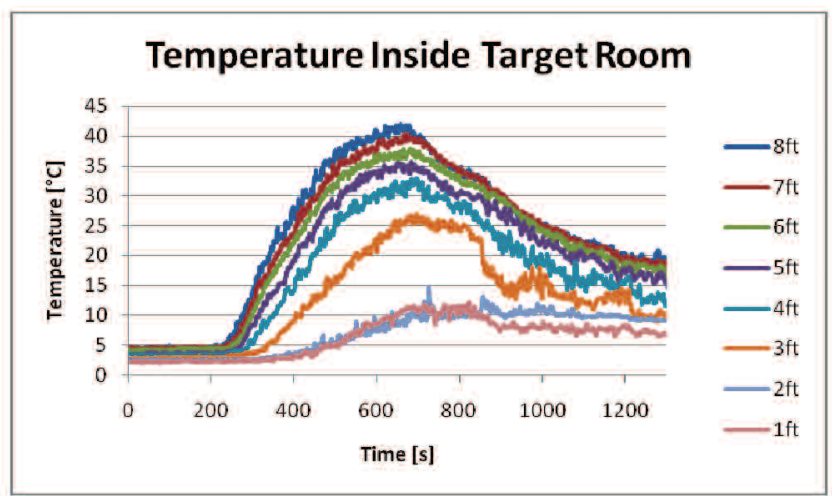

3-Person, Early Arrival

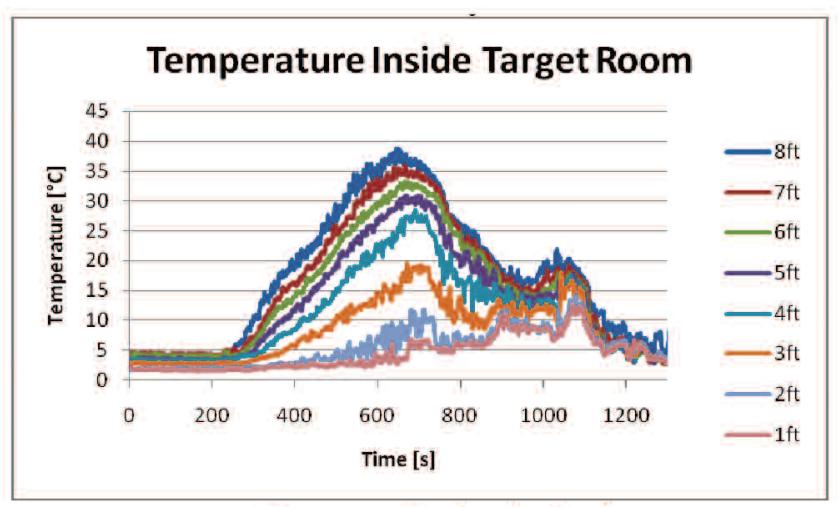

4-Person, Early Arrival

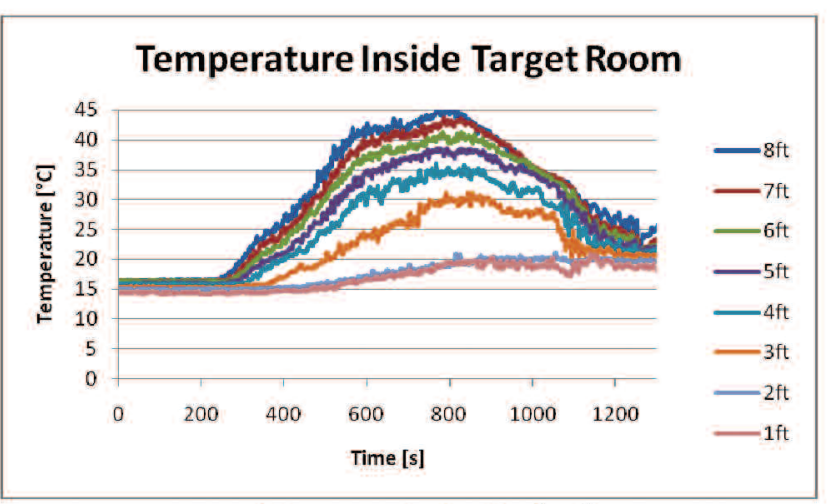

2-Person, Late Arrival

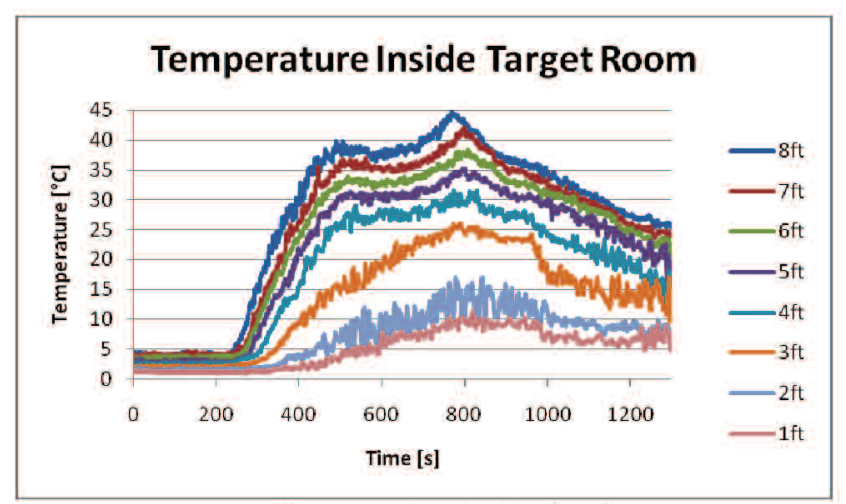

3-Person, Late Arrival

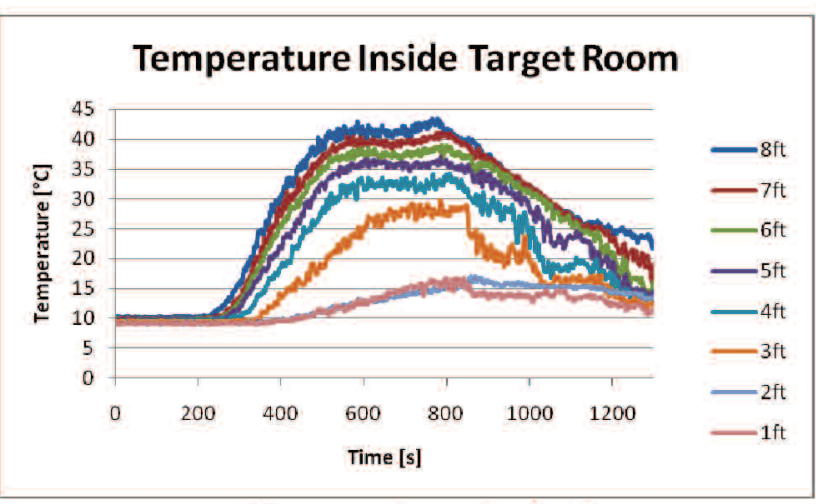

4-Person, Late Arrival

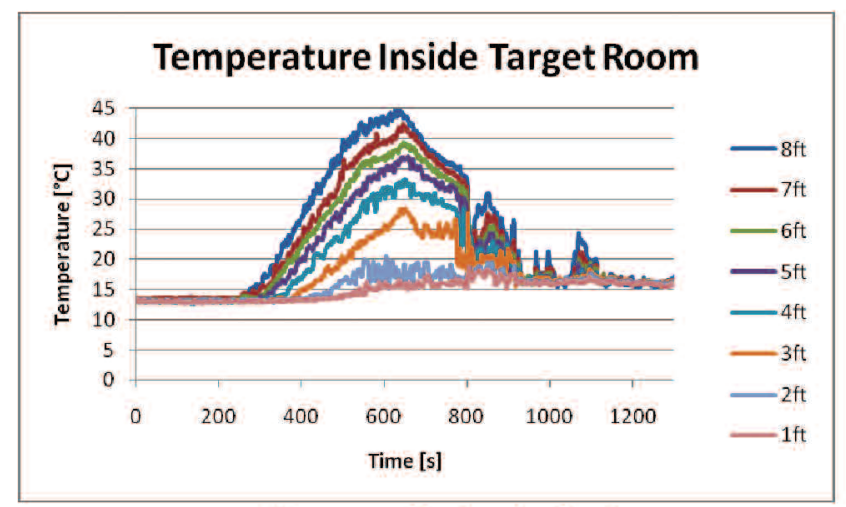

5-Person, Early Arrival 


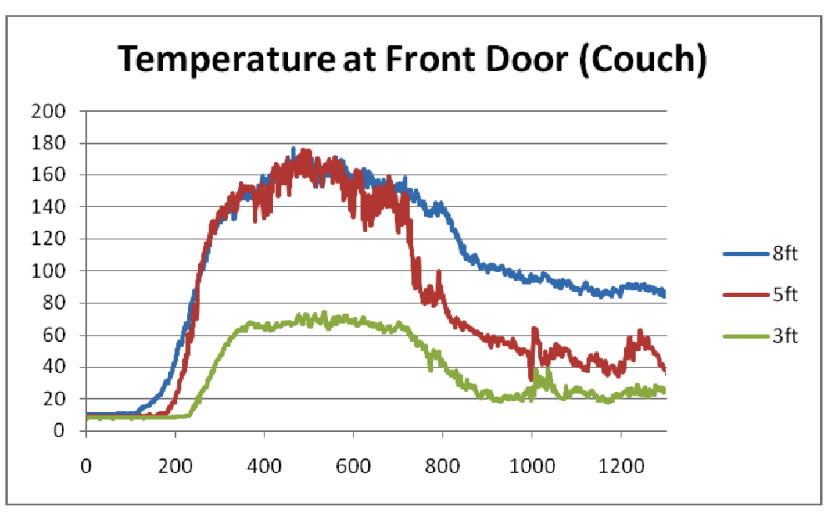

2-Person, Early Arrival

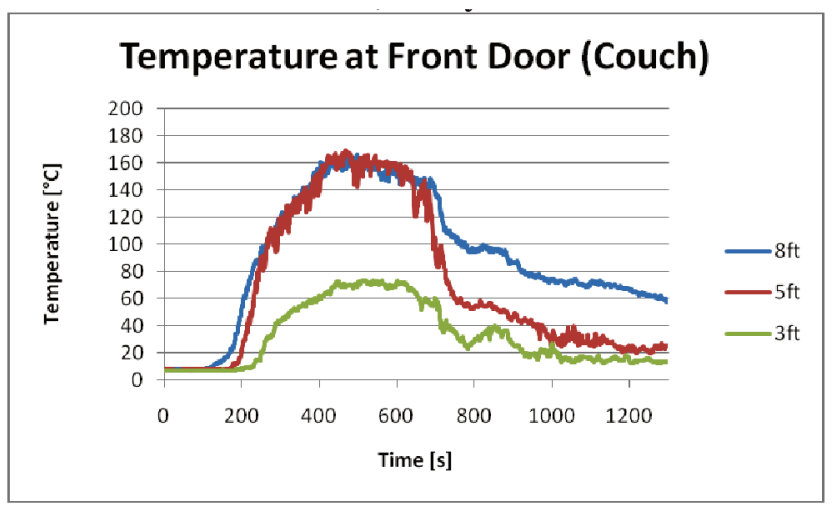

3-Person, Early Arrival

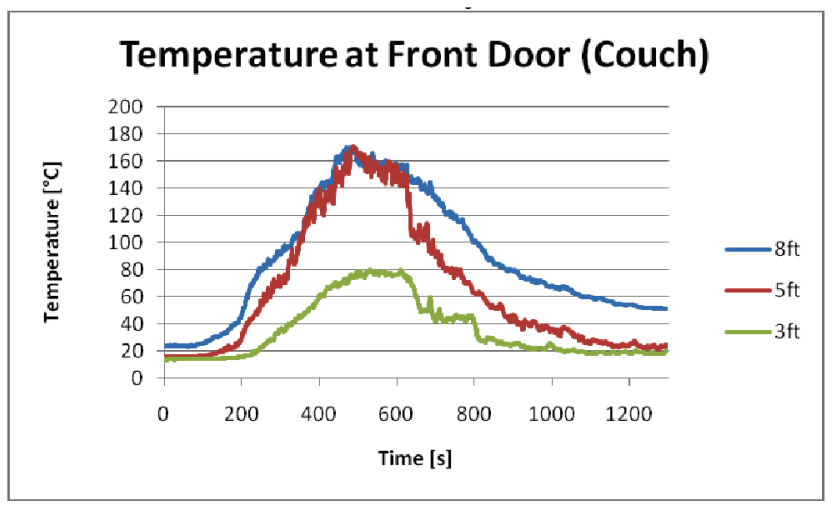

4-Person, Early Arrival

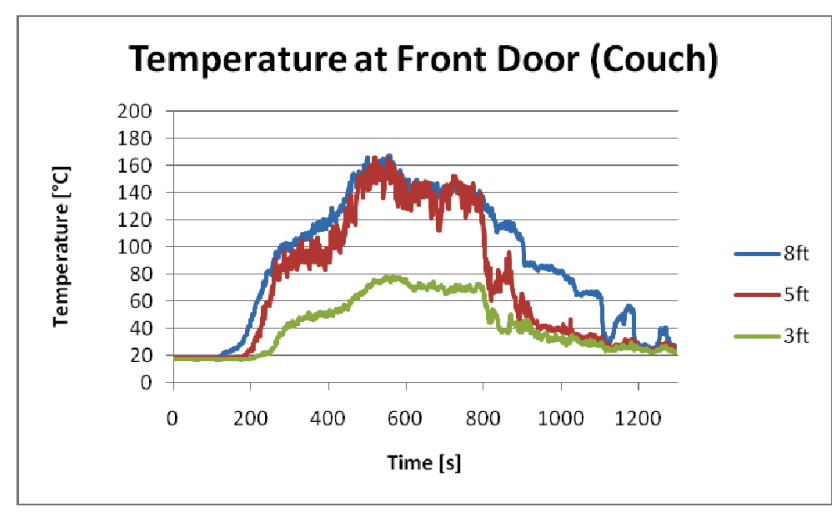

2-Person, Late Arrival

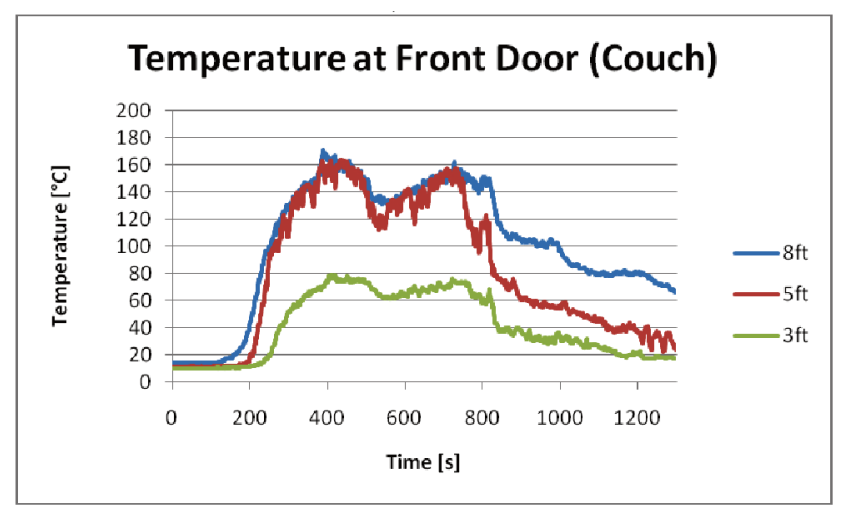

3-Person, Late Arrival

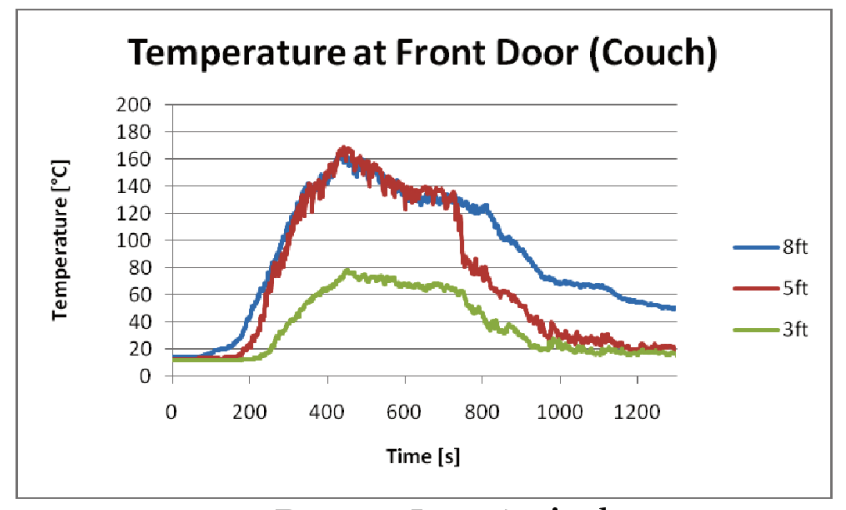

4-Person, Late Arrival

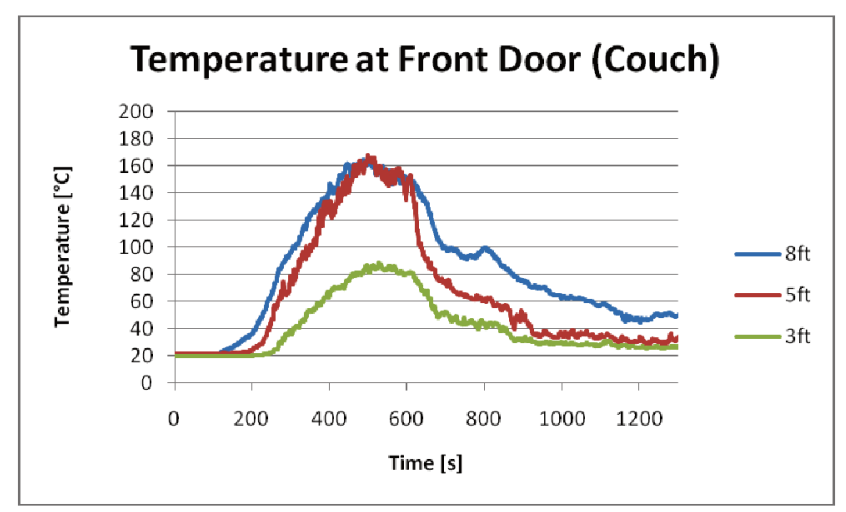

5-Person, Early Arrival 
NOTES: 
101 
